\title{
Onordon
}

\section{Arctic Social Indicators}

ASI II: Implementation

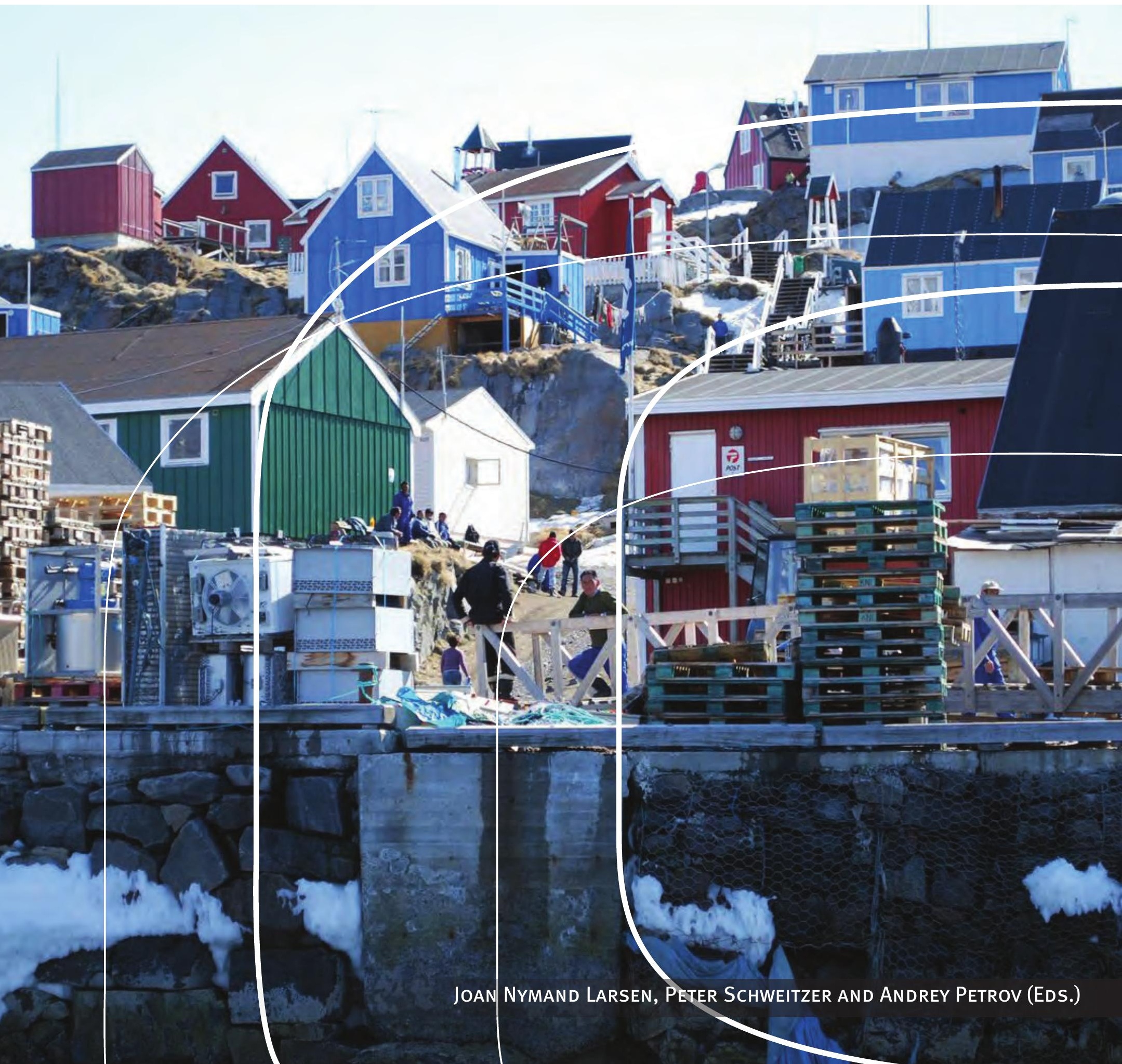



2 norden 



\section{Arctic Social Indicators}

ASI II: Implementation 
Arctic Social Indicators

ASI II: Implementation

ISBN 978-92-893-3886-8 (PRINT)

ISBN 978-92-893-3888-2 (PDF)

ISBN 978-92-893-3887-5 (EPUB)

http://dx.doi.org/10.6027/TN2014-568

TemaNord 2014:568

ISSN 0908-6692

(C) Nordic Council of Ministers 2014

Layout: Hanne Lebech

Cover photo: Rasmus Ole Rasmussen

Print: Rosendahls-Schultz Grafisk

Copies: 200

Printed in Denmark

This publication has been published with financial support by the Nordic Council of Ministers. However, the contents of this publication do not necessarily reflect the views, policies or recommendations of the Nordic Council of Ministers.

www.norden.org/en/publications

Nordic co-operation

Nordic co-operation is one of the world's most extensive forms of regional collaboration, involving Denmark, Finland, Iceland, Norway, Sweden, and the Faroe Islands, Greenland, and Åland.

Nordic co-operation has firm traditions in politics, the economy, and culture. It plays an important role in European and international collaboration, and aims at creating a strong Nordic community in a strong Europe.

Nordic co-operation seeks to safeguard Nordic and regional interests and principles in the global community. Common Nordic values help the region solidify its position as one of the world's most innovative and competitive.

\section{Nordic Council of Ministers}

Ved Stranden 18

DK-1061 Copenhagen K

Phone (+45) 33960200

www.norden.org 


\section{Contents}

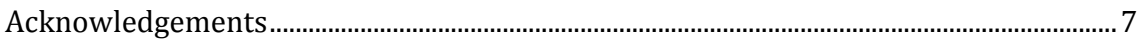

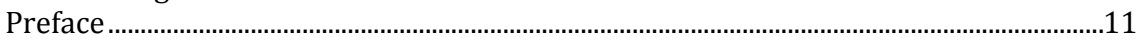

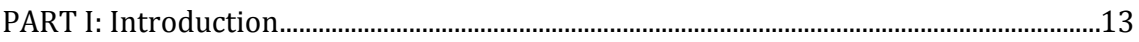

1. Tracking Change in Human Development in the Arctic

Joan Nymand Larsen, Peter P. Schweitzer, Andrey Petrov and Gail Fondahl.............15

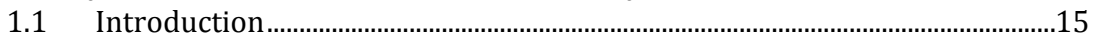

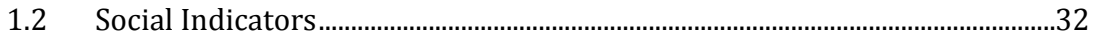

1.3 Developing a Set of Arctic Social Indicators: The Process ................................33

1.4 Summary of ASI indicators ....................................................................................3

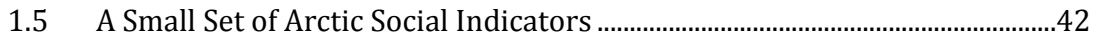

1.6 Data Availability and Limitations ......................................................................43

1.7 Introduction to Focus Studies ...........................................................................

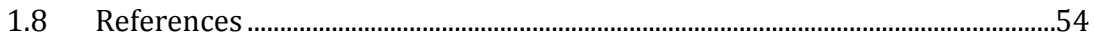

PART II: Case Studies

2. Sakha Repubic (Yakutia), Russian Federation

Gail Fondahl, Susie Crate and Viktoriia V. Filippova.....................................................57

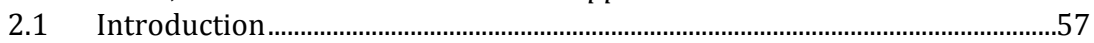

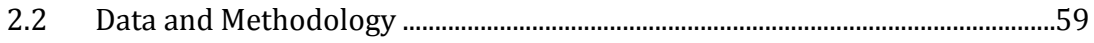

2.3 Health and Population Domain...............................................................................61

$2.4 \quad$ Material Wellbeing Domain..................................................................................68

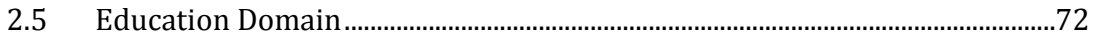

2.6 Cultural Wellbeing and Cultural vitality ........................................................... 74

$2.7 \quad$ Contact with Nature ............................................................................................

2.8 Fate Control Domain .................................................................................................

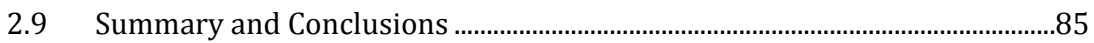

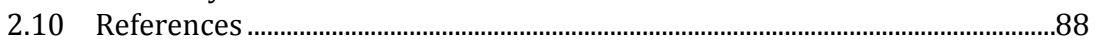

3. The Northwest Territories, Canada

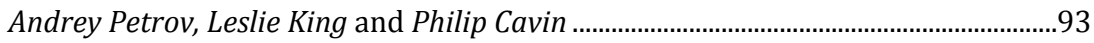

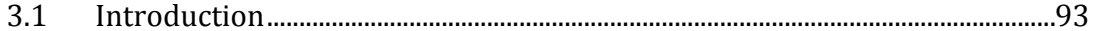

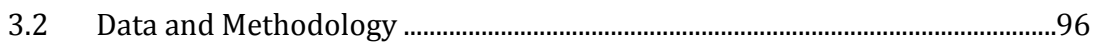

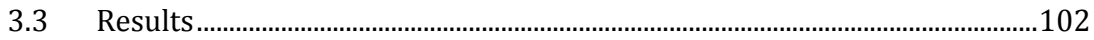

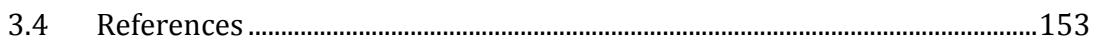

4. West-Nordic Region

Rasmus Ole Rasmussen, Johanna Roto and Lawrence C. Hamilton .............................155

4.1 Introduction: The West-Nordic Region..........................................................155

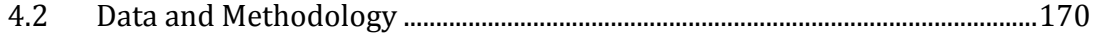

4.3 Health and Population Domain............................................................................171

4.4 The Material Wellbeing Domain......................................................................178

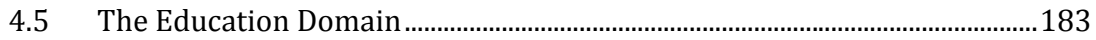

4.6 Cultural Wellbeing and Cultural Vitality Domain ...........................................190

4.7 Contact with the Nature Domain ........................................................................198

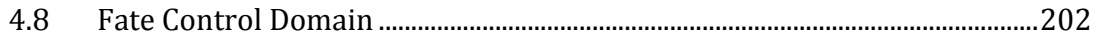




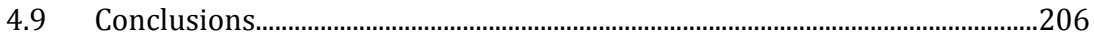

4.10 References.........................................................................................................20

5. Inuit Regions of Alaska

Peter P. Schweitzer, Raymond Barnhardt, Matthew Berman and

Lawrence Kaplan...

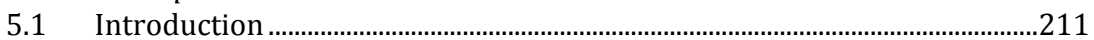

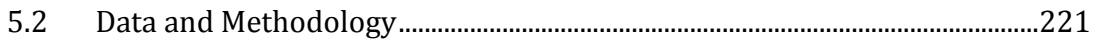

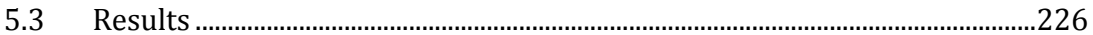

5.4 Conclusions and Discussion ........................................................................248

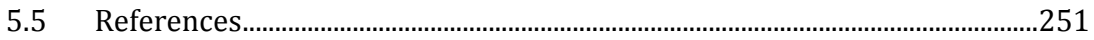

6. The Inuit World: Measuring living conditions \& subjective wellbeing monitoring human development using Survey of Living Conditions in the Arctic (SLiCA) to augment ASI for the Inuit World

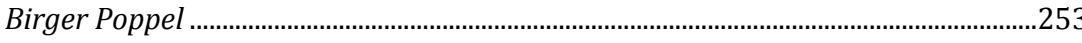

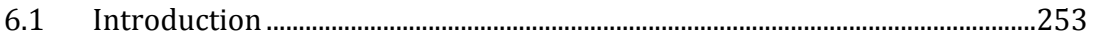

6.2 The Concept of Subjective Wellbeing .................................................................257

6.3 ASI Domains and SLiCA Indicators ....................................................................257

6.4 A Case study: SLiCA as a Provider of Indicators to the ASI

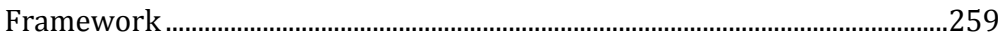

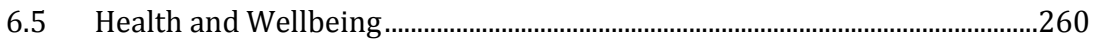

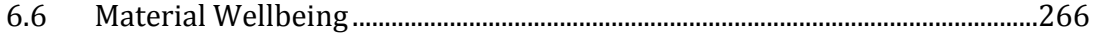

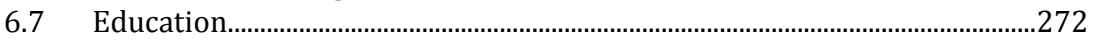

6.8 How well does SLiCA apply to the ASI domain Education and

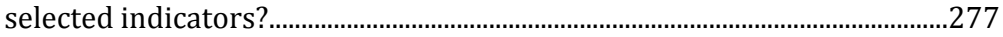

6.9 Cultural wellbeing and cultural vitality ......................................................27

6.10 Contact with Nature (Closeness to Nature) ....................................................282

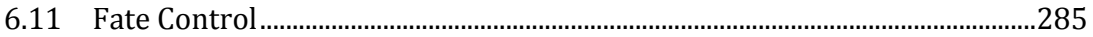

6.12 Summary and Concluding Remarks .................................................................2290

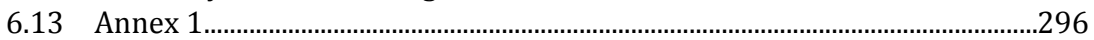

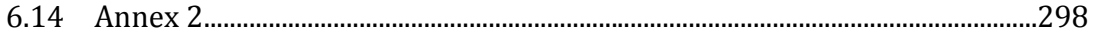

6.15 Annex 3 ...........................................................................................................29

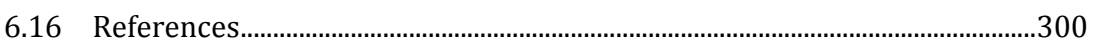

PART III: Conclusion ................................................................................................................303

7. Conclusion: Measuring Change in Human Development in the Arctic

Joan Nymand Larsen, Peter P. Schweitzer and Andrey Petrov .................................305

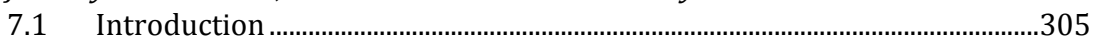

7.2 Summary of Major Findings ...............................................................................309

7.3 ASI Monitoring System .....................................................................................315

7.4 The International Polar Year and the Monitoring of Human

Development in the Arctic.......................................................................................322

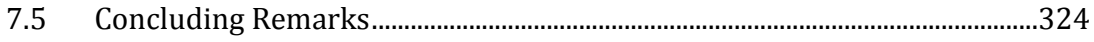

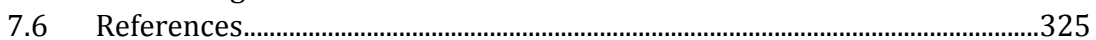

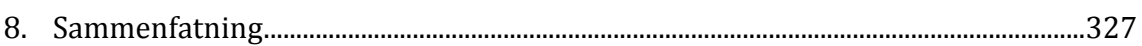




\section{Acknowledgements}

\section{Editorial team}

Joan Nymand Larsen

Peter Schweitzer

Andrey Petrov

\section{Project manager and co-editor}

Joan Nymand Larsen

\section{Executive Committee}

Joan Nymand Larsen - Project Leader, Iceland

Peter Schweitzer - Co-Project Leader, USA

Gail Fondahl - Executive Member, Canada

\section{ASI Secretariat}

Stefansson Arctic Institute / Stofnun Vilhjálms Stefánssonar, Akureyri, Iceland: www.svs.is

Lead authors, contributing experts, and ASI-II team participants

Andrey Petrov

Birger Poppel

Bruce Forbes

Ellen Inga Turi

Erik Gant

Florian Stammler

Gail Fondahl

Gerard Duhaime

Gorm Winther

Gunn-Britt Retter

Igor Krupnik

Jack Kruse

Joan Nymand Larsen

Jón Haukur Ingimundarson

Johanna Roto

Lawrence D. Kaplan

Lawrence C. Hamilton

Leslie King 
Matthew Berman

Michael Laiho

Mike Gill

Natalia Loukacheva

Oran Young

Peter Schweitzer

Philip Cavin

Rasmus Ole Rasmusssen

Raymond Barnhardt

Stephanie Irlbacher Fox

Susan Crate

Søren Bitsch

Torunn Pettersen

Tekke Terpstra

Victoria Filippova

Yvon Csonka

\section{Arctic Maps}

Winfried Dallmann (AHDR map)

Rasmus Ole Rasmussen, Nordregio

Johanna Roto, Nordregio

Melodié Martin, Nordregio

José Sterling, Nordregio

We are grateful for all the invaluable feedback from anonymous peer reviewers, including review comments received on ASI-II findings at numerous international conferences, workshops, and seminars.

The Sustainable Development Working Group of the Arctic Council: Indigenous peoples organizations, permanent participants, international organizations

- Aleut International Association (AIA)

- Arctic Athabaskan Council (AAC)

- Gwichín Council International (GCI)

- Inuit Circumpolar Conference (ICC)

- Russian Association of Indigenous Peoples of the North (RAIPON)

- Saami Council

- Canada

- Denmark/Greenland/Faroe Islands 
- Finland

- Iceland

- Norway

- Sweden

- Russian Federation

- United States of America

- International Arctic Science Committee (IASC)

- International Arctic Social Sciences Association (IASSA)

- Indigenous People's Secretariat (IPS)

- International Work Group for Indigenous Affairs (IWGIA)

- University of the Arctic (UArctic)

Special thanks are due to Mr. Bruno Pilozzi, executive secretary of the SDWG secretariat and to the Swedish Chairmanship of the Arctic Council, and Chair of the SDWG, Mr. Mikael Anzén. Special thanks are also due to the Icelandic representative on the SDWG, Mr. Jonas G. Allanson.

\section{Financial Support}

The project could not have been completed without the generous financial support received from:

- Nordic Council of Ministers' Arctic Cooperation Programme.

- Icelandic Ministry for the Environment and Natural Resources.

- Stefansson Arctic Institute / Stofnun Vilhjálms Stefánssonar.

- University of Alaska Foundation, USA.

- Circumpolar Directorate of Indian and Northern Affairs Canada

- Aboriginal Affairs and Northern Development Canada.

- IASC - International Arctic Science Committee.

- Canadian Embassy in Reykjavik, Iceland.

- Department of Environmental, Social and Spatial Change (ENSPAC), University of Roskilde, Denmark.

The above list of contributors to the ASI-II is not comprehensive as it only includes our main contributors. Therefore, many thanks are due to numerous individuals who have been involved in the project but who are not mentioned by name. 



\section{Preface}

When the Arctic Social Indicators (ASI) process got underway in 2006, we were moving into uncharted territory for the Arctic social sciences. While its predecessor, the Arctic Human Development Report (AHDR), also constituted a first - no comprehensive social science/humanities report had previously been endorsed by the Arctic Council. Suddenly, we found ourselves in the business of devising indicators that can serve as proxies for social, economic and cultural trajectories of change - a task quite new for most team members.

Ever since the publication of ASI in 2010, we have received feedback that by far exceeded our initial expectations. It was not only pleasant to receive overwhelmingly positive reactions but, more importantly, it was exciting to see ASI being used, applied and modified. To mention just one example, the U.S. Bureau of Ocean Energy Management EM used ASI-I as a key reference in its Statement of Work for a competitive procurement process. While ASI-I personnel were involved in conducting the actual research, the project went beyond what we were able to do in our first report. It serves as a good illustration of the fact that ASI intends to encourage "spin-offs", while at the same time learning from their experiences.

This book is an important milestone in the ASI process. Where our 2010 report marked a theoretical intervention, this book applies principles that have been established back in 2010. This is a critical test for the appropriateness of our indicators. Given the data challenges which continue to plague the tracking of human development in the Arctic, this cannot be more than an intermediate step either. As we detail in our Conclusion, the time is ripe for an ASI Monitoring System that provides better and diachronic data for our purpose.

For now, we invite you to engage with ASI-II and look forward to gaining your critical feedback.

Joan Nymand Larsen and Peter Schweitzer

Project Leaders, ASI 



\section{PART I: \\ Introduction}





\title{
1. Tracking Change in Human Development in the Arctic
}

\author{
Authors \\ Joan Nymand Larsen, Stefansson Arctic Institute \& University of Akureyri, \\ Iceland; Peter P. Schweitzer, University of Alaska, Fairbanks, USA \& Uni- \\ versity of Vienna, Austria; Andrey Petrov, University of Northern Iowa, \\ USA; Gail Fondahl, University of Northern British Columbia, Canada.
}

\subsection{Introduction}

Communities in the Arctic, the peoples, cultures, and societies of the region, are today facing multiple stressors, the sources of which are by now fairly well understood. They reach far beyond Arctic local and regional contexts - with change experienced in terms of both increasing rates and magnitude. Rapid change - now broadly accepted as a fact, with its multi-faceted impacts and many complex interactions of social, natural and physical systems - manifests itself in the socio-economic transformations of daily living and at different geographical scales. Beyond doubt, change puts human wellbeing and community adaptability to the test in today's Arctic.

The wellbeing of Arctic residents and the ability to adapt in a time of rapid global change has long been a focus of attention of the Sustainable Development Working Group (SDWG) of the Arctic Council. However, the sense of urgency in addressing transformation and its complexity, the impacts on different human systems, and the ability of our regions and communities to adapt is increasing. Rapid socio-economic change demands our attention and calls for an in-depth understanding of its many facets, including the development of a system to help facilitate the tracking, monitoring and assessment of change. It is this need for understanding wellbeing in a more holistic way in the context of rapid change and the desire to assess change in terms of the different components of wellbeing that is the point of departure in our desire to construct, measure and apply Arctic social indicators (ASI). 
The motivation to construct, measure and apply Arctic social indicators dates back to the early years of the Arctic Human Development Report process. In the first years of the twenty-first century, the Arctic Council commissioned the first Arctic Human Development Report (AHDR), which was developed under the auspices of the Icelandic Chairmanship of the Arctic Council (2002-2004). Its main objective was to provide "a comprehensive knowledge base for the Arctic Council's Sustainable Development Program," which could serve as a point of departure for assessing progress in the future (AHDR, 2004:15). The first AHDR presented a point of departure for the discussions of human development in the Arctic. During the process of completing the AHDR the steering group, which included broad representation from the permanent participants of the Arctic Council, identified three thematic or so-called domain areas that help move our discussion of human wellbeing in the Arctic beyond the usual domains included in the United Nations Human Development Index (UNHDI) - describing aspects of wellbeing that are considered prominent features of wellbeing in the Arctic. These are:

- Fate control - guiding one's destiny.

- Cultural vitality - belonging to a viable local culture.

- Contact with nature - interacting closely with the natural world (AHDR 2004:11).

These three aspects of Arctic human development are relevant to all Arctic residents of both indigenous and non-indigenous populations. Indeed, ASI is concerned with the wellbeing of all residents of the Arctic region, although the level of relevance may differ. In some regions of the Arctic the identified domains may be more relevant to indigenous livelihoods just as geographical and other factors, such as self-government arrangements and the importance of large scale resource projects, may affect their relevance.

In its policy-relevant conclusions, the AHDR noted the need to develop a system for tracking trends in human development in the Arctic over time, through the identification of a set of indicators (AHDR 2004:11). It proposed that the development of a system for monitoring change in wellbeing and for tracking long-term trends would be extremely helpful from the perspective of those involved in the policy process. The ability to track change enabled by systems like those introduced by ASI presents an important tool for measuring change and facilitating priority setting not only for policy makers but for a diverse set of Arctic stakeholders. Thus, ASI-I 
was formulated to fill a critical gap identified by the AHDR: to devise a set of Arctic social indicators to help facilitate monitoring of trends in human development. In many ways it represents a pioneering attempt at creating a system for tracking change in Arctic human wellbeing and, in terms of the small suite of ASI indicators (ASI, 2010), for understanding the direction of change.

ASI-I chose six domains in which to develop indicators for monitoring human development, which were the three domains identified by the AHDR (2004), as well as three domains constituting elements of the UNHDI. ASI indicators were developed during a process spanning the period 2006-2009 for the following domains:

- Health and Population.

- Material Wellbeing.

- Education.

- Cultural Wellbeing.

- Contact with Nature.

- Fate Control.

ASI-I devised indicators based on a strict set of selection criteria. A small set of indicators - the ASI suite of 7 indicators - was identified as a set which could assist those with an interest for a quick overview of the state of human development in the Arctic, at a reasonable cost in terms of time and other resources. Naturally, a small suite of indicators carries important trade-offs when we try to strike a balance between using a single indicator representing each of the identified domains, versus the alternative option of attempting to obtain a more nuanced picture by choosing a broader range of indicators for each domain. The discussion of this trade-off has been the focus of much debate. While the ASI-I mandate was to develop a small suite of indicators, some nagging doubts about the real cost of this trade-off as well as a genuine desire to ensure as accurate a measurement as possible of each individual indicator and of wellbeing overall left us with a compromise in terms of the number and type of indicators put forward: ASI-I thus presents a small suite of indicators but in addition it offers a broader set of indicators for those interested in measuring wellbeing using different, or a broader range, of indicators. While using a large suite of indicators may have a certain appeal, it does come at a significant cost in terms of time and other resources. It also runs the risk of setting high costs which prevent the use of the system, or at best only infrequently, when resources allow. But change is occurring fast in the Arctic, and this calls for a system that in 
contrast to large-scale surveys can be applied with higher frequency or updated on an on-going basis. The ASI mandate was to come up with a suite of indicators that could be measured at a reasonable cost, thereby making the system more accessible and enabling the application at more frequent and regular intervals.

ASI-II is a follow-up activity to Arctic Social Indicators (ASI, 2010) and the Arctic Human Development Report (AHDR, 2004). Following in the footsteps of AHDR and ASI-I, ASI-II is produced under the auspices of the SDWG. The objectives of the current volume of ASI are to measure the final set of recommended ASI indicators; to systematically identify and describe data challenges; to conduct a series of regional case studies to illustrate and further test the strength and applicability of the selected ASI indicators; to draw conclusions about the ability of ASI to track changes in human development and to show its strength in making inter-regional comparisons; and to formulate policy relevant conclusions for the long-term monitoring of human development. ASI-II also helps facilitate continuity between AHDR processes and provides input into the Arctic Council endorsed assessment of Arctic human development.

The core content of ASI-II is a set of carefully selected case studies. Five case studies form the basis for drawing conclusions about the applicability of the ASI set of indicators and for formulating policy relevant conclusions. Case studies are performed on the following regions: SakhaYakutia; the West-Nordic Region; Northwest Territories; Inuit Regions of Alaska, and the Inuit World, using Survey of Living Conditions in the Arctic (SLiCA) to augment ASI. 
Drying of fish, Kuumiut, East Greenland

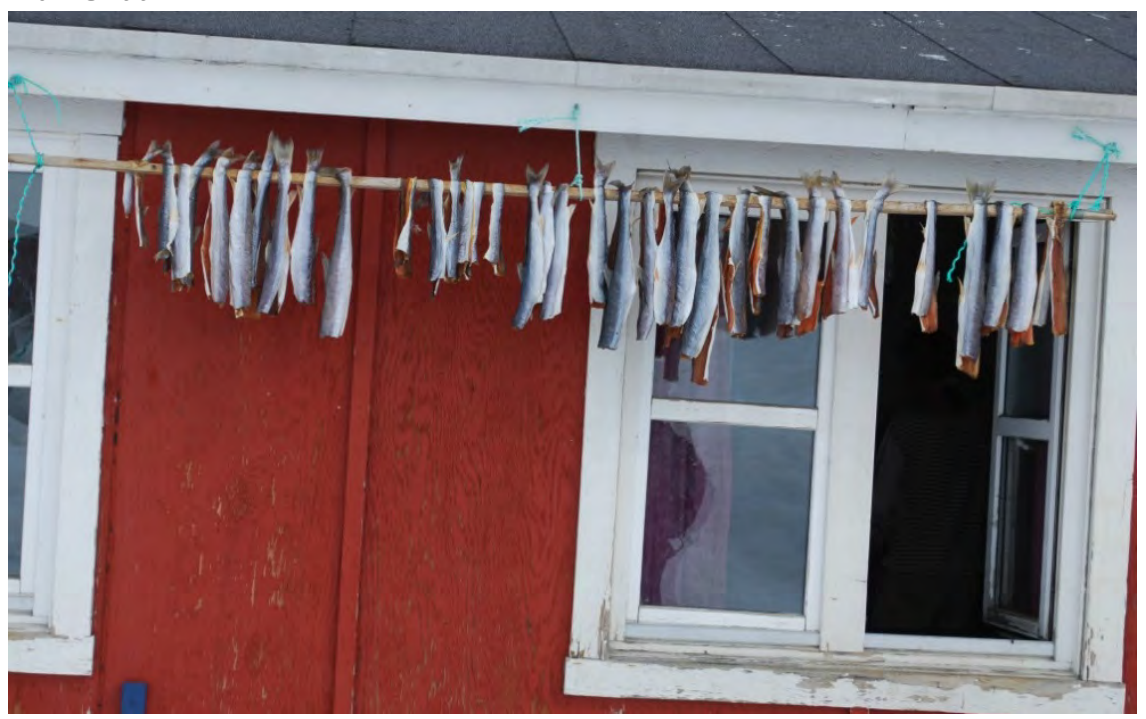

Photo: Rasmus Ole Rasmussen.

Let us take a look at the concept of human development and its measurement. Though relatively easy to grasp conceptually, the idea of human development poses problems when it comes to empirical applications. To meet the challenge of devising usable measures of human development, the work of the UNHDI was considered. The UNHDI is based on the premise that human development is a multi-dimensional phenomenon. It has achieved considerable influence as a measure of trends in human welfare over time at the level of individual countries. The UNHDI is a composite index with three components: life expectancy at birth, education (represented by a combination of adult literacy and school enrolments), and gross domestic product (GDP) per capita. Although controversial in some quarters, the UNHDI has made an important contribution to thinking about human development and social welfare more generally. As emphasized earlier, in an effort to understand human development in the Arctic, the UNHDI was used as a point of departure in the AHDR and ASI processes. This effort soon revealed an anomaly that was to become one of the central issues in the preparation of the first volume of the AHDR. As argued by Young (2010), many areas of the Arctic and especially the more remote areas with substantial indigenous populations would not achieve high scores on the UNHDI. Does this mean that human development and wellbeing is less in the Arctic? Not necessarily. A different set of domains will give a different insight into wellbeing. The critical challenge is to identify the relevant domains; i.e. domains that 
reflect what the Arctic population considers important aspects of human development. Many Arctic communities do not rank high in terms of life expectancy, particularly among indigenous peoples where suicide rates and accidental-death rates are high. Most Arctic residents today are literate, but school enrolments, especially at the secondary and tertiary levels, are comparatively low in the Far North. Also GDP per capita is often deceptive as a measure of wellbeing in the Arctic. Much of the income associated with extractive industries flows out of the Arctic and into the income streams of large multinational corporations. GDP per capita at the community level is comparatively low in many parts of the Arctic and does not take into account transfer payments and the informal or subsistence economy. Nonetheless, despite the relatively low score on measures found in the UNHDI, many individuals in this region exhibit a strong sense of wellbeing (Young, 2010). Thus, there are aspects of human development and wellbeing that are prominent in the Arctic but not captured in measures found in the UNHDI. Subsequently, the AHDR process identified the additional three domains listed earlier, which all constitute critical domains in the ASI work: Fate Control; Cultural Wellbeing and Cultural Vitality; and Contact with Nature (AHDR, 2004; ASI, 2010).

\section{Bridge in Krasnoyarsk over the Yenisei River, one of the major connections to the Arctic in Russia}

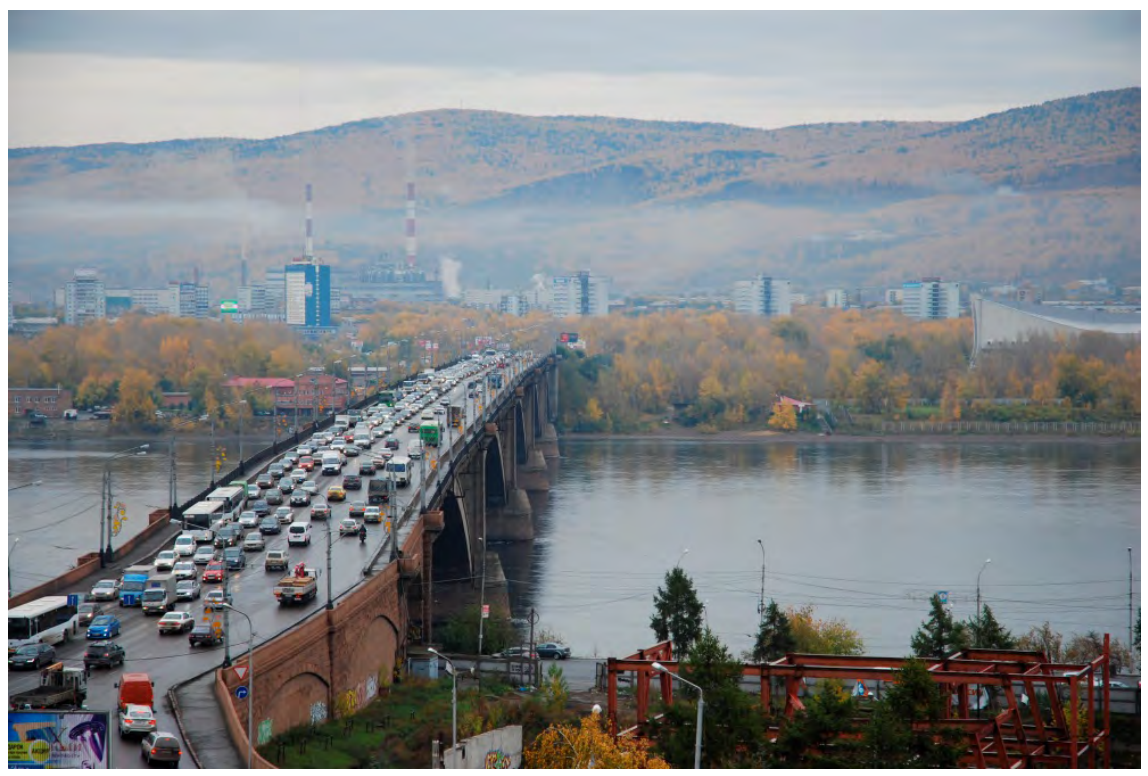

Photo: Rasmus Ole Rasmussen. 
Fate control is a matter of being in charge of one's own destiny. Arctic residents have argued that fate control is a matter of profound importance to them. This is true not only of the region's indigenous peoples but also of many settlers who have made a conscious choice to reside in the Arctic perceived as a frontier area in which the individual can escape many of the restrictions or constraints associated with life in the mainstream of modern societies (Fondahl et al., 2010; ASI, 2010).

Cultural vitality is another value of great importance to many of the Arctic's residents and particularly to indigenous peoples, even under conditions of rapid social change that have eroded aboriginal languages and brought technologies (e.g. television and various forms of IT) to the region that make it easier for residents of remote areas to compare their lifestyles with those prevalent in other parts of the world. Cultural vitality is a matter of being surrounded by and able to interact regularly with others who share belief systems, norms, and a common history (Schweitzer et al., 2010; ASI, 2010).

Contact with nature or the opportunity to interact on a regular basis with the natural world constitutes the third supplementary dimension of human development. The residents of the Arctic are clear in their thinking about contact with nature as a significant element in their quality of life. Many Arctic residents come into contact with nature on a day-to-day basis as they go about their routine activities. They value this aspect of life in the Arctic (King et al., 2010; AHDR, 2004; ASI, 2010).

The Arctic includes about four million inhabitants, of whom about $10 \%$ are indigenous. Arctic demography is diverse, with different areas characterized by varying shares of indigenous, settler and transient populations, varying levels of urbanization, and different rates of population growth or contraction. The Arctic population tends to be younger than that of the national average. Some areas are characterized by high levels of out-migration, which tends to involve a larger number of females than males (Maps 1-4). 
Map 1: Population in the Arctic regions

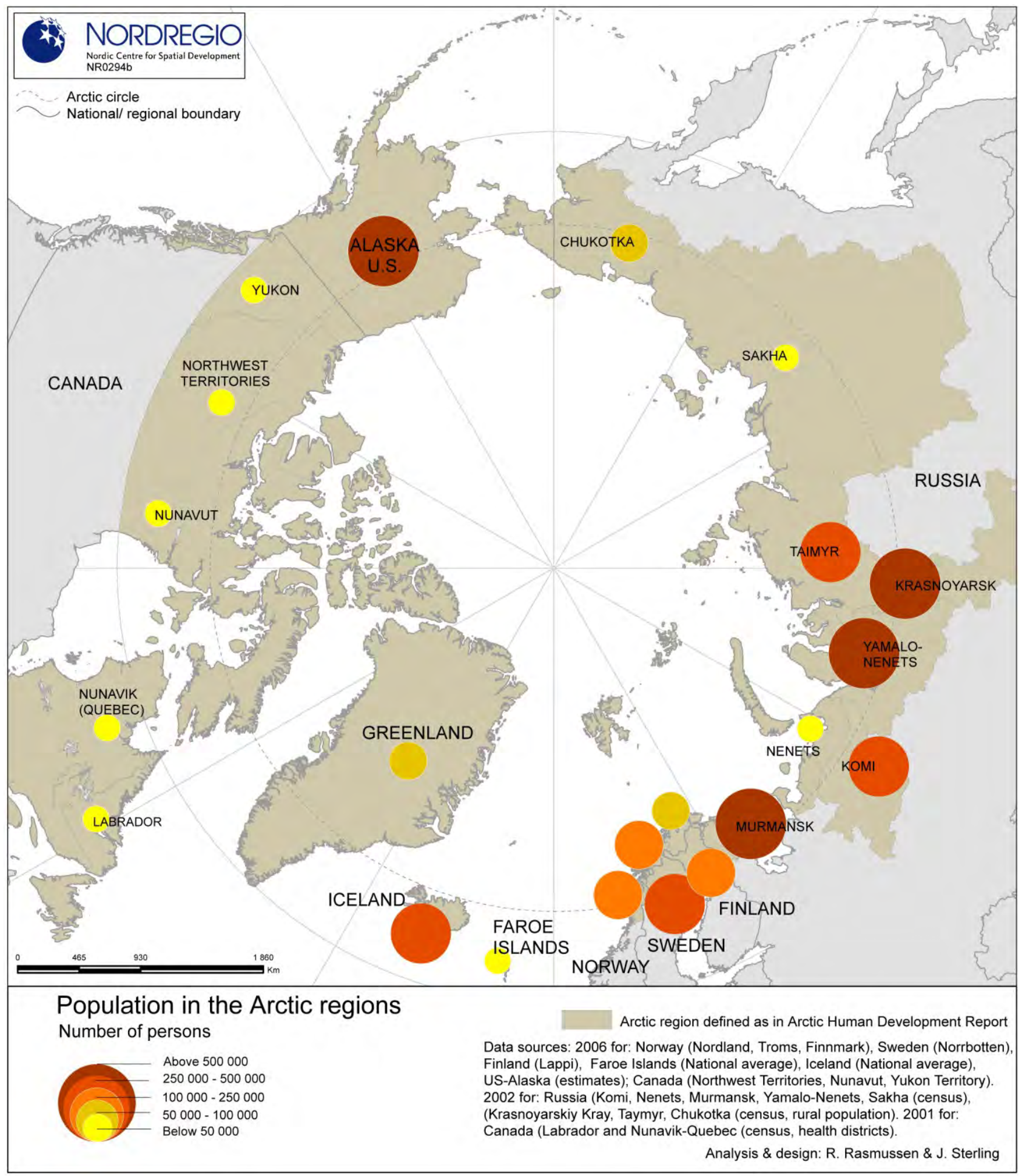


Map 2: Indigenous Population in the Arctic Regions

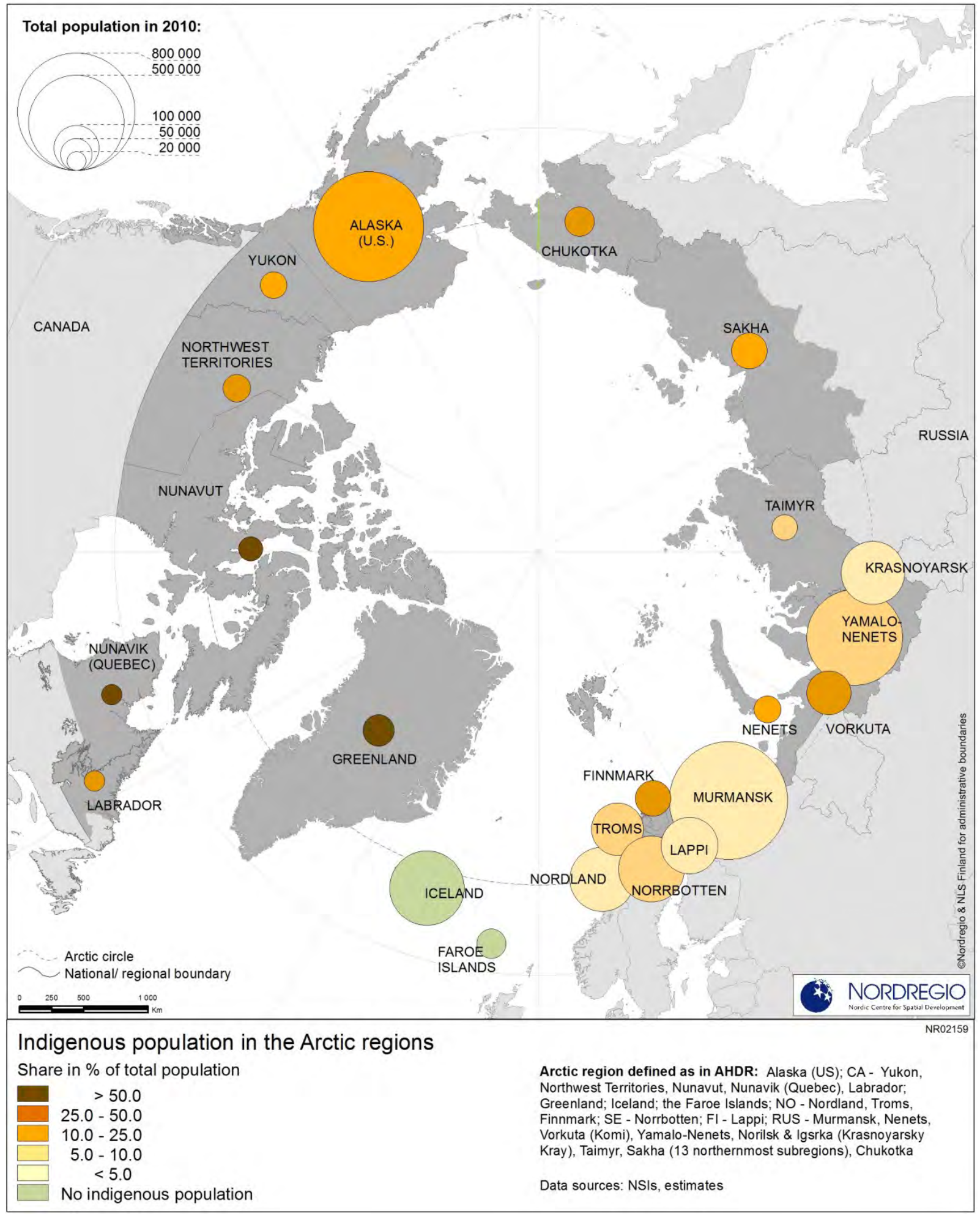


Map 3: Population in Cities and Rural Settlements in 2010

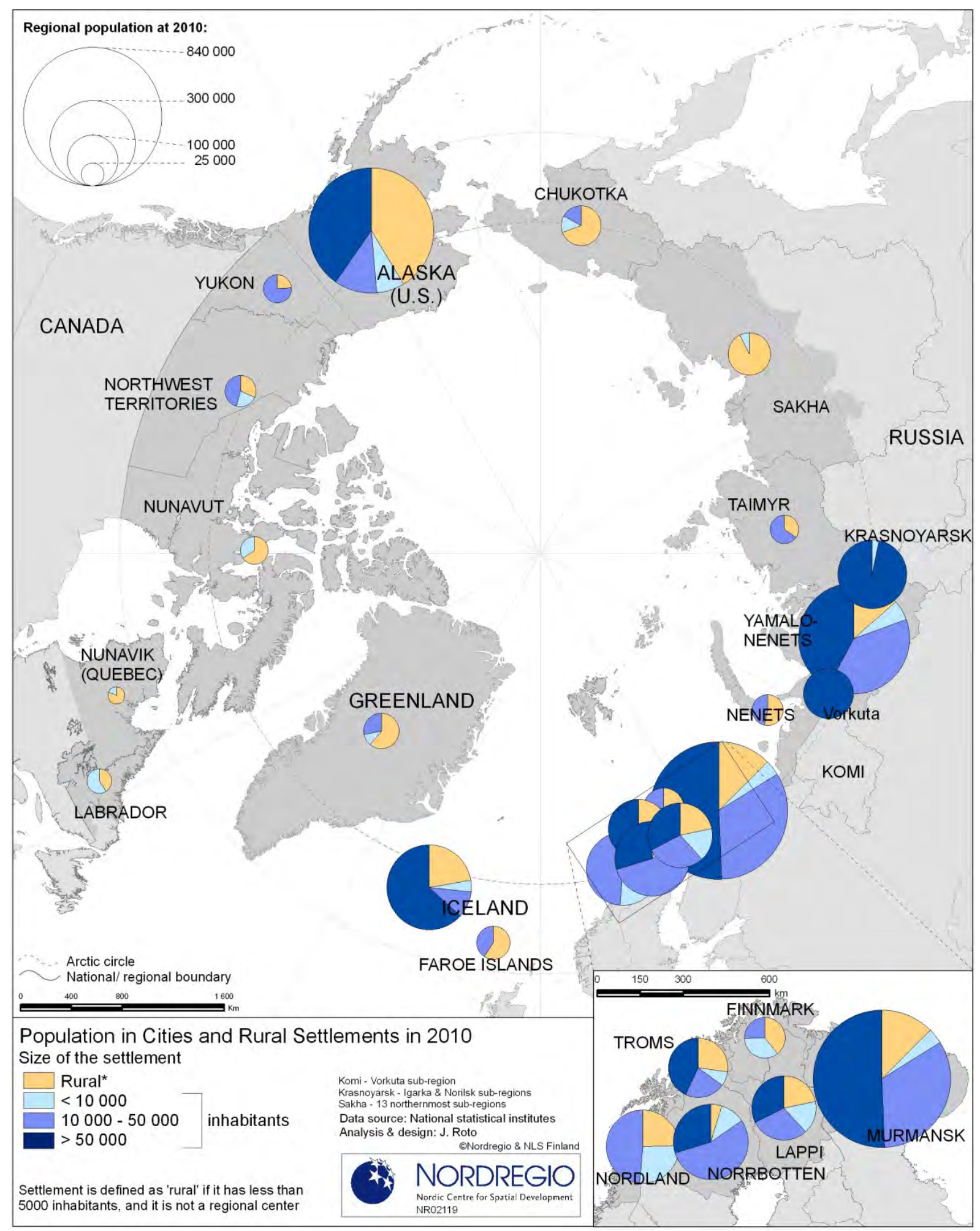


Map 4: Population Change in Arctic Settlements in 1990-2010

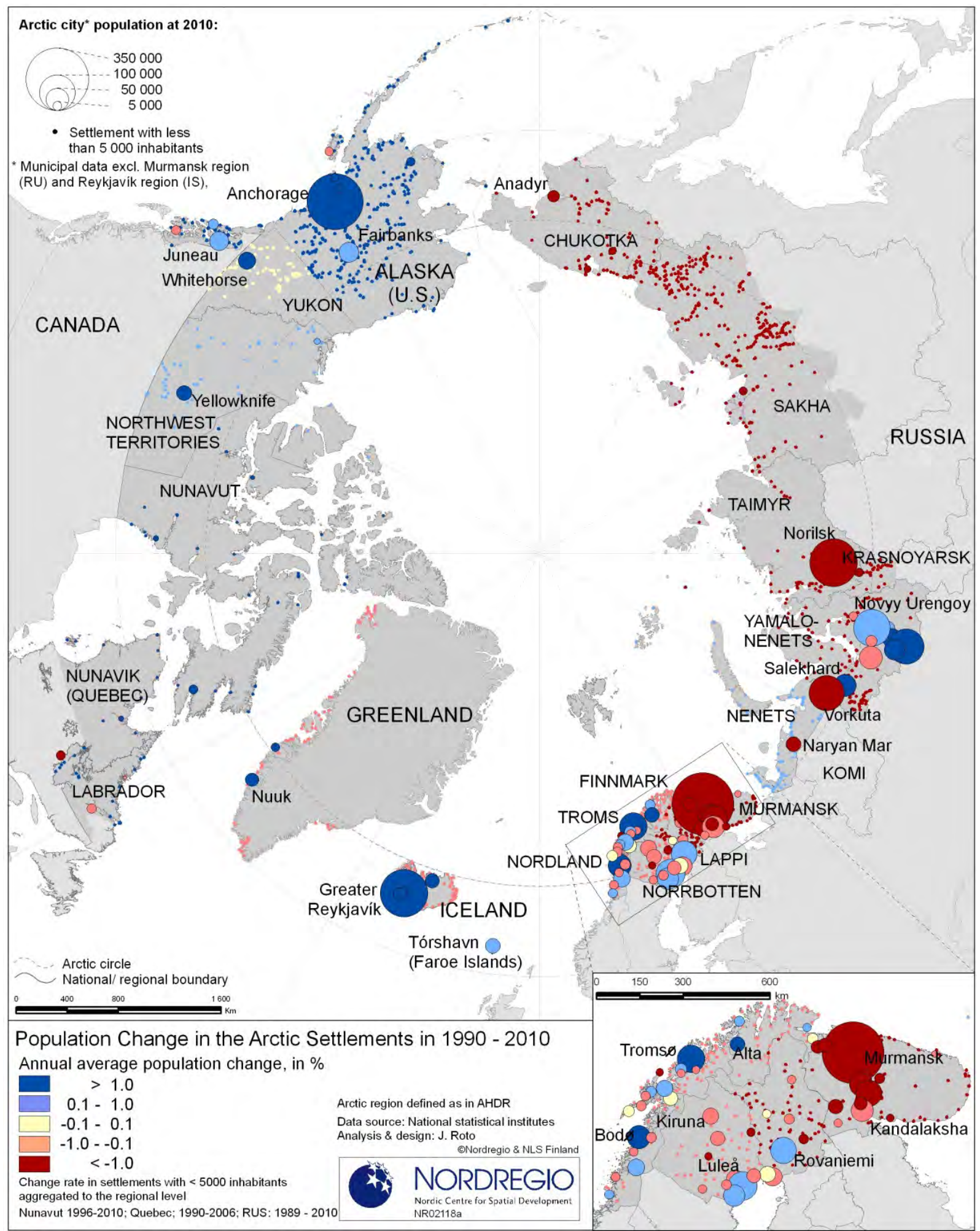


Disparities in health are observed both across regions and ethnic groups, with the health status of northerners in each Arctic state being considerably worse, on average, than the state's national average. While infant mortality has been declining in the Arctic, mental health remains a critical challenge as measured, for example, in terms of the persistently high rates of suicide, particularly among the male population (ASI, 2010).

The formal economy of the Arctic is largely based on natural resource extraction. Many of these resources are of critical geopolitical importance, both nationally and globally. However, a large share of resource rents flow out of the Arctic and Arctic communities are often highly dependent on state subsidies. Primary (extraction) and tertiary (service) sectors predominate in Arctic economies, with little development of secondary activities (manufacturing) due to the high cost of processing. At the same time informal economic activities are of great importance in many areas of the Arctic: a combination of subsistence activities with wages or transfer payments is a common strategy for pursuing wellbeing among Arctic residents (AHDR, 2004; ASI, 2010). Labour market participation varies throughout the Arctic region, with the lower rates of participation found in Arkhangelsk, for example, compared with higher rates in Greenland and the Northwest Territories. The proportion of the Arctic population working in the primary, secondary and tertiary sectors also vary considerably across the Arctic; as does the rate of labour market participation, as illustrated in the following series of maps (Maps 5-8). 
Map 5: Labour Market Participation in the Working Age Population

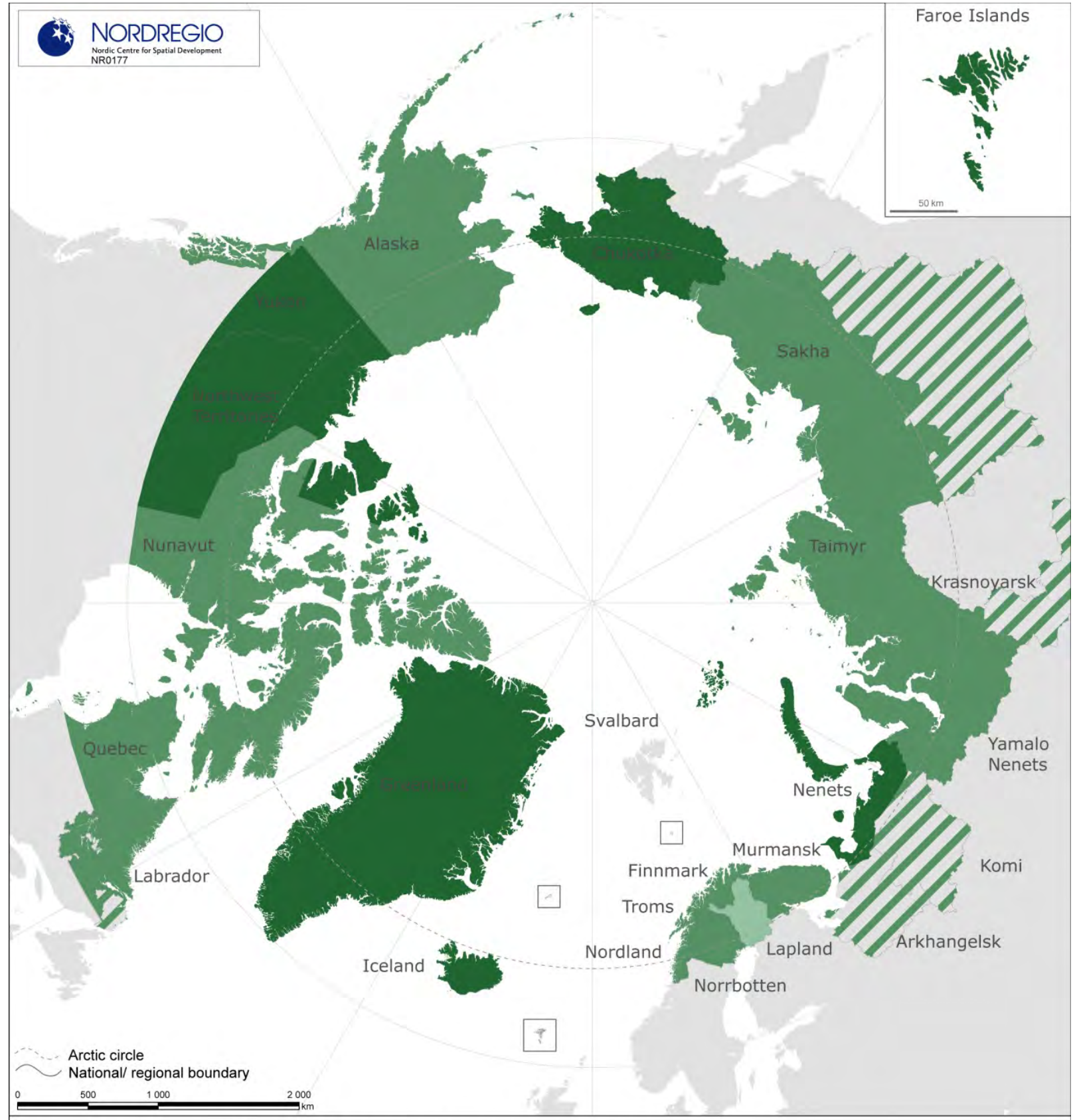

Labour market participation, in the working age population

2006, \%

$90-100$

$80-90$

$70-80$

Labour market participation: proportion of the population which is employed or unemployed $65-70$ 
Map 6: Proportion of Employees Working in the Primary Sector

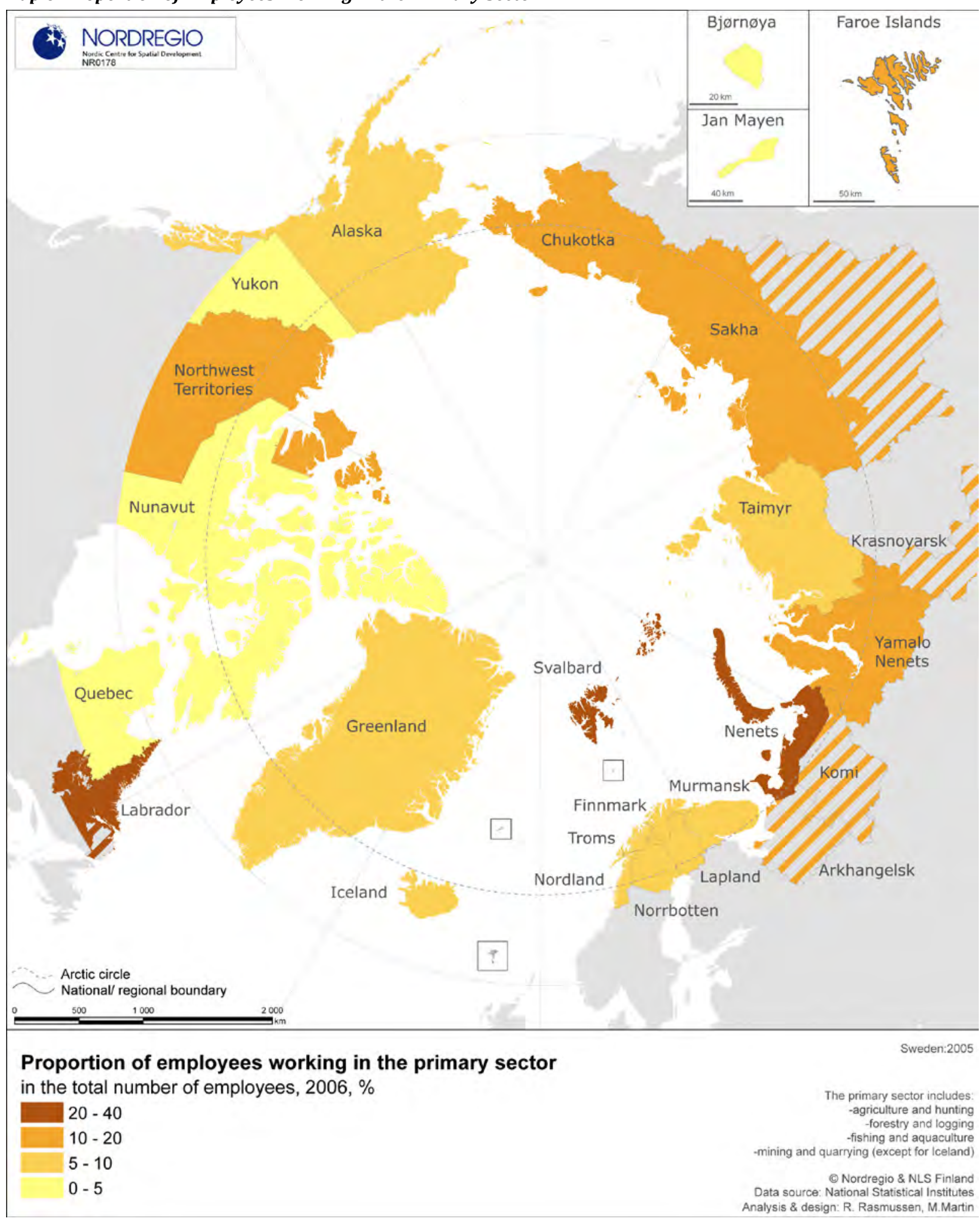


Map 7: Proportion of Employees Working in the Secondary Sector

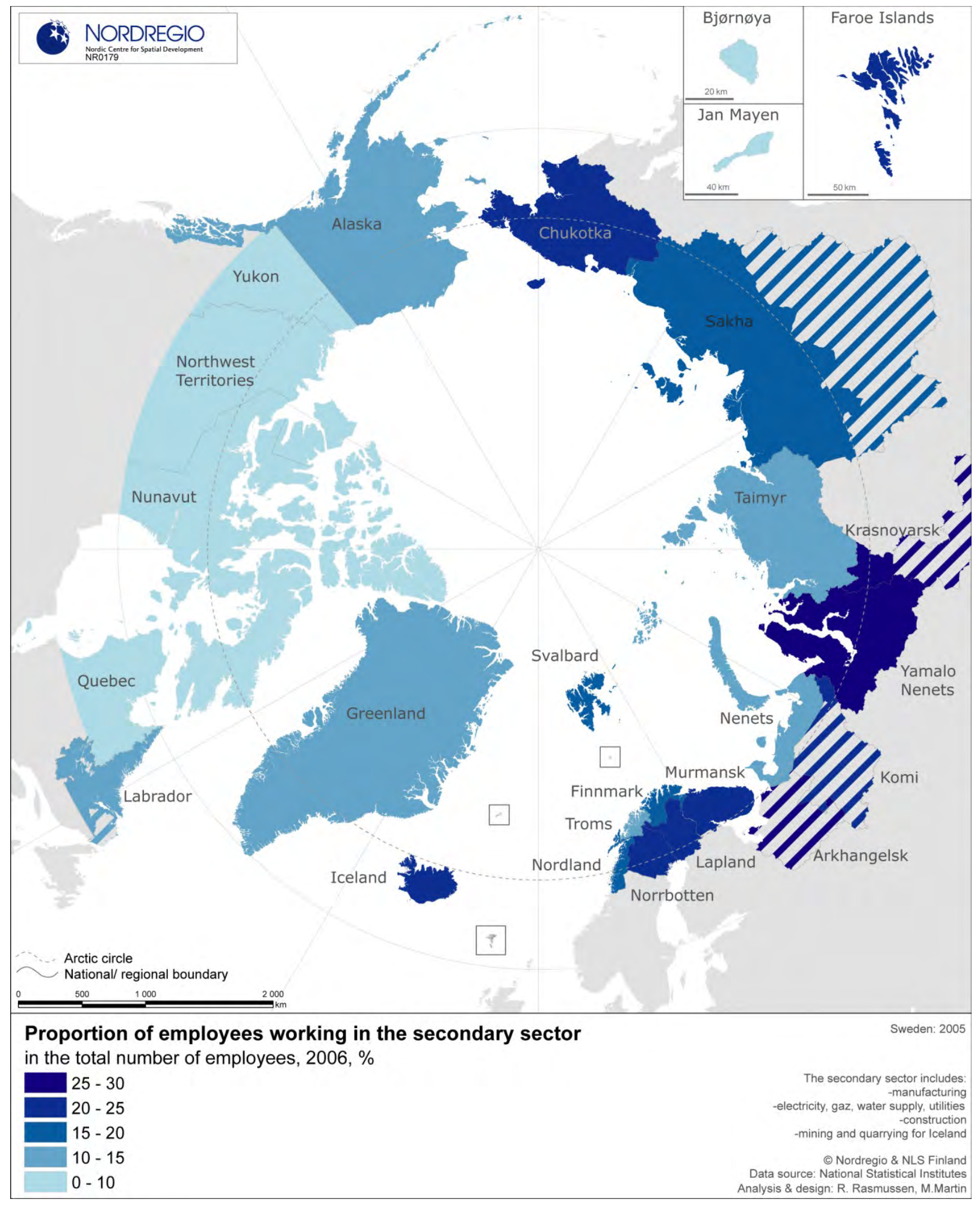


Map 8: Proportion of Employees Working in the Tertiary Sector

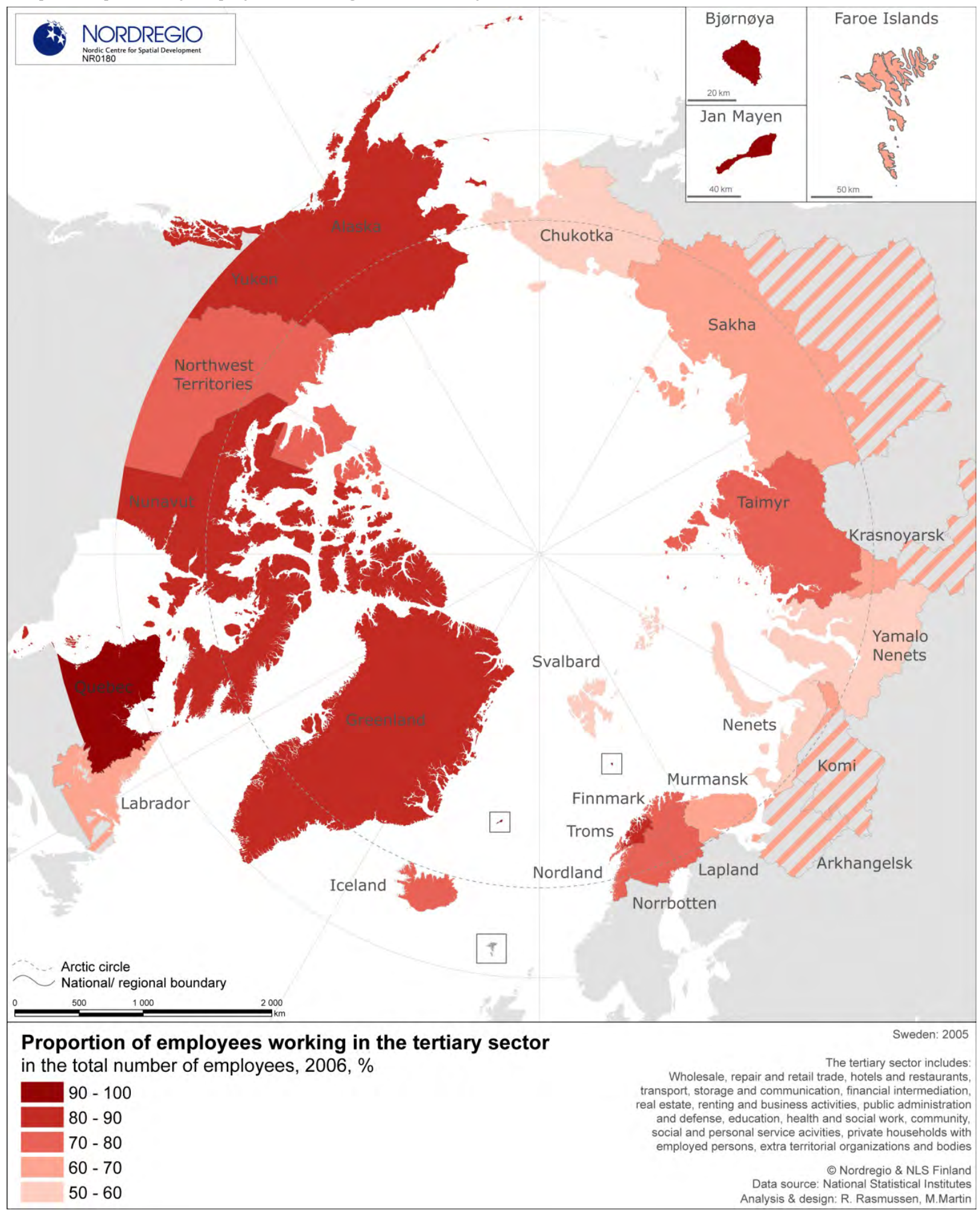




\section{Historical means of transportation and housing in Central Siberia. Museum of Krasnoyarsk}

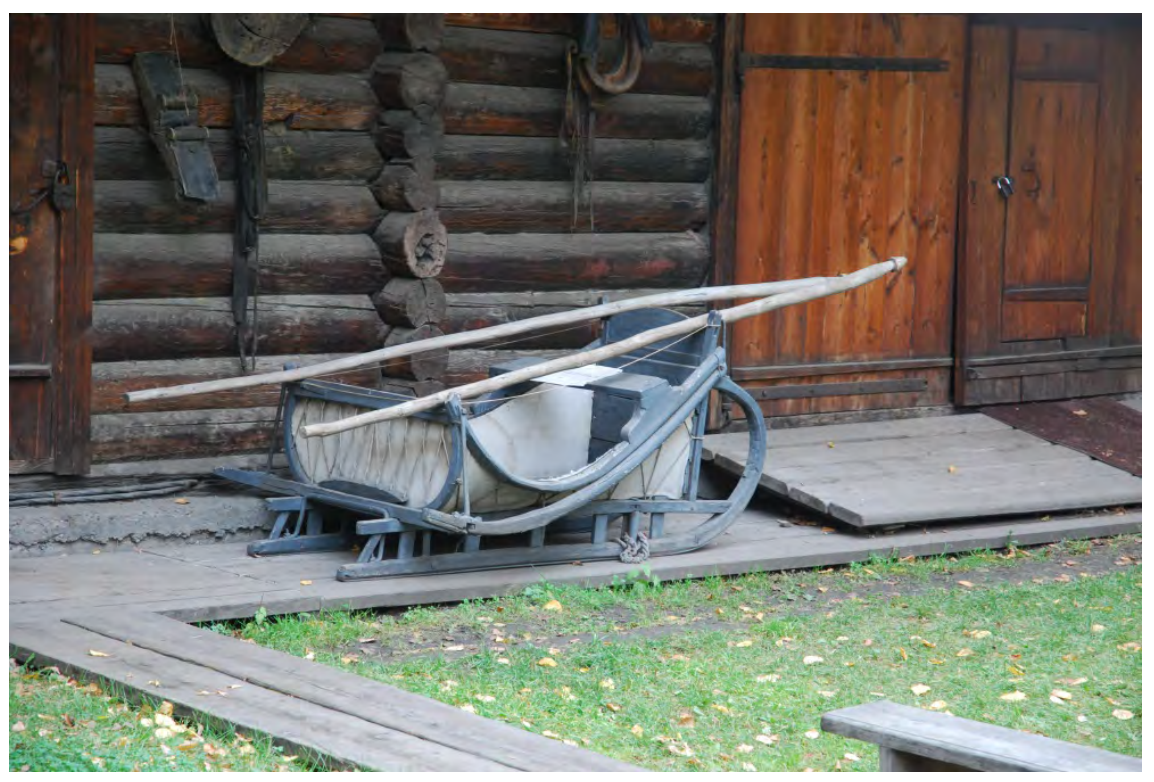

Photo: Rasmus Ole Rasmussen.

Education in the Arctic is characterized by lower rates of attainment, particularly among indigenous residents and more remote local communities. One challenge deals with access, which is also reflected in the increasing number of females leaving northern communities in pursuit of higher education elsewhere. The introduction of compulsory formal education has been challenged by the vast, thinly populated spaces of the Arctic, which have been managed by residential schooling. Very uneven distribution of higher educational opportunities has resulted in low utilization by Arctic residents, especially by males. More recently, a move to see education as a distributed resource is addressing issues of access, as is the greater inclusion of content that speaks to local needs and conditions (ASI, 2010).

The Arctic has been affected by both global environmental change and globalization. Human-environment connections are especially close in the Arctic and for many local communities changes to sea ice, permafrost, storm surges and increased coastal erosion is going to have direct consequences at many levels, including for subsistence livelihoods, travel on ice, the ability to engage in cultural pursuits, and for community infrastructure and housing. But clearly, change in the Arctic is more than a changing climate. As we have seen above, there is a great concern for rapid socio-economic change and the many facets of globalization interacting with different sources of wellbeing - the sources of wellbeing that make up ASI. 
The AHDR (2004) observes that "[h]uman societies in the circumpolar North are highly resilient; they have faced severe challenges before and adapted successfully to changing conditions" (AHDR, 2004, 230). Many observers have documented the historical role of adaptiveness among Arctic residents as a source of resilience in local communities. Although circumstances have changed in many of these communities in ways that increase their vulnerability, it would be a mistake to overlook the capacity of Arctic peoples to adapt to a range of emerging stresses arising from the effects of globalization and biophysical developments like climate change. Still, Arctic communities today are subject to social, cultural, economic, and environmental forces that have given rise to a suite of interactive stresses affecting the cultural vitality dimension of human development (AHDR, 2004; ASI, 2010).

\subsection{Social Indicators}

Indicators are useful aids for planning, informing policy, and for guiding decisions and actions. They are valuable simply in building awareness of current conditions and trends over time. Indicators are used by some groups to predict change, while other groups use them to promote change (ASI, 2010).

Groups like governments and non-governmental organizations are increasingly using indicators to monitor trends in human development. Indicators, as simple measurements of key phenomena in complex human systems, enable us to track the direction and rate of change, and thus performance in various domains, as well as progress toward specified goals.

Human development is extraordinarily complex. To document all its facets would be impossibly complicated, time-consuming, and costly. Even a single domain (or category for the construction of indicators), such as education or health, has countless aspects that could be measured. A pragmatic approach is to choose a small, representative set of indicators for key domains, to track over time and across space. Such indicators condense real-life complexity into a manageable amount of meaningful information. They are proxy measures used to infer the condition and, over time, the trends in a system.

Such indicators may be quantitative or qualitative measurements. Often a statistic is used as a simple measurement of what is happening in a system. Indicators should be clearly defined, reproducible, unambiguous, understandable and practical. They should be relatively easy to measure in an accepted manner, stable, and suitable for use in longitudinal anal- 
yses. Harmut Bossell paraphrases a famous Einstein quote in observing that indicators should be "as simple as possible but not too simple" (Bossell, 1999:11). They must also reflect the interests and views of different stakeholders.

Efforts to develop a set of indicators to measure human development require striking a balance between the analytic attractions of relying on a single indicator and the temptation to introduce a large number of indicators in the interests of developing a more accurate picture of complex and multi-dimensional phenomena (ASI, 2010).

\subsection{Developing a Set of Arctic Social Indicators: The Process}

The ASI work to devise a small number of tractable indicators to be used in tracking changes in key elements of human development in the Arctic over time started in 2005. An international working group was constituted with representation from a broad range of disciplines, including Anthropology, Demography, Economics, Education, Geography, Linguistics, Political Science, and Sociology. Indigenous participants were actively solicited during the start-up phase. The first ASI report was tabled in 2010. The process involved in ASI-I included the identification of the relevant domains for indicator selection; the establishment of the key criteria for indicator selection; and group discussion and selection of potential indicators within the identified domain areas; and finally the preliminary testing of the viability of the candidate indicators.

The ASI working group confirmed the three domains suggested by the AHDR: fate control, cultural vitality, and contact with nature, in addition to the domains represented in the UN HDI; material wellbeing, education, and health/population. Indicators specific to the Arctic context were to be developed for these six domains. Criteria for selection of indicators were developed during the first phase of ASI. Selection criteria chosen were data availability, data affordability, ease of measurement, robustness, scalability and inclusiveness.

The ASI working group adopted the selection criteria as a set of principles to guide indicator selection, recognizing that the criteria themselves were not precisely defined, and that trade-offs in their application had to be considered. For instance, measures that might be easily available may be relatively less robust than others that are less accessible. Thus, criteria were applied not to rule out candidate indicators but to 
consider the challenges each indicator might pose across several conditions if it were to be selected.

In creating a tractable set of social indicators for the Arctic, several criteria were initially considered in order to evaluate candidate indicators. Six criteria were ultimately chosen for this purpose: data availability, data affordability, ease of measurement, robustness, scalability and inclusiveness. ASI (2010) provides a brief explanation for each of the selection criteria:

Data availability concerns whether the data that an indicator will use as a measure exist, and whether they are retrievable. A number of the indicators considered could draw on data collected by national agencies. Other considerations in terms of availability included whether nationally collected data are comparable across countries, and whether the data are accessible in hard copy or electronic format from the collecting agency, or whether data could be compiled by researchers from other existing information. A further element of availability is the periodicity with which regularly collected data are gathered: to monitor human development in the rapidly changing socio-economic and environmental context of the Arctic, data collected on at least a five-year frequency were preferred.

The criterion of data affordability considers the on-going costs of data collection and monitoring. Can the indicator (continue to) be measured at a reasonable cost? Indicators that can be garnered from data sets that are regularly collected, for example during government censuses, are more affordable than those requiring special tabulation or primary data collection. If new data collection is necessary, could the data be collected using no more than ten minutes of interview time?

Ease of measurement takes into account how simple and straightforward the data are to measure in a broadly accepted manner. Here issues of whether the indicator measure is quantitative or qualitative, nominal, ordinal, interval or ratio, etc., are considered.

Robustness considers aspects of the temporal stability of the indicator over time. Will the indicator track changes over time? Will it remain stable and relevant over time (for instance, not lose its significance?). This criterion also considers the sensitivity of the indicator - how responsive is it to change? Will it measure change over time?

Scalability is concerned with the extent to which the data used to measure the chosen indicator can be collected at different geographical scales. For instance, can the data be collected at the individual, household and community level? Can it be collected at the regional and national level?

The criterion of inclusiveness when selecting indicators, in the case of Arctic social indicators, is the indicator inclusive of all sectors of the Arctic population: male and female, indigenous and non-indigenous, 
rural and urban, etc. While a few of the indicators chosen focused on the indigenous Arctic population, the project ensured that the indicators as a group addressed human development for the whole Arctic population.

An indicator should be the most accurate statistic for measuring both the level and extent of change in the social outcome of interest. It should adequately reflect what it is intended to measure and, ideally, there should be wide support for the indicators chosen so they will not be changed regularly. It is critical that the chosen indicators are consistent over time and across places, as the usefulness of indicators is related directly to the ability to track trends over time and to compare levels of wellbeing in different regions. There are a number of possible trade-offs that need to be considered when selecting the best indicator among a set of possible indicators. The desire for longer time series rather than single measurements may be compromised if the measure changes substantially from one year to the next. Also, if the measure is collected by survey, the sample size may be too small, making a chosen indicator less reliable. Furthermore, some data are not available for smaller regions (ASI, 2010). Several of the indicators presented in ASI-I (2010) have weaknesses related to availability of data, affordability, and scalability and applicability to both indigenous and non-indigenous inhabitants of the Arctic.

\section{Technical Definitions}

In the following we provide the technical definition of the chosen ASI indicators for each of the six ASI domains. The technical definitions provide a brief description or basic formula for measuring the indicators. Under ideal circumstances, all of the regions of the Arctic at different scales would have a common standard for data protocol, which would enable us to measure the indicators using the same method across the region, thus also enabling us to attempt scientifically valid comparisons across time and space. However, the challenges with data in the Arctic region prevent us from applying standard measures and also restrict our ability to make broad-scale regional comparisons for most indicators across time. The five case studies highlight the challenges in measuring ASI indicators and show the adjustments needed for specific indicators due to, for example, lack of access to data and/or variations in regional context. 
(1) Health and Wellbeing Domain

Infant mortality is the number of deaths of children under one year of age per 1,000 live births.

INFANT MORTALITY $=\frac{\text { NUMBER OF DEATH UNDER } 1 \text { YEARS OF AGE }}{\text { LIVE BIRTHS }} * 1000$

Net migration is the difference between in-migration and out-migration.

NET MIGRATION = INMIGRATION - OUT MIGRATION

NET MIGRATION RATE $=\frac{\text { INMIGRATION }- \text { OUTMIGRATION }}{\text { TOTAL POPULATION }} * 1000$

(2) Material Wellbeing Domain:

Per capita household income is the combined income of all households per capita

PER CAPITAL HOUSEHOLD INCOME $=\frac{\text { TOTAL HOUSEHOLD INCOME }}{\text { TOTAL POPULATION }}$

(3) Cultural Wellbeing Domain

Language retention rate is a percentage of a population that speaks its ancestral language

LANGUAGE RETENTION RATE $=\frac{\text { POPULATION THAT SPEAKS ANCESTRAL LANGUAGE }}{\text { TOTAL POPULATION OF THAT ANCESTRY }} * 100$

(4) Contact with Nature Domain:

Consumption of traditional food is a per capita intake of traditional food (in $\mathrm{kg}$ ).

Harvest of traditional food is a total weight of traditional food harvested in a given period (in $\mathrm{kg}$ )

(5) Education Domain:

Post-secondary completion rate is the proportion of students successfully completing post-secondary education within a given number of years from entry

POST-SECONDARY COMPLETION RATE

NUMBER OF STUDENTS COMPLETING POST-SECONDARY EDUCATION AFTER X YEARS $* 100$ NUMBER OF STUDENTS ENTERING POST-SECONDARY EDUCATION

(6) Fate Control Domain:

Political control: percentage of indigenous/local members in governing bodies

POLITICAL CONTROL $=\frac{\text { NUMBER OF INDIGENOUS AND LOCAL MEMBERS IN GOVERNING BODIES }}{\text { TOTAL NUMBER OF GOVERNING BODIES MEMBERS }} * 100$

Control over land/resources: percentage of surface lands legally controlled by indigenous/local inhabitants

CONTROL OVER LAND $=\frac{\text { AFREA UNDER LEGAL CONTROL OF INDIGENOUS AND LOCAL POPULATIONS }}{\text { TOTALAREAOFTHE REGION }} * 100$

Economic control: percentage of public expenses generated within the region raised locally

ECONOMIC CONTROL $=\frac{\text { AMOUNT OF PUBLIC EXPENSES IN THE REGION RAISED LOCALLY }}{\text { TOT AL AMOUNT OF PUBLIC EXPENSES IN THE REGION }} * 100$

Control over knowledge construction (= language retention rate) is a percentage of a population that speaks its ancestral language

CONTROL OVER KNOWLEDGE CONSTRUCTION $=\frac{\text { POPULATION THAT SPEAKS ANCESTRAL LANGUAGE }}{\text { TOTALPOPULATIONOFTHAT ANCESTRY }} * 100$

Note: See ASI (2010) for more details on the definitions of ASI indicators. 


\subsection{Summary of ASI indicators}

This section briefly summarizes the ASI indicators identified and selected during the first phase of ASI (ASI-I), and the rationale for the choice of indicator. The indicators are explored in depth in the five case studies presented in PART II of this report. For further details on the choice of indicators, including a comprehensive list of indicators being considered and discussion on the final selection of a "small suite of ASI indicators", please see ASI (2010).

\section{(1) Health and Population Domain}

In ASI-I infant mortality was chosen as the best indicator for health based on ASI selection criteria. A key rationale put forward by the ASI Health and Population team was that infant mortality relates directly to quality of life and people's sense of wellbeing, and it integrates a wide range of health-relevant conditions including health infrastructure, sanitation, nutrition, behavior, social problems and disease. Net-migration was chosen as the best indicator for population - again based on weighing the various selection criteria. The main rationale for doing so was that netmigration reflects the current local sum of various push and pull factors; it integrates different forces; and it tells something basic about where one place is heading or how it compares with others (ASI, 2010).

\section{(2) Material Wellbeing Domain}

ASI-I defined Material Wellbeing of a place as a measure of local residents' command over goods and services. A number of possible indicators were selected based on selection criteria. The table summarizing these indicators and their strength in terms of various criteria is reproduced here: 


\begin{tabular}{|c|c|c|c|c|c|c|c|}
\hline Indicator & $\begin{array}{l}\text { Data } \\
\text { Availability }\end{array}$ & $\begin{array}{l}\text { Data } \\
\text { Cost }\end{array}$ & $\begin{array}{l}\text { Ease of } \\
\text { measure- } \\
\text { ment }\end{array}$ & $\begin{array}{l}\text { Internal } \\
\text { Validity }\end{array}$ & $\begin{array}{l}\text { Robust- } \\
\text { ness }\end{array}$ & Scalability & $\begin{array}{l}\text { Inclusi- } \\
\text { veness }\end{array}$ \\
\hline $\begin{array}{l}\text { Per Capita Gross } \\
\text { Domestic Product }\end{array}$ & Tier 2 & Medium & High & Low & High & Region & No \\
\hline $\begin{array}{l}\text { Per Capita House- } \\
\text { hold Income }\end{array}$ & Tier 1 & Low & High & High & High & $\begin{array}{l}\text { Household } \\
\text { through Region }\end{array}$ & No \\
\hline $\begin{array}{l}\text { Unemployment } \\
\text { rate }\end{array}$ & Tier 1 & Low & High & Low & Medium & $\begin{array}{l}\text { Household } \\
\text { through Region }\end{array}$ & No \\
\hline Poverty rate & Tier 1 & Low & High & Low & Medium & $\begin{array}{l}\text { Household } \\
\text { through Region }\end{array}$ & No \\
\hline $\begin{array}{l}\text { Subsistence } \\
\text { harvest (weight) }\end{array}$ & Tier 3 & High & High & High & High & $\begin{array}{l}\text { Household } \\
\text { through Region }\end{array}$ & No \\
\hline Net-migration rate & Tier 1 or 2 & Low & High & Medium & Medium & $\begin{array}{l}\text { Community and } \\
\text { Region }\end{array}$ & Yes \\
\hline
\end{tabular}

Reproduced from ASI (2010), p. 62.

The ASI team on material wellbeing concluded that devising and measuring the perfect indicator of material wellbeing that captures the uniqueness of the Arctic economy and the importance of market and non-market activity and transfers is both challenging and costly. Thus, in selecting an appropriate indicator it is necessary to balance or trade-off the information provided with the cost of constructing the indicator.

Based on a range of selection criteria, four indicators were highlighted as holding promise: per capita household income, net-migration, subsistence harvest, and a composite index that takes into account each of the three sectors of the Arctic economy. Based on selection criteria ASI-I (2010) identified per capita household income as the best available indicator. One of the particularly important strengths of this indicator is that it provides a more accurate estimate of income in the North than does the standard measure of GDP. A major limitation with the income indicator, however, is that it ignores both direct services purchased with public transfers and also production in the traditional economy. Thus, until better access to data can be obtained on the non-market economy and the size of the transfer sector contribution a measure of the contribution that material wellbeing makes to overall wellbeing is incomplete (Larsen and Huskey, 2010). 


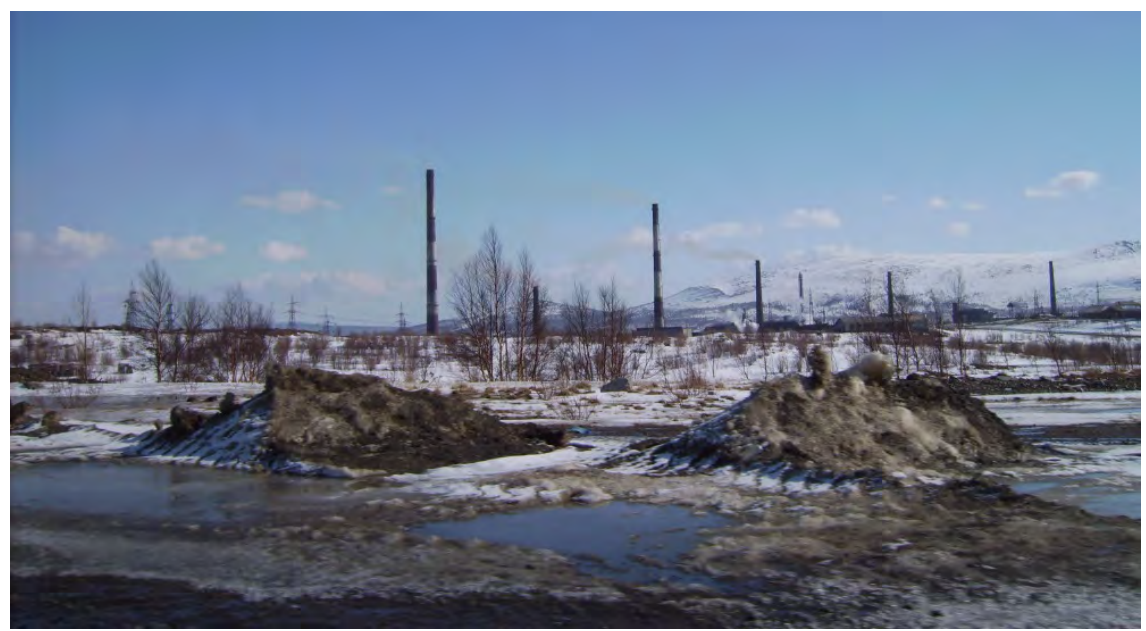

Photo: Rasmus Ole Rasmussen.

\section{(3) Education Domain}

In constructing an indicator of education appropriate to the Arctic context ASI-I decided to focus on the post-secondary level, as this allows us to encompass and recognize all forms of educational attainment at an advanced level, including the development of vocational, technical and subsistence skills and expertise as well as the completion of certificate and degree programs that are of benefit to the individual and the community (Rasmussen et al., 2010).

The following table (reproduced from ASI (2010)) provides the list of three preferred indicators identified by the ASI Education team.

\begin{tabular}{|c|c|c|c|c|c|c|}
\hline Indicator & $\begin{array}{l}\text { Data } \\
\text { Availability }\end{array}$ & $\begin{array}{l}\text { Data } \\
\text { Afforda- } \\
\text { bility }\end{array}$ & $\begin{array}{l}\text { Ease of } \\
\text { Measure- } \\
\text { ment }\end{array}$ & $\begin{array}{l}\text { Robust- } \\
\text { ness }\end{array}$ & $\begin{array}{l}\text { Scal- } \\
\text { ability*• }\end{array}$ & $\begin{array}{l}\text { Inclusi- } \\
\text { veness }\end{array}$ \\
\hline $\begin{array}{l}\text { Rationale for Indicator } 1 \text { : } \\
\text { The proportion of students } \\
\text { pursuing post-secondary } \\
\text { education opportunities }\end{array}$ & Tier 1 & $v$ & High & $v$ & $\begin{array}{l}(1,2) \\
3-5\end{array}$ & v \\
\hline $\begin{array}{l}\text { Rationale for Indicator } 2 \text { : } \\
\text { The ratio of students success- } \\
\text { fully completing post- } \\
\text { secondary education }\end{array}$ & Tier 2 & v & High & $(v)$ & $\begin{array}{l}(1,2) \\
3-5\end{array}$ & v \\
\hline $\begin{array}{l}\text { Rationale for Indicator } 3 \text { : } \\
\text { The proportion of graduates } \\
\text { who are still in the community } \\
10 \text { years later }\end{array}$ & Tier $2 / 3$ & V? & Medium & $(\mathrm{V})$ & $\begin{array}{l}(1,2) \\
3-5\end{array}$ & v \\
\hline
\end{tabular}

Reproduced from ASI (2010), p. 88. 
Of these possible indicators the team recommended as the best indicator the ratio of students successfully completing post-secondary education opportunities. The rationale behind this choice is that many factors can come into play in determining whether a student completes a program or not. Completion rates provide an indication of the level of prequalifications a student has acquired prior to entering a program. Participation in and completion of post-secondary education opportunities is one sign of a healthy community, and as such can serve as a reliable indicator of the general role of education in terms of contributing to the wellbeing of Arctic communities. This is especially the case in small, remote, indigenous communities where education can serve as a vehicle not only for achieving individual aspirations but also for community aspirations as well (Ibid.).

\section{(4) Cultural Wellbeing Domain}

The ASI team on Cultural Wellbeing and Cultural Vitality concluded that three components of cultural wellbeing are important to consider in the Arctic context: Language retention, cultural autonomy, and sense of belonging. The team suggested that one way to monitor "cultural vitality" in the many distinct Arctic societies (ethnic minorities, etc.) that do not enjoy a high degree of self-governance, is to construct a composite indicator taking into account diverse dimensions of culture (Schweitzer et al., 2010). The following table (reproduced from ASI (2010)) summarizes these findings:

Table 4: Cultural Well-being Indicators

\begin{tabular}{ll}
\hline Indicator Elements & Indicator \\
\hline $\begin{array}{l}\text { Do laws and policies exist in a given state or region that recognize institutions that } \\
\text { advocate for the cultural autonomy of national minority populations? }\end{array}$ & Cultural autonomy \\
Do institutions representing national minority cultures exist? & \\
What is the proportion of such institutions to minority peoples, e.g. are all peoples & \\
represented through such organizations? & \\
Are resources available to such institutions? & \\
Are funding policies in place and how well-resourced are they? & Language retention \\
What percentage of a population speaks its ancestral language compared with the & \\
population as a whole? & \\
What percentage of people are engaged in recreational or subsistence activities on & Belonging \\
the land? & \\
What is the relative size of the informal (subsistence-based) sector of the economy? & \\
\hline
\end{tabular}

Reproduced from ASI (2010), p. 106.

The team proposed as best indicator the cultural vitality index, a multidimensional composite indicator (incorporating cultural autonomy, language retention, and belonging), which reflects the complexities and dynamics of culture in the circumpolar North. An alternative indicator was 
also suggested - language retention, or language vitality. The rationale for doing so was that it is accepted as valid, readily understood by both policy makers and Arctic populations, and universal both in the circumpolar world and within the various populations constituted by it. More importantly, it is relatively easy to measure as long as data is collected from a number or percentage of speakers of ancestral language (Ibid.).

\section{(5) Contact with Nature Domain}

The ASI Contact with Nature team arrived at three robust indicators based on selection criteria: harvest (kilograms per annum per capita); consumption of country foods (kilograms per annum per capita); and number of people or households engaged in the traditional economy. Of these the ASI team recommended consumption or harvest of country food, with the rationale being the centrality of country food consumption to Arctic cultures and peoples, the availability of data and ability of communities across the Arctic to collect those data, as well as the generalizability of the concept across Arctic regions, for indigenous and non indigenous people, for rural and urban residents, and for women and men (Crate et al., 2010).

\begin{tabular}{lllllll}
\multicolumn{3}{l}{ Table 5: Contact with Nature Indicators } & & & \\
\hline Indicator & $\begin{array}{l}\text { Data } \\
\text { Availability }\end{array}$ & $\begin{array}{l}\text { Data } \\
\text { Affordability }\end{array}$ & $\begin{array}{l}\text { Ease of } \\
\text { Measurement }\end{array}$ & Robustness & Scalability & Inclusiveness \\
\hline $\begin{array}{l}\text { Consumption } \\
\text { of Traditio- } \\
\text { nal Food }\end{array}$ & Tier 3 & Low & Medium & High & $1-4$ & High \\
$\begin{array}{l}\text { Harvest of } \\
\begin{array}{l}\text { Traditional } \\
\text { Food }\end{array}\end{array}$ & Tier 3 & Medium & High & High & $1-4$ & Medium \\
\hline
\end{tabular}

Reproduced from ASI (2010), p.125.

- 1 = scalable to individual; 2 - scalable to household; 3 - to community; 4- to region; 5- to country. Tier 3 data: measurement of indicator requires primary data collection.

Contact with nature is a somewhat intangible attribute of human development and indicators are extremely challenging to develop and difficult to measure. One major constraint to measuring contact with nature is the lack of current data. The challenge of measuring subsistence harvest also has implications for measuring material wellbeing more broadly by including the contribution made by harvest. The traditional food indicator is one example of an ASI indicator that "pushed the limits" as far as being chosen by the ASI team despite its measurement requiring primary data collection. After lengthy discussions the team decided that the indicator 
was simply too important to be excluded for reasons of data affordability, availability, and ease of measurement.

\section{(6) Fate Control Domain}

Fate control refers to the ability to guide one's own destiny, which can be experienced at the personal, household, community, and regional levels. It is the collective control of fate which seems of critical concern to Arctic residents (Dahl et al., 2010; ASI, 2010). In devising an indicator for fate control the ASI Fate Control team arrived at a composite index that incorporates the sub-domains of fate control (see table reproduced from ASI (2010)).

\begin{tabular}{|c|c|}
\hline Component Indicators & Sub-Domains \\
\hline $\begin{array}{l}\text { The percentage of indigenous members in governing bodies (municipal, community, } \\
\text { regional) relative to the percentage of the indigenous people in the total population }\end{array}$ & $\begin{array}{l}\text { Political power/ } \\
\text { human rights }\end{array}$ \\
\hline $\begin{array}{l}\text { The percentage of surface lands legally controlled by the inhabitants through public } \\
\text { governments, Native corporations, and communes }\end{array}$ & $\begin{array}{l}\text { Decision-making } \\
\text { power/ } \\
\text { human rights }\end{array}$ \\
\hline $\begin{array}{l}\text { The percentage of public expenses within the region (regional government, municipal } \\
\text { taxes, community sales taxes) raised locally }\end{array}$ & Economic control \\
\hline $\begin{array}{l}\text { The percentage of individuals who speak a mother tongue (whether Native or not) } \\
\text { in relation to the percentage of individuals reporting corresponding ethnicity }\end{array}$ & $\begin{array}{l}\text { Knowledge con- } \\
\text { struction/ } \\
\text { human rights }\end{array}$ \\
\hline
\end{tabular}

Reproduced from ASI (2010), p. 142.

\subsection{A Small Set of Arctic Social Indicators}

The main objective of the ASI project has been to arrive at a small set of Arctic specific social indicators that as a collective can be used for tracking and monitoring change in human development in the Arctic. The ASI suite of indicators is listed here:

1) Infant Mortality (Health/Population).

2) Net-migration (Health/Population and Material wellbeing).

3) Consumption/harvest of local foods (Closeness to Nature and Material wellbeing).

4) Per capita household income (Material wellbeing).

5) Ratio of students successfully completing post-secondary education (Education). 
6) Language retention (Cultural wellbeing).

7) Fate control index (Fate Control).

For more details see ASI (2010).

\subsection{Data Availability and Limitations}

ASI (2010) identified data availability as one of the main challenges in developing and implementing social indicators in the Arctic. Data constraints put limits on the ability to analyze and compare human development, and it places practical constraints on how small the unit of comparison can be. Data collection methods, accuracy and level of aggregation vary widely among jurisdictions, data collecting agencies and indicators. A serious problem with using data for a sparsely settled area like most northern regions is related to issues of missing (suppressed) and erratic data (e.g. Hamilton et al., 2010). In very small communities it is extremely difficult to have a complete dataset or ensure its accuracy. In addition, the "small numbers problem" creates datasets with high variances and generally erratic behavior, conditions that gravely diminish confidence and may invalidate statistical analysis. For this reason a substantial number of variables are suppressed and all available ones must be used with caution. Given the persistent challenge with social data in the Arctic, including quality, accessibility, and consistency, the ASI (2010) Report concluded that an ideal set of indicators is largely unattainable because the best measures may not be collected frequently enough, or not at all, to allow yearly comparisons.

ASI-I presents primary definitions and criteria for selecting data that could be used in regional case studies:

\begin{tabular}{ll}
\hline National & data are collected by a national agency. \\
Comparable & data collected are comparable to that collected elsewhere. \\
Publication & data are available from the collecting agency. \\
Spatial & data are available at the county level (e.g. census area, district). \\
Period & data are available over time on at least a 5 year frequency. \\
Special tabulation & data could be available if the collecting agency made special tabulations. \\
Compilation & data could be compiled by researchers from existing information. \\
New data collection & data could be collected using no more than 10 minutes of interview time. \\
\hline
\end{tabular}


According to the ASI recommendations, an ideally chosen indicator fits one of the following combinations of criteria:

1. Data are collected by a national agency, are comparable, are published, are available at a county level, are collected at least every five years, and are available for indigenous populations.

2. Data can be made available with special tabulations and otherwise meet all criteria listed in \#1.

3. Data can be compiled from existing information and otherwise meet all criteria listed in \#1.

4. New data could be collected that otherwise meet all criteria listed in \#1.

In addition, the ASI-I recommendations indicate that data used in a proposed ASI monitoring system should:

1. be available at a regional level

2. be available separately for indigenous and non-indigenous populations

3. be available on at least a five-year reporting period.

In terms of data collection requirements, ASI-I also distinguished three tiers of indicators:

- Tier 1: based on existing published data.

- Tier 2: data that would be produced by special tabulations from existing unpublished data.

- Tier 3: would require primary data collection.

Following its charge to establish a practically attainable system of human development monitoring in the Arctic, ASI-I emphasizes that most of the data necessary for implementing the ASI framework must come from existing published sources in order to reduce costs and ensure data accessibility for a variety of stakeholders. Most of the suggested indicators follow this recommendation, although some are thought to require special tabulations and data collection in certain regions. ASI-II case studies closely follow these guidelines wherever possible.

Spatial Scales and Data Disaggregation: Availability of data varies depending on the scale of analysis. In most instances, ASI indicators are well represented at national and regional levels (province, district, borough, census division, county, etc.). However, at further levels of spatial dis- 
aggregation, such as individual communities, the data challenge is significant. Due to small populations and/or lack of published data the analysis of human wellbeing at the local scale is often limited or impossible. Typical problems include suppressed or missing data, erratic nature of datasets, privacy issues and other difficulties associated with studying small samples. It is important to mention that the scale of analysis has critical importance for the validity and reliability of a study of human development. Moving between scales we encounter the so-called modifiable areal unit problem (MAUP), a situation when the results of analysis may change depending on the scale at which data were collected. Therefore, it is necessary to take MAUP into account by analyzing different indicators and making comparisons at appropriate scales.

Comparisons: Although each case study has a unique framework of reference associated with the nature of data collected in a given jurisdiction, the overall ASI data principles are closely upheld. At the same time, the ASI authors largely refrain themselves from making direct comparisons between regions (case studies) mostly due to the uncertainty in data comparability. Instead, most chapters are focused on regional analysis and comparison within case study areas, where data availability and comparability are consistent. Plans are being made to develop a methodology in the future to attain valid and reliable ways to make interjurisdictional comparisons in the Arctic.

Health and Population Domain: The main indicator recommended by ASI-I is infant mortality. This indicator is generally available at national and regional scales but presents a considerable challenge at further levels of spatial disaggregation. In sparsely populated areas and small communities it severely suffers from missing data and the "small numbers problem". If local data is collected, we generally recommend using five-year averaging to alleviate the data volatility problem. The net migration rate selected by the ASI-I as another measure of both economic vitality and population/health is usually available or can be estimated from census or other demographic data. This is true at the national and regional scales but may be a challenge for individual communities. In addition, migration data are not uniformly available for Indigenous and non-Indigenous populations.

Material Wellbeing Domain: ASI-I recommends using per capita household income as a core indicator of economic wellbeing alongside five supporting indicators. Not all jurisdictions directly provide such an indicator but typically it can be approximated by dividing the total household income by population. These datasets are readily available and regularly collected. 
Education Domain. ASI-I emphasizes the post-secondary education completion rate. This and two ancillary indicators are all based on educational attendance (the proportion of students pursuing and completing education) or retention of educated people in a community. This information is easily obtainable in Nordic countries but is limited in other Arctic jurisdictions. In Russia attendance statistics are not well spatially disaggregated and completion rates can only be obtained at local offices. A similar situation occurs in Canada, where educational attendance data can only be obtained through custom tabulations.

Cultural Vitality Domain: The composite indicator of cultural vitality suggested in ASI-I incorporates cultural autonomy (an indicator of the institutional arrangements for cultural self-determination), language retention and belonging (measured through the engagement in traditional subsistence activities). However, the ASI-I Report emphasizes language retention as the key indicator in this domain. In most regions the language retention data are available through census. Other components may be available through surveys but many jurisdictions lack data on subsistence engagement and cultural autonomy. The main limitation associated with these indicators is their reliance on data pertaining to Indigenous people. Although ASI-I insists that the ASI framework must apply to both Indigenous and non-Indigenous Arctic residents, the nature of the data and indicators themselves in the Cultural Vitality, Contact with Nature, and Fate Control domains allow measuring wellbeing of Indigenous people and often precludes us from considering other groups. This is a major limitation in many case studies presented in the current report.

Contact with Nature Domain: ASI recommends using consumption or harvest of traditional foods as the main indicator of closeness to nature. As indicated in ASI-I these data are difficult to obtain and may require custom tabulation or availability of special-purpose surveys. For example, in Canada the occasional Survey of Country Food Consumption is conducted in Northwest Territories. Therefore, the data are limited to certain years. In contrast, Greenland has elaborate information on harvest. Some official harvest data are published in Russia but their reliability is not always certain.

Fate Control Domain: a four-component indicator (Fate Control Index) of community fate control is proposed in ASI-I. The index includes political power, economic self-reliance, control over land and cultural empowerment. All of these indicators are complex and present a challenge for direct measurement. Exact measures suggested in the report in most cases could be estimated only by proxies constructed from census 
and survey data, as well an analysis of legal documents and records. Not all components of the FCI are attainable in all Arctic regions as they may require additional data collection and analysis.

The following case studies are based on the best possible set of data available for regions in question. Some applications develop their own proxies and surrogate measures to substitute unavailable ASI indicators and account for the regional context. Generally, the ASI framework allows conducting comparisons between regions, although they require particular caution due to issues discussed earlier. However, ASI-I provides primarily regional characterization of human development and therefore relies heavily on national, regional and local data sources. Most applications work with spatially-disaggregated datasets and therefore focus on spatial patterns within application regions.

Dynamics of Human Development: The analysis of the temporal dynamics of human wellbeing brings its own data challenges, both in terms of availability and comparability. The researchers are faced with major issues as data collection agencies change definitions and survey content, conduct data collection unsystematically (e.g. occasional surveys) or abruptly modify or shorten census questionnaires, so that a reliable multiyear analysis is impossible. As indicated in ASI-I, consistent and systematic data collection is a key prerequisite for a successful Arctic social indicators monitoring system. While it is our hope that this goal will be met in the future, faults in past data collection complicate retroactive analysis and make it difficult to identify and trace trends.

\subsection{Introduction to Focus Studies}

The Arctic Social Indicators Report II intends to implement the principles, domains, and indicators developed during the ASI-I process. In a way, the current report adds data to the ASI framework, thus providing a proof of concept. Significant data challenges and incompatible units of measurement across national and administrative borders prohibit the application of ASI indicators to all regions of the Arctic.

Instead, we initiated five "focus studies" or "applications" that are supposed to fulfill the same functions of implementation and proof of concept. The selection of these focus studies was based on data availability, while at the same time ensuring that most of the areas of the circumpolar North are being covered. The next five chapters will introduce these ASI "applications". Their order of presentation is roughly geographic, starting with the easternmost (as seen from the International 
Dateline) focus study and moving westward. The final application deals with the entire Inuit World from Greenland to Russia, thereby escaping straightforward geographic localization.

Chapter 2 is situated in the eastern parts of the Russian Federation, addressing Sakha Republic (Yakutia). The republic occupies one-fifth of the entire Russian Federation and is more than twice the size of Alaska. It has a total population of about one million people, roughly half of them are Sakha, while Russians constitute a bit more than one-third and numerically small peoples of the North make up less than 5\%. The industrial economy of Sakha Republic is oriented toward resource extraction (diamonds, tin, gold, etc.), while the traditional economy was focused on animal husbandry, hunting, fishing, and gathering.

The authors of chapter 2 managed to locate data for all ASI domains and indicators, which is probably partially due to the fact that all three of them have conducted research there for extended periods of time, and one author is a resident and citizen of the republic. The scale of the data available, however, varies a lot. Yakutia is divided into 35 administrative districts and in some cases data are available on the district level. Because of the "problem of small numbers", the authors decided to aggregate them into larger economic regions in most cases. The data originate primarily from the Federal State Statistics Service of the Sakha Republic, while federal census data have also been used. A particular problem of data availability in the Russian North is the fact that the distinction between indigenous and non-indigenous populations, which characterized Soviet approaches, seems to have been abandoned in several post-Soviet contexts.

The results for individual domains and indicators vary a lot across the Republic, often with marked rural/urban differences, and typically lower scores in the northern parts of Yakutia. Regarding health, there seems to be a positive trend regarding infant mortality. Likewise, suicide rates are decreasing while still being above national averages. Net outmigration continues to be high in all areas other than the capital city, indicating quality-of-life challenges for many residents of the republic. In terms of material wellbeing, per-capita income has increased notably over the past two decades. Large income differences persist, however, across the republic. 


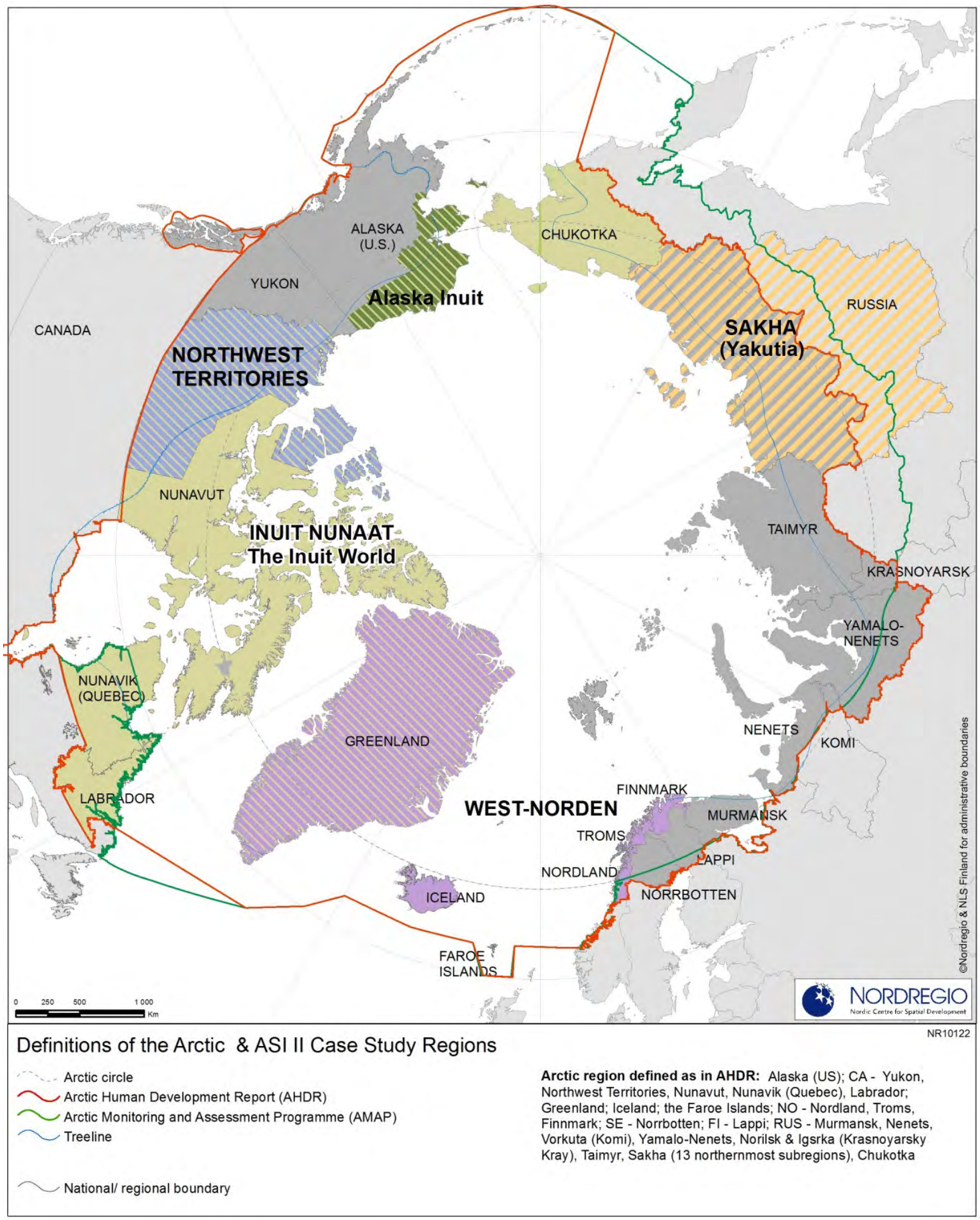


The rate of post-secondary degree completion has not changed much since 2005. Regarding language retention, available data are often treated with suspicion, since some of the recorded increases go beyond what cultural revitalization can realistically achieve. Still some of these selfreported numbers may be significant by expressing a growing pride of one's native language among indigenous peoples. The harvest and consumption of country food seems to have increased in recent years. It is unclear, however, whether this trend is a sign of increased wellbeing or just an effect of economic hardship. In terms of "fate control", only the amount of lands allocated to obshchinas, as a proxy for control over land, is available. Since obshchinas have not been pursued everywhere in the Russian North, the applicability of this indicator is limited. Overall, the indicators paint a mixed picture of human development in the Sakha Republic, suggesting that some aspects of life in the republic are improving, while others continue to be troublesome.

Chapter 3 has the West-Nordic Region as its subject matter, which encompasses the countries of the Faroe Islands, Greenland, Iceland and coastal Western and Northern Norway. The four countries share strong historical and cultural bonds but also common elements in basic natural and economic conditions. Understanding the development characteristics of the WestNordic region is difficult without seeing the development in a general Nordic perspective. The trends and patterns of regional development do in many ways reflect the general Nordic setting, shaped by the specific geographical situation in each of the regions. Moreover, the historical background - especially the cooperation through Nordic Council and Nordic Council of Ministers - both creates and maintains marked similarities.

The Nordic countries show many similarities as well as differences in respect to demographic and socio-economic development, compared with other Arctic regions. Ageing has become an issue of common concern, especially as life-expectancy at birth is high when compared to the Arctic and most European countries. The combination of reliance on renewable resources, the island characteristics of the settlements, and the history of economic dependency has resulted in internal and external relations that influence the population structure today. The small size and the level of isolation of local communities means that a number of demographic challenges are more clearly exposed, sometimes to a degree that may challenge the future of settlements. Access to education and to qualified jobs has an impact on the age structure characteristics of the region, with young adults migrating temporarily or, with increasing frequency, permanently for education and jobs. There exist marked differences in gender approaches to issues, such as education, job re- 
quirements and access to cultural opportunities, giving the rise in migration-related gender imbalances that have become an issue for many West-Nordic communities.

The authors of chapter 3 go through all six ASI domains and, in contrast to some of the other applications, the data are relatively accessible. Therefore, the analysis for the West-Nordic Region makes it possible to compare and contrast wellbeing in terms of a broad set of indicators.

Chapter 4 deals with Northwest Territories, Canada. It is the only application or focus study that deals exclusively with Canada. As one of three northern territories, Northwest Territories (NWT) have significant Inuit, First Nation, and settler populations. Interestingly, NWT have the highest per capita GDP of all Canadian provinces and territories. Given the fact that Nunavut was part of NWT until 1999, a side box is devoted to an abbreviated analysis of four of the six ASI domains in Nunavut.

Despite the fact that NWT present a data challenge to implementing the ASI indicators, the data situation is relatively good if compared to other regions. The Canadian Census, held every five years, provides the majority of datasets and allows chapter 4 to cover the 15-year-span from 1991 to 2006. Time-series data are critical in enabling a dynamic perspective of human development in the Arctic. Additional data come from the Aboriginal People's Survey, conducted in 2001 and 2006, as well as from NWT Bureau of Statistics. A particular challenge in NWT is the fact that $50 \%$ of the territory's communities have fewer than 500 inhabitants. Rounding practices by Statistics Canada and the "small numbers problem" make data for these small communities difficult to interpret.

The authors of chapter 4 go through all six ASI domains and apply as many indicators developed by ASI-I as the data situation permits. While one domain ("Contact with Nature") is covered by only one indicator, another domain ("Fate Control") is addressed by four indicators. The other four domains are covered by two or three indicators each. Data for these individual indicators are presented and mapped on a community basis, enabling comparisons within the study region. Of particular interest is table 2, which presents correlations among social indicators. It demonstrates that some of the ASI indicators are interconnected. The overall result of chapter 4 is confirmation that the ASI indicators are suitable for monitoring human development in NWT.

Chapter 5 moves even farther west and addresses the Inuit Regions of Alaska. These are the three administrative units in the state of Alaska that are home to most of the Inuit (or Inupiaq) population of the 49th state of the U.S. In all three cases, administrative (census) units more or less coincide with the boundaries of regional, Native corporations set up by the 
Alaska Native Claims Settlement Act (ANCSA) in 1971. The northernmost of the three is North Slope Borough with the regional center of Barrow. Southwest from there are Northwest Arctic Borough (with Kotzbue as its hub) and the Nome Census Area. All three regions are characterized by varying degrees of Inuit demographic dominance. Thus, while data used in the chapter typically do not distinguish between Inuit and non-Inuit, chapter 5 is a good proxy for the quality of Inuit lives in Alaska outside the cities of Anchorage and Fairbanks.

The data for chapter 5 come from a variety of sources: the U.S- Census, which is being conducted every ten years, as well as the American Community Survey, which was implemented in 2005 and is being conducted annually. In addition, data from state agencies, private corporations, and SLiCA (see below) augment the data mosaic for chapter 5. Given that many of the communities in the study regions are extremely small (200 or fewer inhabitants), the data are presented in aggregated form on a regional level, which means that the comparisons are primarily among the three regions. In addition, for individual indicators, the regional centers - which often house half of the region's population - are presented separately to see how similar or different regional trends are from trends in regional centers (and thus from aggregated rural locations). Each domain is covered by at least one indicator.

The overall results of chapter 5 show an application with relatively good data availability. Despite some residual questions about the reliability of some of the datasets, there are some unexpected results. For example, the North Slope Borough data show relatively little difference between Barrow and small communities, while the differences are markedly higher in the Nome Census Area. Some of the indicators in the material wellbeing and education domains (e.g., per-capita income, employment, and post-secondary education levels) seem to be interrelated and can be dubbed "modernity indicators". Despite the fact that North Slope Borough was the primary staging area for the Alaskan oil boom of the last few decades, the Nome Census Area seems to be overtaking the North Slope on these measures.

Chapter 6-Inuit Nunaat - The Inuit World - differs from most of the other chapters in two respects. First, by taking the transnational community of the Inuit as its focus, the chapter evades easy geographic localization, as the Inuit world ranges from the eastern tip of Russia through Alaska and Canada to Greenland. In doing so, it is the only chapter that is mono-ethnic in orientation. Second, chapter 6 uses a unique instrument, the Survey of Living Conditions in the Arctic (SLiCA), as its primary data source. SLiCA was an in-depth survey con- 
ducted in several arctic countries between 2001 and 2006. While the richness of its data is enviable, SLiCA suffers from the fact that it is (fiscally) rather unlikely that a survey of similar scope and extent will be repeated in regular intervals.

Since SLiCA precedes ASI, the preliminary results of the Survey of Living Conditions informed the initial steps of the Arctic Social Indicators project. At the same time, the analysis of SLiCA made use of the Arctic Human Development Report (AHDR) that introduced some of the domains later to be used by ASI. These connections between SLiCA indicators and ASI domains are systematically explored in chapter 6 .

It is generally feasible to apply SLiCA indicators into the ASI framework and to most of the selected indicators. Furthermore SLiCA is able to contribute with further valuable indicators. SLiCA indicators apply directly to three out of six domains (material wellbeing; education; cultural continuity and vitality). The selected ASI indicator for contact with nature demands quantitative estimates of "consumption and harvest of traditional food", whereas SLiCA have results expressed in relative terms. The last two ASI domains rely heavily on vital statistics and publicly gathered information.

Finally, Chapter 7 - Conclusions: Measuring Change in Human Development in the Arctic - brings the results of the focus studies back to the overarching questions of the ASI endeavor. The chapter starts out with a summary of major findings by providing a synthesis of Part II or chapters 2 through 6.

A major component of chapter 7 is the introduction of the ASI Monitoring System. It describes the core principles and elements of such a system and proposes an organizational structure. In addition, there is a set of specific ideas regarding the establishment of a monitoring system and includes information about the Inuvialuit Baseline Indicators (IBI) project, which is a collaborative monitoring project also fulfilling the role of a pilot study.

Chapter 7 puts the focus studies of ASI-II into dialog with the 25+ community-based monitoring projects that were part of IPY 2007-2008. The final sections of the chapter and the report include reflections on what the ASI process has achieved to date and what the major future tasks are. 


\subsection{References}

AHDR (Arctic Human Development Report) (2004). Akureyri: Stefansson Arctic Institute. Arctic Social Indicators (ASI). (2010). J.N. Larsen, P. Schweitzer, and G. Fondahl (eds.). TemaNord 2010:519. Copenhagen: Nordic Council of Ministers.

Bossel, H. (1999). Indicators for Sustainable Development: Theory, Method, Applications. A Report to the Balaton Group. Winnipeg: International Institute for Sustainable Development.

Crate, S., Forbes, B.C., King, L., and Kruse, J. (2010). Contact with Nature. In: Arctic Social Indicators (ASI). 2010. J.N. Larsen, P. Schweitzer, and G. Fondahl (eds.). TemaNord 2010:519. Copenhagen: Nordic Council of Ministers.

Dahl, J., Fondahl, G., Petrov, A., and Sverre Fjellheim, R. (2010). Fate Control. In: Arctic Social Indicators (ASI). 2010. J.N. Larsen, P. Schweitzer, and G. Fondahl (eds.) TemaNord 2010:519. Copenhagen: Nordic Council of Ministers.

Hamilton, L., Bjerregaard, P., and Poppel, P. (2010). Health and Population. In: Arctic Social Indicators (ASI). 2010. J.N. Larsen, P. Schweitzer, and G. Fondahl (eds.). TemaNord 2010:519. Copenhagen: Nordic Council of Ministers.

Larsen, J.N. and Huskey L. (2010). Material Well-being. In: Arctic Social Indicators (ASI). 2010. J.N. Larsen, P. Schweitzer, and G. Fondahl (eds.). TemaNord 2010:519. Copenhagen: Nordic Council of Ministers.

Schweitzer, P., Irlbacher Fox, S., Csonka, Y., and Kaplan, L. (2010). Cultural Wellbeing and Cultural Vitality. In: Arctic Social Indicators (ASI). 2010. J.N. Larsen, P. Schweitzer, and G. Fondahl (eds.). TemaNord 2010:519. Copenhagen: Nordic Council of Ministers.

Young, O. (2010). From AHDR to ASI. Textbox 2.0. In: Arctic Social Indicators (ASI). J.N. Larsen, P. Schweitzer, and G. Fondahl (eds.). TemaNord. 2010:519. Copenhagen: Nordic Council of Ministers. 


\section{PART II: \\ Case Studies}





\title{
2. Sakha Repubic (Yakutia), Russian Federation
}

\author{
Authors \\ Gail Fondahl, University of Northern British Columbia, Canada; Susan Crate, \\ George Mason University, USA; Viktoriia V. Filippova, Institute of the Hu- \\ manities and the Indigenous Peoples of the North, Siberian Branch, Russian \\ Academy of Sciences, Russian Federation.
}

\subsection{Introduction}

Sakha Republic (Yakutia), occupying one-fifth of the Russian Federation, encompasses over 3.1 million square kilometers, an area over twice the size of Alaska and only slightly smaller than India. Stretching from below $56^{\circ} \mathrm{N}$ in the south to above $77^{\circ} \mathrm{N}$ in the Arctic Ocean (the Novosibirsk Island Archipelago), it embraces vast tundra and taiga landscapes, some of Russia's largest rivers, and numerous mountain ranges. Its climate is continental, with the coldest temperatures outside of Antarctica regularly registered within its bounds; yet summer temperatures in many areas exceed $30{ }^{\circ} \mathrm{C}$. Despite its vastness, it is home to only about one million people. Like many other areas of the North, Sakha Republic (Yakutia) is sparsely populated, with an average of 0.3 persons/sq. $\mathrm{km}$, compared to 8.3 persons/sq. km for the Russian Federation (2007). The majority of the Republic's population is concentrated in its several major urban centers.

According to the 2010 census data, the Republic's population includes the indigenous and eponymous $49.9 \%$ Sakha (a non-Russian, Turkicspeaking indigenous people, formerly called the Yakut), 37.8\% Russian, and a small percentage of other indigenous peoples, the so-called numerically small peoples of the North (Evenk, Even, Dolgan, Chuckhi, Yukagir), comprising together about $4.2 \%$ of the population. Many other peoples, most notably Ukrainians (2.2\%), also inhabit the Republic.

Many Sakha historically and to this day engage in livestock (cattle and horse) husbandry, while the other indigenous groups more frequently practice reindeer husbandry and subsistence activities of hunting, fishing, and gathering. The majority of Slavic inhabitants (Russians, 
Ukrainians and Belorussians) are concentrated in the republic's larger settlements, working as administrators, in commerce, and in industry, although some have taken up the herding and hunting practices of the area's indigenous peoples.

The economy of Sakha Republic (Yakutia) is strongly resourceoriented, with about $40 \%$ of the gross regional product based on the extraction and industrial processing of diamonds, gold and coal (Yegorov 2011). The Republic provides all of the Russian Federation's antimony, $98 \%$ of its diamonds, $86 \%$ of its tin, and $15 \%$ of its gold (Shtyrov 2008). The majority of industrial enterprises were established in the post WWII period, with the Soviet government's push to progress and "catch up with the West" (gold was mined earlier). To speed industrialization, the Soviet government brought Slavic workers from the western Soviet Union, which created substantial population centers of inmigrants around the natural resource exploitation areas.

The subsistence activities in which the indigenous populations are involved were consolidated into state farms during the Soviet period. With the post-Soviet dissolution of those farms, such activities are often a main source of household-level economy and, in some cases, income (Crate 2006). Village households depend on a mixed cash economy with much of their cash originating from state transfer payments in the form of state subsidies and pensions.

After the fall of the Soviet Union in 1991, the population of the Republic fell annually except from 2004-2005. The Republic lost 161 thousand people between 1990-2005, due to the economic crisis, which specifically hit areas of gold, coal and tin ore production, formally subsidized by the government (Ivanov 2007:624). This period also saw outmigration of urban populations, mainly Russians and other Slavs, while the rural population grew slightly across the Republic.

Since 1991, inhabitants have had increasing access to global media sources, a wide array of consumer goods, and most of the technological advances found in the West, though these are often unaffordable, and largely absent from the lives of villagers in the far-flung settlements of the Republic. The period following 1991 was also characterized by the dissolution of a centralized system of supports for infrastructure of many types. 


\subsection{Data and Methodology}

In this chapter, we attempt to apply the indicators selected and identified by the Arctic Social Indicators project (ASI Phase I; Larsen et al. 2010) to Sakha Republic (Yakutia). We discuss difficulties of data collection for some of the indicators, and suggest revisions to these. In some cases we have had to adjust the indicator due to data availability. For some domains we have looked at secondary and even tertiary indicators, in order to illustrate how one indicator may suggest quite a different picture than another - or might corroborate the trends suggested by the primary indicator. Of course, in order to provide for comparison across time and space, it is preferable to use the primary indicator; presenting further indicators is mainly for illustrative purposes of the limitations of the primary indicators. Any future use of such indicators will need to take such limitations into account, while fully recognizing that secondary indicators have their own weaknesses, and the primary indicator was chosen as the best proxy for each domain.

Table 2.1 summarizes the indicators proposed by ASI-I, and specifies the indicators that we have used in this chapter.

\begin{tabular}{|c|c|c|c|c|}
\hline Domain & $\begin{array}{l}\text { Preferred indicator } \\
\text { (ASI 2010; Chapter } 1 \\
\text { of this report) }\end{array}$ & $\begin{array}{l}\text { Sakha Republic: } \\
\text { indcator } 1\end{array}$ & $\begin{array}{l}\text { Sakha Republic: } \\
\text { indicator } 2\end{array}$ & $\begin{array}{l}\text { Sakha Repub- } \\
\text { lic: indicator } 3\end{array}$ \\
\hline Health \& Population & $\begin{array}{l}\text { Infant Mortality/ } \\
\text { Net Migration }\end{array}$ & $\begin{array}{l}\text { Infant Mortality/ } \\
\text { Net Migration }\end{array}$ & Suicide Rate & \\
\hline Material wellbeing & $\begin{array}{l}\text { Per capita House- } \\
\text { hold Income }\end{array}$ & $\begin{array}{l}\text { Per capita House- } \\
\text { hold Income }\end{array}$ & Net Migration & Unemployment \\
\hline Education & $\begin{array}{l}\text { Ratio of Students } \\
\text { Completing Post- } \\
\text { Secondary Education } \\
\text { Opportunities }\end{array}$ & $\begin{array}{l}\text { Ratio of Students } \\
\text { Completing Post- } \\
\text { Secondary Educa- } \\
\text { tion Opportunities }\end{array}$ & & \\
\hline Cultural Vitality & Language Retention & Language Retention & & \\
\hline Contact with Nature & $\begin{array}{l}\text { Consumption/ } \\
\text { Harvest of Tradi- } \\
\text { tional Foods }\end{array}$ & $\begin{array}{l}\text { Harvest of Traditio- } \\
\text { nal Foods }\end{array}$ & $\begin{array}{l}\text { Consumption of } \\
\text { Traditional Foods }\end{array}$ & \\
\hline Fate Control & Fate Control Index* & $\begin{array}{l}\text { Control of Surface } \\
\text { Lands }\end{array}$ & & \\
\hline
\end{tabular}

* See discussion in Fate Control Section below, for components of Index.

As noted in the first ASI report (Larsen et al. 2010, p. 146), it is preferable to use data that "are collected by a national agency, are comparable, are available at the county level, are collected every five years, and are 
available for indigenous populations." We have depended for the most part on data published by the Federal State Statistics Service of Sakha Republic (Yakutia). Statistical yearbooks are published annually. Compilations on various topics (e.g. labor, standard of living) are also published. We have also used federal (Russian Federation/Russian Soviet Federated Socialist Republic) data. The last Soviet census was conducted in 1989, with the previous census conducted in 1979. Post-Soviet censuses were conducted in 2002 and 2010, with the results of the 2010 census still being released; some data from it are included.

Sakha Republic (Yakutia) is divided into 35 administrative units, called ulusy (singular ulus), akin to rayony in other parts of the Russian Federation, and very roughly equivalent to districts or counties. Only some statistics are available at the ulus level. Even where data are available at the ulus level, the "small population problem" confounds the usage of these to assess trends over time. For many demographic statistics, such as infant mortality, numbers are so tiny as to make year-to-year "trends" highly erratic and essentially meaningless. Thus, in order to look at trends where data are available by ulus, we have grouped the ulusy into six economic regions for the purposes of a more robust statistical analysis. The six economic regions were adopted from the Geographical Atlas "Sakha Republic (Yakutia)" (Lazebnik, 2000:46; see also Atlas YaASSR 1989, p.12).

Table 2.2 provides information on the composition and characteristics of the six regions.

\begin{tabular}{|c|c|c|}
\hline Region & Included Ulusy & Economic Characteristics \\
\hline Central & $\begin{array}{l}\text { Amginskiy, Churapchinskiy, Gornyy, Khangalaskiy, } \\
\text { Kobyyskiy, Megino-khangalaskiy, Namskiy, Tattinskiy, } \\
\text { Ust-Aldanskiy, Vilyuyskiy, City of Yakustk and subor- } \\
\text { dinate settlements }\end{array}$ & $\begin{array}{l}\text { Manufacturing, financial \& other } \\
\text { services, construction, forestry, cattle } \\
\text { husbandry, grain \& vegetable raising }\end{array}$ \\
\hline Southern & Aldanskiy, Olekminskiy, Neryungrinskiy & Gold, coal mining, forestry, fur trapping \\
\hline Western & $\begin{array}{l}\text { Anabarskiy, Mirinskiy, Nyurbinskiy, Olenekskiy } \\
\text { Evenk National, Lenskiy, Suntarskiy, Verkhne- } \\
\text { Vilyuyskiy }\end{array}$ & $\begin{array}{l}\text { Diamond mining, oil and gas, coal } \\
\text { mining, forestry, fur raising }\end{array}$ \\
\hline Eastern & Omyakonskiy, Tomponskiy, Ust'-Mayskiy & Gold mining, forestry \\
\hline Northern & $\begin{array}{l}\text { Bulunskiy, Zhiganskiy Evenk National, Ust'-Yanksiy, } \\
\text { Verkhoyanskiy, Eveno-Bytantayskiy National }\end{array}$ & Gold, tin mining, fishing, fur trapping \\
\hline $\begin{array}{l}\text { Northea- } \\
\text { stern }\end{array}$ & $\begin{array}{l}\text { Abyyskiy, Allaykhovskiy, Momskiy, Nizhnekoly- } \\
\text { mskiy, Srednekolymskiy, Verknekolymskiy }\end{array}$ & $\begin{array}{l}\text { Forestry, fur trapping \& raising, rein- } \\
\text { deer husbandry, fishing }\end{array}$ \\
\hline
\end{tabular}

Sources: Lazebnik, 2000; Atlas YaASSR 1989; Official Information Portal of the Republic of Sakha (Yakutia). (http://www.sakha.gov.ru/node/7849). 
Two other groupings of ulusy are used in the presentation of some statistics in the Sakha Republic (Yakutia) and will be drawn on occasionally in this chapter: the "regions inhabited by the indigenous numerically small peoples of the North" and the "Arctic Regions". These are both recognized in various legal and administrative documents of the Republic.

Table 2.3: Other Regional Groupings of Sakha Republic (Yakutia)

\begin{tabular}{|c|c|}
\hline Grouping & Included Ulusy \\
\hline $\begin{array}{l}\text { "Regions Inhabited by the } \\
\text { Indigenous Numerically Small } \\
\text { Peoples of the North" } \\
\text { (21 ulusy) }\end{array}$ & $\begin{array}{l}\text { Abyyskiy, Aldanskiy, Allaikhovskiy, Anabarskiy, Bulunskiy, Eveno- } \\
\text { Bytantayskiy National, Kobyayskiy, Mirinskiy, Momskiy, Neryungrinskiy, } \\
\text { Niznekolymskiy, Olekminskiy, Olenekskiy Evenk National, Omyakonskiy, } \\
\text { Srednekolymskiy, Tomponskiy, Ust'-Mayskiy, Ust-Yanskiy, Verkh- } \\
\text { nekolymskiy, Verkhoyanskiy, Zhiganskiy Evenki National }\end{array}$ \\
\hline Arctic Region (13 Ulusy) & $\begin{array}{l}\text { Abyyskiy, Allaykhovskiy, Anabarskiy, Bulunskiy, Eveno-Bytantayskiy Natio- } \\
\text { nal, Momskiy, Niznekolymskiy, Olenekskiy Evenk National, Srednekoly- } \\
\text { mskiy, Ust-Yanskiy, Verkhnekolymskiy, Verkhoyanskiy, Zhiganskiy }\end{array}$ \\
\hline
\end{tabular}

Note: The "Arctic Region" includes all of the ulusy of the Northern and Northeastern region, plus the northern two ulusy of the Western Region.

The "regions inhabited by the indigenous numerically small peoples of the North" account for $36.4 \%$ of the population of Sakha Republic (Yakutia). The Arctic Region accounts for $7.7 \%$ of the republic's population.

In numerous cases statistics are not easily available at the ulus level, and are only reported for Sakha Republic (Yakutia) as a whole.

\subsection{Health and Population Domain}

The chosen indicator for health is infant mortality rate. Other indicators suggested for measuring population health are child mortality rates, access to health care, suicide rate, self-assessed health, obesity rate and smoking rate (Larsen et al., 2010). Of these, government statistics are available for infant and child mortality rate and suicide rate. Below we provide data on infant mortality rates; we also offer the suicide rates, for reasons explored below. Infant mortality rates are available at the regional as well as republic level; suicide rates until recently were only available at the republic level.

For population dynamics the chosen indicator is net migration. While for infant mortality, a decrease in rate is a clearly desired trend, trends in net migration are harder to appraise as "good" or "bad", as pointed out in the first Arctic Social Indicators Report (2010). For a community as a whole, negative net migration may portend the demise of a community, or at least contribute to a declining standard of living for those who remain. 
In that it is frequently the younger, working-age population that is outmigrating, the sustainability of communities can often be challenged by out-migration. However, in some cases in the North, and perhaps most notably in the Russian North, many population centres were highly subsidized; some feel that a decline in artificially high levels of population was needed (see Heleniak 2009), especially as the withdrawal of subsidies encouraged greater dependence on subsistence activities such as hunting, and thus increased pressures on ecosystems. At the same time, while a community may suffer from out-migration, individuals relocating elsewhere may experience an improvement in their quality of life.

\section{Infant Mortality Rate}

Infant mortality is measured in terms of the number of children dying prior to their first birthday per 1,000 live births. Infant mortality is a problematic indicator in areas of low population. Even in aggregating ulus-level data into regional data, one has to exercise caution in assessing trends over time. Table 2.4 provides data for the past 30 years. Infant mortality has declined significantly over this period in the Republic: in 2005 it was about one-third of what it was in 1980. The decline has characterized all regions. There is still marked difference between the regions (Table 2.5).

Table 2.4: Infant Mortality in Sakha Republic (Yakutia)* (Number of infant deaths per 1,000 births)

\begin{tabular}{lccccc}
\hline Region & $\mathbf{1 9 8 0}$ & $\mathbf{1 9 9 0}$ & $\mathbf{2 0 0 0}$ & $\mathbf{2 0 0 5}$ & $\mathbf{2 0 1 0}$ \\
\hline Central & 35.3 & 20.3 & 15.8 & 9.3 & 6.9 \\
Central w/o Yakutsk & 33.3 & 21.1 & 14.8 & 9.6 & 9.4 \\
Yakutsk & 37.7 & 19.0 & 16.9 & 9.0 & 5.0 \\
Southern & 21.8 & 16.1 & 16.4 & 11.6 & 7.1 \\
Western & 25.2 & 22.4 & 20.1 & 14.6 & 6.1 \\
Eastern & 32.1 & 21.8 & 21.7 & 5.1 & 4.8 \\
Northern & 28.8 & 23.5 & 22.8 & 9.7 & 8.1 \\
Northeastern & 33.2 & 15.7 & 19.3 & 14.3 & 11.8 \\
Sakha Republic (Yakutia) & $\mathbf{3 0 . 0}$ & $\mathbf{2 0 . 1}$ & $\mathbf{1 7 . 5}$ & $\mathbf{1 0 . 7}$ & $\mathbf{7 . 2}$ \\
Russian Federation* & 22.1 & 17.4 & 15.3 & 11.0 & 7.5 \\
\hline
\end{tabular}

* Statistics for Russian Federation offered for comparison.

Source: Statistical Yearbook RS(Ya), various years; for Russian statistics, http://www.gks.ru/wps/wcm/ connect/rosstat/rosstatsite/main/population/demography/b273bf80446245b682bcb26964b99b0f\# 
Table 2.5: Infant Mortality for Sakha Republic (Yakutia) and for Regions of the Republic inhabited by the Indigenous Numerically-Small Peoples of the North (Number of infant deaths per 1,000 births)

\begin{tabular}{lccccc}
\hline & $\mathbf{2 0 0 2}$ & $\mathbf{2 0 0 3}$ & $\mathbf{2 0 0 4}$ & $\mathbf{2 0 0 5}$ & $\mathbf{2 0 0 6}$ \\
\hline $\begin{array}{l}\text { Sakha Republic (Yakutia) as a whole } \\
\begin{array}{l}\text { Regions inhabited by the Indige- } \\
\text { nous Numerically-Small Peoples of } \\
\text { the North }\end{array}\end{array}$ & 15.2 & 13.2 & 13.5 & 10.6 & 10.6 \\
\hline
\end{tabular}

Source: Burtseva et al. 2009:58.

Infant mortality in Sakha Republic (Yakutia) has in the past decade slipped below the Russian Federation average. The most common reasons for death include "various situations arriving in the perinatal period", "natural anomalies of development (deformities, chromosome anomalies)" and "trauma, poisoning and other external factors" (On the status 2009:13), all of which have decreased significantly since 1990. Even more noteworthy is the decrease in infant mortality from "breathing system illness", which in 1990 comprised 14\% of deaths, but by 2008 accounted for only $4 \%$ of deaths.

While infant mortality rated by different ethnic groups are not available, Table 2.5 shows the rate of infant mortality for the republic as a whole, compared with the rates for "regions inhabited by the numerically-small indigenous peoples."

In order to analyze the demographic and medical trends among the indigenous peoples of Sakha Republic (Yakutia), the republican Ministry of Health is discussing the collection of data by ethnicity once again. This would provide objective information about the health of such groups, as a basis to develop medical interventions for improvement of health (Burtserva et al. 2009:59).

\section{Suicide Rate}

While declining infant mortality suggests improved wellbeing, and a positive trend in human development in Sakha Republic (Yakutia), looking at other indicators provides a different picture. Suicide rate is considered a "supplementary proxy indicator" for measuring the health of the population (Hamilton et al. 2010). Suicide rate is measured by the number of suicides per 100,000 population. Republican level statistics until recently have painted a grim picture (Table 2.6), one that is at odds with the positive outlook provided by falling infant mortality rates. After falling dramatically between 1980 and 1990, rates rose dramatically again, and were more-or-less stagnant from 2000 to 2008. However, the past two years show a promising downward trend. 
Table 2.6: Suicide Rate, Sakha Republic (Yakutia) and Russian Federation (per 100,000 population)

\begin{tabular}{lrrrrrr}
\hline & $\mathbf{1 9 8 0}$ & $\mathbf{1 9 9 0}$ & $\mathbf{1 9 9 5}$ & $\mathbf{2 0 0 0}$ & $\mathbf{2 0 0 5}$ & $\mathbf{2 0 1 0}$ \\
\hline Sakha Republic (Yakutia) & 39.6 & 24.2 & 35.1 & 48.4 & 48.3 & 40.8 \\
Russian Federation & --- & 26.5 & 41.4 & 39.1 & 23.2 & 26.5
\end{tabular}

Source: Statistical Yearbook RS(Ya), various years.

It is likely that at least part of the marked increase in suicide rates in the post-Soviet period (post-1990) are the result of more accurate reporting. Nevertheless, the rates remain substantially higher in Sakha Republic (Yakutia) than for the Russian Federation as a whole. Indeed, Russian Federation rates have been declining since 1995, after a steep rise. Rates in Sakha Republic (Yakutia) increased in the 1990s, and continued to do so in to the 2000s, with a decline in the last couple of years. In 2005, they were double the Russian Federation average, and in 2010 they were still 1.5 times higher.

Suicide rates are not easily accessible at the ulus level until 2008, but are published after that (Mortality 2010). Thus it is likely that in the future we will be able to use ulus-level suicide data to track this indicator of human development. Table 2.7 shows suicide data by region for 2008 and 2009.

Table 2.7: Estimated Regional Suicide Rates, 2008-2011

\begin{tabular}{lcccc}
\hline Region & $\mathbf{2 0 0 8}$ & $\mathbf{2 0 0 9}$ & $\mathbf{2 0 1 0}$ & $\mathbf{2 0 1 1}$ \\
\hline Central & 43.4 & 45.4 & 42.3 & 50.5 \\
Yakutsk & 26.1 & 29.0 & 23.8 & 23.3 \\
Central without Yakutsk & 66.0 & 67.7 & 44.1 & 53.2 \\
Southern & 49.2 & 38.3 & 47.5 & 52.5 \\
Western & 52.8 & 47.3 & 53.5 & 66.4 \\
Eastern & 40.7 & 67.0 & 59.2 & 53.2 \\
Northern & 82.1 & 66.1 & 123.7 & 91.1 \\
Northeastern & 71.4 & 72.4 & 51.3 & 33.7 \\
\hline
\end{tabular}

Source: Mortality 2010.

These statistics should be approached with great care, and are only provided to indicate what appear to be regional trends that are mirrored in other areas of the Arctic. Reported suicide rates vary in 2008 from rates of 0 (Nizhnekolymsk Ulus, in the Northestern Region) to 180.0 (Anabarskiy Ulus in the Western Region). At the same time, Omyakonskiy Ulus (Eastern Region) shows an increase in suicide rate to 71.4 in 2011 from 8 in 2008, while in the Allaykhovskiy Ulus (also Northeastern Region) the statistics indicated a drop to 68.4 in 2009 from 100.7 in 2008, and then to 0 in 2010 (rising to 33.6 in 2011). Again we witness the "small population problem" of dealing with statistics where total popula- 
tions are very small - one suicide can make a huge difference in the reported rate. This is true, even when data is aggregated by region.

The statistics do suggest a trend of higher rates of suicide in the most northerly areas of Sakha Republic (Yakutia). Of course, it is these same northern regions that have very small populations: all of the northern ulusy with reported suicide rates over 100 have populations of well under 5,000 people.

The other interesting geographical trend is the comparatively low suicide rate in the capital city of Yakutsk compared to the rest of the republic (Table 2.7). The regional capital would be both the centre of much more advanced social services, including mental-health services. It is also the single area of substantial population growth in the whole republic. It may also be that those in desperate situations who can migrate to the centre find some relief from their challenges, compared to those who cannot leave an adverse situation. It is interesting to note that Mirnyy ulus, a major industrial center, is one other area where the suicide level remains notably below the republican average (24.6 and 23.9 in 2008 and 2009 respectively).

Suicide among adolescents, as elsewhere in the Circumpolar North, is a particularly distressing phenomenon. In Sakha Republic (Yakutia), suicides and accidents have become the leading cause of death of adolescents (10-19 years old), while in Russia as a whole, and countries of Europe the leading cause of death from external causes for this group are road traffic injuries. For those from 15-19 years old, suicide and murder predominate as the leading cause of death. Death rates from these causes are highest in those areas where indigenous populations predominate. Contributing factors of social deprivation and youth disadvantage are exacerbated by inadequate and poor-quality prevention strategies in terms of education, social support, and health care, and family support (Savvina et al. 2012:46-69).

\section{Net Migration}

As noted in the Arctic Social Indicators report, in-migration and outmigration "reflect the current local sum of various push and pull factors..." (Hamilton et al. 2010:43). Substantial out-migration from the Russian Federation's northern regions has characterized the last two decades, since the end of the Soviet Union, with $17 \%$ of the population leaving between 1989 and 2006. The figure for outmigration from Sakha Republic (Yakutia) for the same time frame was even greater, at $26 \%$ (Heleniak 2009). Motivations included people moving to the lands of their ancestors after the breakup of the Soviet Union (e.g. Ukrainians moving to Ukraine; so-called "diasporic" migration), mostly in the first years of the 1990s. This factor was felt more 
strongly in Siberia than in many areas of the Russian Federation, as the Slavic population included a relatively higher percentage of Ukrainians and Belarusians. More continuously since the early 1990s, economics have driven migration. As prices were liberalized, state subsidies withdrawn, and many northern economic organizations collapsed, the Far North experienced a significant deterioration in quality of services, and of life generally, in remote northern settlements (Heleniak 2009).

Migration patterns in the Sakha Republic (Yakutia) for the most part mirrored these general trends (Table 2.8). Net migration rate is calculated by subtracting out-migrants from the region from in-migrants to the region, dividing by number of residents, and then dividing by 1,000.

Table 2.8: Net Migration Rates, Sakha Republic (Yakutia), 1990-2010 (per 1,000 residents)

\begin{tabular}{lccrc}
\hline Region & $\mathbf{1 9 9 0}$ & $\mathbf{2 0 0 0}$ & $\mathbf{2 0 0 5}$ & $\mathbf{2 0 1 0}$ \\
\hline Central & -0.1 & -0.3 & 0.0 & -0.2 \\
Central w/o Yakutsk City & -0.5 & -0.6 & -0.5 & -0.8 \\
Yakutsk City & 0.3 & 0.1 & 0.4 & 1.5 \\
Southern & -0.3 & -1.1 & -1.0 & -1.1 \\
Western & -0.1 & 0.1 & -0.8 & -1.6 \\
Eastern & -0.8 & -2.0 & -2.2 & -2.0 \\
Northern & -1.2 & -4.1 & -1.8 & 0.2 \\
Northeastern & -0.9 & -2.3 & -1.3 & -1.0 \\
Sakha Republic (Yakutia) & -0.3 & -0.7 & -0.5 & -0.7 \\
\hline
\end{tabular}

Source: Calculated from Statistical Yearbook RS ( $\mathrm{Ya})$, various years.

While in 1990 the Sakha Republic (Yakutia) saw a net migration of 3,306 persons, by 1995 it had reached a net migration of $-16,907$ persons (Fedorova et al. 2003:156). Mining regions and those focused with an economic specialization in transportation were hardest hit; agricultural centres (including cattle and reindeer husbandry) were less affected. If in the earliest post-Soviet years, political factors played an important role, with Ukrainians, Belorussians, Moldovans and Kazakhs returning to their titular homelands, by 1994 social and economic factors (e.g. decrease in availability of consumer goods, non-payment of wages) became the main drivers. Indeed, by 1995-6, some reverse migration from Ukraine and Kazakhstan began to occur, though in small numbers (Fedorova et al. 2003:157). Arctic worker's villages were especially hard hit: for instance Ust'-Yanksiy (Northern Region), a mining region, lost over $47 \%$ of its population in the 1990s (Suknëva et al. 2001:28). This outmigration of the working-age population in turn negatively affected the birth rates of the regions: $70 \%$ of the out-migrants were of working age (Suknëva et al. 2001:68).

The only area to experience continuous positive net migration has been the capital city, Yakutsk. By 1988, 114 settlements in the republic 
were considered to be "without a future" (besperspektivnye) (Fedorova et al. 2003:158). Outmigration has been especially strong from the Northern, Northeastern and Eastern regions in the 2000s. Yet one anomaly is noted. The 2010 show a positive growth in the Northern Region. This is wholly due to reported strong in-migration to Bulunsky ulus; all other ulusy of this region experienced net out-migration in 2010, with the exception of the Eveno-Bytantaisky ulus (which gained 2 individuals). Whether the gain in Bulunskiy ulus is due to real trends or inaccurate statistics is unclear. Meanwhile 2010 saw a significant increase in the outmigration from the Western region, mostly attributable to a heavy loss of population from the Mirnyy ulus, a centre of diamond mining (net migration rate of -3.1).

Currently, among the migrants women predominate (54.7\%). Especially noticeable is the preponderance of women at the age of retirement (73\% of migrants in this category are female). A large proportion of those aged 16-19 years who migrate area also women (67\%), who in large numbers are relocating for education. Among those of in the age bracket of 30-39 years men predominate (Suknëva 2008).

For people aged 16-29 years, migration to cities is common, for education, skills development, and employment. The rate of return migration among this group is low, which leads to an aging population and the deterioration of the demographic situation in the rural areas of the country. A main reason for migration of the rural population is dissatisfaction with working and living conditions in rural areas. A public opinion poll conducted in 1995 revealed that the relocation of rural residents to urban settlements was driven by poor housing conditions in rural areas, lack of work, and the desire to give their children a good education $(0$ migratsionnykh... 1996). The reasons identified during the survey remain relevant. The attractiveness of the North that prevailed during the Soviet period, due to higher wages and well-supplied communities, has largely been lost. Future implementation of new megaprojects in the Republic will likely rely on migrant workers working in shift-work, including from outside the republic, as well as some redistribution of local population, which will help to reduce unemployment, especially in rural districts (Suknëva 2008).

Migration data suggest that community viability, and thus human development, is under significant threat in many of the Republic's regions, as net migration for most regions is negative, and in a number of regions actually increased between 2005 and 2010. Along with suicide data, this proxy for demographic "wellbeing" paints a gloomy picture of the situa- 
tion in Sakha Republic (Yakutia) that is not evident in looking at infant mortality rates alone.

Thus our indicators and measures for the Population and Health Domain suggest a mixed situation. While the decrease in infant mortality indicates an improvement in wellbeing, the high suicide rates until recently, and continuing high rates of out-migration imply a decline in wellbeing. The capital city of Yakutsk, where infant mortality, suicide and outmigration have all decreased, is an anomaly. Socio-economic conditions outside of the capital, and especially in rural areas, are still depressed. It appears this situation of declining wellbeing is experienced especially in the northernmost areas of Sakha Republic (Yakutia). The statistics corroborate our own observations in the field.

\subsection{Material Wellbeing Domain}

The chosen indicator for the material wellbeing domain is per capita household income. For Sakha Republic (Yakutia), we have figures for per capita household (monetary) income per year at the republican level, but not by ulus. Urban and rural averages are available. The annual figures were divided by 12 to calculate the average monthly household income (see Table 2.9).

Table 2.9: Average Monthly Household Income, Sakha Republic (Yakutia), 2000-2009 (in Rubles)

\begin{tabular}{|c|c|c|c|c|c|c|}
\hline \multirow[t]{2}{*}{ Year } & \multicolumn{3}{|c|}{ Average Monthly Income } & \multicolumn{3}{|c|}{$\begin{array}{l}\text { Average Monthly Income, Adjusted for Infla- } \\
\text { tion }\end{array}$} \\
\hline & $\begin{array}{r}\text { Sakha } \\
\text { Republic } \\
\text { (Yakutia) }\end{array}$ & $\begin{array}{l}\text { Urban } \\
\text { Places }\end{array}$ & Rural Places & $\begin{array}{r}\text { Sakha } \\
\text { Republic } \\
\text { (Yakutia) }\end{array}$ & $\begin{array}{l}\text { Urban } \\
\text { Places }\end{array}$ & Rural Places \\
\hline 2000 & 7,515 & 8,043 & 6,288 & 7,515 & 8,043 & 6,288 \\
\hline 2001 & 9,814 & 10,981 & 7,108 & 7,515 & 9,141 & 5,917 \\
\hline 2002 & 12,983 & 14,124 & 10,339 & 8,169 & 9,896 & 7,244 \\
\hline 2003 & 17,117 & 19,040 & 12,615 & 9,096 & 11,594 & 7,682 \\
\hline 2004 & 20,867 & 23,314 & 15,156 & 10,423 & 12,677 & 8,241 \\
\hline 2005 & 24,420 & 26,416 & 19,857 & 11,346 & 12,855 & 9,663 \\
\hline 2006 & 29,679 & 32,406 & 23,504 & 11,883 & 14,218 & 10,312 \\
\hline 2007 & 35,032 & 37,976 & 28,195 & 13,021 & 15,286 & 11,349 \\
\hline 2008 & 41,501 & 44,932 & 33,312 & 14,101 & 16,167 & 11,986 \\
\hline 2009 & 52,458 & 57,579 & 40,211 & 12,605 & 18,288 & 12,772 \\
\hline
\end{tabular}

Source: Statistical Yearbook of the RS (Ya) 2008:131; 2010:149-50. Website

http://inflationinrussia.com/inflation_calculators.aspx used to calculate inflation adjustment.

The data suggest that material wellbeing, measured by household income, has been improving over the past decade, even when adjusted for inflation. The trend is not surprising, as during the 2000s, Russia 
emerged from the economic crisis that characterized the mid- and especially late-1990s.

Secondary literature provides some indication of the geographical variation of per capita (not household) income by ulus: Gavrileva and Tarasova (2011) provide a chart of per capita income by ulus. The differences are significant, with the highest average monthly per capita income, in the Mirinskiy Ulus (Western Region) exceeding the lowest, in Namskiy Ulus (Central Region) by 3.9 times. The graph shows that seven out of the eight ulusy with the lowest per capita incomes are located in the Central Region, while the Arctic ulusy are mostly in the mid-range of per capita income. It is noteworthy however that only in Mirinskiy (Western Region) and Anabarskiy (Northern Region) ulusy, and Yakutsk and Neryungri (cities) are incomes above the republican average, which points to concentration of income earning capacity in a few places (Gavrileva and Tarasova 2001:53).

The largest part of monetary income derives from wages. However, compared with 2002, the share of wages in 2010 decreased, from 53.6\% to $49.6 \%$. Income from business activities and social benefits increased, while income from property and other income fell (Prokohorova et al. 2012).

\section{Berekozvka village, Srednekolysmkiy Ulus}

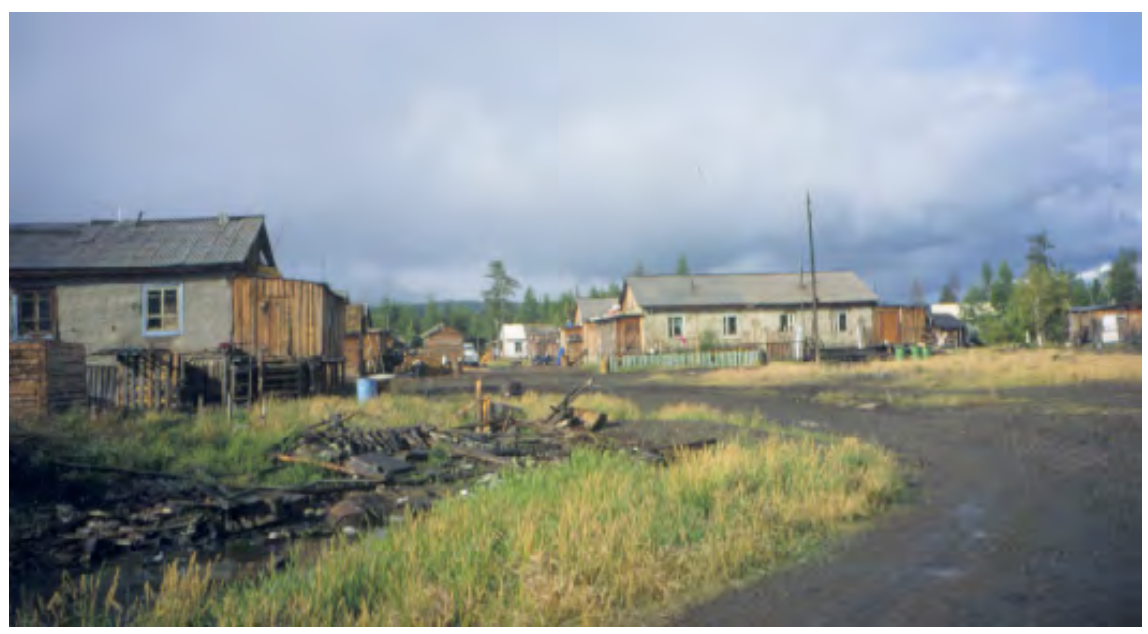

Photo: Gail Fondahl.

It must be noted that the aggregate data mask significant variations between as well as within ulusy of Sakha Republic (Yakutia). Limited employment opportunities in many small villages, and an increased dependence on subsistence farming, hunting, gathering and reindeer herding, characterize many remote communities (Crate 2006). The figures in 
Table 2.9 do provide some idea of the discrepancies: average rural income is $77 \%$ of the republican average income. In many rural areas an appreciable move toward a non-monetized economy marked the 1990s, a trend which continued on to the 2000s. Subsistence activities grew in importance, especially with the failure of many economic enterprises, the withdrawal of state supports, and the delay in receipt of wages, or total loss of such.

Table 2.10: Distribution of Ulusy by Average Income (per capita), January-December 2010

\begin{tabular}{|c|c|c|c|c|c|c|c|}
\hline \multicolumn{2}{|c|}{$\begin{array}{c}\text { Under } 12,000 \text { rubles } \\
\text { (9 ulusy) }\end{array}$} & \multicolumn{2}{|c|}{$\begin{array}{c}12,000-15,000 \text { rubles } \\
\text { (10 ulusy) }\end{array}$} & \multicolumn{2}{|c|}{$\begin{array}{c}15,000-20,100 \text { rubles } \\
\text { (11 ulusy) }\end{array}$} & \multicolumn{2}{|c|}{$\begin{array}{c}\text { Over } 20,000 \text { rubles } \\
\text { (5 ulusy) }\end{array}$} \\
\hline Namskiy & 8,293 & $\begin{array}{c}\text { Eveno- } \\
\text { Bytantayskiy } \\
\text { National }\end{array}$ & 12,088 & Allaykhovskiy & 15,010 & Lenskiy & 20,882 \\
\hline $\begin{array}{l}\text { Ust- } \\
\text { Aldansky }\end{array}$ & 9,689 & $\begin{array}{l}\text { Sredne- } \\
\text { kolymskiy }\end{array}$ & 12,466 & $\begin{array}{l}\text { Verkhoyan- } \\
\text { skiy }\end{array}$ & 15,282 & $\begin{array}{l}\text { Neryungri \& } \\
\text { area }\end{array}$ & 24,433 \\
\hline $\begin{array}{l}\text { Verkhne- } \\
\text { vilyuskiy }\end{array}$ & 10,383 & $\begin{array}{l}\text { Mengino- } \\
\text { Kangalasskiy }\end{array}$ & 12,486 & Kobyayskiy & 15,289 & Anabarskiy & 28,126 \\
\hline Gornyy & 10,545 & Vilyuyskiy & 12,505 & Ust-Mayskiy & 15,925 & $\begin{array}{c}\text { Yakutsk } \\
\text { (City) } \\
\text { \& area }\end{array}$ & 30,221 \\
\hline $\begin{array}{l}\text { Churap- } \\
\text { chinsnskiy }\end{array}$ & 11,038 & Nyurbinskiy & 12,676 & Ust-Yanskiy & 15,987 & Mirinskiy & 33,273 \\
\hline Tatinksiy & 11,317 & Olenekskiy & 13,719 & Zhiganskiy & 16,118 & & \\
\hline Amginskiy & 11,430 & $\begin{array}{l}\text { Nizhne- } \\
\text { kolymskiy }\end{array}$ & 13,869 & Abyyskiy & 16,208 & & \\
\hline $\begin{array}{l}\text { Khangalas- } \\
\text { skiy }\end{array}$ & 11,636 & Momskiy & 14,698 & Tomponskiy & 16,449 & & \\
\hline \multirow[t]{3}{*}{ Suntarskiy } & 12,046 & Olekminskiy & 14,732 & $\begin{array}{l}\text { Verkne- } \\
\text { kolymskiy }\end{array}$ & 17,116 & & \\
\hline & & Bulunskiy & 14,805 & Aldanskiy & 17,848 & & \\
\hline & & & & $\begin{array}{l}\text { Oymyakon- } \\
\text { skiy }\end{array}$ & 19,982 & & \\
\hline
\end{tabular}

Shading: Blue = Central ulusy; Green = Southern ulusy; Yellow = Western ulusy; Orange $=$ Eastern ulusy; Purple $=$ Northern ulusy; Pink = Northeastern ulusy; italicized - Arctic ulusy

The shading in Table 2.10 helps identify regional trends. Most of the Central Region's ulusy are characterized by low income, whereas higher income characterizes the Eastern Region's ulusy. The North and Northeastern Regions' ulusy fall in the middle range, income wise (as does the "Arctic Region", which largely overlaps with these two regions). Mirnyy (the main diamond-mining region), the city of Yakutsk and its subordi- 
nate settlements, and the city of Neryungri are among the highest per capita income areas.

Strong differences characterize the levels of material wellbeing between the urban and rural populations. Rural areas are characterized by low income, unemployment, poor state of infrastructure, and an increasing proportion of elderly inhabitants. The bulk of the rural population is engaged in agriculture, which is traditionally characterized by a low levels of pay compared to other industries. A sample survey of household budgets was conducted in November 2010 by the Center for Social Problems Labour Sciences of Sakha (Yakutia) in three rural areas of the Republic: Olenek (Western region), Verkhnevilyuisk (Western Region) and Namsky (Central Region). According to the survey the average monthly income per person was 15,100 rubles, or $163 \%$ above of the official poverty income line. Analysis of the decile distribution of the average monthly income of rural residents showed that $10 \%$ of the poor villagers had income of 6,568 rubles per month. Half of the respondents had incomes of up to 13,000 rubles, while $20 \%$ had incomes of over 18,000 rubles.

More than $40 \%$ of rural residents surveyed in these three ulusy felt that they were "poor", with a major feature of poverty being constantly not having enough money even for food. Only 1.6\% considered themselves "rich", not having to deny themselves anything. The presence of children in a family dramatically lowers the level of material wellbeing, with the largest group of rural poor being the families with small children, and families with more than three children. The birth of a child removes the mother from active professional life.

Comparisons with an earlier sociological survey, conducted in 2008, found deteriorating estimates of personal material wellbeing among villagers, as well as increased pessimism regarding future improvements. The proportion of rural residents reporting themselves as "poor" in 2008 was $22.9 \%$, compared to over $40 \%$ by 2010 . In terms of perceived change, $55 \%$ of rural residents reported that their financial situation had neither changed for the better or worse in the past five years. About 25\% felt that their situation had improved, while 20\% felt that their situation had worsened. In terms of assessing the future, $36.6 \%$ of respondents were optimistic, $47.6 \%$ simply hoped for stability in the coming years, and $15.8 \%$ of households expected deterioration (Neustroeva 2011). It should be noted that populations in small villages, and especially small, indigenous villages, are often highly dependent on transfer payments, such as pensions. 
Supplementary indicators suggested for material wellbeing include net-migration and unemployment (Larsen and Huskey 2010). Netmigration has been described above. The outflow from almost all ulusy suggests that the potential for achieving material wellbeing in the Republic's ulusy continues to be perceived as unpromising relative to the Republic's capital and to other areas of the Russian Federation to which out-migrants are heading, assuming that material wellbeing is a major contributing factor to decisions to migrate.

Unemployment data are available for the Republic as a whole, but not by ulus (Table 2.11).

Table 2.11: Unemployment Rates, Sakha Republic (Yakutia), 2000-2008
\begin{tabular}{lccccccccr}
\hline Year & 2000 & 2001 & 2002 & 2003 & 2004 & 2005 & 2006 & 2007 & $\mathbf{2 0 0 8}$ \\
\hline \% Unemployment & 11.2 & 8.2 & 7.1 & 9.3 & 8.8 & 8.9 & 9.5 & 7.6 & 9.0 \\
\hline
\end{tabular}

Source: Labour 2009, p.228.

The indicators for the Material Wellbeing domain indicate that there has been a substantial increase in per household average income in the republic, but that the improvement is much less marked in rural areas. The fact of high out-migration and stagnant unemployment rates suggest that wellbeing is not improving throughout much of Sakha Republic (Yakutia). Examining the secondary indicators, net-migration and unemployment, offer a less sanguine picture of human development than do the income statistics, and once again underscore the constraints and dangers of depending on a single indicator.

\subsection{Education Domain}

The chosen indicator for the education domain is the ratio of students successfully completing post-secondary education (persons per 1,000 population). This statistic is available by ulus for the Sakha Republic (Yakutia). Counted in the published numbers are graduates from universities, technical schools and institutions offering professional training. Table 2.12 shows trends in such educational attainment. However, the data need to be treated with great caution. In the Eastern, Northern and Northeastern regions especially, the total population numbers are so low that notable fluctuations in rates (e.g. from 1.0 to 4.4) are relatively meaningless. 
Table 2.12: Students Completing Post-Secondary Degree in Sakha Republic (Yakutia) (per 1,000 population)

\begin{tabular}{lrrrrrrr}
\hline Region & $\mathbf{1 9 9 0}$ & $\mathbf{2 0 0 0}$ & $\mathbf{2 0 0 5}$ & $\mathbf{2 0 0 6}$ & $\mathbf{2 0 0 7}$ & $\mathbf{2 0 0 8}$ & $\mathbf{2 0 0 9}$ \\
\hline Central & 14.9 & 15.3 & 24.0 & 23.5 & 23.5 & 23.2 & 23.3 \\
Central w/o Yakutsk & 8.1 & 4.9 & 6.5 & 6.3 & 8.0 & 6.8 & 6.6 \\
Yakutsk & 21.6 & 24.7 & 38.6 & 37.7 & 35.9 & 35.8 & 35.9 \\
Southern & 4.7 & 5.5 & 11.1 & 11.0 & 12.8 & 10.5 & 9.9 \\
Western & 6.7 & 6.7 & 6.7 & 6.5 & 6.7 & 6.6 & 6.8 \\
Eastern & 0 & 0 & 3.6 & 3.9 & 4.3 & 2.4 & 3.8 \\
Northern & 1.7 & 3.5 & 1.8 & 3.3 & 2.4 & 4.0 & 2.9 \\
Northeastern & 2.4 & 1.0 & 4.4 & 2.3 & 4.5 & 2.6 & 2.0 \\
Sakha Republic (Yakutia) & 8.3 & 9.8 & 15.5 & 15.3 & 15.8 & 15.1 & 15.4 \\
\hline
\end{tabular}

Source: Statistical Yearbook of the RS (Ya) 2010:242.

Yukagir pupil in front of bust of Tekki Odulok, the first Yukagir writer, Verkhneykolymskiy Ulus

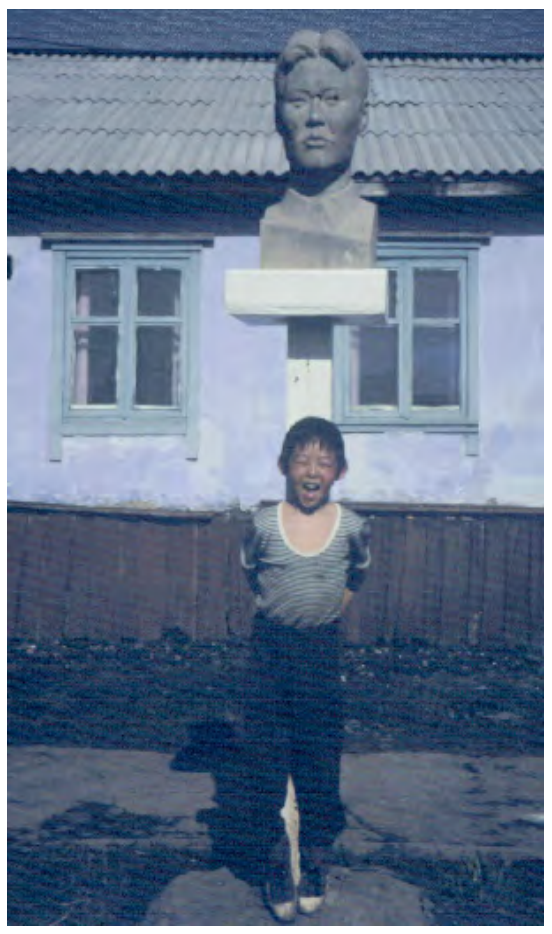

Photo: Gail Fondahl.

The data indicate that, on average, post-secondary education is increasing among the population of Sakha Republic (Yakutia). This is especially true for the capital city, Yakutsk and in the southernmost region. Changes in post-secondary education attainment in the north are likely in part due to the addition of post-secondary institutions. Many of the Republic's ulusy do not have any post-secondary institutions: in the Northern region, four of the five ulusy had no such institutions in 1990, and three 
of the five ulusy still had none in 2009. In the Northeastern Region, only one of the six ulusy offers post-secondary education at a local institution. Such institutions are also missing from the northern ulusy of the Western Region (Anabarskiy ulus, Olenekskiy Ulus). However, these Arctic ulusy have enjoyed some recent additions. Bulunsky and Verkhoyanskiy ulusy (Northern Region) had no post-secondary institutions in 1990, but each had added beginning post-secondary professional training capacity by 2000. Nizhnekolmysk ulus added mid-level post-secondary professional training capacity in 2007 (Statistical Yearbook of the RS (Ya) 2010). Such institutions were created to address the problems of inaccessibility for many high-school graduates to higher education (due to lack or high cost of transport); they focus mainly on preparation for participation in traditional branches of the economy.

Where we see decline in post-secondary graduates, we may be witnessing a combination of decline in number of persons in "traditional" postsecondary age cohorts with out-migration. Again, the very small populations in the northern regions make it difficult to use the statistics for more than very general trend analysis. Overall this indicator used suggests that Sakha Republic (Yakutia) is experiencing positive human development in the Education domain, though the experience is still very geographically disparate between the capital city and the rest of the Republic.

\subsection{Cultural Wellbeing and Cultural vitality}

Measuring cultural wellbeing and vitality in Arctic communities is based in three inter-related components: language retention, cultural autonomy, and belonging. The ASI-recommended indicator for this domain is a composite of all three. However, there is some overlap with other of the five domains' components, for example, the notion of cultural autonomy tied to fate control and engagement with subsistence used in the contact with nature domain. Therefore, to distinguish from those overlapping areas, the indicator used to gauge cultural wellbeing and vitality here is language retention.

Language retention figures in Sakha Republic (Yakutia) have been collected in the past. However, such figures are not available on an ulus level beyond 1989. Additionally, the data that were collected were limited to indigenous Sakha and the Numerically Small Peoples of the North. Thirdly, the wording of the question used to collect such data has changed over time, making longitudinal comparisons impossible. Finally, the data collected appear to be problematic in terms of accuracy, as the 
following tables indicate: they likely say more about changing identity politics than about language use or retention.

Table 2.13 indicates reported changes in native language or "mother tongue" (rodnoy yazyk) among Russians, Sakha (Yakut) and four of the five numerically small peoples of the North in the republic (Dolgan are not included), based on the 1979 and 1989 census results, and the 1994 micro-census.

Table 2.13: "Mother tongue" of the Main Nationalities of Sakha Republic (Yakutia) According to Data from the Censuses $(1979,1989)$ and Micro-census (1994)

\begin{tabular}{|c|c|c|c|c|c|c|c|c|c|}
\hline \multirow{3}{*}{ Nationality } & \multicolumn{9}{|c|}{ "Mother Tongue" (\% claiming given language as "mother tongue") } \\
\hline & \multicolumn{3}{|c|}{ Language of one's nationality } & \multicolumn{3}{|c|}{ Sakha Language } & \multicolumn{3}{|c|}{ Russian Language } \\
\hline & 1979 & 1989 & 1994 & 1979 & 1989 & 1994 & 1979 & 1989 & 1994 \\
\hline Russians & & 99.7 & 99.8 & & 0.2 & 0.2 & & & \\
\hline Sakha & & 95.1 & 97.1 & & & & & 4.9 & 2.9 \\
\hline Evenki & 11.2 & 8.5 & 5.0 & 82.2 & 82.5 & 90.8 & 6.4 & 8.9 & 4.2 \\
\hline Evens & 44.1 & 34.7 & 57.0 & 48.5 & 54.3 & 34.9 & 7.0 & 10.7 & 8.0 \\
\hline Yukagirs & 39.7 & 35.2 & 18.6 & 23.0 & 28.1 & 32.6 & 30.2 & 33.4 & 39.5 \\
\hline Chukchi & 71.1 & 63.2 & 28.6 & 4.5 & 7.4 & 14.3 & 23.1 & 28.5 & 57.1 \\
\hline
\end{tabular}

Source: Mestnikova 2010: 227.

In most cases we see the reported loss of ability to speak one's language over the 15-year period among the numerically small peoples, with the Evens being the exception (reporting a 22\% gain). Sakha people also report a slight gain (2\%). The use of Sakha language increased and the use of Russian language reportedly dropped among the Evenki and Yukagir between 1989 and 1994.

Collection of data regarding language in the 2002 Census involved two questions:

1) Do you speak Russian? and 2) What other languages do you know? The question of the "mother tongue" was removed, making it impossible to unconditionally compare the results with previous censuses' data. However, the statistics can be used to suggest trends. Unfortunately the 2002 Census only reports on knowledge/ use of Russian, not Sakha, among the indigenous Numerically Small Peoples of the North living in Sakha Republic (Yakutia). Moreover, data on Chukchi residing in the republic are not presented. See Table 2.14. 
Table 2.14: Indigenous Numerically Small Peoples Able to Speak Own Language and Russian, Sakha Republic (Yakutia), 2002

\begin{tabular}{|c|c|c|c|c|c|c|}
\hline \multirow{3}{*}{ People } & \multirow{3}{*}{\multicolumn{2}{|c|}{ Total Population (Individuals) }} & \multicolumn{4}{|c|}{ Indicating Language Spoken } \\
\hline & & & \multicolumn{2}{|c|}{ Of one's people } & \multicolumn{2}{|c|}{ Russian } \\
\hline & & & $\#$ & $\%$ & $\#$ & $\%$ \\
\hline \multirow[t]{4}{*}{ Evenki } & Russian Federation & 34,610 & 6,780 & 19.6 & 32,511 & 93.9 \\
\hline & Sakha Republic & 18,232 & 1,384 & 7.6 & 16,241 & 89.1 \\
\hline & Urban & 4,221 & 363 & 8.6 & 4,103 & 97.2 \\
\hline & Rural & 14,011 & 1,021 & 7.3 & 12,138 & 86.6 \\
\hline \multirow[t]{4}{*}{ Even } & Russian Federation & 18,642 & 6,080 & 32.6 & 17,358 & 93.1 \\
\hline & Sakha Republic & 11,657 & 3,272 & 28.1 & 10,430 & 89.5 \\
\hline & Urban & 3,569 & 777 & 21.8 & 3,434 & 96.2 \\
\hline & Rural & 8,088 & 2,495 & 30.8 & 6,996 & 86.5 \\
\hline \multirow[t]{4}{*}{ Yukagir } & Russian Federation & 1,176 & 323 & 27.5 & 1,125 & 95.7 \\
\hline & Sakha Republic & 1,097 & 310 & 28.3 & 1,046 & 95.3 \\
\hline & Urban & 426 & 99 & 23.2 & 412 & 96.7 \\
\hline & Rural & 671 & 211 & 31.4 & 634 & 94.5 \\
\hline \multirow[t]{4}{*}{ Dolgan } & Russian Federation & 7,077 & 4,538 & 64.1 & 6,574 & 92.9 \\
\hline & Sakha Republic & 1,272 & 41 & 3.2 & 1,024 & 80.5 \\
\hline & Urban & 156 & 19 & 12.2 & 149 & 95.5 \\
\hline & Rural & 1,116 & 22 & 2.0 & 875 & 78.4 \\
\hline Chukchi & Russian Federation & 14,034 & 6,418 & 45.7 & 13,619 & 97.0 \\
\hline
\end{tabular}

Source: http://www.perepis2002.ru/ct/html/TOM_13_02.htm

It is interesting to note that in a couple of cases the urban indigenous population reports more use of its own language than the rural indigenous population (Evenki, Dolgans). This may be in part due to political positioning.

The 2010 Census provided data on what different nationalities report as their "mother language" (Table 2.15):

Table 2.15: Language Reported as “Mother Language” (rodnoy yazyk) in Sakha Republic, by \% of Nationality, 2010, selected nationalities

\begin{tabular}{lrrrrrrr}
\hline \multirow{2}{*}{ Nationality } & \multicolumn{7}{c}{ Reported “Mother Language” } \\
\cline { 2 - 8 } & Sakha & Russian & Evenki & Ukrainian & Even & Tatar & Buryat \\
\hline Sakha & 94.2 & 5.8 & 0 & 0 & 0 & 0 & 0 \\
Russian & 0.4 & 99.5 & 0 & 0.1 & 0 & 0 & 0 \\
Evenki & 81.2 & 12.1 & 6.4 & 0 & 0.3 & 0 & 0 \\
Ukrainian & 0.2 & 74.7 & 0 & 25.0 & 0 & 0 & 0 \\
Even & 65.4 & 13.3 & 0.7 & 20.5 & 0 & 0 & 0 \\
Tatar & 1.6 & 61.6 & 0 & 0 & 0 & 36.3 & 0 \\
Buryat & 2.1 & 44.5 & 0 & 0 & 0 & 0 & 53.4 \\
\hline
\end{tabular}

Source: http://www.gks.ru/free_doc/new_site/perepis2010/croc/perepis_itogi1612.htm Note: This table shows nationalities with more than 5,000 individuals in the republic; the original data includes a few more nationalities (but no more of the indigenous numerically small peoples of the North). 
The information above is not completely comparable with the previous table as in the previous (2.14) individuals could indicate use of more than one language (and thus totals exceed $100 \%$ in a number of cases), whereas in the 2010 table an individual could only indicate one language. More comparable are the following statistics, which indicated what languages different nationalities report as having mastered. The statistics do provide some interesting conundrums that illustrate the problems of using language retention as an indicator. For instance, whereas $6.4 \%$ of Evenki indicate the Evenki language as their "mother language" (Table 2.15), only 5.7\% of Evenki indicate that they can speak Evenki (Table 2.16). The data also speak to the degree to which the two largest indigenous numerically small peoples of the Republic (Evenki, Even) are linguistically assimilating toward Sakha language versus Russian language.

Table 2.16: Languages Spoken by Various Nationalities, Sakha Republic (Yakutia), 2010 (\% of Nationality Responding, Reporting to Speak Language)

\begin{tabular}{lrrrrrrr}
\hline \multirow{2}{*}{ Nationality } & \multicolumn{7}{c}{ Speaks Language (\%) } \\
\cline { 2 - 7 } & Sakha & Russian & Evenki & Ukrainian & Even & Tatar & Buryat \\
\hline Sakha & 87.0 & 90.4 & 0 & 0 & 0 & 0 & 0 \\
Russian & 2.0 & 99.9 & 0 & 1.1 & 0 & 0 & 0 \\
Evenki & 81.0 & 91.1 & 5.7 & 0 & 0.4 & 0 & 0 \\
Ukrainian & 0.8 & 99.8 & 0 & 43.6 & 0 & 0 & 0 \\
Even & 76.9 & 91.4 & 0.6 & 0 & 22.4 & 0 & 0 \\
Tatar & 4.0 & 99.7 & 0 & 0.3 & 0 & 35.1 & 0.1 \\
Buryat & 4.9 & 99.5 & 0 & 0 & 0 & 0 & 42.4 \\
\hline
\end{tabular}

Source: Calculated from http://www.gks.ru/free_doc/new_site/perepis2010/croc/perepis_itogi1612.htm

Language retention - or the lack thereof - suggests a challenging and adverse situation in terms of cultural vitality for the indigenous numerically small peoples of the the Sakha Republic (Yakutia), though the situation differs among the various indigenous peoples and even within these peoples depending on where they live (Robbek 2011). Indeed, the UNESCO Interactive Atlas of World's Languages In Danger includes all the languages of the numerically small peoples of the North, as well as Sakha (Metsnikova 2010:228). Dependence on this indicator may mask other measures of cultural vitality that have more positive trends, such as ethno-political engagement. However language loss has been identified as a major challenge to indigenous peoples across the globe. 


\subsection{Contact with Nature}

Contact with Nature is an important aspect of human wellbeing in the Arctic due to how a relationship with nature serves an irreplaceable role in mental, physical and spiritual health for Arctic residents (Crate et al. 2010:109). The choice of harvest and consumption of traditional foods as the indicator is based on the assumption that the extent to which inhabitants continue their historically-based subsistence practices reflects a human-nature relationship and increased wellbeing. In the other circumpolar areas covered in this report, for example Northwest Territories, Canada, consumption data are readily available down to the household level. For the Russian Federation such a fine scale of data is not available. Instead, data are only available at republic level (Table 2.17).

Table 2.17: Harvest and Consumption of Traditional Foods in Sakha Republic (Yakutia), 2000-2008

\begin{tabular}{lrr}
\hline Year & $\begin{array}{r}\text { Harvest of Traditional Foods } \\
\text { (per capita, kg/year) }\end{array}$ & $\begin{array}{r}\text { Consumption of Traditional Foods } \\
\text { (Avg per household member, kg/year) }\end{array}$ \\
\hline 2000 & 22.7 & 296 \\
2001 & 27.5 & 258 \\
2002 & 29.4 & 320 \\
2003 & 37.1 & 340 \\
2004 & 42.3 & 325 \\
2005 & 44.3 & 365 \\
2006 & 47.8 & 351 \\
2007 & 48.8 & 354 \\
2008 & 49.9 & 358 \\
\hline
\end{tabular}

Source: Social Situation 2009 (Harvest statistics, p.153; Consumption statistics, p.144).

These data suggest improved wellbeing since they indicate that both harvest and consumption of traditional foods has increased during the period 2000-2008. However, there are many problems with the data. First, the trends at the republic level obscure the substantial rural-urban differences, and difference across regions, villages and households. Second, the harvest data show a steady increase, but does not clarify what part of the harvest was sold and what part was kept for consumption. Consumption data also show a general increase, but provide only an average per household member, and tell us nothing on individual bases or across households.

Beyond readily available data for Sakha Republic (Yakutia) as a whole, data can be combined from various sources to show regional trends. For example the following table (Table 2.18) shows trends over the past two decades for three ulusy. 
Table 2.18: Harvest of Traditional Foods (Meat, Fish, Milk) in Three Ulusy, Sakha Republic (Yakutia) (per capita, kg)

\begin{tabular}{lrrrrrrr}
\hline Region & $\mathbf{1 9 9 0}$ & $\mathbf{2 0 0 0}$ & $\mathbf{2 0 0 4}$ & $\mathbf{2 0 0 5}$ & $\mathbf{2 0 0 6}$ & $\mathbf{2 0 0 7}$ & $\mathbf{2 0 0 8}$ \\
\hline $\begin{array}{l}\text { Nizhnekolymskiy } \\
\text { (Northeastern Region) }\end{array}$ & 2,855 & $\mathbf{7 3 1}$ & $\mathbf{7 5 0}$ & $\mathbf{5 1 9}$ & 709 & 935 & 985 \\
$\begin{array}{l}\text { Nurbinskiy } \\
\text { (Western Region) }\end{array}$ & 21,925 & 12,828 & 16,365 & 18291 & 18,046 & 17,412 & 17,259 \\
$\begin{array}{l}\text { Suntarskiy } \\
\text { (Western Region) }\end{array}$ & 24,505 & 15,466 & 17,012 & 177,776 & 18,318 & 17,648 & 15,255 \\
\hline
\end{tabular}

Source: Economy 2009:185.

These data show a substantial drop in the harvest of traditional foods across all three ulusy shortly after the fall of the Soviet Union, a gradual increase in harvest in the early 2000s, and then, in the Nurbinskiy and Suntarskiy ulusy, a drop again. This trend reflects the historical reality of state production in Sakha Republic (Yakutia) and, for that matter, in most parts of the Russian North. State production was relatively high at the end of the Soviet period. After the break-up of the state farm system production fell, then gradually increased due largely to rising production of cooperatives, which routinely reported their production levels to the authorities. To some extent, those numbers again began to wane with the forces of economic globalization that are increasingly bringing meat products from lands as distant as Argentina for lower costs than they can be produced locally. Although these data reflect important trends, they do so for state production and not household-level production, which are the data we would need to use this indicator accurately. 


\section{Box 1}

\section{The End of Cows and Kin?}

Another possible inroad to understand the Contact with Nature Domain within Russia, albeit outside the purview of this exercise since it is not founded on state-level statistics, is via long-term ethnographic research. Following the fall of the Soviet Union in 1991, most of the state farms (sovkhozy) in the Sakha Republic (Yakutia) disbanded, dividing farm resources among the administrators and workers. This change left many individuals unemployed and transformed the food production that supplied households. Ethnographic research conducted in 1999-2000 revealed that to adapt to this sudden change, many rural Sakha residents had developed a system of 'cows \& kin'.

\section{Herding cows to the frozen river for daily water, Suntarskiy ulus}

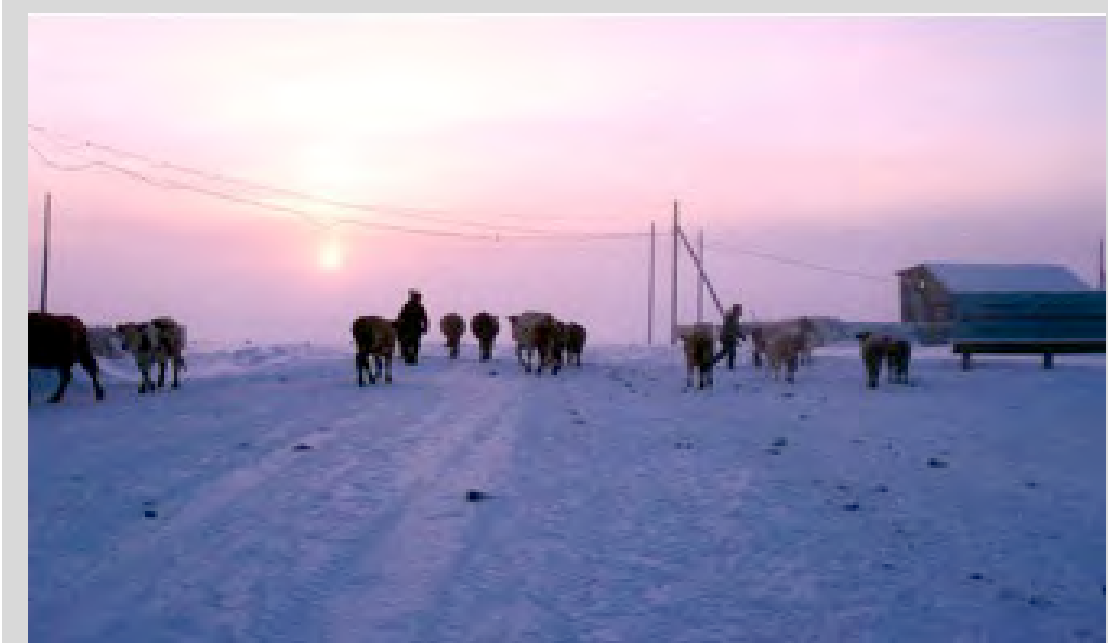

Photo: Susan Crate.

This system, in its most basic form involved one, usually elderly, household that held cows, performed the daily cow-care activities and supplied meat and milk to one or more other, usually younger, households, which reciprocated by harvesting and preparing sufficient hay to see the herd through the long winter months (Crate 2006). A brief decade later, it appears there is yet another transformation in food production occurring. In the summer of 2011, the Suntarsky ulus statistics department revealed that $50 \%$ or households that were keeping cows shortly after the end of the Soviet Union had stopped. Follow-up research in the summer of 2012 showed that there had been a $49 \%$ and a 54\% drop in cow-keeping since the 1999 levels among participating households. Reasons for this change are diverse. For one, environmental conditions, largely as a result of climate change, had made 
the procurement of hay difficult, with hayfields inundated with water, and the timing of cow-care activities disrupted due to changing seasonality. Secondly, the "work force" of cow care is all elderly and the next generation is disinterested. In fact, regional statistics show a steady out-migration of youth from the area. Lastly, as mentioned above, many households are finding it preferable and oftentimes cheaper to buy products at the local stores, which are now well-stocked as compared to the decade following the fall of the Soviet Union.

Increased water on the land due to climate change is making horse and cattle husbandry increasingly difficult, Suntarskiy ulus

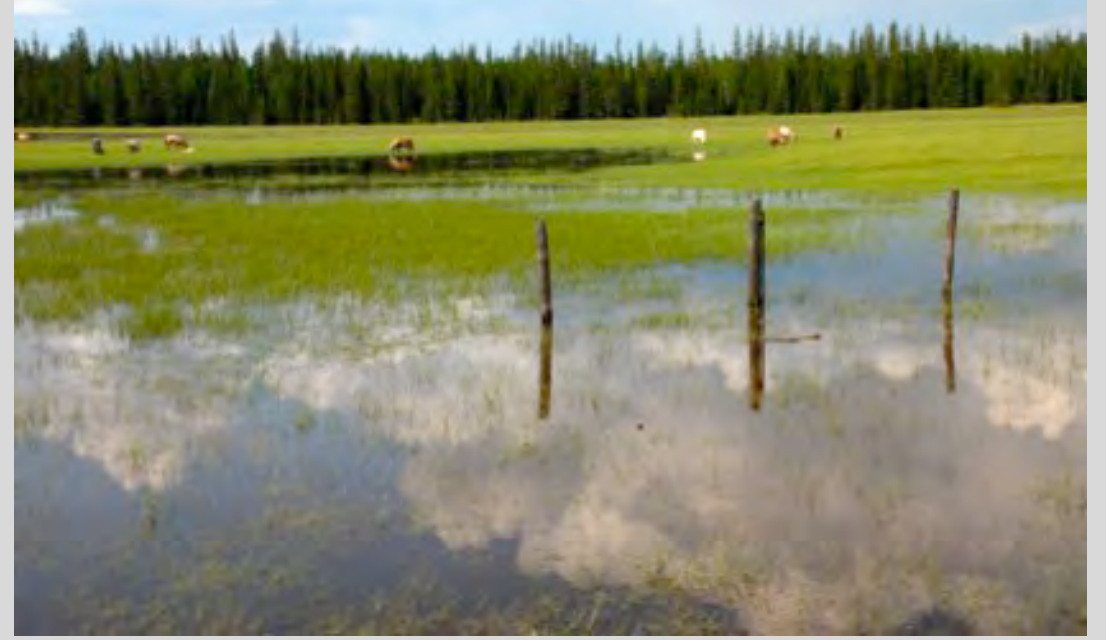

Photo: Susan Crate.

\subsection{Fate Control Domain}

Implementing the Fate Control index in Sakha Republic (Yakutia) proved very difficult. As reported in the Arctic Social Indicators Report (Dahl et al. 2010), the Fate Control Index is composed of four measures: a measure of political control (percentage of local people in the governing body of the jurisdiction), a measure of economic control (\% of public expenses from locally generated funds), cultural control (\% of people speaking their "mother tongue"), and control over land. 
In terms of the measure of political control, there is no public record of the percentage of local or indigenous members in governmental bodies at the ulus or even republican level. Moreover, as the Russian census no longer collects information on ethnicity, trying to identify this using governmental sources, or other sources easily and regularly available, is not possible. Nor were we able to identify useful data for addressing the measure of economic control.

In terms of language retention, the data available was presented earlier in this chapter. As noted, the data are not available by ulus, but rather by ethnic group. In the past they are only been easily available for the Sakha people and the Numerically Small Northern Peoples of the Republic (Chukchi, Dolgan, Even, Evenk, Yukagir). While Russians will likely mostly retain Russian as their native language, historically a small part of the Russian population experienced "Yakutization" linguistically, and bilingualism is a common situation in many areas of the Republic for many peoples (see, e.g. Mestnikova 2010; Robbek 2011). We have partial information on language retention among other ethnic groups living in Sakha Republic (Yakutia) (see Tables 2.15, 2.16; information is also available for Krygyz, Armenians, Uzbek but not included in these tables). Given that the type of language statistics collected has changed recently (i.e. the way the questions have been posed in the census has been altered), our current ability to compare data over time is limited. This may be addressed in the future, making language retention as a measure of the cultural component of fate control more useful.

The other component of the suggested "Fate Control" indicator is the percentage of surface lands controlled by local/ indigenous inhabitants. In Sakha Republic (Yakutia), the land allocated to indigenous obshchinas can be used as an admittedly very imperfect proxy for this measure (Table 2.19). Obshchinas (roughly translating to "communities" or "communes") are collectives formed by indigenous numerically small peoples in order to pursue a "traditional" activity (reindeer husbandry, hunting, fishing) (Sirina 1999; Fondahl et al. 2000). Obshchinas may apply for an allocation of land on which to pursue such "traditional" activities, and receive such, which is then allegedly at least partially protected from competing activities that might undermine the "traditional" ones, such as various forms of industrial development. The collectives may include non-indigenous persons, but the leader usually must be from a Numerically Small Northern People, and in some cases local officials have interpreted the law to require majority membership of such indigenous persons. The activities pursued by the obshchina may include non"traditional" ones (such as cattle herding), but "traditional" ones must 
predominate. Whether obshchinas can pursue such activities as mineral extraction, in the form of auxiliary activities to the main traditional one(s) remains not only debated, but the subject of a number of ongoing legal cases.

Table 2.19: Land Allocated to Obshchinas in Sakha Republic (Yakutia), 1999 and 2008

\begin{tabular}{lrrrrr}
\hline \multirow{2}{*}{ Region } & \multicolumn{2}{c}{1999} & \multicolumn{2}{c}{$\mathbf{2 0 0 8}$} & \\
\cline { 2 - 5 } & $\begin{array}{r}\text { Territory of } \\
\text { obshchinas, } \\
\text { hectares }\end{array}$ & $\begin{array}{r}\text { \% of Region's } \\
\text { territory allocat- } \\
\text { ed to obshchinas }\end{array}$ & $\begin{array}{r}\text { Territory of } \\
\text { obshchinas, } \\
\text { hectares }\end{array}$ & $\begin{array}{r}\text { \% of Region's } \\
\text { territory allocat- } \\
\text { ed to obshchinas }\end{array}$ & $\begin{array}{r}\text { Change, } \\
\text { 1999-2008, \% }\end{array}$ \\
\hline Central & 201,291 & 0.6 & $1,192,233$ & 3.5 & 466.9 \\
Southern & $11,761,297$ & 28.2 & $19,084,441$ & 45.8 & 62.3 \\
Western & $3,380,858$ & 4.4 & $6,457,514$ & 8.4 & 91.0 \\
Eastern & $9,855,000$ & 30.5 & $2,639,942$ & 8.2 & -73.2 \\
Northern & $13,421,079$ & 19.9 & $9,963,174$ & 14.8 & -25.8 \\
Northeastern & $8,659,119$ & 15.4 & $17,288,254$ & 30.8 & 99.6 \\
Sakha Republic & $47,287,644$ & 15.3 & $56,635,558$ & 18.4 & 19.7 \\
(Yakutia) & & & & & \\
\hline
\end{tabular}

The territory allocated to such obshchinas is not at all a measure of Fate Control for the entire population: indeed, it only captures the "control" of land by the Numerically Small Northern Peoples and their collectives, which account for a very small percentage of the Republic's population. In Sakha Republic (Yakutia) Sakha persons and persons of other ethnic groups can only apply for such land allocations if they are pursuing a "traditional" activity of the Numerically Small Northern Peoples (e.g. reindeer husbandry). Cattle- and horse-raising, "traditional" activities of the indigenous Sakha, cannot be the primary basis for forming an obshchina and receiving an allocation of land.

Another criticism of the measure entails the concern that in many places once such "land-claim"-type settlements are reached, little changes in land control, and thus the measure does not help track human development and more specifically improvements or deterioration in control over one's destiny. However, two arguments counter this criticism. First, reaching a stage of substantial control over land may be a step that is important enough in wellbeing to merit measurement. When the Fate Control indicator was presented to the Arctic Council's Sustainable Development Working Group in 2010, several of the Permanent Participants applauded and endorsed this measure as an important one. Moreover, in the past two decades the implementation of indigenous rights, including land rights, has tracked closely with the general observation of rights to greater self-determination and to greater local self-government. Second, changing laws, and changing interpretations of those laws may result in the increase or decrease of lands controlled. In the Russian Federation as a whole, a law 
on obshchinas was passed in 2000, which provided for the allocation of lands to obshchinas in perpetuity and without charge. By 2004, changes to other laws modified these provisions. Land was no longer granted free of charge and in perpetuity: legal revisions imposed a rent on the land and a term of lease. Re-registration under the new laws and under these new terms meant that some indigenous peoples ceded their recently gained obshchina lands. Thus, despite the significant limitations noted above, the territory allocated to obshchinas in Sakha Republic (Yakutia) may be a useful proxy for control over one's destiny.

\section{Father and son on reindeer herding obhshina lands, Olekminskiys Ulus}

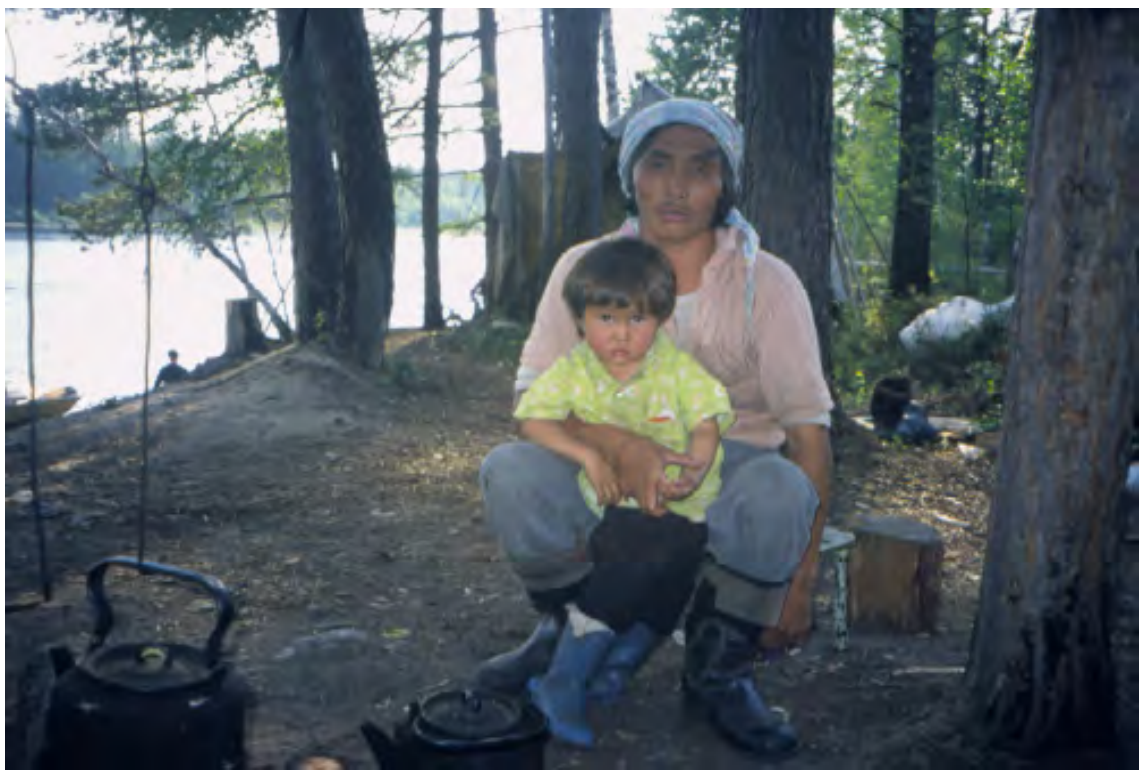

Photo: Gail Fondahl.

Overall, the area of land allocated to obshchinas grew in Sakha Republic (Yakutia) by almost 20\% from 1999 to 2008 (Table 2.19). The data show a very varied situation across the landscape of the Republic. In some regions (Southern, Western, Northeastern) we see a substantial increase in land allocated, while in others (Eastern, Northern) we see a significant drop.

The numbers of obshchinas provides some further context (Table 2.20). Using the amount of land allocated to obshchinas as a proxy measure of Fate Control, we would assess an improvement in Fate Control over the past decade (Table 2.19). Table 2.20 suggests that obshchina lands are increasingly concentrated in fewer obshchinas. Whether this concentration suggests any decline in Fate Control since 
2003 cannot be judged from the data available, but would require more detailed study of the reasons for consolidation and outcomes of such.

Table 2.20: Number of Registered Obshchinas, Sakha Republic (Yakutia), 1997-2008

\begin{tabular}{lrrrrr}
\hline & 1997 & 1999 & 2000 & $\mathbf{2 0 0 3}$ & $\mathbf{2 0 0 8}$ \\
\hline Central & 3 & 4 & 4 & 12 & 2 \\
Southern & 76 & 80 & 80 & 83 & 89 \\
Western & 14 & 14 & 18 & 43 & 48 \\
Eastern & 25 & 26 & 28 & 25 & 15 \\
Northern & 52 & 75 & 83 & 87 & 49 \\
Northeastern & 17 & 16 & 16 & 16 & 16 \\
Sakha Republic (Yakutia) & $185^{*}$ & $213^{*}$ & $226^{*}$ & $264^{*}$ & $215^{*}$ \\
& $(190)$ & $(215)$ & $(229)$ & $(266)$ & $(219)$ \\
\hline
\end{tabular}

Source: Table compiled from data from the Departments of Traditional Activities of the North and of Fisheries, Ministry of Agriculture, Republic of Sakha (Yakutia).

Note: the total number of obshchinas reported for each year $\left({ }^{*}\right)$ differed from the sum of the number of obshchina for each region, which is provided in parentheses. This is due to the fact that some obshchinas register, but then fail to work, and thus are not included in the data.

Given the difficulties experienced in gaining access to much of the information needed for calculating the Fate Control Index that was proposed in the initial Arctic Social Indicators Report (Dahl et al. 2010), but also the great interest in this measure, especially among the Arctic Council Permanent Participants, it will be critical to further examine the Fate Control measure. Its "land control" component especially deserves attention (a point also stressed by several Permanent Participants) as we move forward with tracking human development in the Arctic. More work is required in this area.

\subsection{Summary and Conclusions}

This chapter has examined the application of social indicators for the six domains identified in the Arctic Social Indicators Report (Larsen et al. 2010) to Sakha Republic (Yakutia). The process of testing and trying to verify each indicator with available data has revealed difficulties on a number of fronts, but also trends in improved data availability. In carrying out the verification, it has also been possible to evaluate whether the indicators seem to "ring true", against the observations of the authors, two of whom have worked in the Republic (Crate has done so extensively over the past two decades) and one of whom is a resident and citizen of Sakha Republic (Yakutia) (Filippova). 


\section{Measuring Human Development in the Sakha Republic (Yakutia): Data Availability}

The ASI report (2010) identified as important criteria that data should be:

- collected by a national agency, preferably published in hard-copy or electronic form

- available at the regional level

- available for the indigenous and non-indigenous populations

- available on at least a five-year reporting period.

Data for Sakha Republic (Yakutia) is in part collected by a national agency, in part by Republic organs. They are published in hard-copy, and increasingly also in electronic form. Much of the data is available at the regional (ulus) level, and it appears that more are becoming available at this level. As discussed above, significant challenges remain in using the data at the ulus level to identify trends, given the very small population sizes, but aggregation can be used to partially address this problem.

To what extent information will be available in the future for the "indigenous" and "non-indigenous" populations remains to be seen. Two distinct challenges face future researchers of such trends. Firstly, the fact that the Russian Federation moved away from documenting ethnic identity in the collection of some information in the early 21st century eroded the ability to track trends by indigenous and non-indigenous groups. This decision is being reconsidered. We can also gain some insights in looking at statistics collectively for the "regions inhabited by indigenous numerically small peoples of the North" though in these same regions, taken as a whole, indigenous peoples comprise a minority of the population.

Secondly, in Sakha Republic (Yakutia) we have an interesting case of different comprehensions of indigeneity. Sakha are indigenous to the region, but do not enjoy the same legal recognition or protection as the "Indigenous Numerically Small Peoples of the North" (Chukchi, Dolgan, Evenki, Even, and Yukagir in Sakha Republic (Yakutia)). Data are sometimes collected specifically on these "numercially small" peoples; sometimes they are collected on the largest ethnic groups of Sakha Republic (Yakutia), including Sakha, and which may include Evenki and Even, but not the other "numerically small peoples" (see, e.g., information from the 2010 census at http://www.gks.ru/ free_doc/new_site/perepis2010/croc/perepis_itogi1612.htm).

In terms of periodicity of data collection, Russian Federation's census (and, prior to it, the Soviet Union's census) has traditionally been carried out every decade, with occasional delays. Thus, the 1999 census was 
delayed until 2002. It is impossible to predict future delays. Sakha Republic (Yakutia) collects some of the key data needed to track human development via the proposed Arctic Social Indicator on a more regular basis (e.g. yearly).

\section{Human Development in Sakha Republic (Yakutia): What do the Indicators Say?}

For each domain above, the trends suggested by the indicator data have been summarized: we reiterate them here briefly.

Health and Population Domain: Using infant mortality as our primary indicator, we assess health in Sakha Republic (Yakutia) to be improving. However, infant mortality rates within the republic vary significantly, with the worst situation in the Arctic regions. In terms of secondary indicators, we see the suicide rate decreasing recently, but the rate still substantially exceeds the national average, and again, significant regional differences underlay the republican average, with some northern areas suffering especially high rates. Net migration, especially of the working-age population continues to be high from all areas other than the capital city, also indicating difficult conditions for many residents of the republic.

Material Wellbeing: Per capital income has improved notably over the past two decades. Large differences in income are experienced across the Republic, and especially along the urban-rural axis. Secondary literature also shed light on the feelings of pessimism by the rural population. Meanwhile, unemployment data remain stagnant. Together, these data suggest that rural areas are still struggling.

Education: The rate of post-secondary degree completion has not changed much since 2005. Once again, large differences in completion rates are experienced across the Republic, with much lower rates experienced in the North.

Cultural Vitality: Language retention rates are problematic to track over time given the changes in information being collected. In some cases, reported increases seem somewhat suspect. However, even if these do not reflect increased use of indigenous language (especially among the indigenous numerically small peoples of the North), they still might reflect cultural vitality, indicating a growing pride among indigenous peoples to declare their use/knowledge of their "mother language". More research needs to be carried out on the nuances of this measure.

Contact with Nature: Harvest and consumption both grew in the first decade of $21^{\text {st }}$ century at the republican level; unfortunately data at the ulus/regional level are not readily available. Like the Cultural Vitality measure, this measure may have unanticipated attributes. While it is unclear from simple statistics whether an increase in consumption of 
country food is due to increased need (and thus a lower wellbeing) or increased capacity to enjoy such harvest (and thus an increased wellbeing), the measure still indicates an increase in time spent on the land, in contact with nature.

Fate Control: While data for three of the four component measures of the Fate Control Index were not available for Sakha Republic (Yakutia), the proxy for control over land - the amount of lands allocated to obshchinas - may provide a useful read of the one dimension of human development for the indigenous population. In doing so, given that it loosely represents a human rights concern, it may be a stronger proxy than initially imagined. However, as obshchinas have been pursued only in some areas of the Russian North, this proxy is not likely to work across the Russian Arctic: it appears to be most likely useful in taiga rather than tundra regions. Its comparability with other areas of the North will be limited, at most, to general trends.

\section{Do We Have Confidence in the Indicators?}

Overall, indicators paint a mixed picture of human development in Sakha Republic (Yakutia) suggesting that certain facets of life in this part of the Arctic are improving, but others are still challenging. Strong regional and rural-urban differences persist. Like many other regions of the North, the areas inhabited by indigenous peoples experience lower-thanaverage attainments for most of the indicators. These data correspond to our field observations in various parts of Sakha Republic (Yakutia).

Importantly, the examination of more than one indicator for several of the domains, and the divergence of trends in terms of human development (e.g. improved infant mortality but worsening suicide rates) accentuates the perils of depending on one indicator. Until we have more fully developed our competence in measuring human development in the Arctic, it would be prudent to continue to collect data on several measures for each domain.

\subsection{References}

Atlas YaASSR (1989). Atlas sel'skogo khozyaystva Yakutskoy ASSR [Atlas of Agriculture of the Yakut ASSR]. Moscow: Main Administration of Geodesy and Cartography of the Soviet of Ministers of the USSR.

Burtseva, T.E., Uvarova, T.E., Makharova, N.V., Tomskiy, M.I. (2008). Dinamika sovremennykh demograficheskikh i mediko-demograficheskikh protsessov u korennykh malocheslennykh narodov Severa Respubliki Sakha (Yakutia) [Dynamics of contemporary demographic and medico-demographic processes among the indig- 
enous numerically-small peoples of the North of Sakha Republic (Yakutia)], Dal'nevostochnyy meditsinskiy zhurnal 2: 112-115.

Burtseva, T.E., Uvarova, T.E., Tomskiy, M.I., Yakovlev, R.V., Chasnykh, V.G., Samsonova, M.I., Dravaeva, G.G., Shadrin, V.P. (2009). Nekotorye demograficheskie pokazateli I zabolevaemost' detey i podrostkov v rayonakh prozhivaniya korennykh malocheslennykh narodov Respubliki Sakha (Yakutia) [Some demographic indicators and disease of children and adolescents in the regions inhabited by the indigenous numerically-small peoples of Sakha Republic (Yakutia)], Dal'nevostochnyy meditsinskiy zhurnal 1: 58-59.

Census 2010 (2010). Vserossiyskaya perepis' naseleniya 2010 [All-Russian Census of the Population 2010]. Website. http://www.gks.ru/free_doc/new_site/ perepis2010/croc/perepis_itogi1612.htm (Accessed last 16 January 2013).

Crate, S. A. (2006). Cows, Kin and Globalization: An Ethnography of Sustainability. Walnut Creek: Alta Mira Press.

Crate, S., Forbes, B., King, L., and Kruse, J. (2010). Contact with Nature, in Arctic Social Indicators, eds. J. Larsen, P. Schweitzer, G. Fondahl. Copenhagen: Nordic Council of Ministers, pp. 109-128.

Dahl, J., Fondahl, G., Petrov, A. and Fjellheim, R. (2010). Fate Control, in Arctic Social Indicators eds. J. Larsen, P. Schweitzer, G. Fondahl. Copenhagen: Nordic Council of Ministers, pp. 129-146.

Economy (2009). Ekonomika rayonov i gorodov Respubliki Sakha (Yakutiya). 1990, 1995, 2000, 2004-2008 gg. Stat. sbornik. [Economy of the regions and cities of Sakha Republic (Yakutia). 1990, 1995, 2000, 2004-2008. Statistical Compilation.] Yakutsk: Territorial'nyy organ FSGS po Respublike Sakha (Yakutiya).

Fedorova, Ye. N. and Zheleznova, G.A. (2003). Migratsii naseleniya Yakutii: proshloe i nastoyashchee. [Migration of the Population of Yakutia: Past and Present]. Novosibirsk: Nauka.

Fondahl, G., Lazebnik, O. and Poelzer, G. (2000). Aboriginal territorial rights and the sovereignty of the Sakha Republic, Post-Soviet Geography and Economics 41(6): 401-417.

Gavrileva, T.N. and Tarasova N.G. (2011). Nekotorye voprosy metodologii izucheniya dokhodov i raskhodov domokhozyaystv Respubliki Sakha (Yakutia) [Some methodological issues in studying household incomes and expenditures in Sakha Republic (Yakutia)], Regional'naya ekonomika: teoriya i praktika 15: 51-55.

Hamilton, L., Bjerregaard, P., and Poppel, B. (2010). Health and population, Arctic Social Indicators (ed. J. Nymand Larsen, P. Schweitzer, G. Fondahl), 29-46. Copenhagen: Nordic Council of Ministers

Heleniak, T. (2009). Growth poles and ghost towns in the Russian Far North, in Russia and the North, (ed. E. Wilson Rowe), 129-164. Ottawa: University of Ottawa.

Ivanov, V. N., ed. (2007). Istoriko-kulturnii Atlas Yakutia. Moscow: Feria Publishers. Labour (2009). Trud i zanyatos'v Respublike Sakha (Yakutia): Statisticheskiy sbornik [Labour and employment in Sakha Republic (Yakutia)]. Yakutsk: Regional organ of the Federal Service of State Statistics of the Sakha Republic (Yakutia), 2009.

Lazebnik, O.A., ed. (2000). Geograficheskii Atlas "Respubliki Sakha (Yakutii)" [Geographical Atlas “Sakha Republic (Yakutia)"], Moscow: Roskartografii.

Mestinkova, A.Ye. (2010). Yazyky korennykh malochislennykh narodov Severa v zerkele perepisey naseleniya [Languages of the Indigenous Numerically Small Peoples of the North in the mirror of the census], Izvestiya Ural'skogo gosudarstvennogo universiteta. Seriya 1. Problemy obrazovaniya, nauki I kul'tury 5(84): 226-230. 
Mortality. (2010). Smertnost' naseleniya Respubliki Sakha (Yakutiya) v 2009 g.: Statisticheskiy sbornik №154/16. [Mortality of the Population of Sakha Republic (Yakutia) in 2009: Statistical Compilation №154/16] Federal service of State Statistics, Territorial organ of the Federal service of State Statistics for Sakha Republic (Yakutia). Editorial college Federal'naya sluzhba gosudarstvennoy statistiki, Territorial'nyy organ Federal'noy sluzhby gosudarstvennoy statistiki po Respbuliki Sakha (Yakutiya). Editorial board: T.A. Torgovkina. Yakutsk. Pp. 35-103.

National Composition. (1990). Natsional'nyy sostave naseleniya Yakutskoy ASSR. Statisticheskiy sbornik. [National Composition of the Population of the Yakut ASSR: Statistical Compilation]. Yakutsk.

Neustroeva A.B., Bolnitskaya, A.N. (2011). Uroven' i kachestvo zhizni sel'skogo naseleniya Respubliki Sakha (Yakutia): sotsiologicheskiy aspekt [The level and quality of life of the rural population of Sakha Republic (Yakutia): sociological aspect], Nauka i obrazovanie 3: 113-118.

Official Information Portal of the Republic of Sakha (Yakutia) - http://www.sakha.gov.ru/ node/7849 (Accessed last 21st January 2013)

On Migration. (1996). O migratsionnykh protsessakh v Respublike Sakha (Yakutiya): Informatsionnaya zapiska [On migration processes in Sakha Republic (Yakutia): Informational Note]. No. 5. Yakutsk: Goskomitet Respubliki Sakha (Yakutkia) po statistike.

On the status. (2009). O polozhenie narodonaseleniya $v$ Respublike Sakha (Yakutiya): voprosy smertnosti naseleniya (doklad) [On the status of the population in Sakha Republic (Yakutia): issues of mortality of the population (report)]. Yakutsk: YaNTs SO RAN.

Prokhorova, M.N., Vinokurova, D.E. (2012). Faktory urovnya zhizni naseleniya v munitsipal'nykh obrazovaniyakh Respubliki Sakha (Yakutiya) [Factors in the level of living of the population of municipalities of the Sakha Republic (Yakutia)], Ekonomika i upravlenie 1: 125-131.

Robbek, V.A. (2011). Ustoychivoy razvitie narodov Severa Rossii: fundamental'nye I prikladnye issledovaniya [Sustainable Development of the Peoples of the North of Russia: Fundamental and Applied Research]. Novosibirsk: Nauka.

Savvina N.V., Sleptsova N.A., Egorov V.B. (2012). Analiz smertnosti podrostkov ot vneshnykh prichin v Respublike Sakha (Yakutia) [Analysis of mortality from external causes adolescents in Sakha Republic (Yakutia)], Yakutskiy meditsinskiy zhurnal 1: 46-49.

Shtyrov, V.A. (2008). Yakutia - vostochnyy vector razvitiya Yakutii [Yakutia - the Eastern Vector of Development of Yakutia). Yakutsk: Media-holding Yakutia.

Sirina, A. (1999). Rodovye obshchiny malochislennykh narodov Severa v Respubliki Sakha (Yakutiya): shag k samoopredeleniiyu? [Clan obshchinas of the Numerically Small Peoples of the North in Sakha Republic (Yakutia): A step toward selfdetermination?] Issledovaniya po prikladnoy i neotlozhnoy antropologii, No.126. Moscow: Institute of Ethnology and Anthropology.

Social situation. (2009). Sotsial'noe polozhenie i uroven' zhizni naseleniya Respubliki Sakha (Yakutia): Statisticheskiy sbornik [Social situation and living standards of Sakha Republic (Yakutia): Statistical Yearbook]. Yakutsk: Regional office of the Federal State Statistics Service of Sakha Republic (Yakutia), 2009

Statistical Yearbook of the RS (Ya). (Various Years) Statsticheskiy ezhegodnik Respubliki Sakha (Yakutiya): Statisticheskiy sbornik [Statistical Yearbook of Sakha Republic (Yakutia): Statistical Compilation] Yakutsk: Regional organ of the Federal Service of State Statistics of Sakha Republic (Yakutia) 
Suknëva, S.A., Vinokurova, T.Z, and Zheleznova, G.A. (2001). Demograficheskie problem Arkticheskoy zony RS (Ya): analiz i prognoz [Demographic problems of the Arctic zone of RS (Ya): analysis and prognosis], Nauka i obrazovanie 2:67-68.

Suknëva, S.A. (2008). Migratsionnye protsessy v RS (Ya) [Migration processes in Republic of Sakha (Yakutia), Prostranstvennaya ekonomika 1: 62-77.

Suknëva, S.A. (2009). Smertnost' naseleniya v Respublike Sakha (Yakutia) [Mortality of the population in Sakha Republic (Yakutia)], Voprosy statistiki 8: 50-55.

Yegorov, Ye.G. (2011). Severo-Vostok Rossii: politika, ekonomika, nauka [The Northeast of Russia: politics, economics, science]. Yakutsk: Dani AlmaS. 



\title{
3. The Northwest Territories, Canada
}

\author{
Authors \\ Andrey Petrov, University of Northern Iowa, USA; Leslie King, Royal \\ Roads University, British Columbia, Canada; Philip Cavin, University of \\ Northern Iowa, USA.
}

\subsection{Introduction}

Arctic Social Indicators Phase II is intended to test and validate indicators generated in ASI Phase I by applying them to specific regions of the circumpolar Arctic. While Phase I (ASI, 2010) focused on developing and recommending a single or composite indicator for each of the six domains, Phase II applies the entire suite of indicators to different regions of the Arctic, which enhances the comparative power of the indicators and enables comparisons in relation to both time and space. For each region, comparisons over time will be most useful, which will empower communities and governments to track progress in order to improve the quality of life of Arctic residents and communities.

This chapter focuses on the application and measurement of indicators for all six domains in the Northwest Territories (NWT), Canada.

\section{The Northwest Territories, Canada:}

The NWT has a land area of approximately 1,140,835 square kilometers, primarily comprising the Boreal Forest. As of 2011 its population stands at 43,554 (Statistics Canada, 2011), which is an increase of $0.1 \%$ over the previous year. "Although the NWT continued to experience net out-migration on an annual basis, the magnitude was lower than in the previous two years." (Statistics Canada, 2011) Nearly half of that population lives in the capital city, Yellowknife, located on the Great Slave Lake (Figure 1). 
Figure 1: The Northwest Territories, Canada

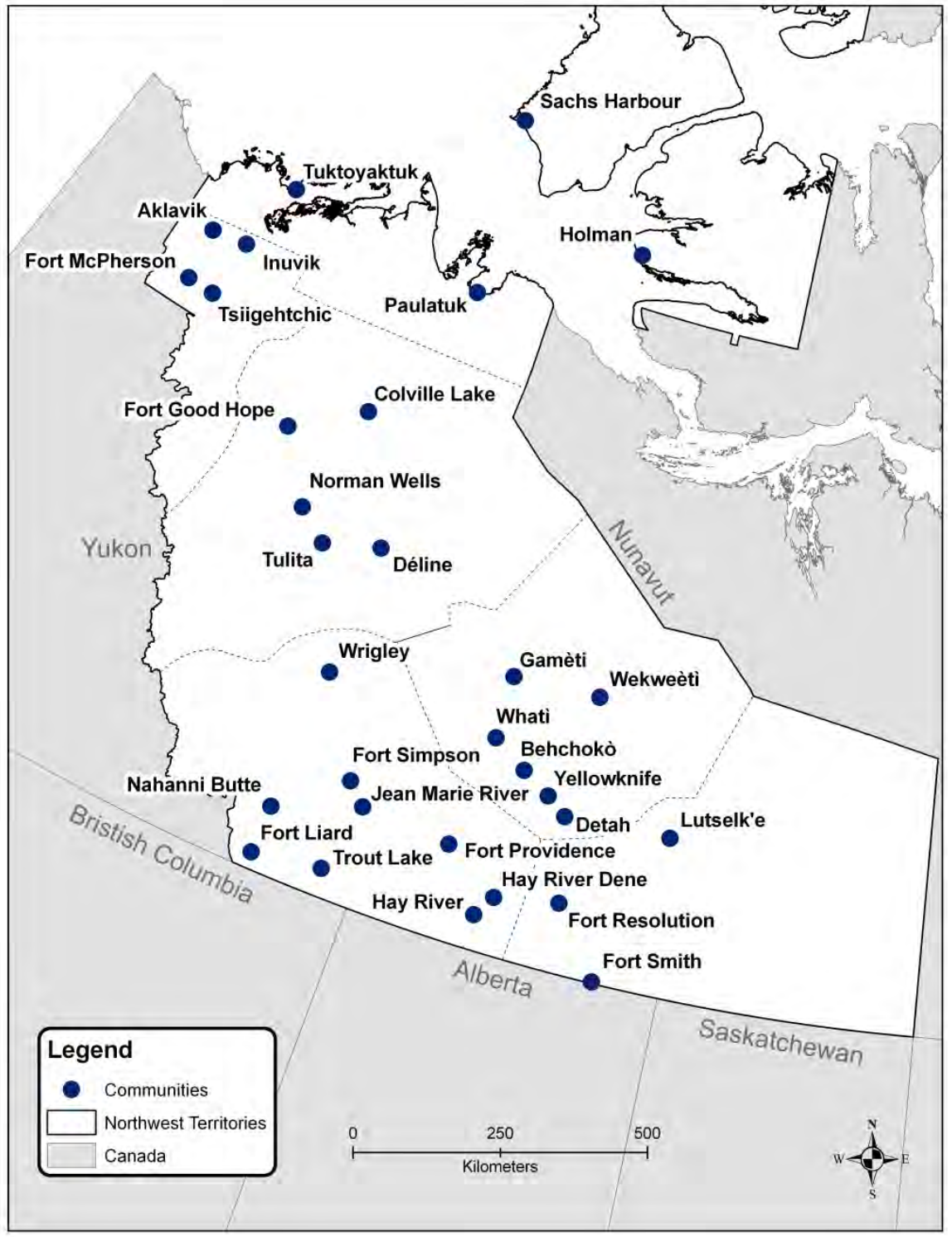

The NWT has one post-secondary institution, Aurora College. The NWT has 11 official languages. The consensus government consists of a Legislative Assembly with 19 elected Members of the Legislature and 7 Aboriginal territorial governments (NWT Government.) The present-day territory was created in June 1870, when the Hudson's Bay Company transferred Rupert's Land and the North-Western Territory to the government of Canada. On April 1, 1999, the eastern three-fifths of the Northwest Territories (including the whole District of Keewatin and much of Mackenzie and Franklin) became a separate Canadian territory named Nunavut. 
As of 2010 there were 33 official communities in the NWT. These range in size from Yellowknife, with a population of 18,700, to Kakisa's 52 inhabitants (Statistics Canada, 2012). The governance of each community differs as some are run by various types of First Nations control, while others are designated as cities, towns, villages or hamlets; though most communities are municipal corporations. Comparatively, Yellowknife is the largest community and has the largest number of Aboriginal people $(4,105$ (or $22.2 \%$ of total population); Behchoko, with a population of 1,894, is the largest First Nations community (1,730 (91.5\%)); and Inuvik, with 3,484 people, is the largest Inuvialuit community $(1,335$ (38.9\%)). There is one Indian reserve in the NWT, the Hay River Reserve, which is located on the south shore of the Hay River. The Northwest Territories boast the highest per capita GDP of all provinces or territories in Canada - around CAD 85,401.70 in 2006 (Statistics Canada, 2006, 2011, NWT Bureau of Statistics, 2011). As of March 2012 the unemployment rate for the NWT is $8.6 \%$ (Statistics Canada, 2012).

Figure 1 shows all of the major settlements in the NWT, as well as its borders with Yukon, Nunavut and the Provinces of British Columbia, Alberta and Saskatchewan. 
Girl with a puppy, Yellowknife Airport

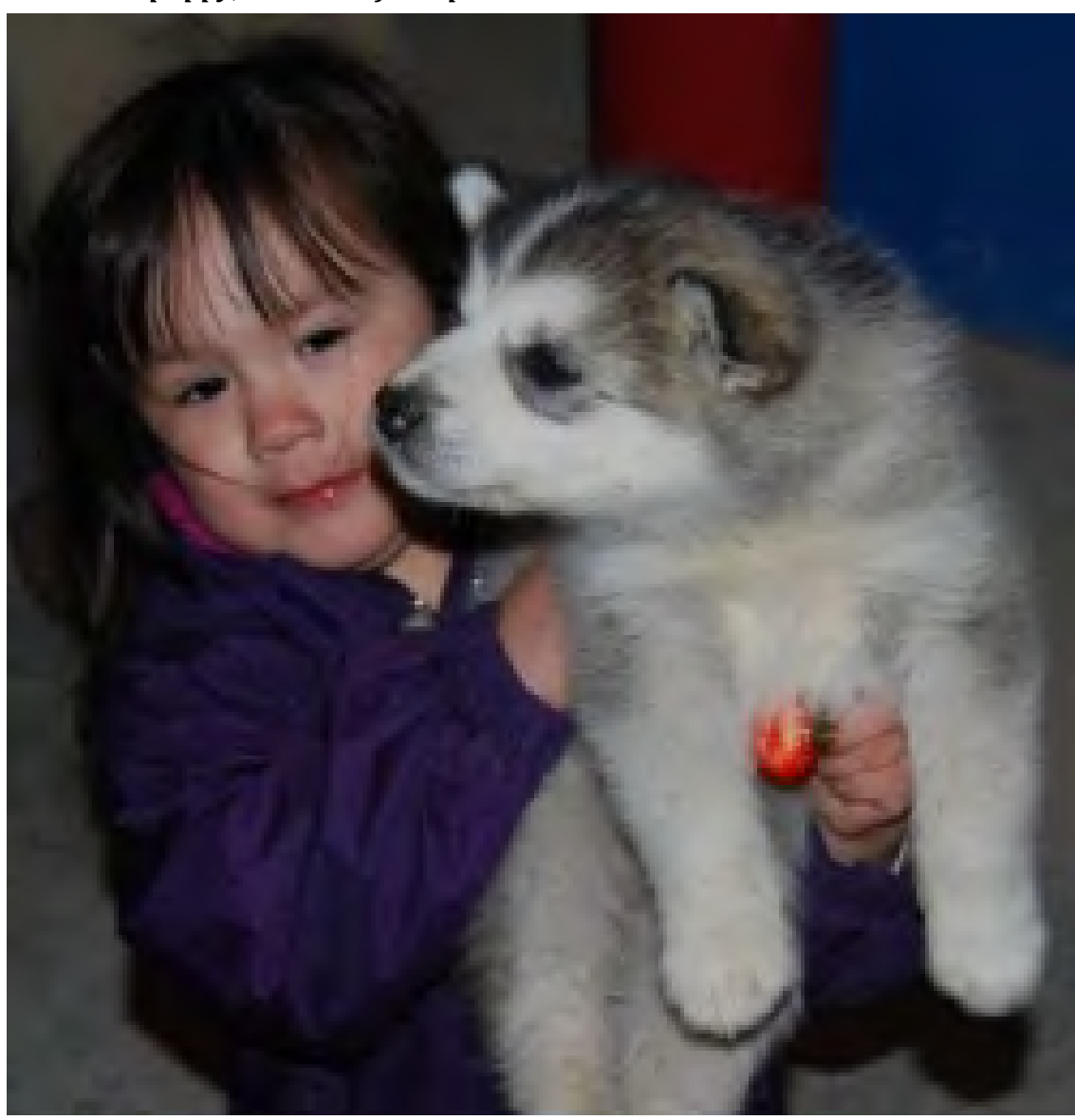

Photo: P. Harrison

\subsection{Data and Methodology}

This chapter follows the general methodology proposed in the first ASI Report (2010). However, as for other regions, the data on Canadian Territories present challenges to the implementation of ASI indicators. Whereas most ASI measures are followed very closely in our case study, we had to redefine or adjust several indicators to ensure compatibility with available data. Table 1 below outlines the definitions and data specifications used to measure human development in the NWT. Wherever appropriate, we used a single indicator (as recommended by the first ASI Report). In some cases, we followed the report's recommendations to use a number of corroborating measures. On several occasions (especially when data for recommended indicators were unavailable) we also 
included and tested alternative variables or proxies. Most datasets were acquired from the Canadian Census. This approach allowed us to extract the most replicable, detailed and comparable data collected during multiple years with five-year regularity. The Censuses analyzed cover 1991, 1996, 2001 and 2006. Additional information required for constructing certain indicators was obtained from the Aboriginal People's Survey (2001 and 2006) and from data provided by the NWT Bureau of Statistics (Community Survey and other periodic and occasional surveys). Unfortunately, a number of territorial datasets are based on occasional surveys and cannot be used for identifying dynamics of human development indicators over time.

The main problem with using data for a sparsely settled area like the NWT is related to issues of missing data. In very small communities (50\% of NWT communities have fewer than 500 residents) it is extremely difficult to obtain a complete dataset or to ensure its accuracy. Statistics Canada rounds its census data to the nearest 0 or 5 , generating a rounding error that may be very significant to smaller populations. For this reason a substantial number of variables are suppressed and all available ones must be used with caution. In addition, the "small numbers problem" creates datasets with high variances and generally erratic behavior; both of which are conditions that can invalidate statistical analysis. At the same time, the ASI II team received many requests from NWT community stakeholders to provide and analyze data for as many communities as possible so that very small communities are not omitted from the observations and conclusions made in this volume. As a result, in this chapter we analyze two datasets: all 33 NWT communities (whenever possible, but with due caution) and the largest communities with populations over 500 (2006) when using the whole dataset is not possible due to data suppression.

Below we report what specific social indicators had been selected for each domain based on data constraints relevant to the NWT. Table 1 presents a summary of indicator names, definitions, and sources of data. 
Table 1: Summary of Indicators

\begin{tabular}{|c|c|c|c|c|}
\hline \multicolumn{5}{|l|}{ Health \& Population } \\
\hline Infant Mortality & TEENAGE BIRTH & NET MIGRATION & SUICIDE RATE & \\
\hline Net Migration & $\begin{array}{l}\text { RATE: } \\
\text { number of births } \\
\text { to mothers under } \\
\text { the age of } 14 \text { per } \\
1,000 \text { residents. }\end{array}$ & $\begin{array}{l}\text { Difference between } \\
\text { number of in and } \\
\text { out-migrants during } \\
\text { the year (estimates) }\end{array}$ & $\begin{array}{l}\text { Number of sui- } \\
\text { cides per } 10,000 \\
\text { people } \\
\text { per year }\end{array}$ & \\
\hline \multicolumn{5}{|l|}{ Material wellbeing } \\
\hline $\begin{array}{l}\text { PER CAPITA HOUSE- } \\
\text { HOLD } \\
\text { INCOME }\end{array}$ & $\begin{array}{l}\text { PER CAPITA } \\
\text { HOUSEHOLD } \\
\text { INCOME } \\
\text { Total household } \\
\text { income per capita }\end{array}$ & $\begin{array}{l}\text { NET MIGRATION } \\
\text { Difference between } \\
\text { number of in and } \\
\text { out-migrants during } \\
\text { the year (estimates) }\end{array}$ & $\begin{array}{l}\text { UNEMPLOYMENT } \\
\text { unemployed } \\
\text { expressed as a } \\
\text { percentage of the } \\
\text { labor force }\end{array}$ & \\
\hline \multicolumn{5}{|l|}{ Education } \\
\hline RATIO OF STUDENTS & \% WITH HIGH & \% WITH UNIVERSITY & & \\
\hline COMPLETING POST- & SCHOOL AND & DEGREE (BACHELOR & & \\
\hline $\begin{array}{l}\text { SECONDARY EDU- } \\
\text { CATION }\end{array}$ & $\begin{array}{l}\text { HIGHER LEVEL OF } \\
\text { EDUCATION of } \\
\text { population aged } \\
15 \text { and over }\end{array}$ & $\begin{array}{l}\text { OR HIGHER) of } \\
\text { population aged } \\
15 \text { and over }\end{array}$ & & \\
\hline \multicolumn{5}{|l|}{$\begin{array}{l}\text { Cultural wellbeing } \\
\text { and cultural vitality }\end{array}$} \\
\hline LANGUAGE & LANGUAGE RETEN- & SUBSIST- & & \\
\hline RETENTION & $\begin{array}{l}\text { TION } \\
\text { Ratio between \% of } \\
\text { respondents who } \\
\text { report an ability to } \\
\text { conduct a conversa- } \\
\text { tion in a Native } \\
\text { language and \% of } \\
\text { Aboriginal popula- } \\
\text { tion in total popula- } \\
\text { tion. }\end{array}$ & $\begin{array}{l}\text { ENCE/TRADITIONAL } \\
\text { ACTIVITIES EN- } \\
\text { GAGEMENT } \\
\% \text { of people } 15 \text { years } \\
\text { of age or older that } \\
\text { hunted, fished, and } \\
\text { trapped during the } \\
\text { year }\end{array}$ & & \\
\hline \multicolumn{5}{|l|}{ Contact with nature } \\
\hline $\begin{array}{l}\text { CONSUMPTION/ } \\
\text { HARVEST OF TRADI- } \\
\text { TIONAL } \\
\text { FOODS }\end{array}$ & $\begin{array}{c}\text { CONSUMPTION OF } \\
\text { TRADITIONAL } \\
\text { FOODS } \\
\% \text { of Households } \\
\text { with Half or More } \\
\text { of Meat \& Fish } \\
\text { Consumed in } 2008 \\
\text { Obtained Through } \\
\text { Hunting or Fishing }\end{array}$ & & & \\
\hline \multicolumn{5}{|l|}{ Fate control } \\
\hline $\begin{array}{l}\text { Fate Control } \\
\text { Index }\end{array}$ & $\begin{array}{l}\text { \% OF LO- } \\
\text { CAL/ABORIG IN } \\
\text { GOVERNING } \\
\text { INST/POSITIONS } \\
\% \text { of Aboriginal } \\
\text { people in govern- } \\
\text { ment and manage- } \\
\text { rial occupations } \\
\text { (defined by the } \\
\text { National Occupa- } \\
\text { tional Classification } \\
\text { (NOC)) }\end{array}$ & $\begin{array}{c}\text { \% OF SELF- } \\
\text { GENERATED } \\
\text { INCOME (est.) } \\
\% \text { of personal } \\
\text { income other than } \\
\text { transfer payments }\end{array}$ & $\begin{array}{l}\text { \% SPEAKING } \\
\text { MOTHER LAN- } \\
\text { GUAGE } \\
\text { Ratio between \% of } \\
\text { respondents who } \\
\text { report an ability to } \\
\text { conduct a conver- } \\
\text { sation in a Native } \\
\text { language and \% of } \\
\text { Aboriginal popula- } \\
\text { tion in total } \\
\text { population. }\end{array}$ & $\begin{array}{l}\% \text { LAND CON- } \\
\text { TROL BY ABO- } \\
\text { RIGINAL/LOCAL } \\
\text { RESIDENTS }\end{array}$ \\
\hline
\end{tabular}

Sources for data: Census (5 years); Comprehensive Land Claims Agreements; NWT Bureau of Statistics. 
Health and population: Infant mortality is the main indicator recommended by ASI (2010). However, it may not be a reliable indicator in sparsely populated areas since it suffers severely from the small numbers problem. Other possible surrogates (which may also suffer from this problem) include suicide rate, self-assessed health, and obesity and smoking rates. In addition, the ASI II team recommended utilizing the teenage birth rate (TBR) as a possible surrogate. In this case study we use the TBR, suicide rate and self assessed health (see Table 1). The first two indicators are taken as five-year averages to alleviate the data volatility problem stemming from small populations. Net migration is the indicator recommended by the first ASI report (2010) to characterize population dynamics. It is possible to estimate net migration using NWT community data (NWT Bureau, 2011). We use net migration rate per 1,000 residents (Table 1 ).

Material wellbeing: The first ASI Report recommends using per capita household income as a core indicator of economic wellbeing alongside five other supporting indicators. Unfortunately, per capita household income is not directly available from the Census or other surveys. However it can be approximated by dividing total household income by population. Both datasets are readily available and regularly collected (see definitions in Table 1). Net migration rate, selected by the ASI as another core measure of economic vitality, can also be estimated from Census and/or community surveys. In this case study we use per capita household income, net migration and unemployment rate as indicators of economic wellbeing. However, we caution that unemployment rate, at least in the context of the NWT, may not be a useful indicator given the nature of the NWT labor market and the manner in which this rate is estimated. We believe that participation rate will be a more useful indicator to demonstrate the degree of a population's engagement in wage employment. We also suggest considering a transfer income measure the relative share of the government transfer in residents' income) as another alternative economic wellbeing measure.

Education: The first ASI Report recommended three indicators, all of which are based on educational attendance (the proportion of students pursuing or completing post-secondary education) or retention of educated people in a community (within 10 years after graduation). Whereas these indicators are important and appropriate, in the case of the NWT the required data are difficult to obtain or are not collected. At the same time, the Canadian Census and the NWT Community Survey contain extensive data on educational attainment, the characteristics of the level of education attained by residents. These data have been routinely collected (alt- 
hough with some definitional changes) and provide a variety of educational characteristics to choose from. In this application we used two indicators: the $\%$ of population over 15 years old who has a bachelor degree or higher (i.e. completed post-secondary education) and the $\%$ of the same population who completed high school. This is a baseline indicator widely used for inter-regional and international comparisons of a population's education and human capital.

Cultural wellbeing and cultural vitality: The composite indicator of cultural vitality suggested by the ASI (2010) incorporates cultural autonomy (an indicator of institutional arrangements for cultural selfdetermination), language retention and belonging (measured in terms of engagement in traditional subsistence activities). The language retention data are available through the Canadian Census. However, the Census only provides information for all persons who claim Aboriginal identity with no differentiation by ethnicity. This is a considerable limitation given that the ASI recommends using ethnic group-specific language retention rates. The Aboriginal People's Survey (2001) includes a question on engagement in subsistence activities (hunting, fishing, trapping, and gathering of wild plants), and therefore can be used to measure "belonging". The cultural autonomy indicator is very complex and difficult to develop, especially at the community scale. We omitted this component at this stage of analysis, thus retaining only two indicators of cultural wellbeing/vitality.

Contact with nature: The recommended indicator for contact with nature is the consumption and/or harvest of traditional foods. The measure has been computed using data from the NWT Survey of Country Food Consumption (2008). Unfortunately, the data for other years are not available. 
Underground food storage locker, Tuktoyaktuk, NWT

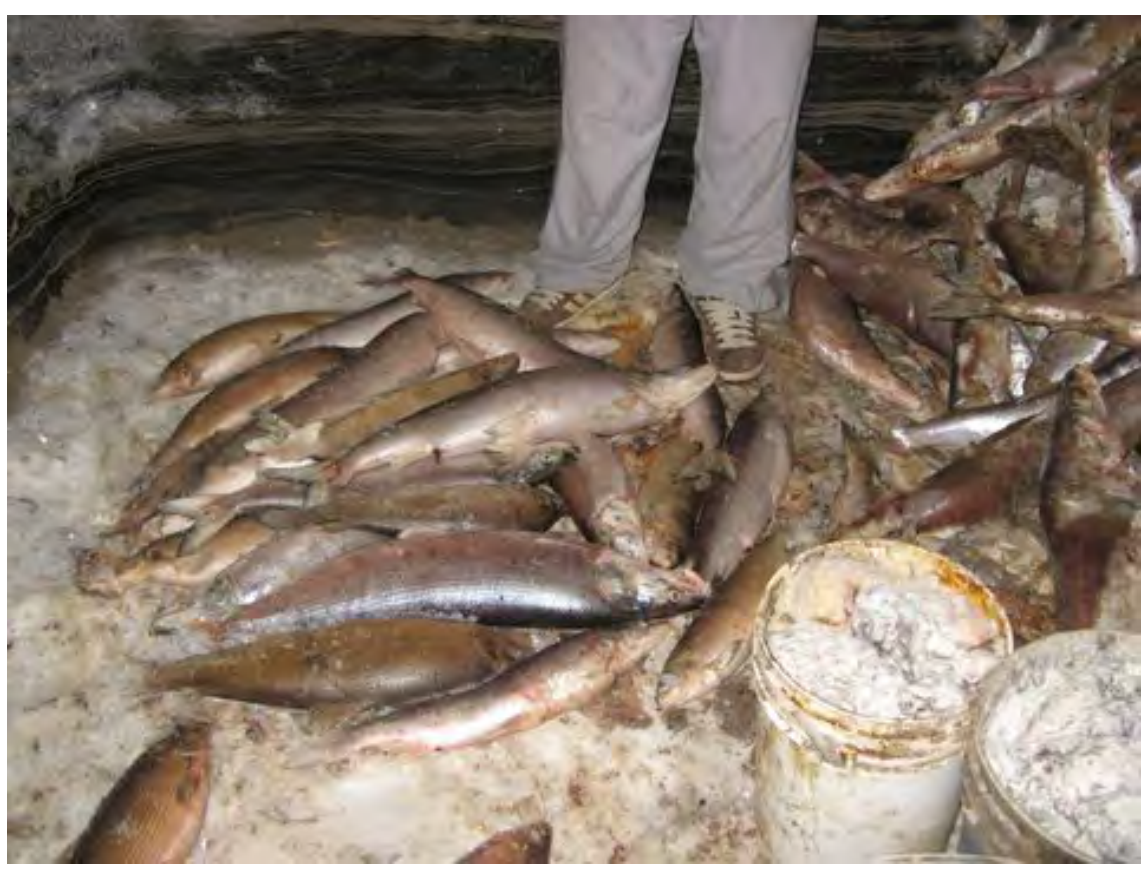

Photo: L. King.

Fate control: The ASI I Report recommended using a four-component composite indicator of community fate control. This includes political power, economic self-reliance, cultural empowerment and control over land. Two exact measures suggested in the report, namely the $\%$ of public expenses paid from locally generated funds (economic control) and the \% of people speaking their mother tongue (knowledge construction/human rights), can be estimated using proxies or direct measures from the Census. We suggest using the \% of self-generated income in total household income to measure economic self-reliance. The language retention component is directly available from Census data. For the indicator of political power (\% of local/Aboriginal peoples in governing institutions/positions), we were able to develop a proxy using the \% of Aboriginal people in managerial and administrative occupations in the NWT. The indicator of land control, however, was difficult to determine at the community level. We therefore used provisions of the Comprehensive Land Claim Agreements (CLCAs), where applicable, to estimate the \% of land over which Aboriginal communities exercise direct control. Albeit not a perfect measure, it gives an indication of the ability of local residents to have access and control over land. A composite index of fate control is calculated as the average of these four components. 
Specific definitions and sources of each indicator are provided in Table 1. Note that Table 1 demonstrates a high degree of overall agreement among the original recommended ASI indicators and the measures used in this case study of the NWT. This demonstrates that Canadian statistical datasets generally have high utility for monitoring human development and wellbeing in the Arctic. On the other hand, it also demonstrates that ASI indicators are well designed to be applied in the context of the Canadian North.

\subsection{Results}

In this section we apply arctic social indicators adapted to the data and context of the NWT in order to provide an overview of human development at the present time. We consider the range and spatial differentiation of social indicators at the community level for six indicator domains using the latest available data (mostly pertaining to 2005-2010). As mentioned earlier, the data have been acquired from the Census and Aboriginal People's Survey (both national datasets), as well as NWT Community Surveys and other NWT-specific surveys conducted by the NWT Bureau of Statistics. Secondly, we attempt to undertake a temporal analysis of human development change over time by comparing current indicators with historical data.

\subsubsection{Health and Population Domain}

The NWT has a relatively young, male-dominated population that makes it very distinct from southern Canada. The Crude Birth Rate in the NWT is substantially higher compared to Canada as a whole (16.8 and 11.3 per 1,000 population respectively in 2009), while the Crude Death Rate is lower. The infant mortality in the territory is substantially higher than in the nation (6.2 versus 5.1 per 1,000 births (2007)). The life expectancy of NWT residents is about four years less than nationwide. The $\%$ of single parent families is $150 \%$ of the Canadian benchmark.

The demographic and health components of human wellbeing in the Arctic are assessed using the teenage birth rate (TBR). TBR is a suggested surrogate for the infant mortality rate. In this capacity the TBR is the integral indicator of health conditions, as well as the indicator of demographic and social processes. High TBR rates indicate possible negative processes in a given community associated with health, health educa- 
tion, the healthcare system and social cohesion. They may also indicate a lagging demographic and epidemiological transition.

The NWT has a high TBR (Figure 2): the five-year average for 20022006 was 1.7 per 1,000 residents. Measured differently, the TBR was as high as 35.7 per 1,000 females aged 15-19 in 2007 or more than a double of the Canadian national figure. In the NWT's larger communities (population over 500) the TBR varied from 0.7 to 4.9 per 1,000 residents. The lowest TBR was registered in Norman Wells, the highest was recorded in Fort Good Hope. Yellowknife and Detah both had TBR below 1.0. Consideration of the TBR among smaller communities is complicated by the small numbers problem. Rates are unstable from year to year and it is uncertain whether five-year averaging alleviates the problem. In these communities TBR varies between zero and 8.4 (in Paulaktuk). Overall, $65 \%$ of all communities for which data were available had TBR above the territorial average. Most of them are remote, isolated settlements facing social and healthcare challenges. 
Figure 2: Teen birth rate in NWT

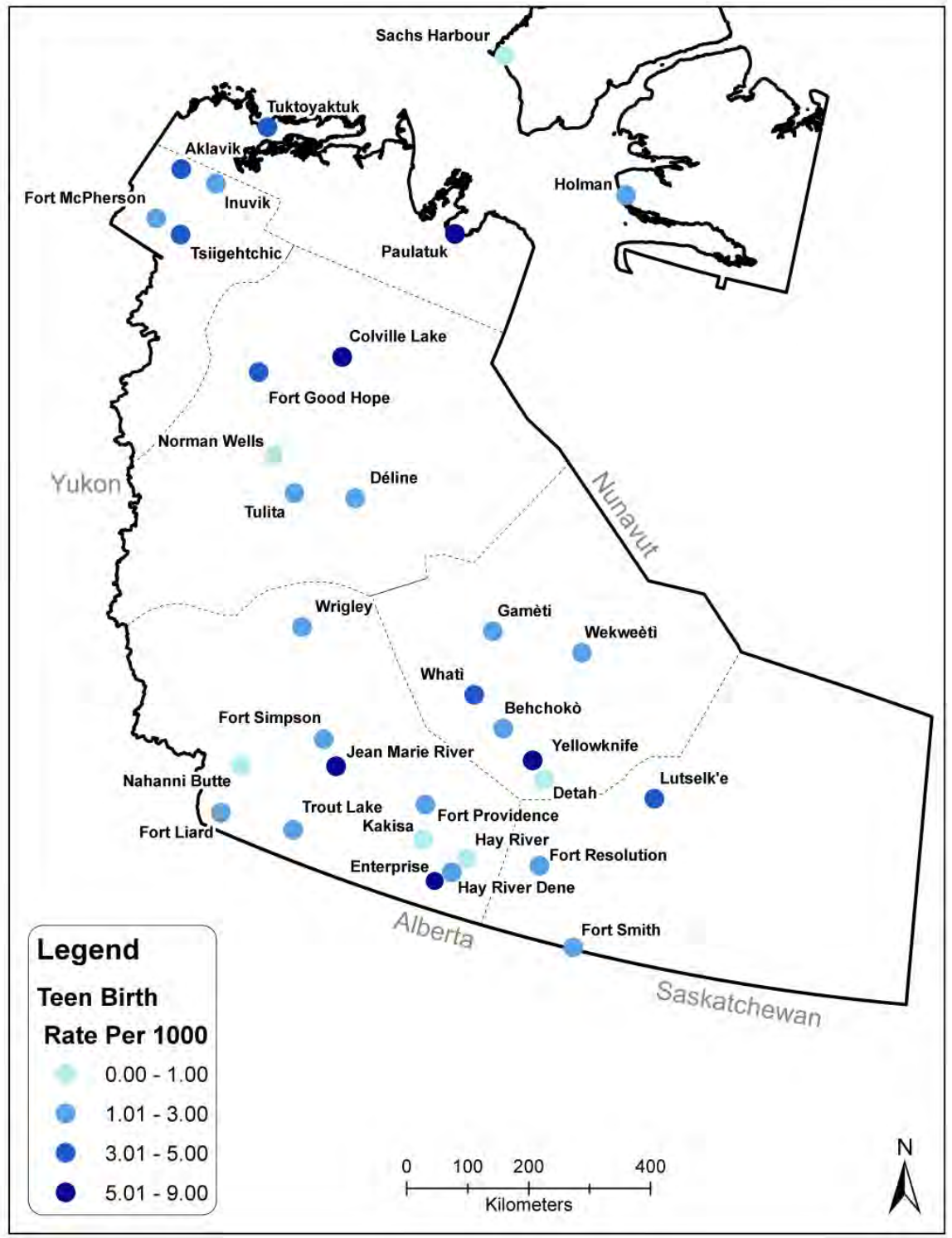

(NWT Bureau of Statistics, 2012).

Other indicators that characterize particular aspects of health conditions mentioned in the ASI Report include suicide rate (a mental health measure), obesity and smoking rates (possible indicators of chronic disease and addictions). The five-year average suicide rate is available from the NWT Bureau of Statistics and is used in this case study as an additional indicator of health. As demonstrated in Figure 3, higher suicide rates generally follow the pattern of other health indicators demonstrating a 
lower state of mental wellbeing in smaller Aboriginal communities. In Tuktoyaktuk $16 \%$ of all deaths between 2001 and 2005 were attributable to suicide. This, however, was not a pattern in other Aboriginal communities, such as Inuvik and Behchoko. In Yellowknife the proportion of suicides in the overall number of deaths was $5.5 \%$.

Figure 3: Suicide rate (\%)

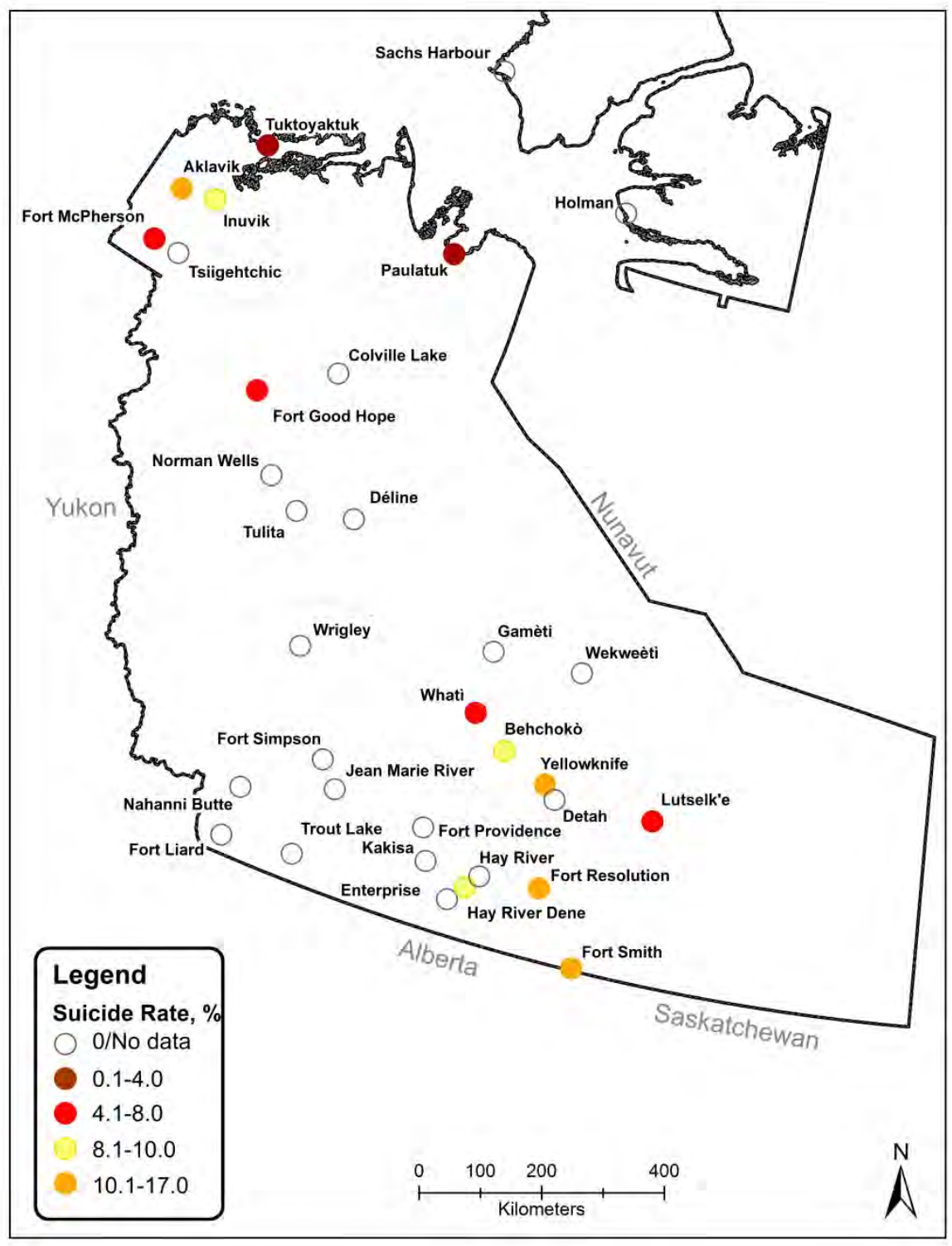

(NWT Bureau of Statistics, 2012). 
Population dynamic is an important indicator of community wellbeing. ASI (2010) proposed to utilize the net migration data to characterize community wellbeing. Net migration has considerable importance in the Arctic since in and out-migration flows can bring noticeable changes to community life, especially in places with smaller populations. Population decline due to departure of young adults can devastate a community and eventually turn it into a ghost town. Alternatively, a mass arrival of newcomers can substantially alter the social, economic and demographic fabric of an Arctic community.

The 2006-2007 net migration map for the NWT is presented in Figure 4 . Figure 4 reveals that migration outcomes vary significantly depending on type, size and location of communities. Substantial losses are observed in Wrigley, Tsiigehthic, Jean Marie River and other small and remote communities. Norman Wells, Aklavik and Tulita, in contrast, demonstrate considerable population gains. Yellowknife also showed a modest loss of population in this period. 
Figure 4: Net migration rates per 1,000 residents

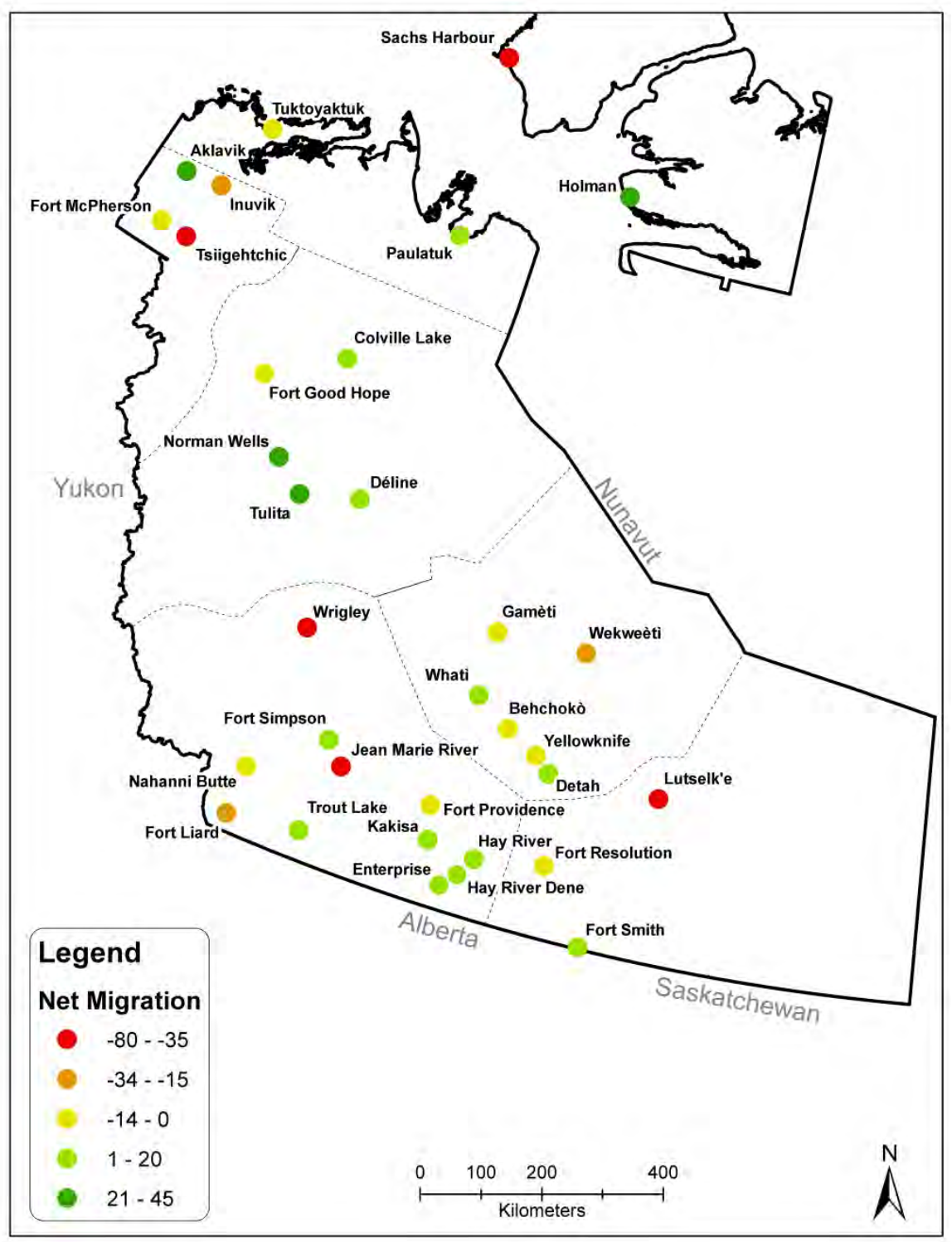

(NWT Bureau of Statistics, 2012). 


\subsubsection{Material Wellbeing Domain}

Per capita household income in the NWT (based on our estimates from the Census corroborated with the Community Survey data) ranged between $C \$ 13,009$ in Gamètì to $C \$ 43,642$ in Norman Wells (see Figure 5). The highest ranking communities also included Yellowknife, Inuvik, Hay River, Fort Smith and Fort Simpson, settlements with the most developed wage sector and considerably sized labor markets. Incomes are also apparently affected by inflated wages in resource and public sectors. According to this measure, the economic wellbeing in smaller, predominantly aboriginal communities is lower, even though the indicator incorporates transfer payments. This is not surprising given the population structure, limited size and seasonal nature of the wage labor market, and the engagement of many residents in subsistence activities. Table 2 reporting correlation among all indices considered in this case study, demonstrates that per capita household income negatively and strongly correlates with the level of consumption of traditional foods. Inter-community income disparities are significant and illustrate the inequities in economic wellbeing among NWT communities. 
Figure 5: Per capita household income

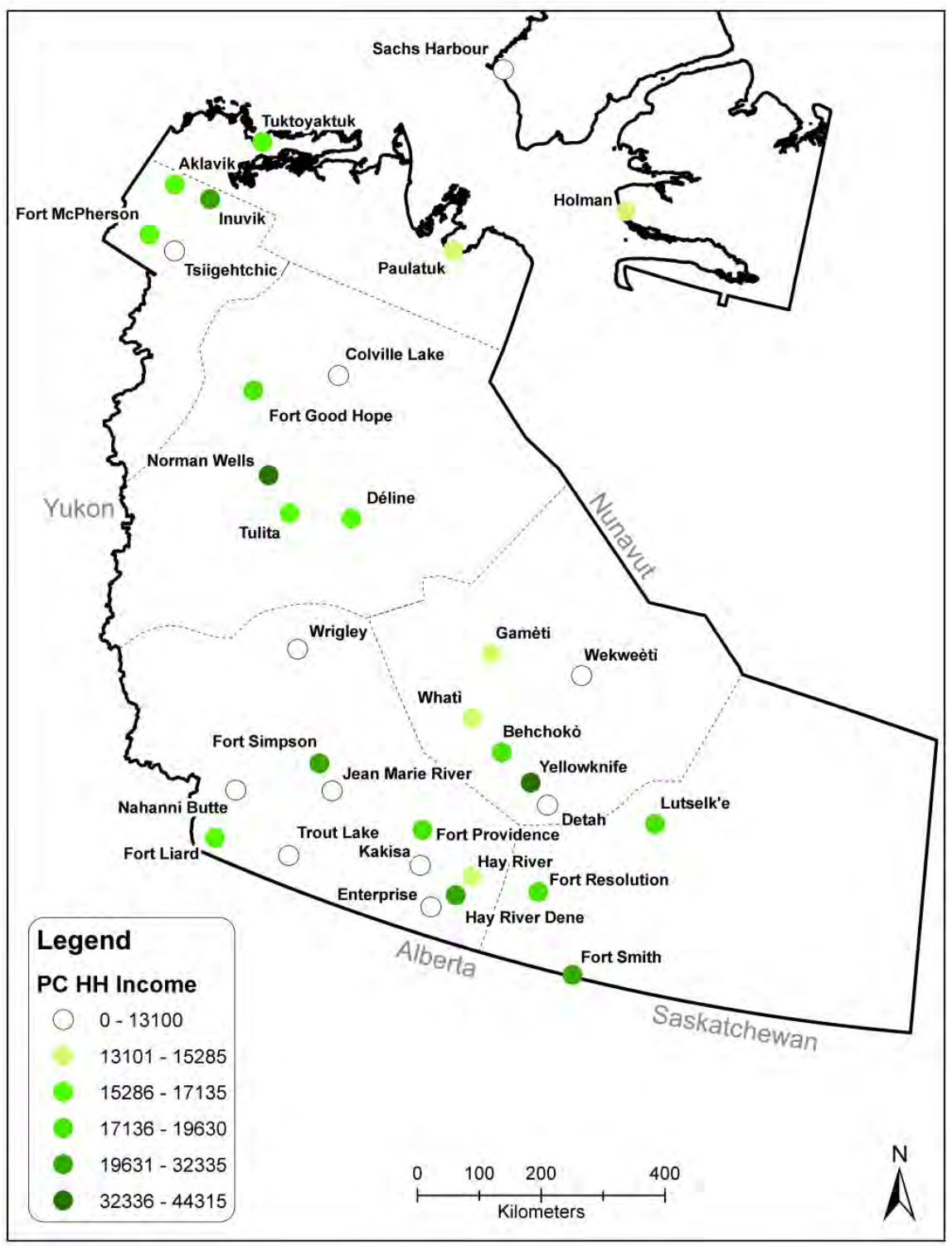

(Statistics Canada, 2008b). 


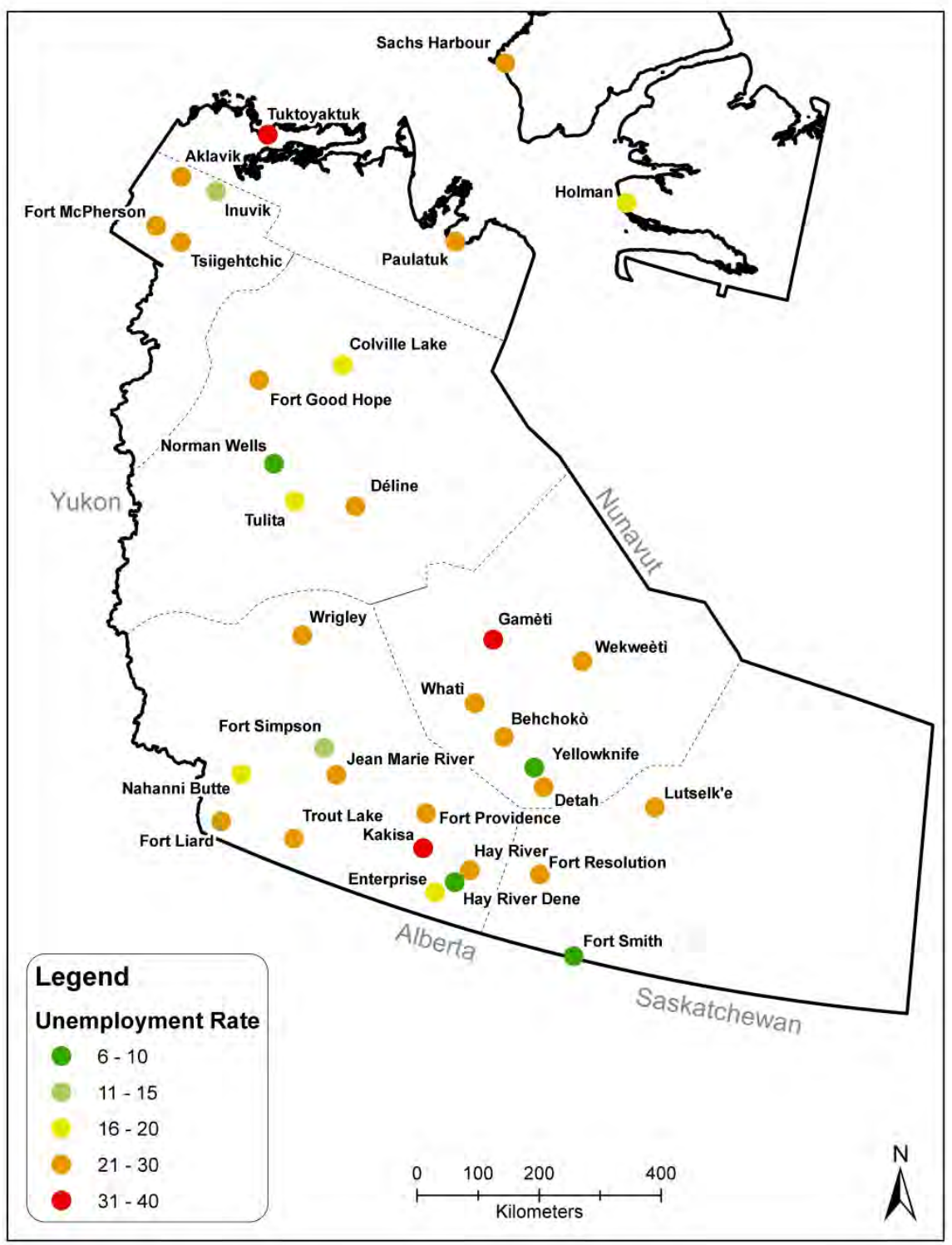

(Statistics Canada, 2008b).

A similar pattern of "haves" and "have-nots" emerges based on the analysis of other economic parameters. The unemployment rate (Figure 6) in most of the smaller communities lacking a stable economic base is extremely high (almost 30\%) as opposed to Yellowknife (5.8\%) and other central settlements. Considering that the rate is reported only for people who have been actively pursuing jobs, this figure does not include unemployed residents who are not active job seekers, thus underrepre- 
senting the real unemployment level. This said, it is important to remember that out of the scarce supply of jobs in small communities many are seasonal, exacerbating the problem and many working-age individuals are engaged in the subsistence sector, partially obviating the need for wage employment. Job scarcity results in limited earned income received by residents of remote, small, largely aboriginal communities. As a result, population in these communities tends to depend on government transfer payments, and therefore exhibits higher vulnerability to outside political and economic forces in maintaining their living standards. A public transfer economy is a reality in many places, in some of which government payments constitute over $20 \%$ of residents' gross income (Statistics Canada, 2008b).

Overall, NWT material wellbeing indicators show that the territory is firmly divided into a small group of "haves" (Yellowknife, Inuvik, Hay River) and a large group of "have-nots". Out of the latter group several communities, some of which being isolated from the wage economy, essentially live on income from transfer payments, seasonal earnings and subsistence activities. Whereas the traditional economy presents the way to maintain material wellbeing, a disengagement of the local labor force with the wage sector may prove to be a serious problem. A solution, perhaps, can be found in reconciling traditional lifestyles and activities with the "capitalist" economy by intertwining these two sectors with economic, institutional and social ties while giving respect and recognition to the role of subsistence activities in the economy. 
Table 2: Correlations among social indicators in the NWT

\begin{tabular}{|c|c|c|c|c|c|c|c|c|c|c|c|c|c|c|c|}
\hline & $\begin{array}{r}\text { Suicide } \\
\text { Rate }\end{array}$ & $\begin{array}{l}\text { Teen } \\
\text { Birth } \\
\text { Rate }\end{array}$ & $\begin{array}{r}\text { Net } \\
\text { Migra- } \\
\text { tion }\end{array}$ & $\begin{array}{c}\text { Unem- } \\
\text { ploy- } \\
\text { ment } \\
\text { rate }\end{array}$ & $\begin{array}{r}\text { Per } \\
\text { Capita } \\
\text { House- } \\
\text { hold } \\
\text { Income }\end{array}$ & $\begin{array}{c}\text { Bache- } \\
\text { lor's or } \\
\text { higher }\end{array}$ & $\begin{array}{r}\text { High } \\
\text { School } \\
\text { Degree } \\
\text { of } \\
\text { Higher }\end{array}$ & $\begin{array}{r}\text { Subsist- } \\
\text { ence } \\
\text { Engage- } \\
\text { ment }\end{array}$ & $\begin{array}{l}\text { Con- } \\
\text { sump- } \\
\text { tion of } \\
\text { Tradi- } \\
\text { tional } \\
\text { Food }\end{array}$ & $\begin{array}{r}\text { Lang } \\
\text { Reten- } \\
\text { tion }\end{array}$ & $\begin{array}{r}\text { Locals } \\
\text { and } \\
\text { Aborigi- } \\
\text { nals In } \\
\text { Govern- } \\
\text { ment }\end{array}$ & $\begin{array}{r}\text { Land } \\
\text { Claim } \\
\text { Agree- } \\
\text { ment }\end{array}$ & $\begin{array}{c}\text { Selfgen- } \\
\text { erated } \\
\text { Income }\end{array}$ & $\begin{array}{r}\text { Fate } \\
\text { Control }\end{array}$ & $\begin{array}{l}\text { Total } \\
\text { Popu- } \\
\text { lation }\end{array}$ \\
\hline Suicide Rate & 1 & $.619(* *)$ & -.249 & .385 & -.203 & -.184 & -.168 & .411 & .235 & -.331 & .048 & .337 & -.181 & -.069 & .004 \\
\hline Teen Birth Rate & & 1 & -.151 & .071 & .012 & .109 & -.057 & .323 & .019 & -.151 & -.112 & .160 & .058 & -.094 & $.537(* *)$ \\
\hline Net Migration & & & 1 & -.273 & .116 & -.066 & .024 & -.140 & -.140 & -.098 & -.028 & .221 & .082 & .015 & -.130 \\
\hline Unemployment rate & & & & 1 & $-.881(* *)$ & $-.868(* *)$ & $-.861(* *)$ & $.453(*)$ & $.853(* *)$ & $.454(*)$ & $.810(* *)$ & .198 & $-.887(* *)$ & $.742(* *)$ & $-.520(*)$ \\
\hline Per Capita Household Income & & & & & 1 & $.834\left({ }^{* *}\right)$ & $.939(* *)$ & -.421 & $-.843(* *)$ & $-.512\left({ }^{*}\right)$ & $-.914(* *)$ & -159 & $.935(* *)$ & $-.821(* *)$ & $.579(* *)$ \\
\hline Bachelor's or Higher & & & & & & 1 & $.879(* *)$ & $-.442(*)$ & $-.774(* *)$ & -.348 & $-.821(* *)$ & -.312 & $.802(* *)$ & $-.736(* *)$ & $.745(* *)$ \\
\hline High School Degree or Higher & & & & & & & 1 & $-.492\left(^{*}\right)$ & $-.871(* *)$ & $-.550(* *)$ & $-.880(* *)$ & -.235 & $.870(* *)$ & $-.859(* *)$ & $.587(* *)$ \\
\hline Subsistence Engagement & & & & & & & & 1 & $.485\left(^{*}\right)$ & 131 & .349 & .299 & -.379 & .360 & -.352 \\
\hline Consumption of traditional food & & & & & & & & & 1 & $.624(* *)$ & $.881\left(^{* *}\right)$ & .102 & $-.842(* *)$ & $.860(* *)$ & $-.594(* *)$ \\
\hline Lang retention & & & & & & & & & & 1 & $.618\left(^{* *}\right)$ & -.411 & $-.516(*)$ & $.775(* *)$ & -.291 \\
\hline $\begin{array}{l}\text { Locals and Aboriginals In } \\
\text { Government }\end{array}$ & & & & & & & & & & & 1 & .080 & $-.877\left(^{* *}\right)$ & $.917(* *)$ & $-.659(* *)$ \\
\hline Land Claim Agreement & & & & & & & & & & & & 1 & -.137 & .154 & -.180 \\
\hline Self-generated Income & & & & & & & & & & & & & 1 & $-.784(* *)$ & $.530(*)$ \\
\hline Fate Control & & & & & & & & & & & & & & 1 & $-.586(* *)$ \\
\hline Total Population & & & & & & & & & & & & & & & 1 \\
\hline
\end{tabular}

** Correlation is significant at the 0.01 level (2-tailed). ${ }^{*}$ Correlation is significant at the 0.05 level (2-tailed). ${ }^{\wedge} 22$ communities with population 250 of higher for which data is available. 
Table 2 presents correlations among selected social indicators. It is interesting to observe some clear patterns: (1) intercorrelation among indicators within each domain and (2) evidence of correlations among several groups. In the Population and health domain we see a correlation between the suicide rate and TBR. Both indicate deep social and public health problems in many northern communities. Indicators from this domain are not correlated to other groups of measures. However, the erratic nature of the TBR and suicide data may affect the significance of these relationships. Notably, it appears that TBR per capita increases with larger community size. In the material wellbeing domain unemployment and income are negatively correlated. Not surprising is the positive correlation between income, levels of education, and population size, and its negative correlation with subsistence engagement, consumption of traditional food, language retention and fate control. Contact with nature (consumption of traditional food) is closely associated with language retention and subsistence engagement. This again suggests that the vitality of traditional activities is essential for maintaining cultural continuity in the North. Fate control is higher in communities that have strong attachments to land or sea and demonstrate cultural vitality. However, it is also associated with lower levels of education and wage income and higher dependency on transfer payments. These relationships illuminate the interconnectedness of social indicators and the complexity of social issues in the NWT. A deeper understanding of these links, especially the causal factors behind them, will be necessary in order to address some of the most acute problems facing the NWT.

\subsubsection{Cultural Wellbeing and Cultural Vitality Domain}

Cultural wellbeing is a complex phenomenon and is difficult to measure. As mentioned above, we are able to measure two indicators of cultural wellbeing/vitality out of three recommended by the ASI Report. It is worth noting that by design these indicators describe cultural wellbeing of Aboriginal peoples that account for approximately 50\% of the NWT population. Cultural wellbeing considers the ability of (a minority) population to maintain cultural identity and to further develop its unique culture. Subdomains of cultural wellbeing include language vitality (language retention) and a sense of "belonging" (to community, region, surrounding nature).

Language vitality is highest in communities where Aboriginal people are in the majority (Figure 7). For example, Behchoko, Wekweètì, and Wrigley are all communities with language retention exceeding $70 \%$ and 
the share of Aboriginal residents above 90\%. Strongest assimilation pressures are observed in Yellowknife, Hay River and Inuvik, where less than $25 \%$ of Aboriginal residents are able to speak their mother tongue. However, in defiance of this trend, language retention levels are surprisingly low in such predominantly Aboriginal communities like Aklavik and Tuktoyaktuk, which are also below $25 \%$.

A sense of belonging (Figure 7) is measured here by the degree of engagement in subsistence and traditional activities. We used the \% of Aboriginal people over the age of 15 who report that they hunted or fished in 2008 (Figure 7). Engagement in these activities varied between $34.4 \%$ in Yellowknife and $58.7 \%$ in Fort McPherson. The apparent correlation between the likelihood of Aboriginal residents to hunt and fish and language retention patterns confirms the validity of both measures, which suggests that culturally secure communities exhibit both higher language retention rates and higher participation in traditional activities. 
Figure 7: Aboriginal language retention and participation in traditional activities

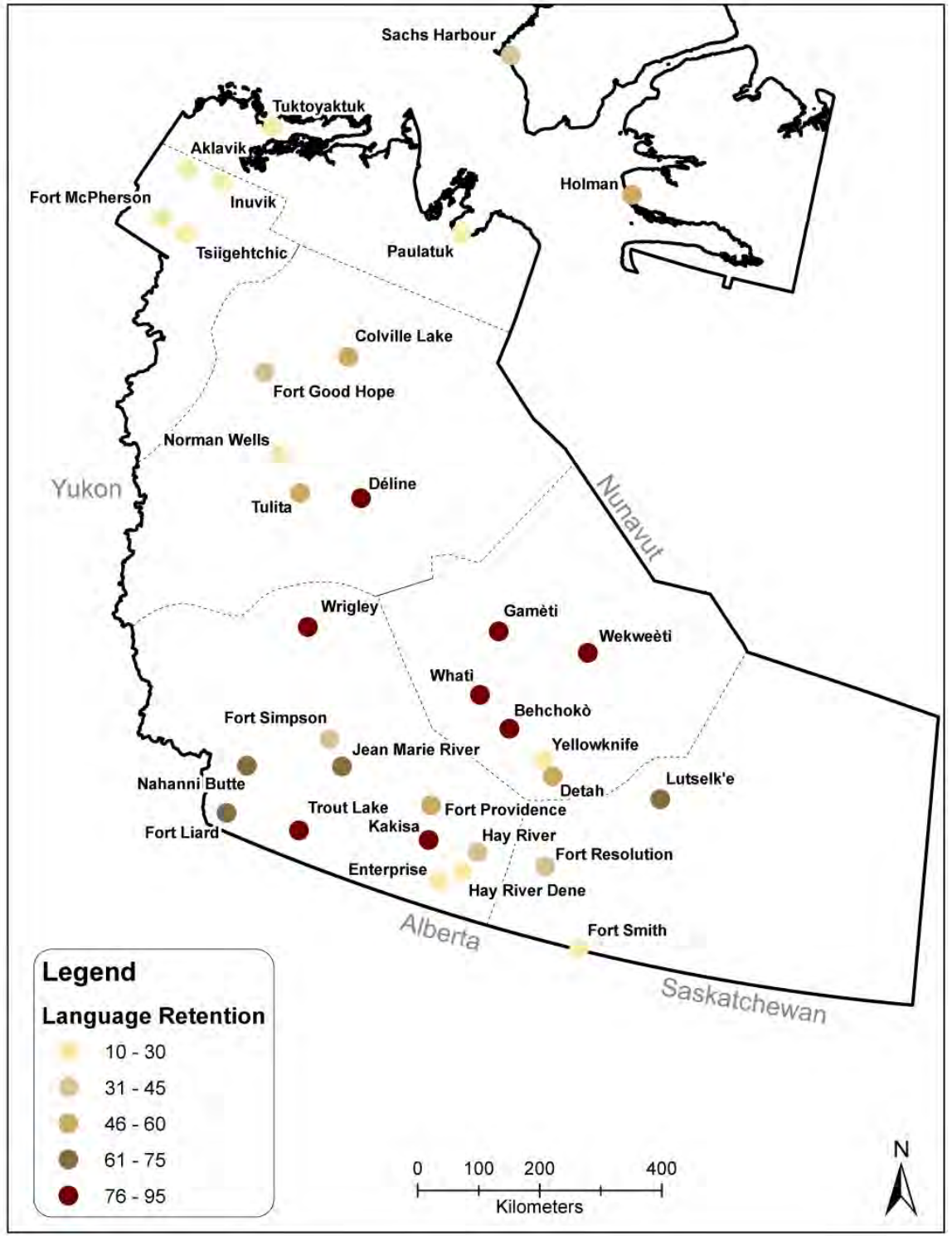


Figure 7 continued. Traditional Activities

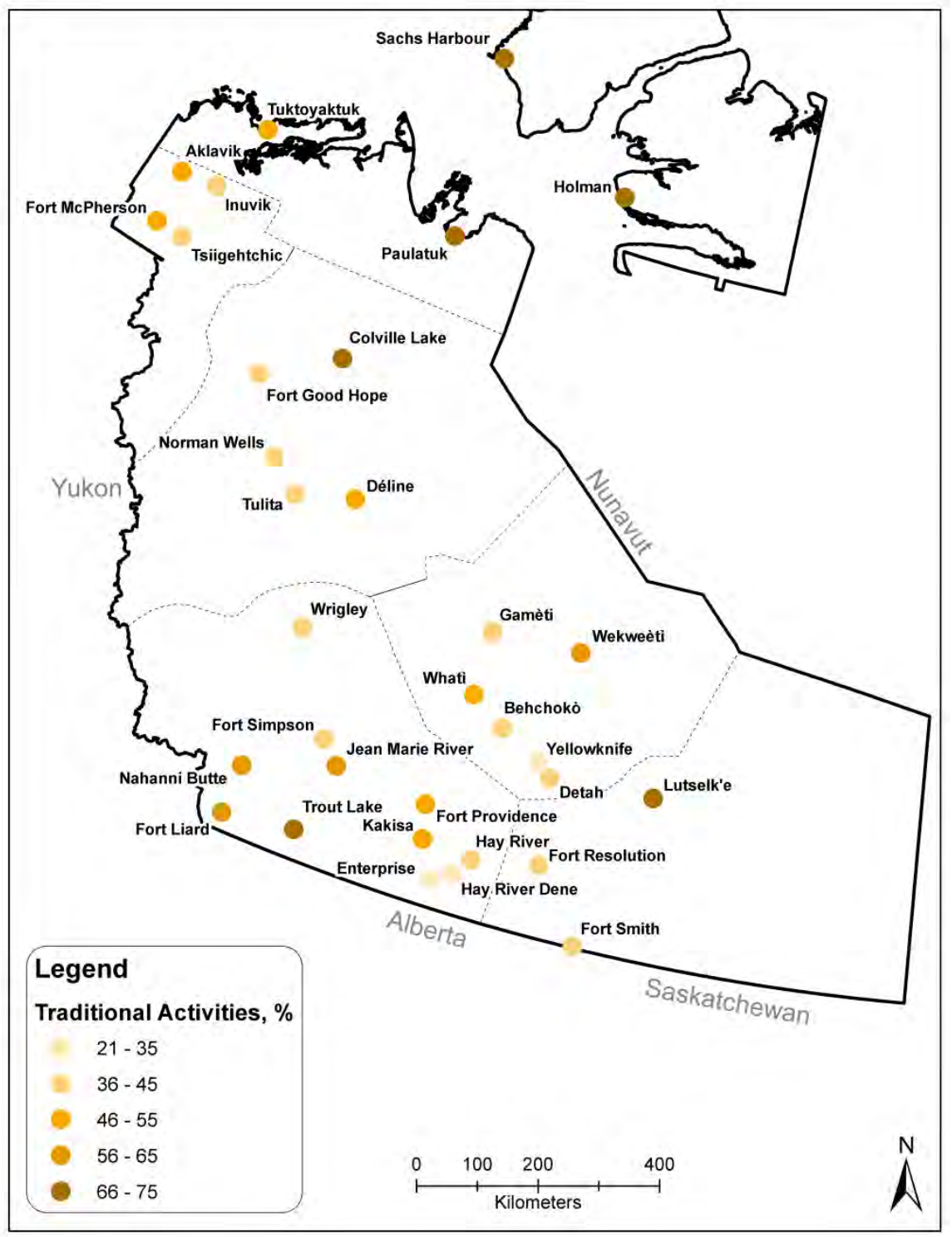

(Statistics Canada, 2009).

\subsubsection{Contact with Nature Domain}

Contact with nature is an indicator of connection to a traditional lifestyle related to livelihood activities on the land and water. This is an important component of human wellbeing as a strong connection to local environments may be a source of a community's vitality (cultural, economic, health) and resilience. Loss of connection with the natural world can re- 
sult in a loss of roots and feelings of alienation. (AHDR, 2004; Louv, 2008). Examples of the most important on-land and on-water activities include harvesting, hunting, trapping, fishing, gathering and consumption of country (traditional) foods. These measures were recommended as indicators of contact with nature by the ASI Report (2010). In this case study we use the consumption indicator, as no harvest data are available.

Figure 8: Consumption of traditional food: \% of households with more than half of consumed meat and fish obtained through hunting or fishing

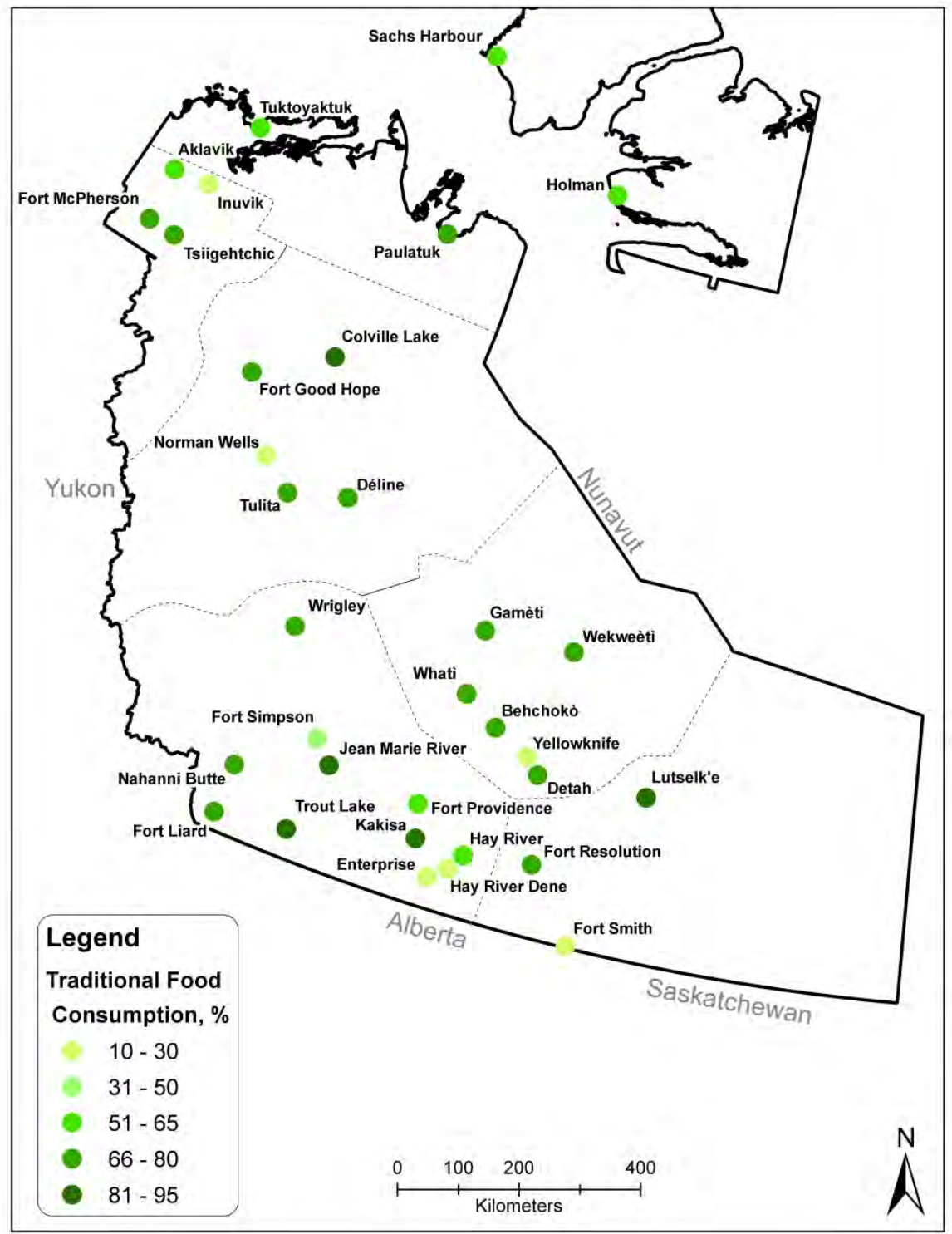

(NWT Bureau of Statistics, 2009). 
The $\%$ of households that obtained more than half of the meat and fish they had consumed through hunting or fishing follows the general pattern of Aboriginal population distribution, community size and location. Larger towns with few Aboriginal households exhibited very low levels of contact with nature as measured by consumption of traditional foods. Only in $10.7 \%$ of Yellowknife households did most of the meat and fish consumed come from residents' hunting and fishing activities (Figure 8). In contrast, in more remote, Aboriginal-dominated communities the majority of households were consuming meat and fish obtained through fishing and hunting (e.g., $76.9 \%$ in Fort Liard, 73.2\% in Fort Good Hope, 69.4\% in Fort Simpson). These data indeed suggest that contact with nature is higher in areas that are "on the land or sea", while in the larger towns people become detached from traditional activities and natural environments. The availability of other sources of food, including big-box stores in cities like Yellowknife, exacerbates the disconnection among arctic residents and the natural world. Communities with stronger Aboriginal cultural ties demonstrate remarkable levels of exchange and sharing in respect to country food (Ulvevadet and Klokov, 2004), which is a pattern not prevalent in westernized towns.

\subsubsection{Education Domain}

To assess the educational attainment level in NWT communities we used two main indicators: the $\%$ of population 15 years or older who completed high school and have attained a bachelor's degree or higher. Only $64.1 \%$ of NWT residents completed high school compared to $79.1 \%$ of all Canadians (2009). Most notably only $38.7 \%$ of the Aboriginal population holds a high school diploma or higher education certificate. This is a sharp contrast, not only with the national benchmark but also with the level of educational attainment in the NWTs non-Aboriginal population (86.2\% completed high school or higher). High-school attainment in NWT communities varies between 11.8 and $80.9 \%$. The highest attainment rates are observed in Yellowknife, Norman Wells, Fort Smith and other predominantly non-Aboriginal communities. Small and remote settlements with few educational opportunities form the groups of communities with less than $25 \%$ high school completion rate.

High School and university degree attainment by community is depicted in Figure 9. 18.5\% of all NWT residents and only 3.4\% of Aboriginal residents hold bachelor's degrees or a higher level of schooling. Among the communities with available data this indicator varies between 2.2 and $21.1 \%$. Eleven communities have university degree attainment at zero but in some instances the data may be suppressed. The highest level of school- 
ing is found in the regional centers and economic hubs (Yellowknife, Inuvik, Fort Smith, Hay River and Norman Wells). Interesting outliers include Wekweètì (21.1\%) and Colville Lake (13.3\%).

Figure 9: Educational attainment: Bachelor's degree and higher

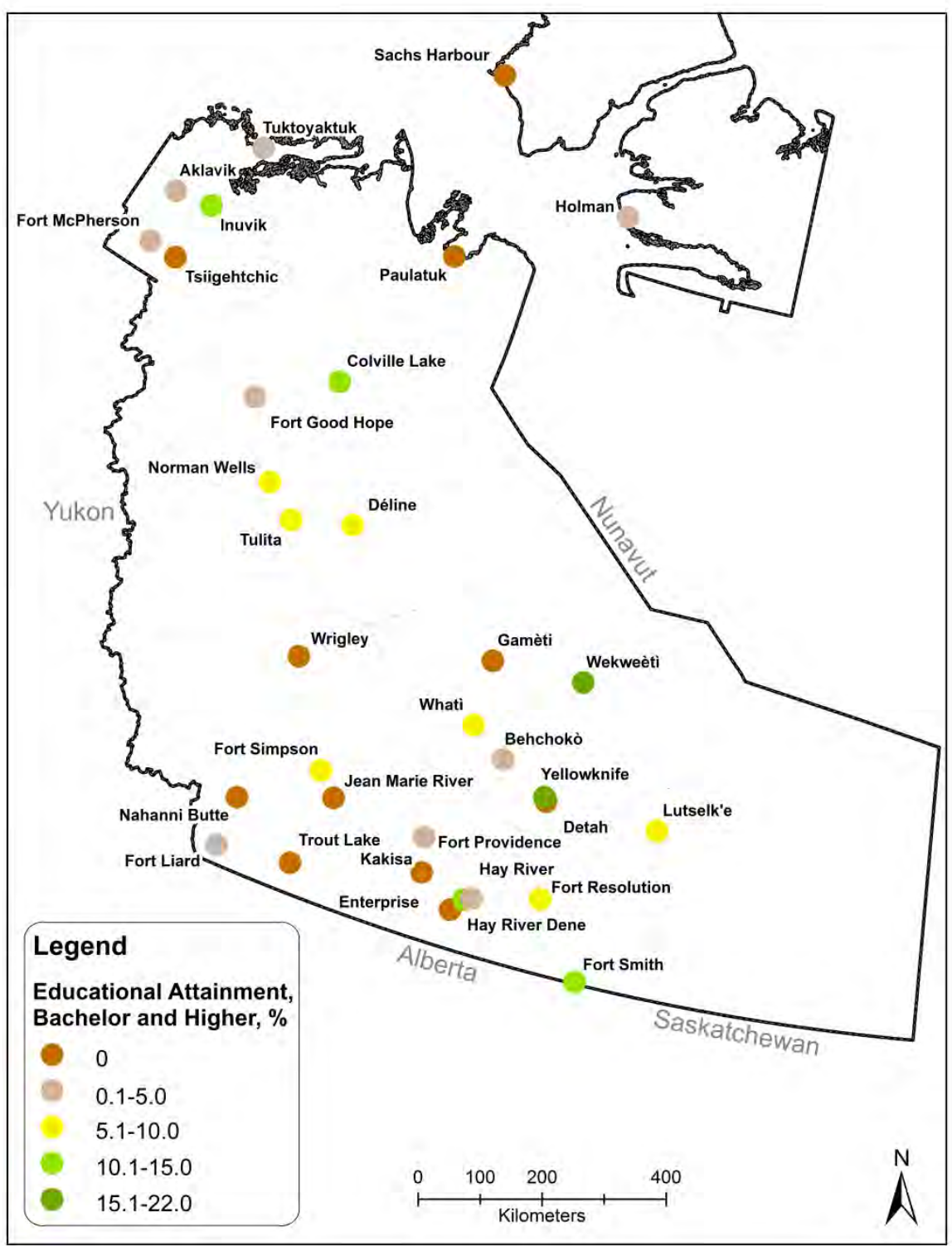


Figure 9 continued. High School or higher

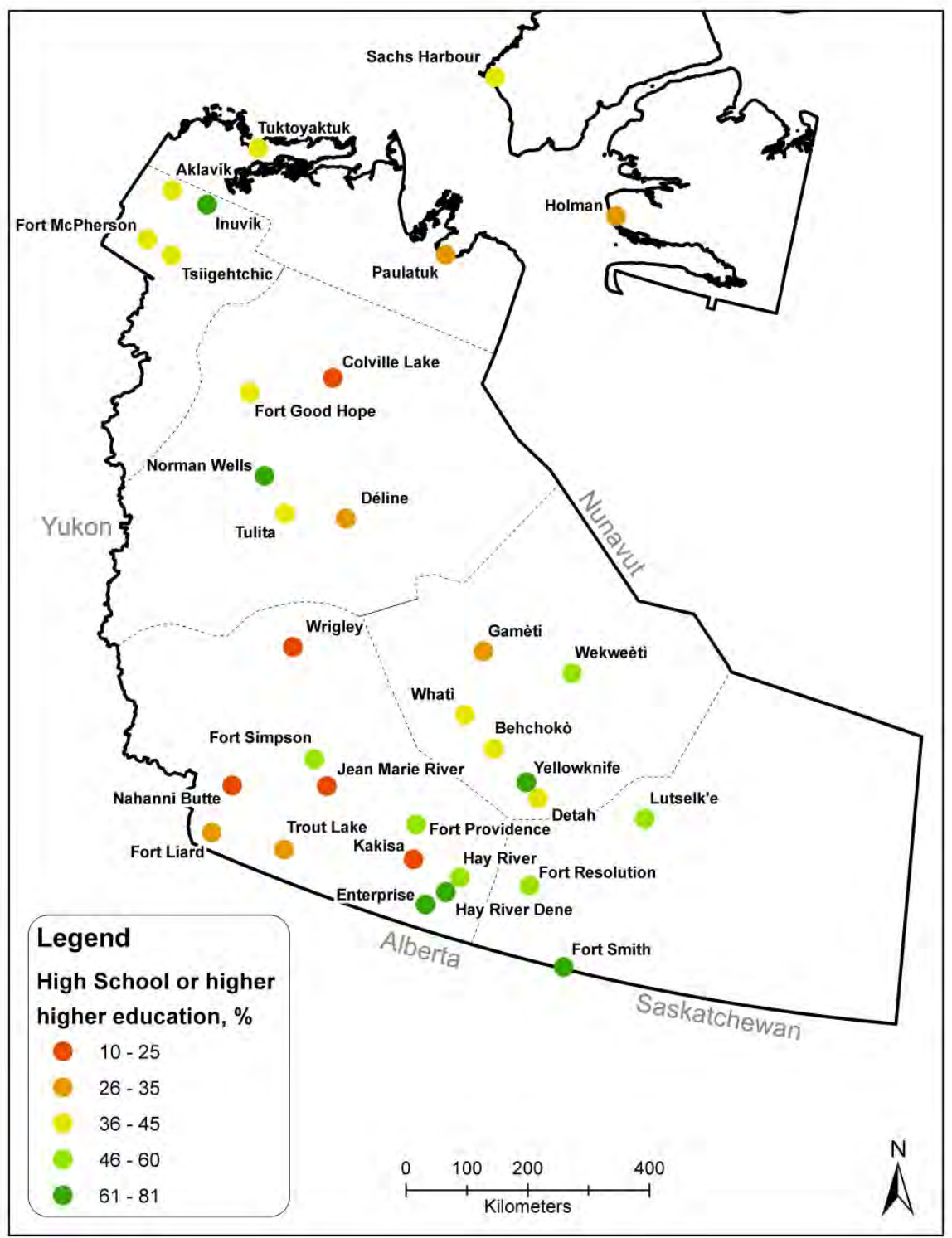

(Statistics Canada, 2008b).

Both high school and university degree attainment rates indicate a considerable education gap between NWT communities and the rest of Canada as well as disparities within the NWT. Access to education and consequently to wage-sector jobs and higher incomes is impeded in many settlements. Improvement of the education system, advancement of distance learning, professional training and adult education are important avenues to bridge both of these gaps. 


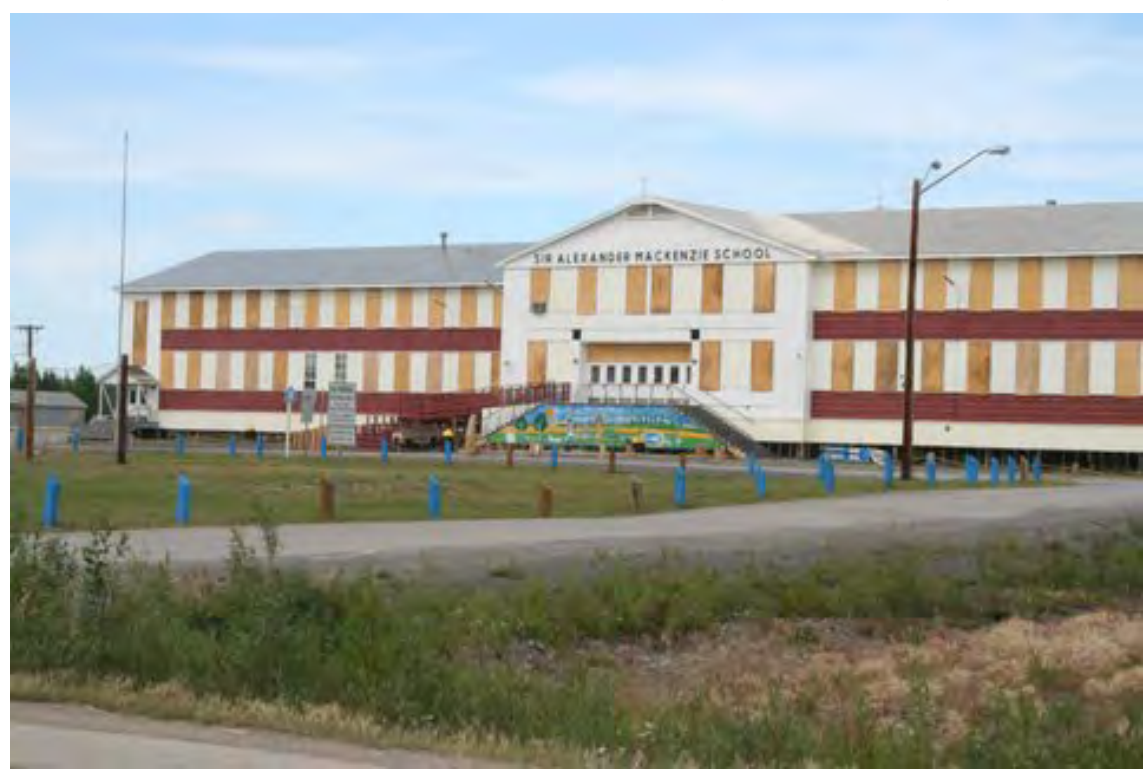

Photo: L. King.

\subsubsection{Fate Control Domain}

Fate control is a very complex category to measure. Fate control is measured using a four-component Fate Control Index (FCI). FCI values vary between 0 and 4 . The first component of fate control is measured using the $\%$ of Aboriginal people in managerial and administrative occupations. This component characterizes the ability of northerners, and specifically Aboriginal residents, to exercise political and administrative power over their affairs. Local control is noticeably higher outside Yellowknife, in which the majority of managers and administrators are not native and Aboriginal residents, but migrants. Given that Aboriginal people constitute about a half of NWT's population, from the positions of fate control it is a concern that the vast majority (83\%) of the leadership in the territorial capital does not report Aboriginal identity. Aboriginal people are underrepresented in managerial and administrative occupations even in predominantly Aboriginal communities. This pattern reflects education and leadership gaps between Aboriginal and nonAboriginal residents that result in considerable power inequities.

Economic control is another important measure of the ability of communities to determine their own destiny. Presumably, a community with less dependency on transfers from the Federal Government has a higher degree of freedom in designing social and economic policies. 
Whereas the ideal measure of economic self-sufficiency would be the $\%$ of public expenses generated within a community (i.e. expenses drawn from locally raised taxes), the unavailability of data prevents us from using this indicator. A reasonable proxy could be the share of selfgenerated income of community residents' total incomes (i.e. personal or household income minus government transfer payments).

Only three communities demonstrate high levels of economic control: Yellowknife, Inuvik and Hay River (Figure 10). The residents of these communities are less dependent on transfer payments, which is why the economic base is less vulnerable to economic and political decisions made outside the community. On the other hand, Aboriginal communities in the Mackenzie River Delta have comparatively low levels of economic selfreliance with about $25 \%$ of residents' incomes coming from government transfers. Clearly, economic fate control is directly related to the material wellbeing of communities, with more prosperous communities taking advantage of a stronger labor market with a developed wage sector.

\section{New Municipal Buildings, Conference Centre, Yellowknife, NWT}

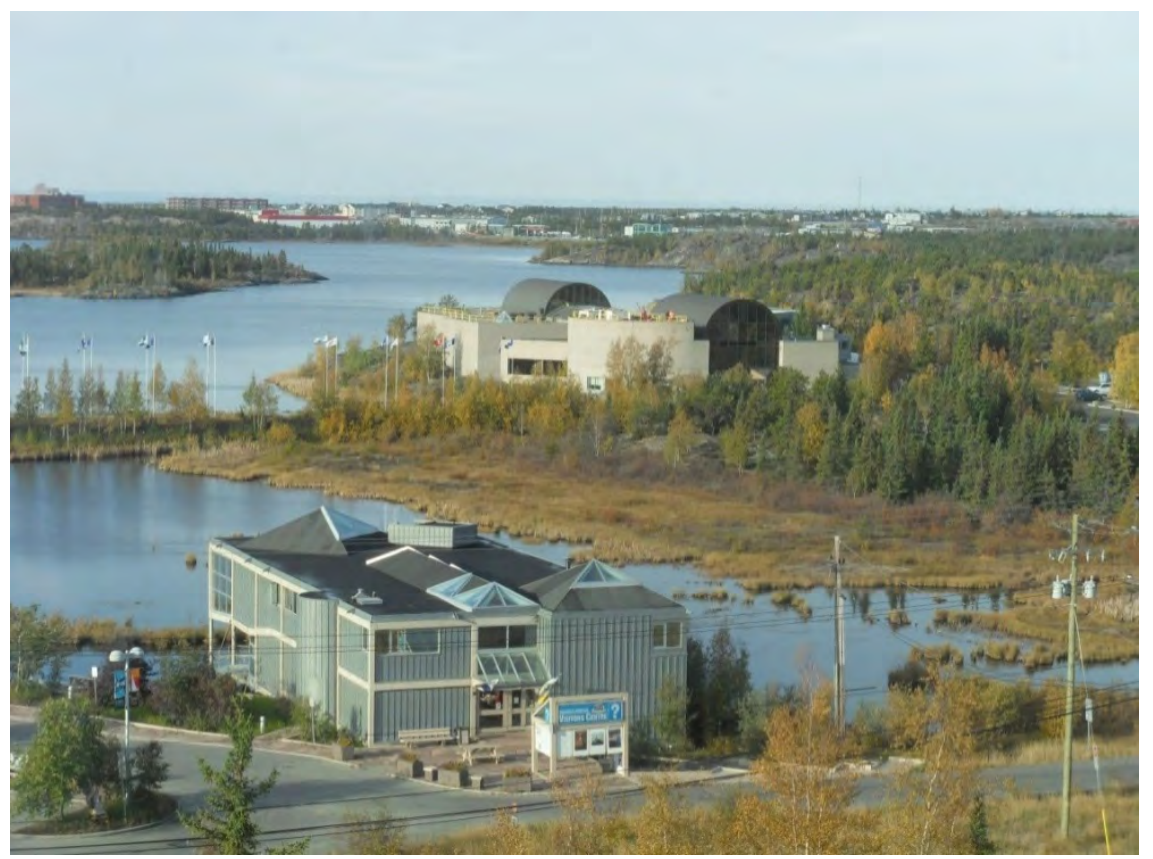

Photo: A. Petrov. 
Figure 10. Fate Control Components and Fate Control Index: Language Retention

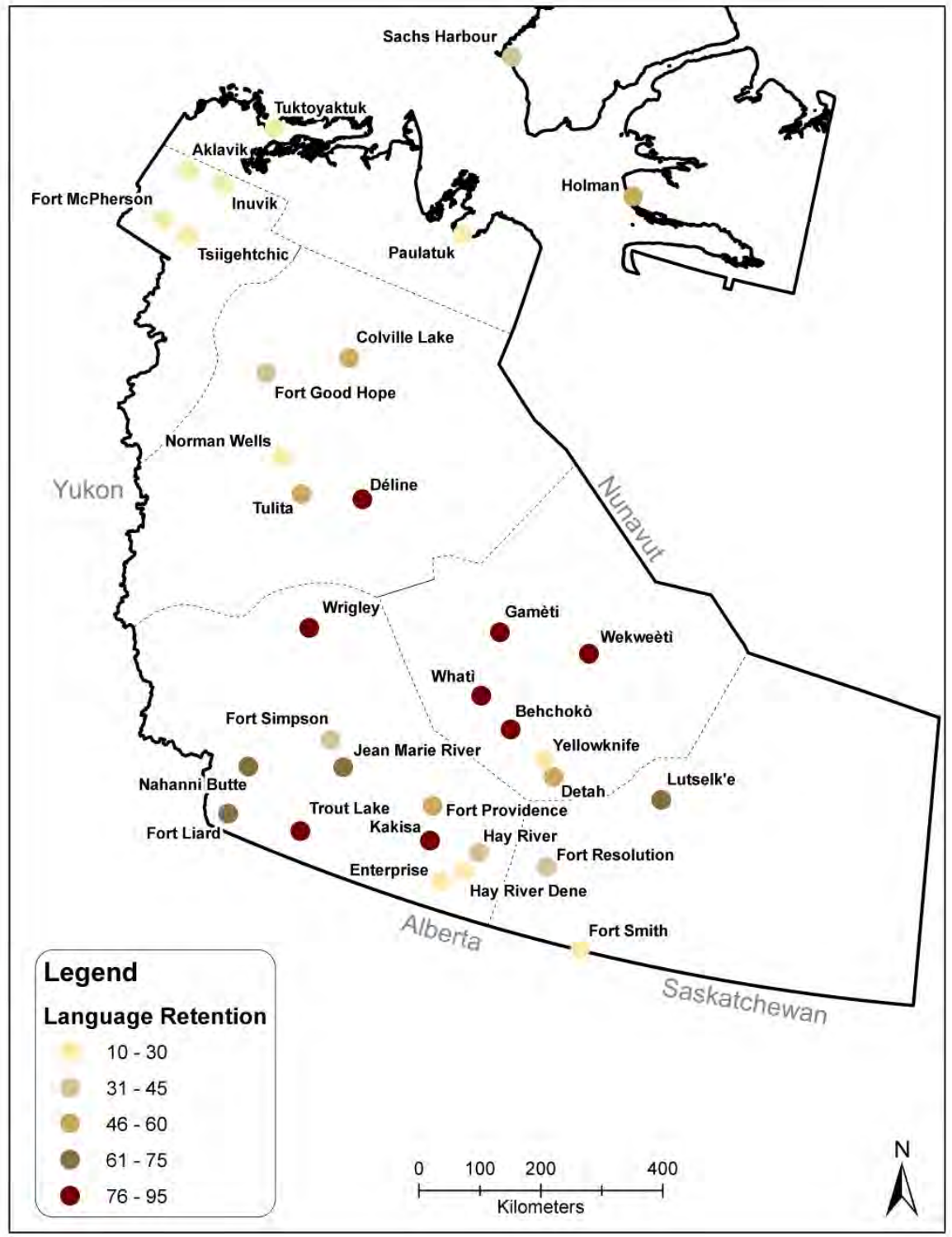


Figure 10 continued. Settled Land Claim Agreement

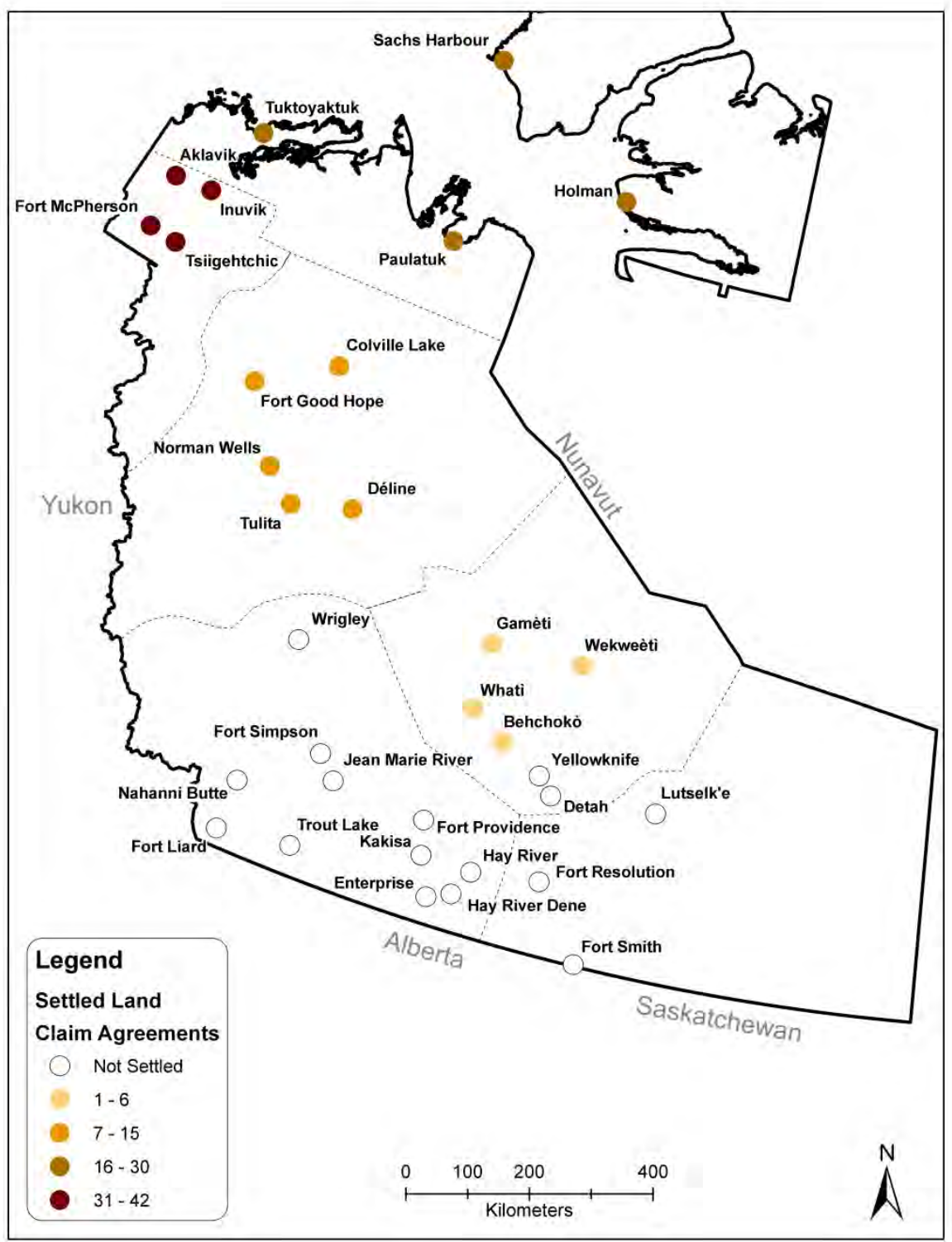


Figure 10 continued. Self-Generated Income

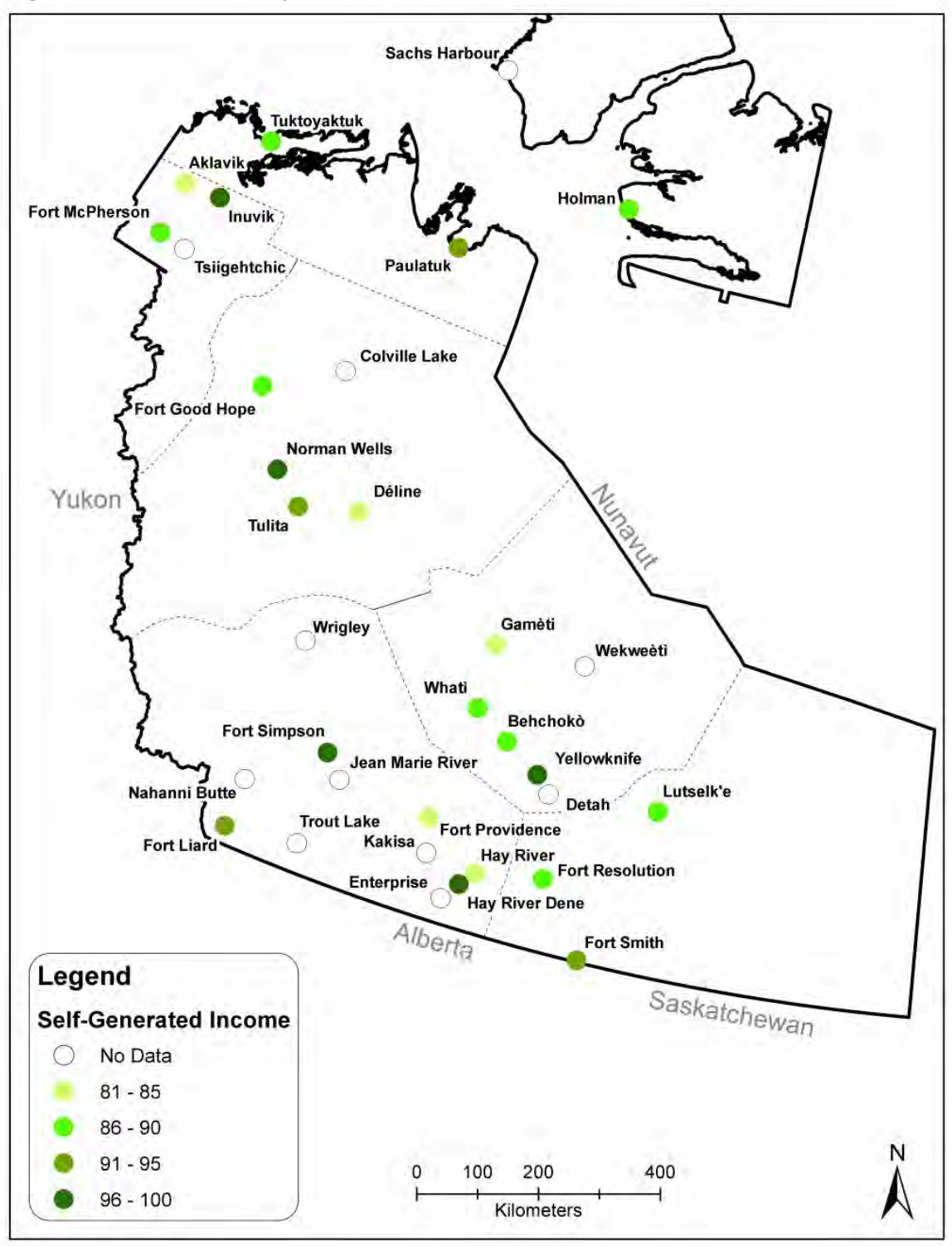


Figure 10 continued. Percent Aboriginal in Government

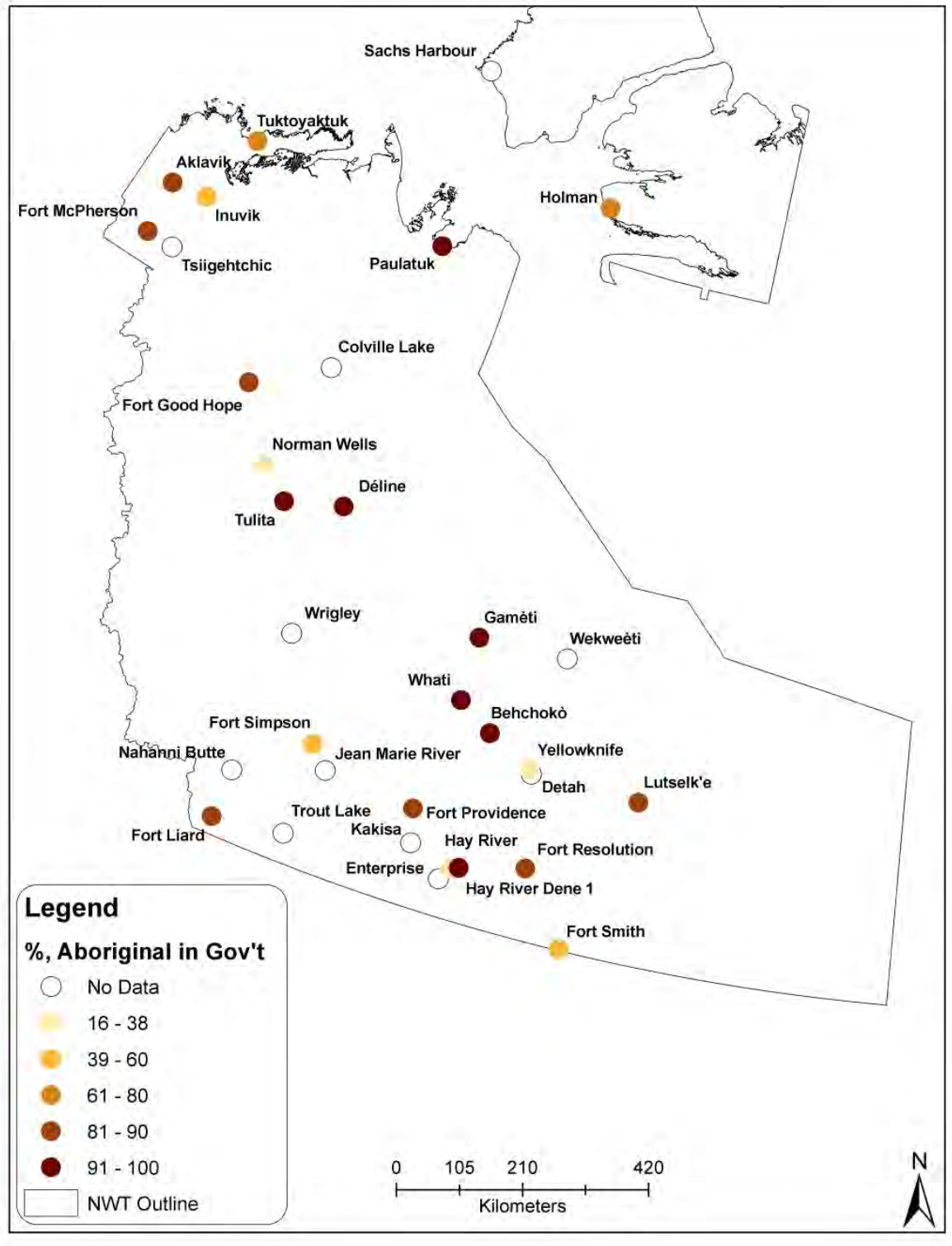


Figure 10 continued. Fate Control

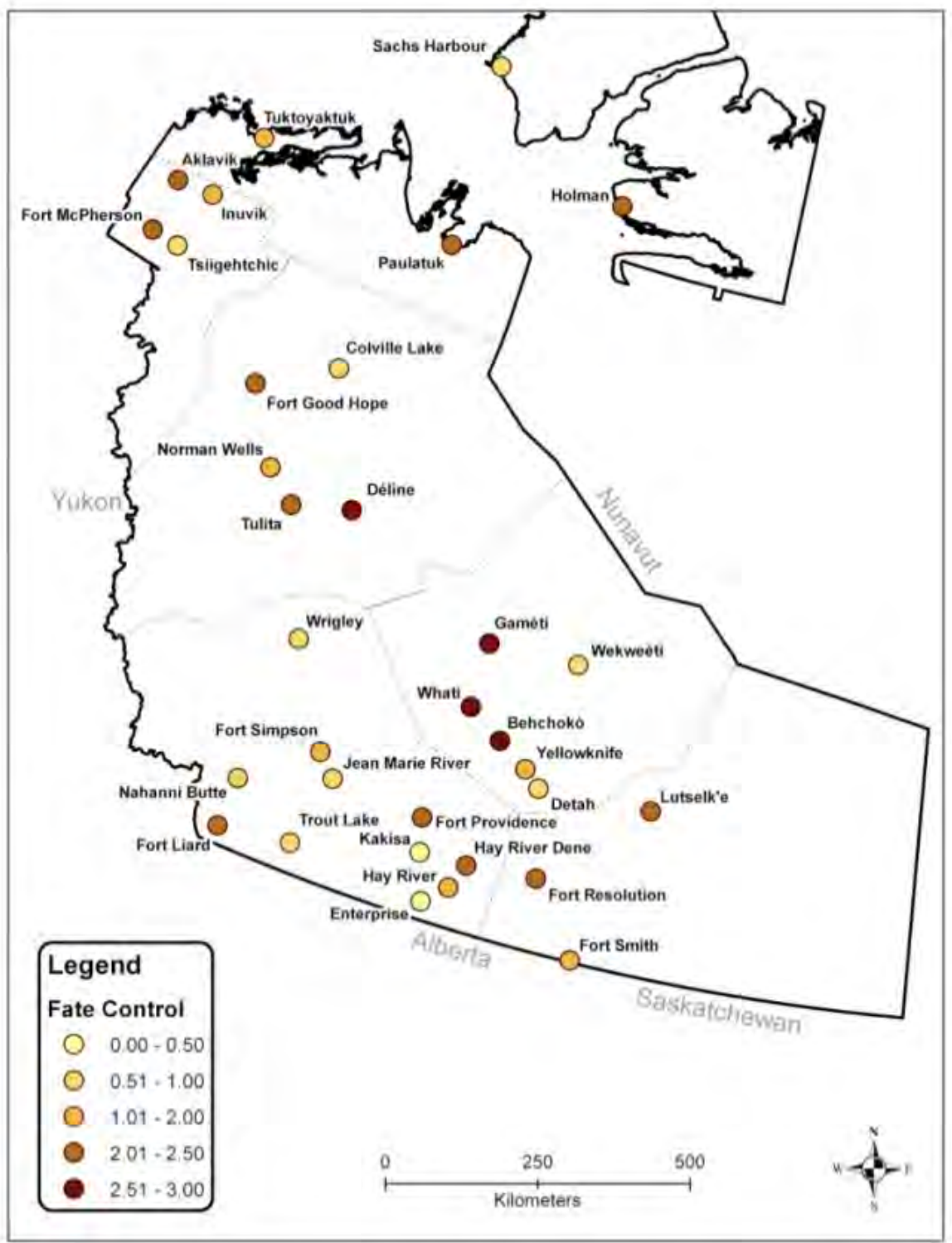

(Data from: Statistics Canada, 2008a, 2008b, 2009).

Language retention is an indicator of control over knowledge construction. In essence it characterizes the fulfillment of the human right to maintain a unique culture. The same indicator has already been used to measure cultural vitality, and therefore it is an integrative measure that pertains to wellbeing in both cultural and fate control domains of Arctic social indicators. As mentioned above, language vitality is highest in communities where Aboriginal people dominate, such as Aklavik, Behchoko, Fort 
Good Hope, and Fort McPherson with the \% of Aboriginal residents who speak their mother tongue exceeding 70\%. Many residents in these communities report using an Aboriginal language both at home and work. In contrast, less than $30 \%$ of the Aboriginal population in Yellowknife, Hay River and Inuvik report an ability to speak a Native language because they have little choice but to use the official languages of Canada in their workplaces as well as outside of the work environment.

Control over land is measured by analyzing texts of the comprehensive land claim agreements (CLCA). The NWT has four settled CLCAs that stipulate control and use of land. The $\%$ of the land area covered by the CLCA that is under direct control of an Aboriginal authority can be used as a proxy to assess the degree of the control over land exercised by Aboriginal people. Based on this measure Gwich'in and Inuvialuit regions have higher control over land.

The composite fate control index (FCI), based on four components, demonstrates the differences among the capital and territorial towns and Aboriginal communities (Figure 10). The latter have higher levels of cultural wellbeing and stronger local control over their affairs, but lack economic self-sufficiency. Aklavik, Fort Providence and Behchoko show the highest fate control when measured in the context of the composite fate control index. However, it is important to remember that we were unable to account for the control over land in the composite measure. Incorporating the fourth component into the final index might have altered the fate control rating of Inuvialuit communities. 


\section{Comparison of Social indicators in six NWT regions}

Through a comparison of the six NWT cultural regions (excluding the Yellowknife area) the analysis reveals a complex regional pattern of wellbeing. South Slave, Inuvialuit and Sahtu territories tend to have higher per capita incomes and lower unemployment, which are both associated with the large resource sector in these areas (diamonds, oil, etc.). With Tlicho and Gwich'in these are also the regions with the highest levels of education. Territories with settled land claims have higher fate control indicators with Tlicho and Sahtu leading the FCI ranking. Gwich'in and Inuvialuit show the strongest control over land. Settled CLCA regions also demonstrate the highest rates of participation in traditional activities and closest contact with nature. For example, $73.7 \%$ of Tlicho and $60.9 \%$ of Sahtu households consume mostly country food. Almost half of Inuvialuit (48.4\%), Deh Cho (46.7\%) and Sahtu (44.7\%) residents hunt and fish for the table. Except for the Inuvialuit, these regions also have high Aboriginal language retention rates (90.4\% in Tlicho, 58.2\% in Deh Cho and 53.3\% in Sahtu). The Inuvialuit and Gwich'in regions are exceptions with only $23 \%$ and $17 \%$ of adult Aboriginal people speaking their mother tongue.

\section{Dynamics of social wellbeing and human development in the NWT: 1991-2006}

This section presents a first attempt to analyze the change in social wellbeing in the NWT using the indicators framework established by the ASI (2010). One of the ASI's goals is to develop a set of measures that can be used to monitor the dynamics of wellbeing over time. Undoubtedly, longitudinal analysis is very important from the policy standpoint as it may illuminate the consequences of policy interventions (or lack of such). It can also assist in testing the appropriateness and sensitivity of social wellbeing benchmarks.

The analysis of ASI indicators in the NWT, while pioneering in nature, has some limitations. Most of these limitations stem from the lack or incompatibility of data between 1991 and 2006. Most data were acquired from the Canadian censuses of 1991 and 2006 and the Aboriginal Peoples Survey of 1991. Data collection and use closely followed the principles described in the previous section. We followed the recommendations for domains and individual indicators, unless there was a problem with data availability, in which case we either omitted the indicator or used a comparable surrogate. Data availability allowed us to complete the analysis of four domains of social indicators: population and health, material wellbeing, cultural vitality, and fate control. It is also worth mentioning that until 1999 the NWT included Nunavut. To ensure 
consistency and comparability, the pre-1999 data used in this analysis excluded Nunavut communities.

Population and Health. In the fifteen years between 1991 and 2006 the population of the NWT grew from about 36,000 to over 41,000 or by $14 \%$. This trend in itself does not provide a clear picture of population status since it lumps together natural and migration change as well as hides considerable regional differences. It should be noted that a large drop in population was observed between 1996 and 2001 when it dropped from 40,000 to 37,000 (although 2001 figures suffer from the high net undercoverage rate). Population instability is indicative of longstanding problems in respect to social wellbeing, cohesion and stability in the resource-dependent economy of the NWT and other regions of northern Canada.

Different regions and communities in the NWT had diverging trends of population change and migration (Figure 11). While most communities gained population, a number of settlements suffered considerable population decline during the reporting time. Excluding very small communities that can be considered outliers, Behchoko, Yellowknife and Norman Wells posted the highest population increases in excess of $20 \%$. On the other hand, Aklavik, Fort Resolution, Fort Smith, Tuktoyaktuk and others were losing population during the same time period. 


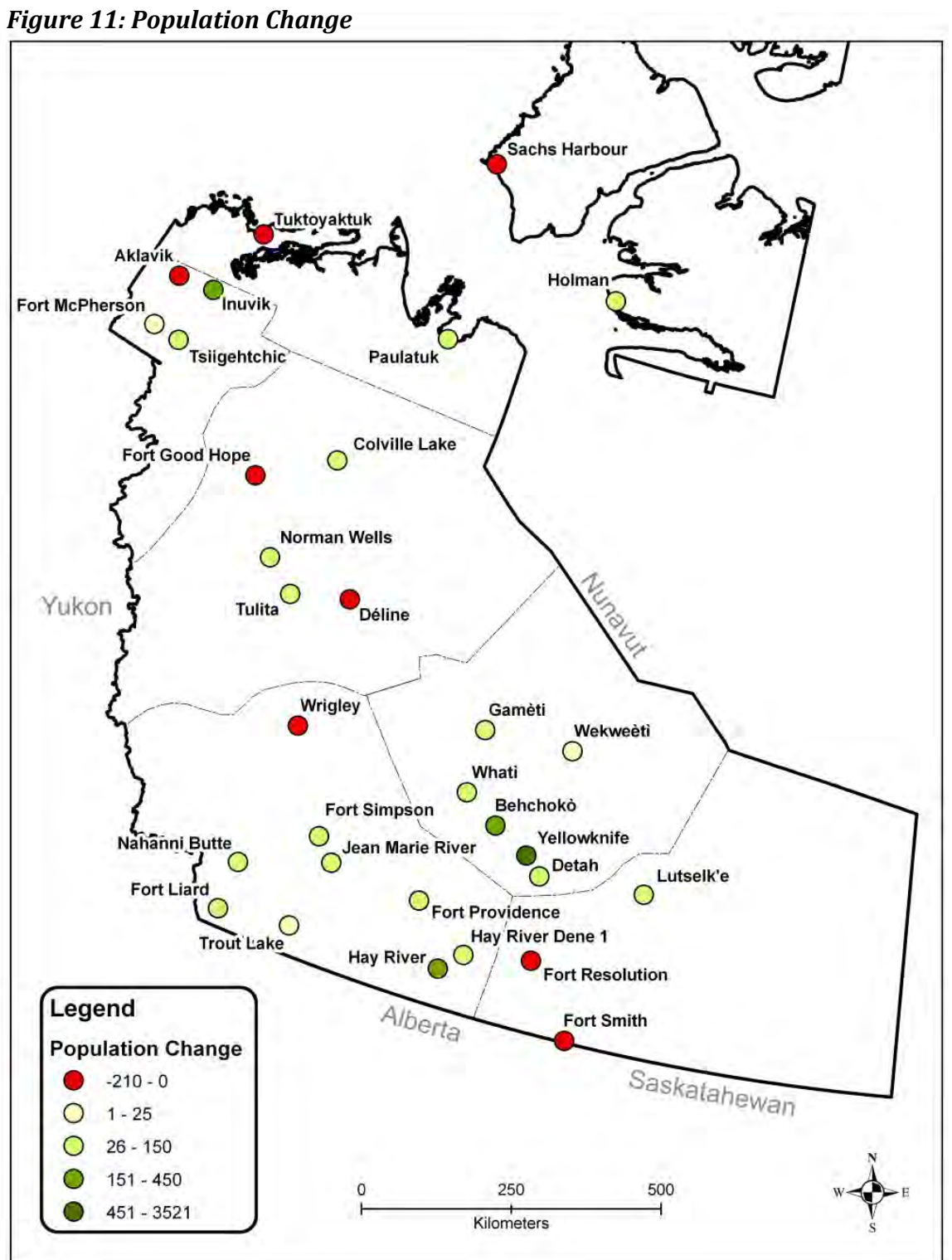




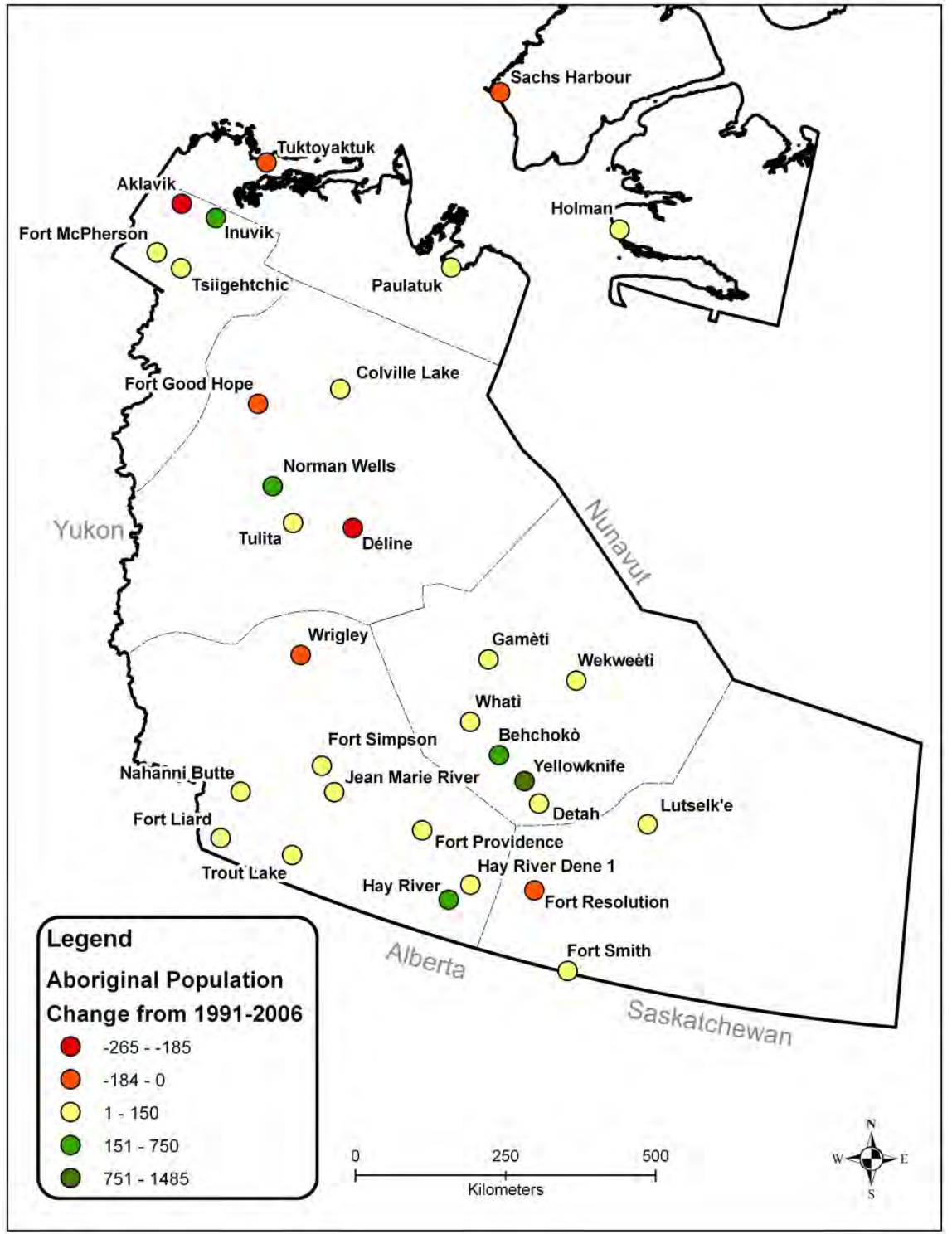

(Statistics Canada, 1991, 2008a, 2008b).

Finally, in recent decades the Teenage Birth Rate in the NWT exhibited a dramatic decline: from 81 per 1,000 women under 20 in 1991 to 37.5 in 2010. Although the TBR is still higher than the Canadian national figure, this measure indicates positive changes in socio-economic wellbeing, public health and social environment. The rate of TBR decline was also much faster than in Canada as a whole. 
Material wellbeing. The dynamics of material wellbeing measured by the per capita average household income are presented in Figure 12. Note that these figures are not adjusted for inflation and therefore should not be directly compared. Overall, the geography of material wellbeing remains fairly constant in the period between 1991 and 2006, although the disparity between poorest and richest communities increased, which slightly highlights a trend in income divergence and increasing disparity in material wellbeing. Highest incomes in both 1991 and 2006 were observed in the capital, as well as in resource towns (e.g. Norman Wells) and administrative centers. Notably, the five communities with the highest incomes remained unchanged (Figure 12).

It is also interesting to explore the geography of income gains. The most substantial increases in per capita average household incomes are found in the richest communities, which are also administrative and economic centers. These include the communities of Norman Wells, Yellowknife, Fort Simpson, Hay River, Fort Smith, and Inuvik (which show an income gain of between $C \$ 12,000$ and $\$ 21,000$ over a 15 year period). However, the rate of increase varied across the NWT. Many mid-tier communities saw large income gains: Behchoko, for example, had a $127 \%$ increase in per capita household incomes that rose from $C \$ 7,861$ in 1991 to $\$ 17,916$ in 2006 . However, it was still far behind the highest income places, such as Norman Wells $(\mathrm{C} \$ 44,310)$ and Yellowknife $(\mathrm{C} \$ 39,414)$. The poorest communities had noticeably smaller gains. This indicates persistent income gaps among communities and reinforces the division of NWT settlements into "haves" and "have-nots". 
Figure 12: Dynamics of Material Wellbeing Indicators, 1991-2006

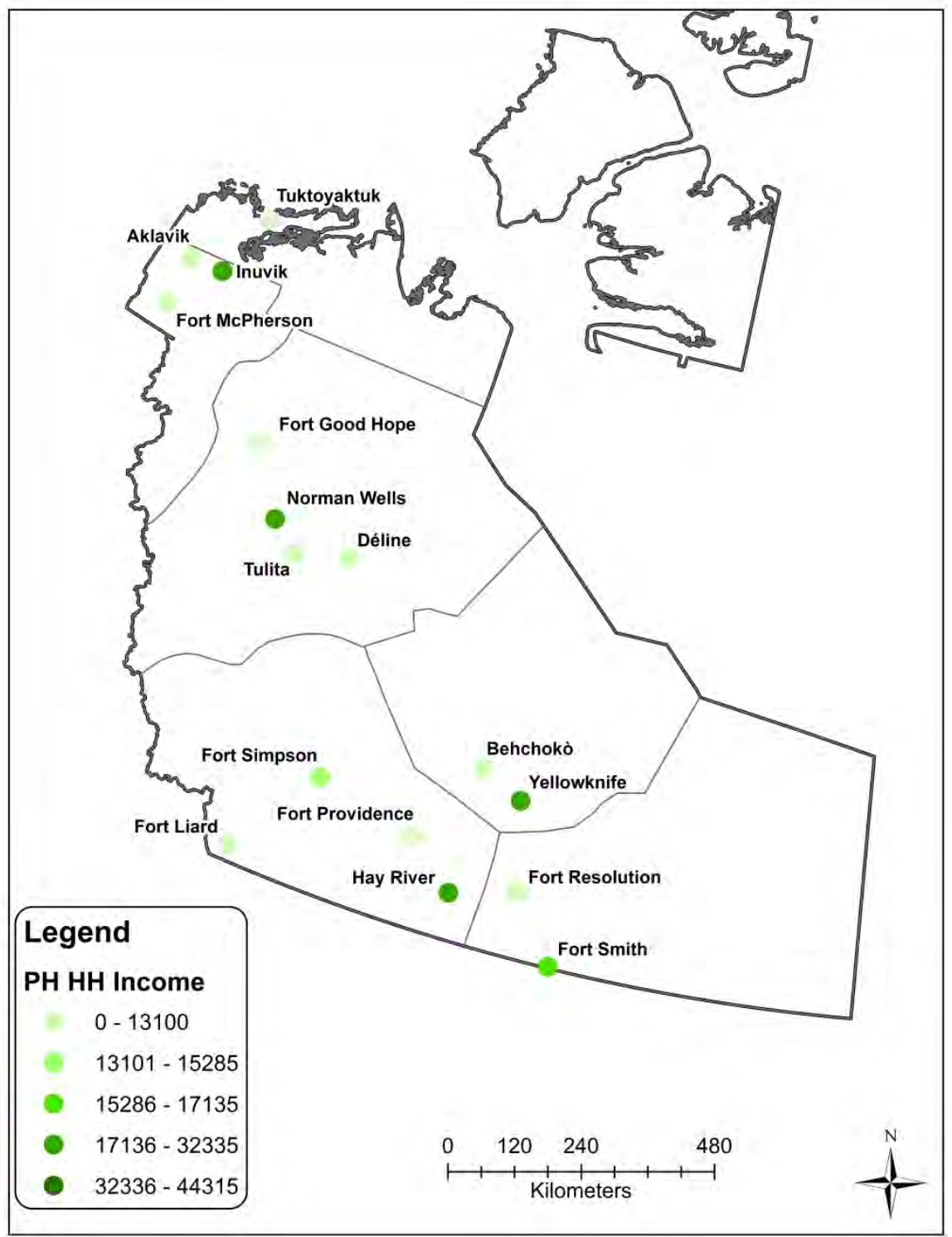


Figure 12 continued. Income per Capita, 2006

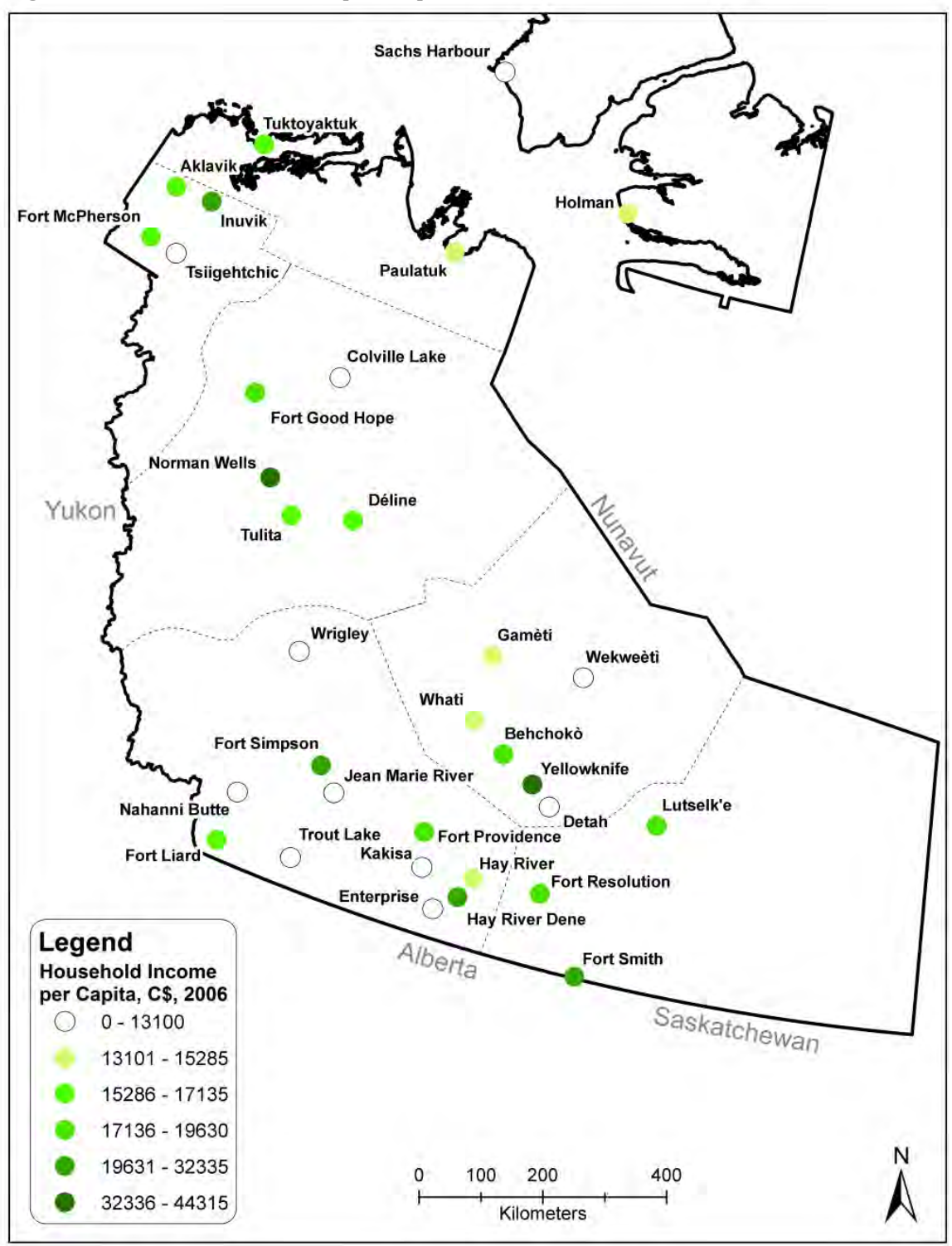


Figure 12 continued. Unemployment Rate, 1991

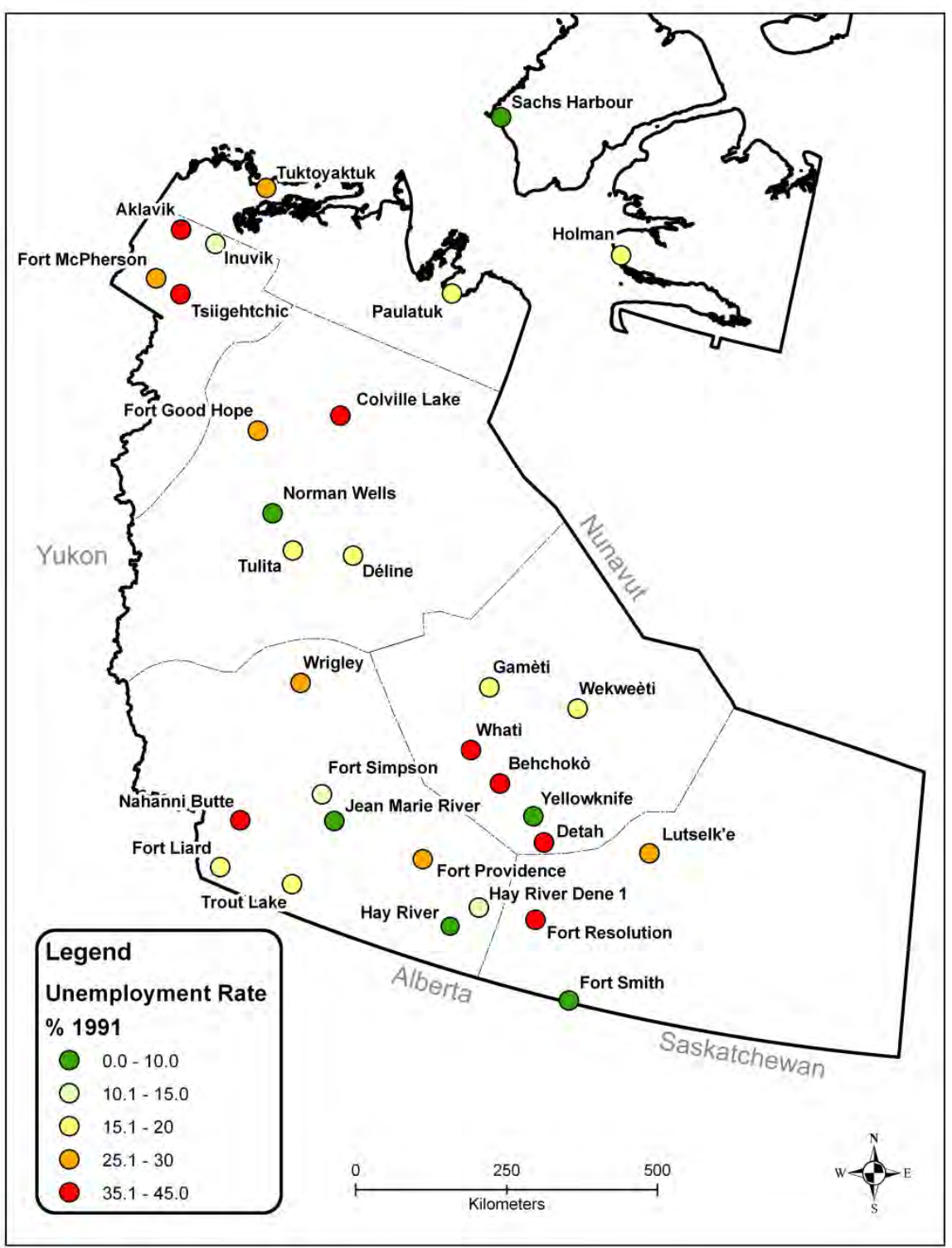




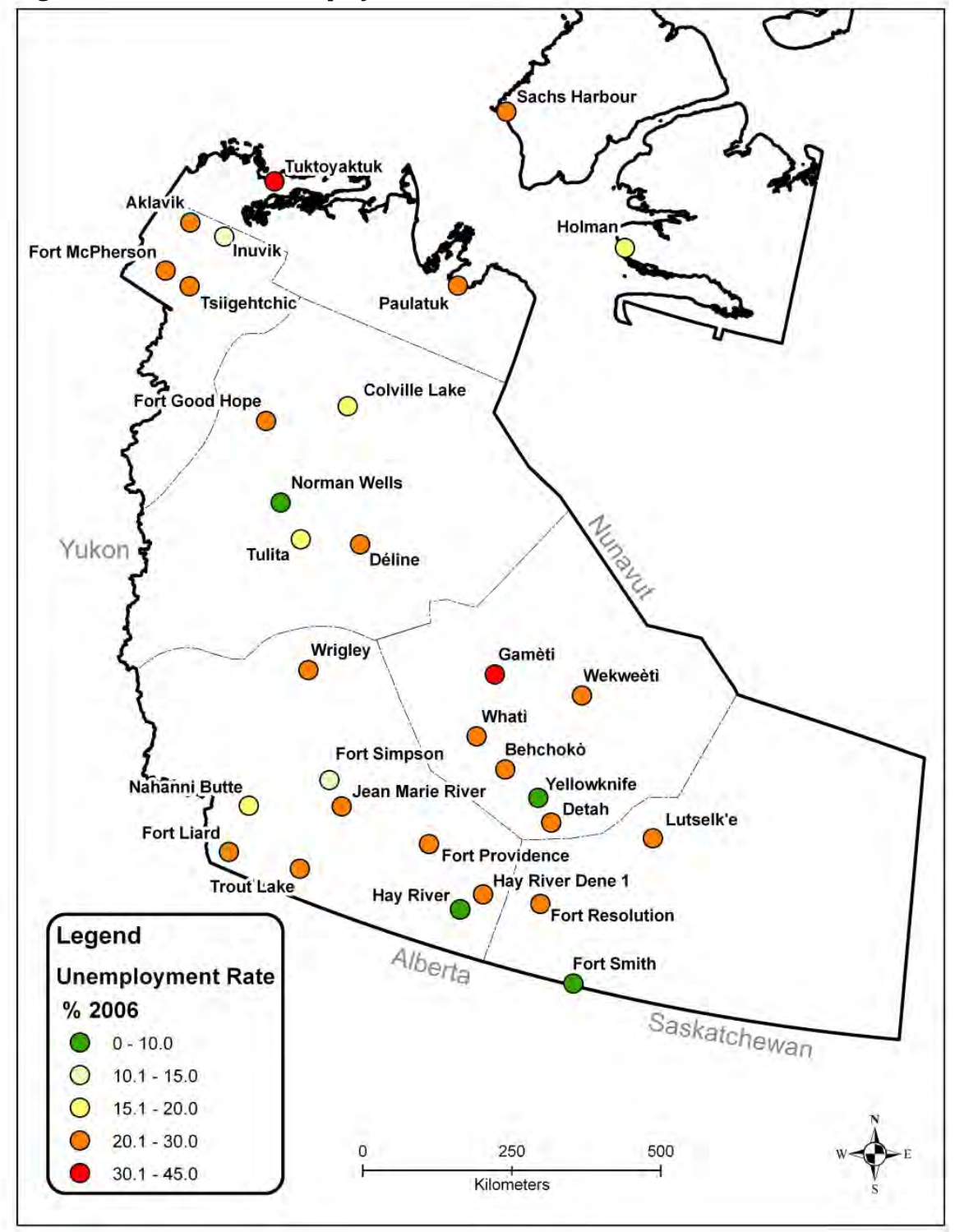

(Statistics Canada, 1991, 2008b).

Unemployment rates in the Territory between 1991 and 2006 remained virtually unchanged. However, there have been some improvements in communities, such as Fort Simpson, Fort Resolution, Fort Providence, Aklavik and several others (Figure 12). Yellowknife and Normal Wells had the lowest unemployment rates ( $6 \%$ and under). In contrast, many remote and Aboriginal communities experienced very high unemployment with little or no improvement. For example, Tuk- 
toyaktuk had an unemployment rate of 34.2 in 1991 and 33.3 in 2006. Aklavik's unemployment rate dropped from 36.9 to 24.5, which is still extremely high. These observations confirm that in terms of material wellbeing the NWT is divided into a small group of "have", and a large group of "have-not", communities.

Cultural wellbeing and cultural vitality. Of the indicators recommended by ASI as measures of cultural wellbeing the only indicator available for temporal analysis is the language retention rate. Figure 13 presents the $\%$ of people with Aboriginal identity who spoke their mother tongue in 1991 and 2006. Generally, there is an evident decline in language retention rates. The mean rate for the 16 largest NWT communities in 1991 was 55\%, while by 2006 it had dropped below 38\%. The average language retention rate for all NWT communities in 2006 was $48.6 \%$ ranging from $12.9 \%$ in Inuvik to $93.6 \%$ in Wekweètì. In Yellowknife the $\%$ of Aboriginal people speaking their mother tongue decreased from $32.2 \%$ to $21.3 \%$. However, the level of retention is higher and the speed of language loss is slower in the NWT than in some other Arctic regions, for example in northern Russia (AHDR, 2004; Petrov, 2008). 
Figure 13: Dynamics of the Cultural Wellbeing Indicator: Language Retention Rate 1991-2006

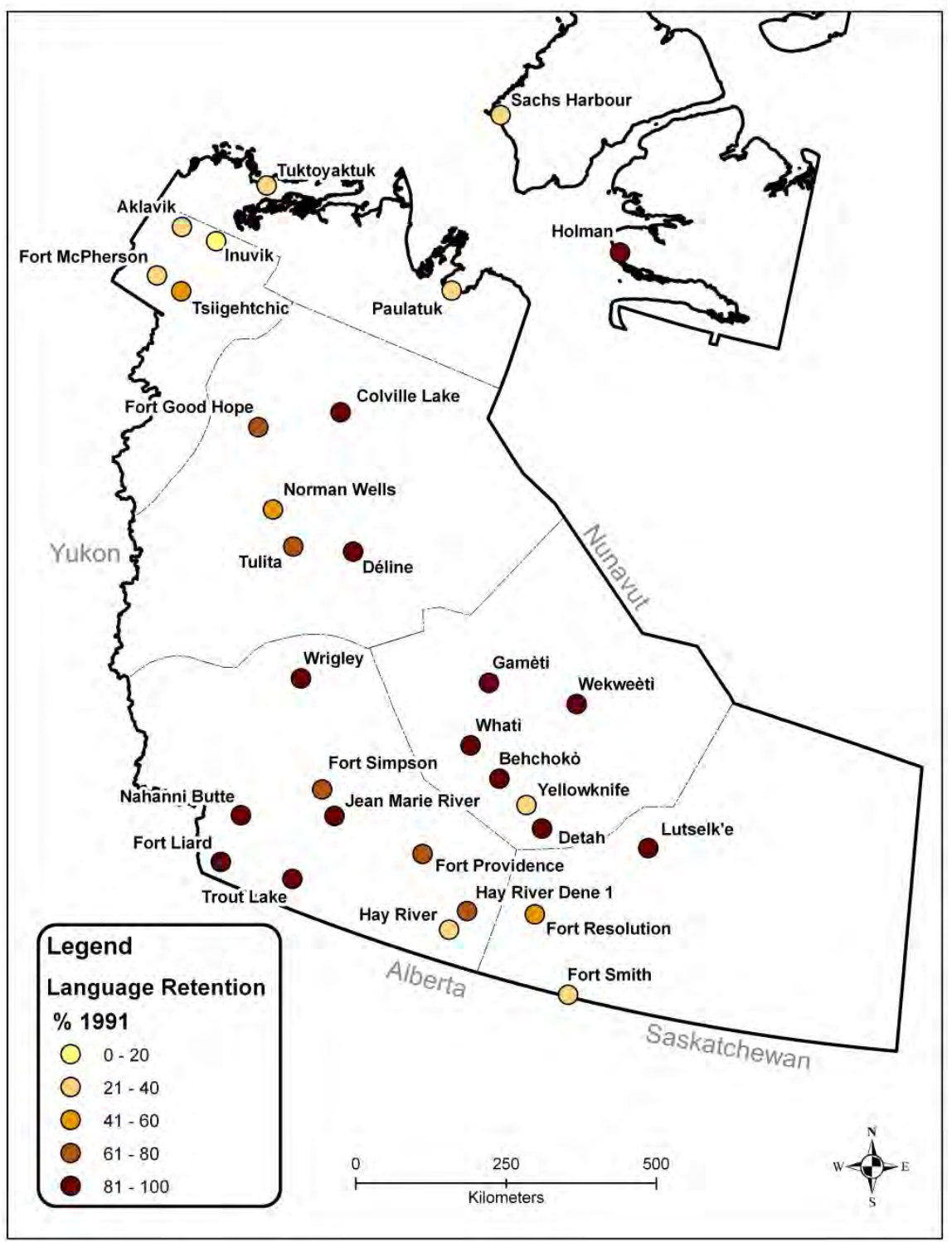




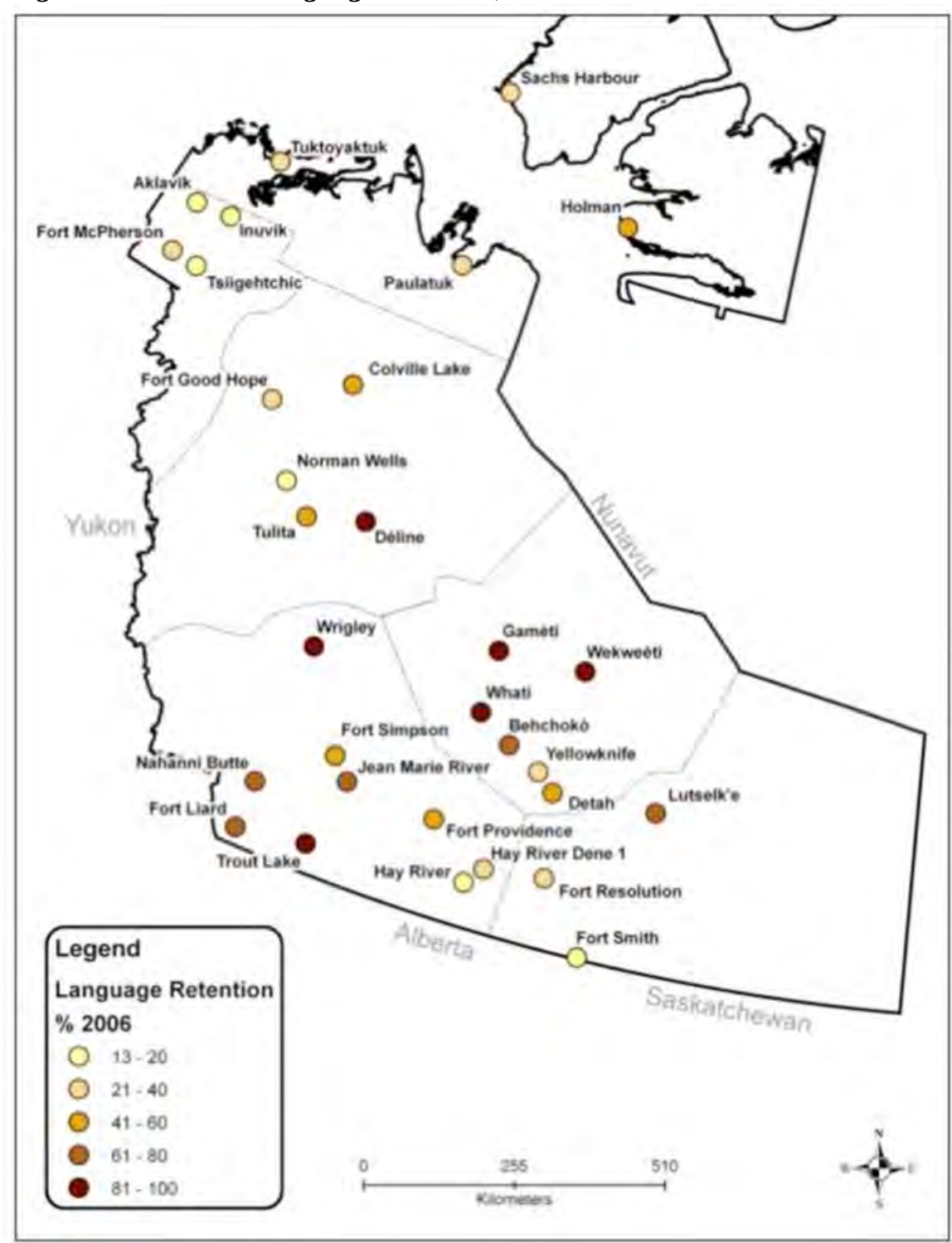

(Statistics Canada, 1991, 2008b).

Fate Control. Only three components of the fate control measure are available for comparison between 1991 and 2006. These include control over land, language retention and self-generated income. As a result, we recalculated the Fate Control Index (FCI) with only three variables. The index will have a range from zero to three (Figures 14-15).

The change in the Fate Control Index between 1991 and 2006 is difficult to characterize because of the complexity of the measure and considerable regional differences, but the FCI generally declined throughout 
the NWT (Figures 14, 15). Many communities were not as strong in Fate Control in 2006 as they were in 1991. In fact, only eight communities showed growth. The increase in fate control was largely related to the completion of the Comprehensive Land Claim Agreement processes that resulted in increasing control over land. At the same time, many communities experienced decline in fate control due to the decreasing language retention (see Figure 13 and earlier discussion of cultural wellbeing). However, many communities with small populations of roughly 250 people and fewer did not have data for self-generated income and could not be included in the analysis.

The last two decades saw gains made by northern communities in attaining more control over land and resources. In 1991 there was only one settled CLCA (Inuvialuit). By 2006 this number increased to four (added Gwich'in, Sahtu, and Tlicho), plus the Nunavut Land Claims Agreement that led to establishing a separate territory. In regions where CLCAs were concluded, we observe a corresponding increase in control over land (Figure 15). The situation with other components of fate control is more complex. Control over knowledge construction manifested in the ability to communicate using a mother tongue generally declined. At the same time there were marginal improvements in political power (increasing \% of Aboriginal people in government and management) and economic self-reliance. 
Figure 14: Dynamics of Fate Control Index, 1991

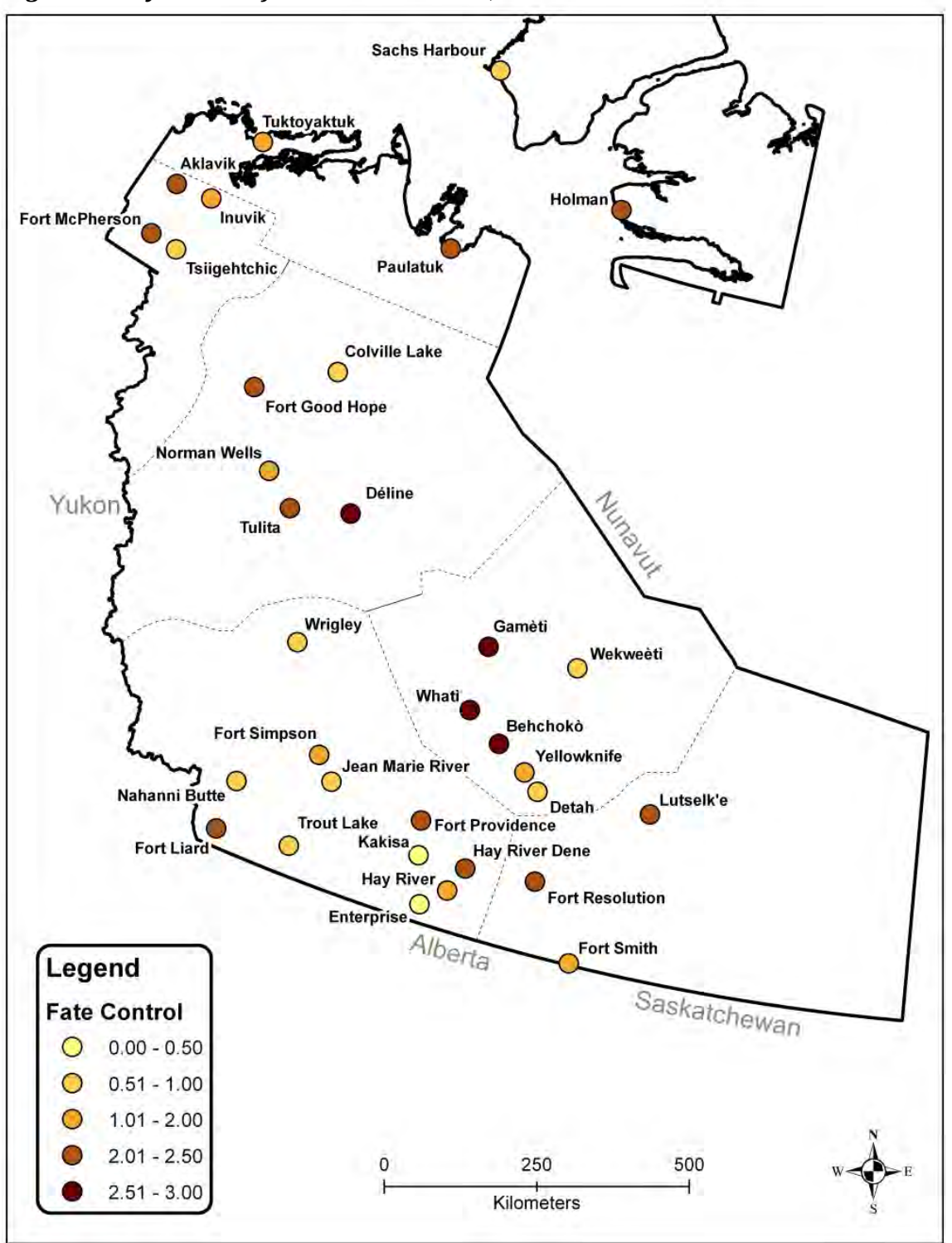


Figure 14 continued. Fate Control, 2006

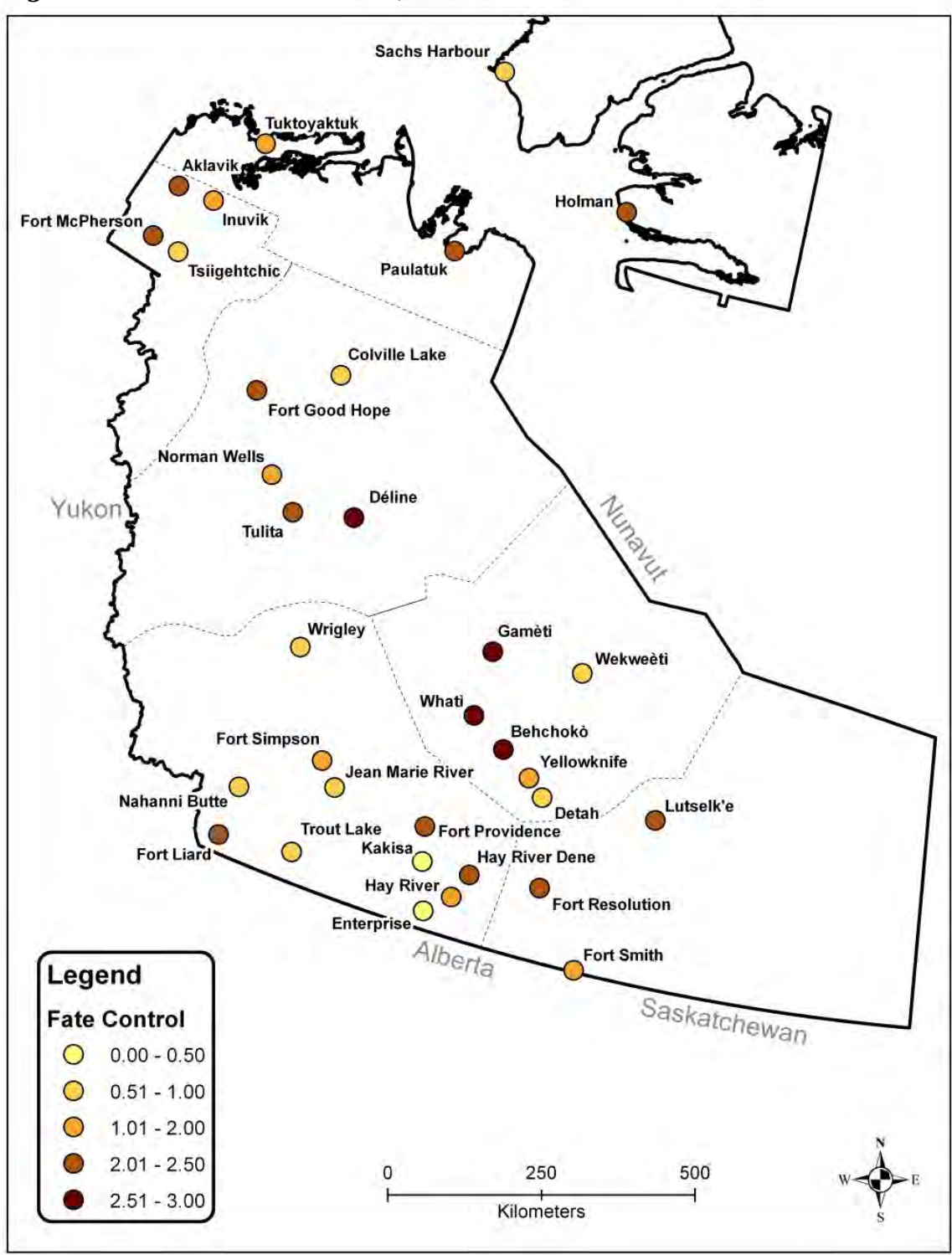


Figure 15: Change in Fate Control Index, 1991-2006

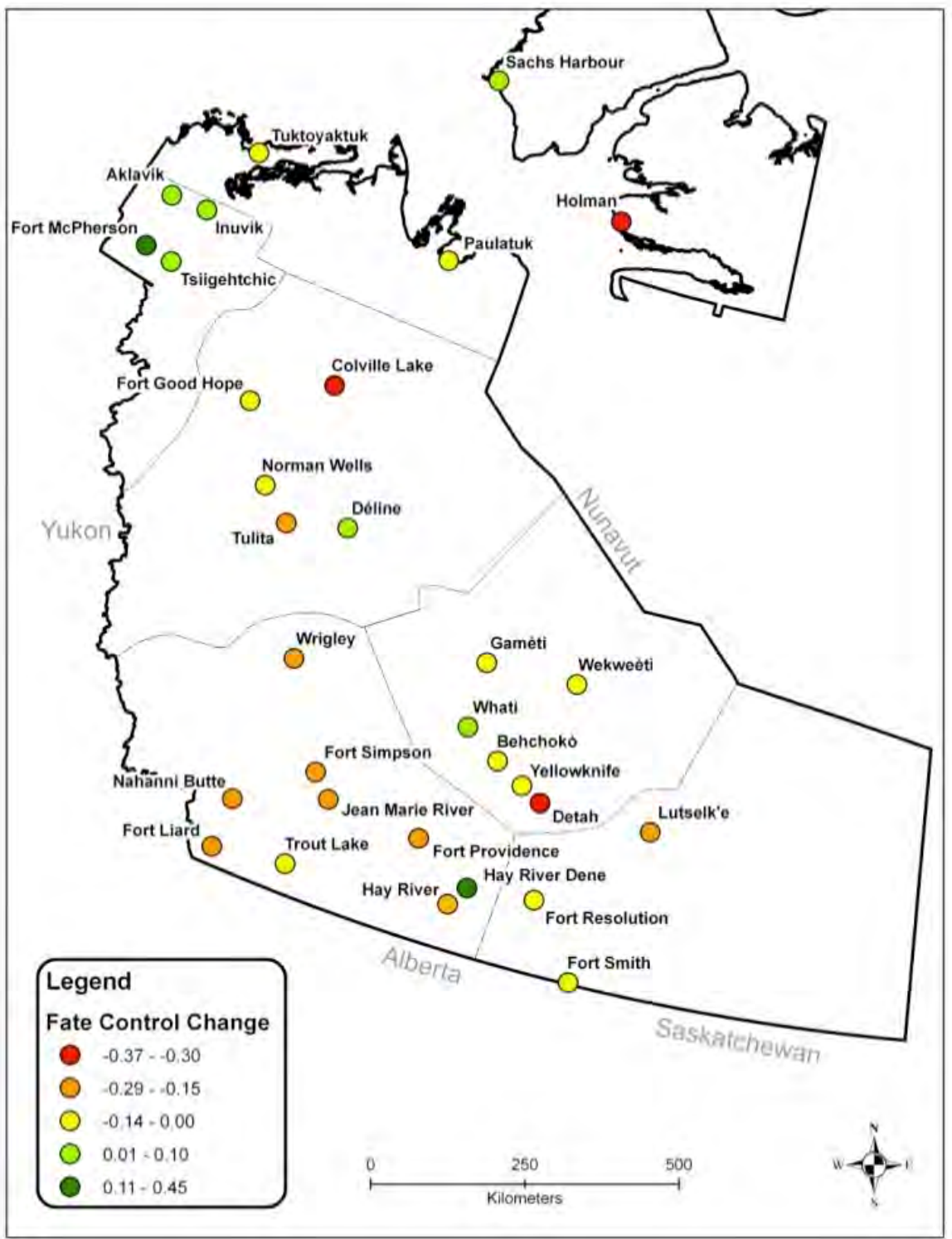

\section{Nunavut}

Nunavut: Until 1999 Nunavut was a part of the NWT. The new territory was created based on provisions of the Nunavut Land Claims Agreement (1993) and became the first and only Canadian province or territory with a predominantly Aboriginal population. The largest city and capital of $\mathrm{NU}$ is Iqaluit (population 6,699). Other large communities include Arviat, Rankin Inlet, Baker Lake, and Cambridge Bay. 


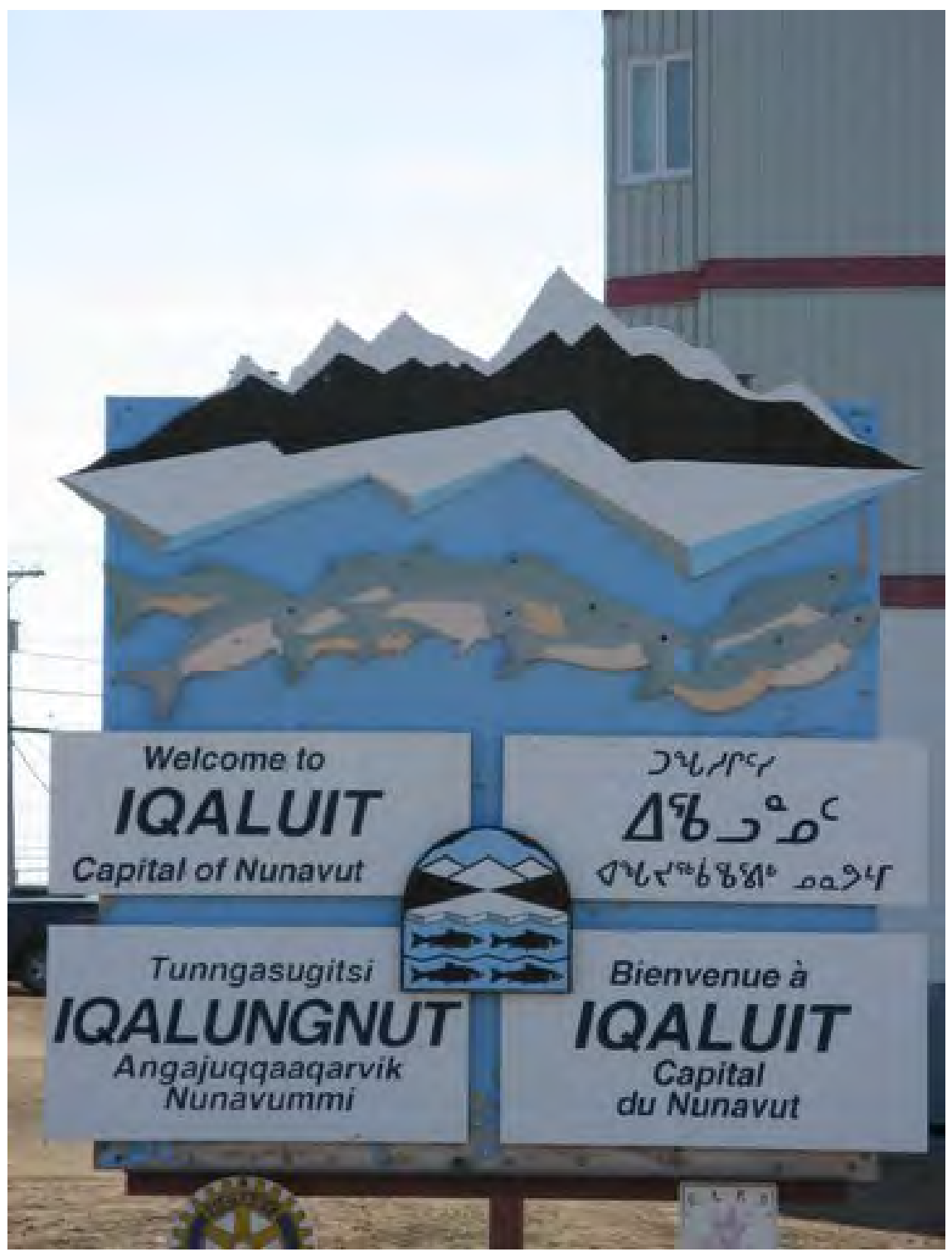

Photo: L.King.

In this abbreviated analysis we considered four domains of human development: fate control, material wellbeing, education and cultural vitality. The indicators were developed based on the Canadian census of 2006 following the same definitions that were used in the NWT case (see Table 1). As seen on the maps (Figure 16A) there is a considerable differentiation in social wellbeing among places included in this analysis. Most $\mathrm{Nu}-$ navut communities demonstrate a high level of fate control (FCI is 3.77 
out of a possible 4.0 for Clyde River) reflecting high levels of language retention and decision-making control among Aboriginal peoples in $\mathrm{Nu}-$ navut. (In Iqaluit, however, fewer than $41 \%$ of leadership (government and management) occupations are held by Aboriginal people). On the other hand, many Nunavut settlements have rather low levels of material wellbeing (Figure 16B) with high dependency on income subsidies. This situation is typical in remote communities throughout the Arctic region. In contrast, privileged places, such as the capital and regional centers, exhibit a much different picture. The per capita household income in the capital city of Iqaluit is more than double the average for Nunavut as a whole. A similar pattern emerges in respect to higher education: the \% of residents with bachelor's degrees ranges from $12.7 \%$ in Iqaluit to $2.2 \%$ in Coral Harbour. Finally, cultural vitality is noticeably higher in Nunavut than in the NWT with most Nunavut communities posting Aboriginal language retention rates in the $80-90 \%$ range (Figure 16C). 
16A: Fate Control

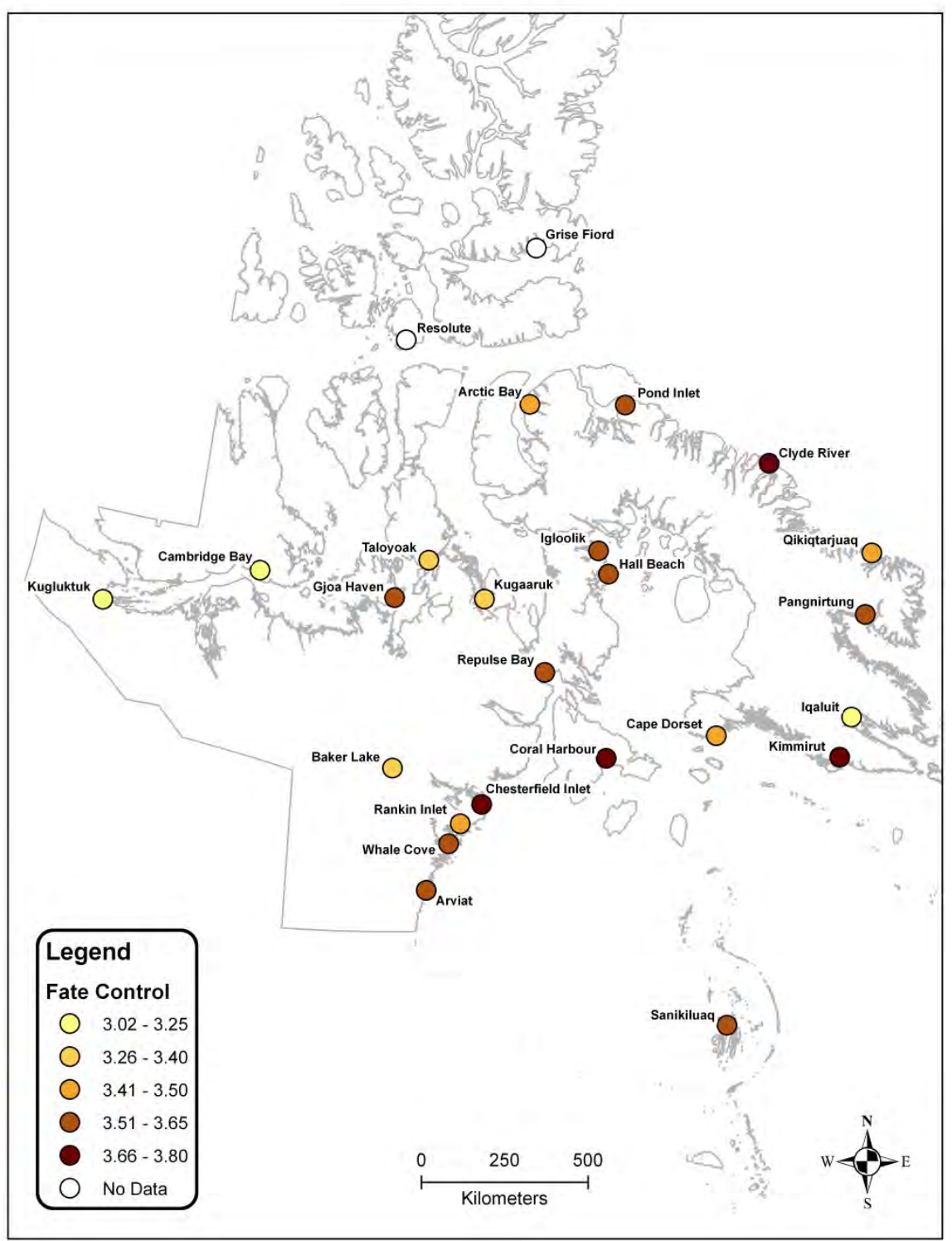


16B: Per Capita Household Income

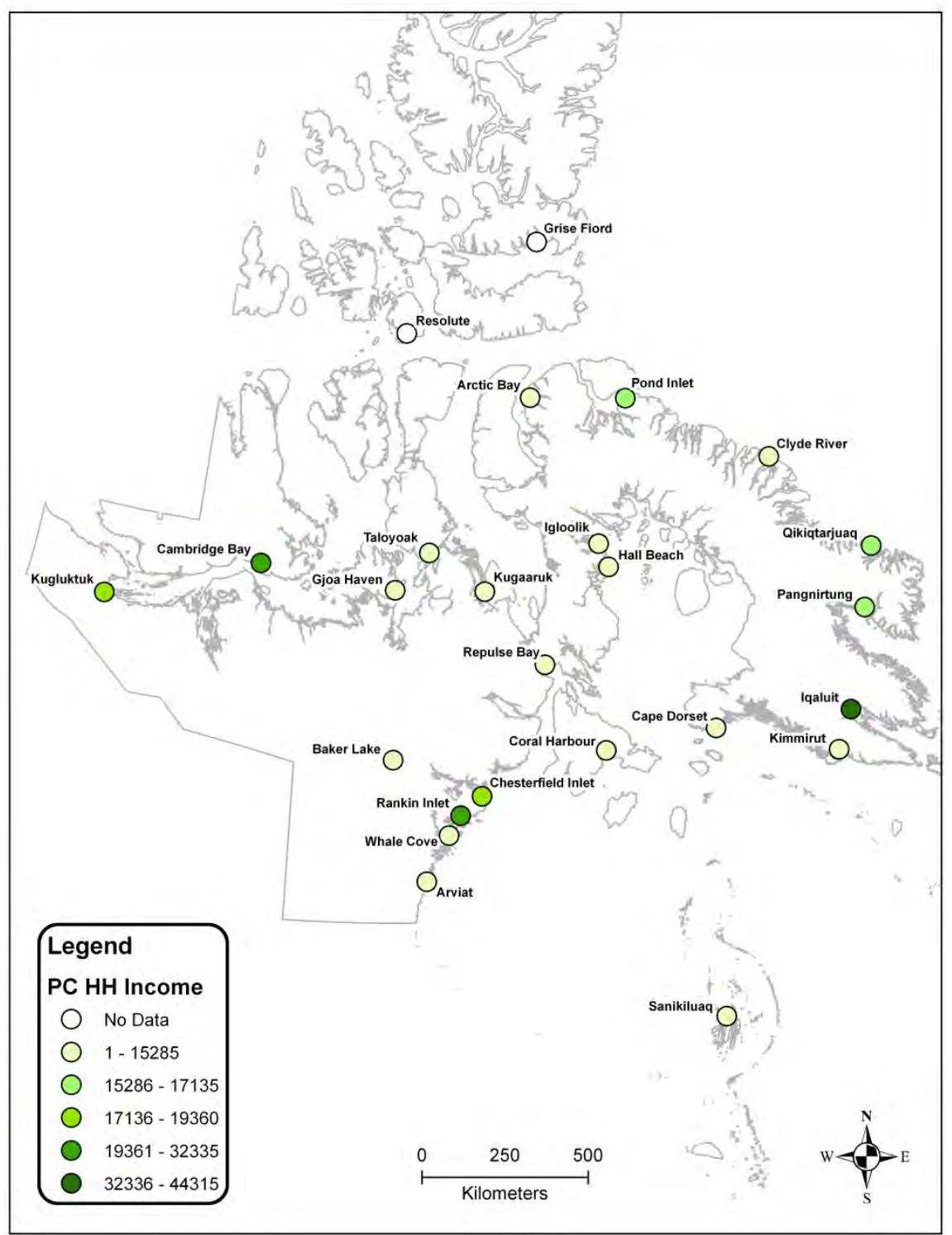




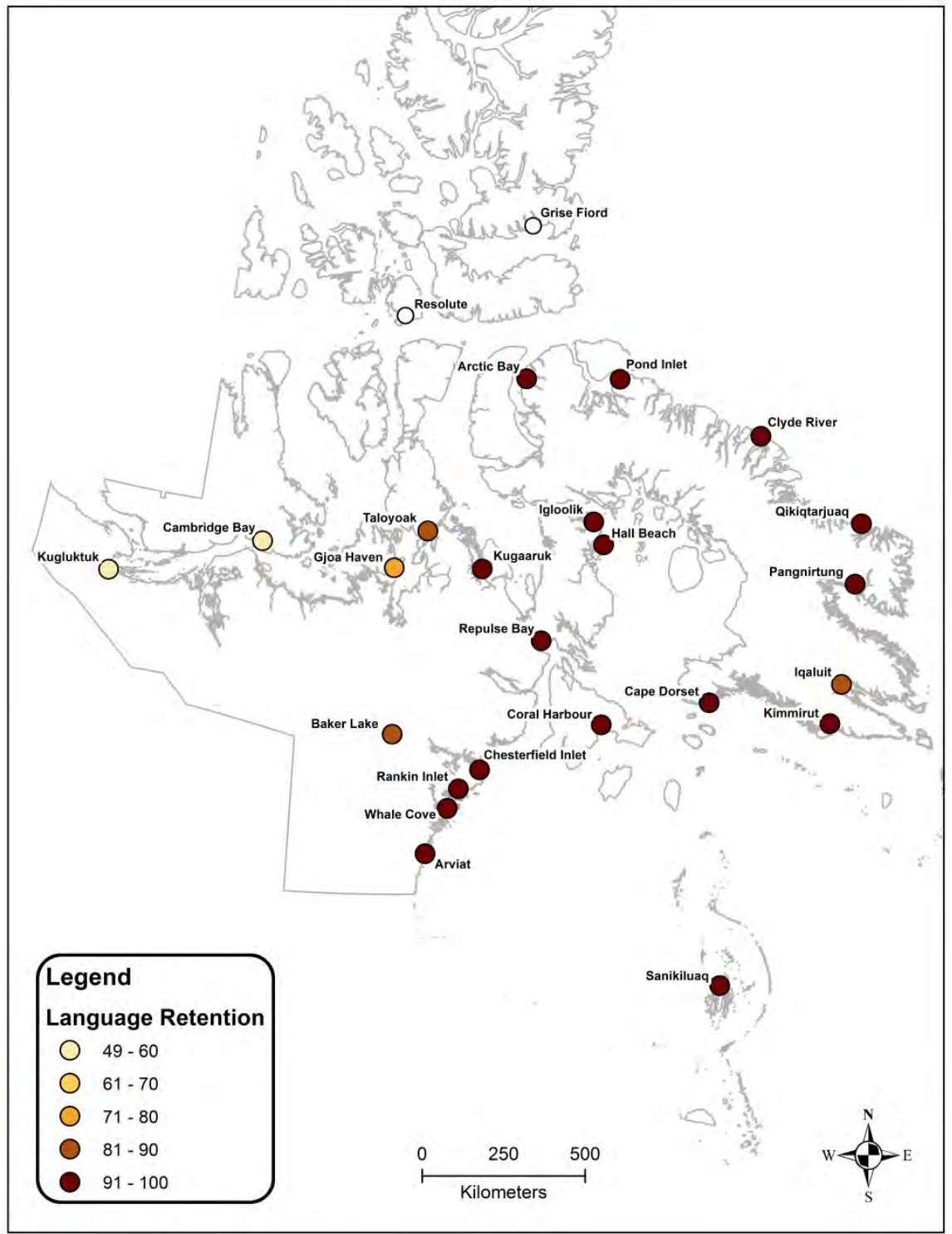

\subsubsection{Limitations}

The limitations of this case study on the NWT in Canada reflect the limitations of the indicator method in general. Indicators are meant to be the best proxy indicator of a trend or situation over time. The effectiveness of indicators in portraying a general, accurate and detailed characterization of a region over time depends on the quality of the data available. For some domains we were able to use data for the entire population of a region, while for others the only data available were for Aboriginal 
populations. Some indicators are more relevant to Aboriginal populations than to non-Aboriginal populations (e.g., language retention rates). Therefore, some of our findings relate to the NWT population as a whole, while others provide a better understanding of Aboriginal wellbeing trends only.

\subsubsection{Summary and Conclusions}

The NWT presents a case of a relatively data-rich region, thus serving as a good demonstration case study for applying Arctic social indicators. It is important that in most instances we were able to develop regionspecific indicators (or proxies) that follow the recommendations of the ASI Report. This confirms the success of the ASI project in providing a social indicators framework that is compatible with available data from existing sources in both geographical and temporal dimensions. The primary data challenge facing the application of Arctic social indicators is the variability and evolving nature of definitions and data collection methods utilized by different sources, which complicate interregional and longitudinal analyses. However, with these limitations in mind, the case of the NWT gives an opportunity to implement ASI indicators to a relatively high degree and assess their utility for monitoring the socioeconomic wellbeing of Arctic residents. We conclude that ASI indicators are suitable for monitoring human development. We also conclude that sufficient data exist that can be applied to construct indicators from all six domains but that population size and composition, as well as regional differences, are all significant variables and should be given particular attention. When using the ASI framework, the overall assessment of human development in the NWT suggests that NWT residents face considerable challenges in terms of their wellbeing and prosperity. Most measures put the NWT behind Canadian national indicators and reveal an unsettling picture of socio-economic conditions. At the same time, recent trends appear to have a positive vector in most of the measured domains. Over the last two decades substantial gains were made in fate control. These gains, however, coincided with rather stagnant material wellbeing and diminishing vitality of Aboriginal cultures (as measured by language retention rates).

This chapter analyzed six domains of social indicators for the Northwest Territories, Canada. High quality and availability of Canadian statistics permit a relatively complete study of social wellbeing that deploys most of indicators recommended by ASI. We were also able to trace the changes in several key indicators over the course of a 15 year period. 
Overall, this analysis confirms the utility and usability of ASI indicators. The goal of ASI was to develop a set of indicators that could be applied to different Arctic regions and time frames by relying on existing and continuously updated datasets. In the Canadian context, where data are rich, one could implement a more comprehensive set of social wellbeing measures than those recommended by the ASI. However, this would greatly complicate comparability with other regions, including those presented in this volume.

The main patterns of social wellbeing in the NWT could be described as follows. First, we observe that many of the domains demonstrate a rather problematic picture with below-expected levels of social wellbeing, such as low incomes, high unemployment and out-migration, and dwindling language retention. Second, there are stark regional differences and disparities among the most prosperous communities, especially in the capital, regional centers, boom resource towns, and the rest of the communities, many of which are remote Aboriginal settlements.

NWT communities do not perform well in respect to health and demographics. The NWT has a high Teenager Birth Rate (TBR), which reaches 8.4 per 1,000 . Sixty-five \% of communities have exceptionally high TBR, which are above the NWT average. The NWT also demonstrates very high suicide rates, which generally follow the pattern of other health indicators demonstrating a poorer state of mental wellbeing in smaller Aboriginal communities. In addition, significant outmigration is a reality for most small remote communities.

Economic wellbeing measured by per capita household income in smaller, predominantly Aboriginal communities is lower, even when incorporating transfer payments. The highest ranking communities for economic wellbeing include Yellowknife, Inuvik, Hay River, Fort Smith and Fort Simpson, which are settlements with the most developed wage sector and considerably sized labor markets. Job scarcity results in limited earned income received by residents of remote, largely Aboriginal communities. As a result, population in these communities experience high unemployment rates and tend to depend on government transfer payments, and therefore exhibit higher vulnerability to outside political and economic forces when maintaining living standards.

We found that the geography of material wellbeing in the NWT remained fairly constant over the last 15 years, although the discrepancy between poorest and richest communities slightly increased, highlighting a trend of increasing disparity in material wellbeing. Most substantial income gains are found in the richest communities, which are also administrative and economic centers. Unemployment rates in the Terri- 
tory between 1991 and 2006 remained virtually unchanged, although some communities saw improvement.

In terms of cultural wellbeing we found that language vitality is the highest in communities where Aboriginal people are predominant. Stronger erosion of Aboriginal languages is observed in Yellowknife and other larger towns. Language retention levels are also surprisingly low in some Aboriginal communities, such as Aklavik and Tuktoyaktuk. Between 1991 and 2006 we observe an evident decline in language retention rates. In other words, based on the language retention indicator the cultural wellbeing of Aboriginal people in the NWT had declined during that period of time.

The contact with nature indicator follows the general geography of Aboriginal population distribution and community size and location. Larger towns with few Aboriginal households exhibited very low levels of contact with nature. In contrast, in more remote, Aboriginaldominated communities the majority of households were consuming meat and fish obtained through traditional fishing and hunting activities.

In respect to education, both high school and university degree attainment rates indicate a persistent education gap between NWT communities and the rest of Canada, as well as disparities within the NWT. The education gap leads to continual earning and employment gaps that most profoundly affect isolated communities and population groups with low access to education and training.

Finally, the Fate Control Index demonstrates differences between the capital city and a few territorial towns and Aboriginal communities. The latter have higher levels of cultural wellbeing and stronger control over their local affairs but lack economic self-sufficiency. Aboriginal communities, such as Deline, Whati, Gameti, and Behchoko, show the highest composite fate control. We also observed a very modest increase in fate control associated with settling CLCAs. This, however, was offset by declining language retention. The NWT has developed a unique consensus governance system consisting of 7 regional Aboriginal governments, each in various stages of negotiating self-governance. We recognize and speculate that this may have an impact on perceptions and measures of fate control in the NWT. However, our fate control index did not detect that impact. Changing the indicator in an attempt to capture that impact would jeopardize comparisons across the Arctic region. The analysis unveils strong and persistent regional differences within the NWT. Material wellbeing indicators show that the NWT is firmly divided into a small group of "haves" (Yellowknife, Inuvik, Hay River) and a large group of "have-nots". Whereas the traditional economy provides a way to maintain material 
wellbeing, disengagement of the local labor force with the wage sector is a serious problem. The wage, education and employment gaps persist. The "have-not" communities, particularly remote Aboriginal settlements, have limited resources and exhibit dependency on government transfers, which negatively affect material wellbeing and fate control. Still, they lead the NWT in terms of contact with nature and cultural vitality. A solution for these communities, perhaps, can be found in reconciling traditional lifestyles and activities with the "capitalist" economy by intertwining these two sectors with economic, institutional and social ties.

\subsection{References}

AHDR (Arctic Human Development Report). (2004). Stefansson Arctic Institute. Akureyri, Iceland.

Arctic Social Indicators (ASI). (2010). TemaNord: 519. Nordic Council of Ministers. Copenhagen.

DuPlessis, H. M. Bell, \& R. Richards, T. (1997). Adolescent Pregnancy: Understanding the Impact of Age and Race on Outcomes. Journal of Adolescent Health, 20(3), 187-197. http://dx.doi.org/10.1016/S1054-139X(96)00174-7

Larsen, J., Schweitzer, P., \& Fondahl, G. (Eds.) (2010). Arctic Social Indicators (ASI) A Follow-up to the AHDR. TemaNord: 519. Nordic Council of Ministers. Copenhagen.

Louv, R. (2008). Last Child in the Woods: Saving Our Children From Nature-Deficit Disorder. Algonquin Books; Updated and Expanded edition.

NWT Bureau of Statistics. (2009). Community Survey 2009. 20, 2012. Retrieved from http://www.statsnwt.ca/recent_surveys on June 20, 2012.

NWT Bureau of Statistics. (2012). Bureau of Statistics. Retrieved from http://www.statsnwt.ca on June 20, 2012.

NWT Bureau of Statistics. (2011). Bureau of Statistics [Data File]. Retrieved from http://www.stats.gov.nt.ca

NWT Government. (2011). Government of the Northwest Territories Official Languages. http://www.gov.nt.ca/active.htm

Petrov, A. (2008). A talent in the cold? Creative class and the future of the Canadian North. ARCTIC - Journal of the Arctic Institute of North America. 61(2), 162-176.

Petrov, A. (2010). Post-staple bust: modeling economic effects of mine closures and post-mine demographic shifts in an arctic economy (Yukon). Polar Geography, 33, 39-61. http://dx.doi.org/10.1080/1088937X.2010.494850

Statistics Canada. (1991). 2B Profile, 1991 - Canada, Using E-STAT (distributor). Statistics Canada. (2008a). Aboriginal Population Profile, 2006 Census. Catalogue Number 92-594-XWE, Ottawa.

Statistics Canada. (2008b). 2006 Community Profiles. Catalogue Number 92-591XWE, Ottawa.

Statistics Canada. (2009). Aboriginal Peoples Survey, 2006. Catalogue Number 89-637XWE, Ottawa.

Statistics Canada. (2012). Census Profile, 2011. Catalogue Number 98-316-XWE, Ottawa. 
Statistics Canada (2006). Statistics Canada [Data File]. Retrieved from http://estat.statcan.gc.ca/cgi-win/cnsmcgi.pgm

Statistic Canada (2011). Statistics Canada [Data File]. Retrieved from http://www.statcan.gc.ca/start-debut-eng.html.

Ulvevadet, B., Klokov, K. (2004). Family-based reindeer herding and hunting economies, and the status and management of wild reindeer/caribou populations. Arctic Council/Centre for Saami Studies, Tromsø, Norway. 


\section{West-Nordic Region}

Rasmus Ole Rasmussen, Nordregio, Stockholm, Sweden; Johanna Roto, Nordregio, Stockholm, Sweden; Lawrence C. Hamilton, University of New Hampshire, USA.

\subsection{Introduction: The West-Nordic Region}

\section{The concept}

In this study the West-Nordic Region encompasses the following countries: the Faroe Islands, Greenland, Iceland and coastal Western Norway. Collectively, these nations of the North Atlantic region cover a very large geographical area. The sea is an important component connecting these territorial areas as it contains fisheries and marine resources as well as signifies historical and modern mobility.

The four countries share strong historical and cultural bonds, as well as basic natural and economic conditions. The special cultural and geographic realities of the Faroe Islands, Greenland and Iceland were subject to political discussions of the early 1980s. Subsequently, the three countries agreed to establish a joint parliamentary organization. The chief aim was cooperation on common issues including West Nordic, or North Atlantic, issues with the Nordic Council and other organizations. The West Nordic Parliamentarian Council of Cooperation was formed in 1985. In 1997 the name was changed to the West Nordic Council when the member parliaments approved the Council's present Charter.

The main objectives of the West Nordic Council are: to promote West Nordic (North Atlantic) interests; to be guardians of North Atlantic resources and North Atlantic culture and to help promoting West Nordic interests through the West Nordic governments - not least with regards to the serious issues of resource management, pollution etc.; to follow up on the government's West Nordic cooperation; to work with the Nordic Council and to be the West Nordic link in Nordic cooperation; and to act as the parliamentary link for inter-West Nordic organizations, including Arctic parliamentary cooperation. 


\section{The West-Nordic Region in the Arctic}

The West-Nordic Region is comprised of Greenland, Iceland, the Faroe Islands and Norway; all of which are being represented in the Arctic Council, with Iceland and Norway participating as individual countries. Greenland and the Faroe Islands are represented as part of the delegation of the Kingdom of Denmark. The map below shows what is generally recognized as the Arctic region: Iceland, the Faroe Islands and Greenland, plus the northernmost regions of Norway, Sweden and Finland (i.e. north of the black line crossing the three countries on Map 1 below signifies the section of the three countries often referred to as "North Calotte"). This division, however, crosses what is generally recognized as being the southern limit of the Sápmi (shown by the blue line on the map). 
Map 1: The Nordic-Arctic Region

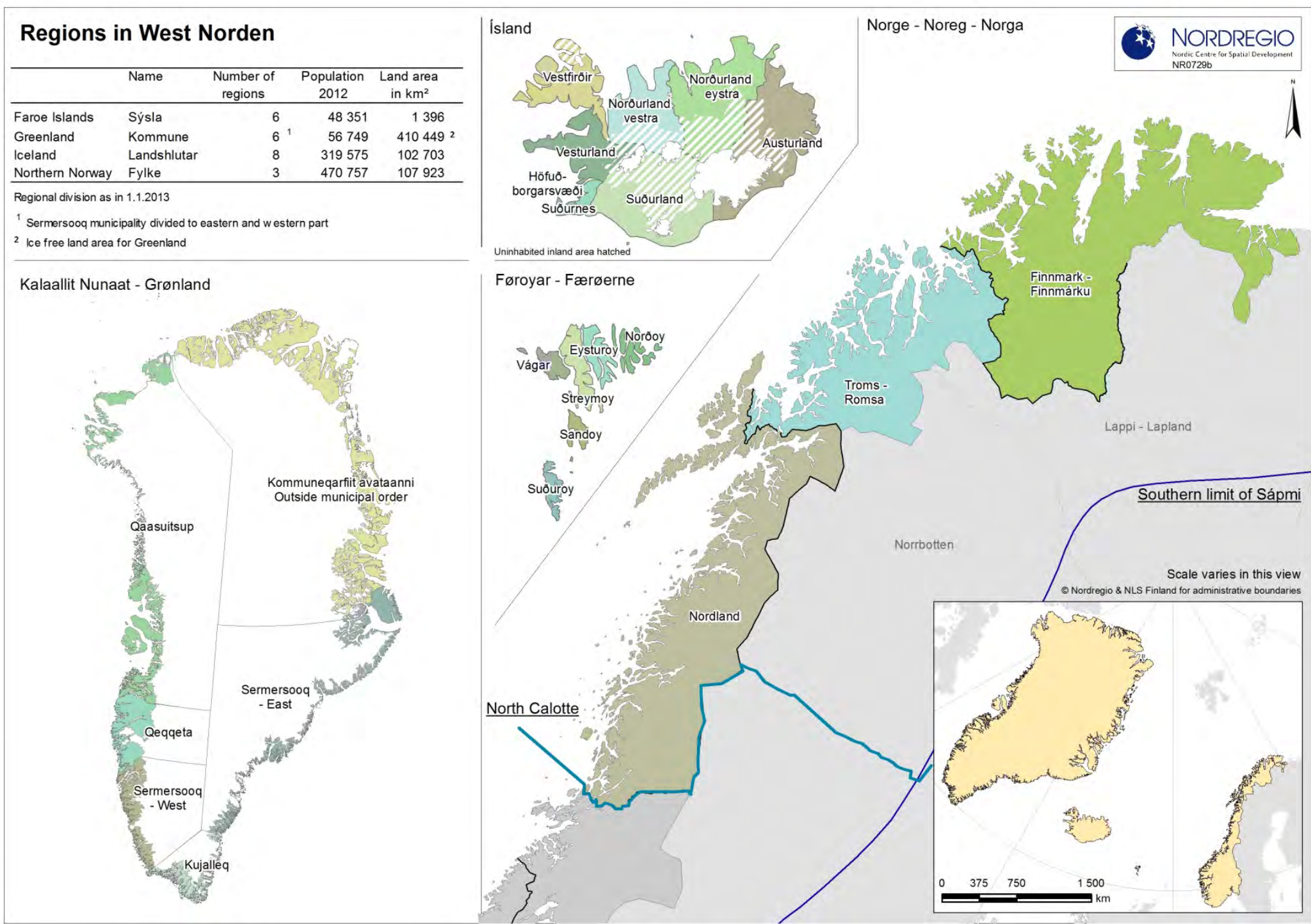


The region encompasses Greenland, the Faroe Islands, Iceland and the northern counties of Finnmark, Troms and Nordland in Norway (shown on Map 1). Also note that the Northeast part of Greenland is an uninhabited National Park outside the municipal structure. The color coding and signatures shown in the maps displaying thematic characteristics refer to populations living outside the municipalities, such as those living on bases or weather stations.

The map shows the overall administrative division in the West Nordic region. If not otherwise mentioned, the analysis in this chapter will follow the regional division presented above. The Faroe Islands, Iceland and coastal Norway are included and represented at the regional level. In the case of Norway we have included only the most northern three counties officially situated in the Arctic region. Greenland is included at the municipal level, according to the present municipal structure established in 2009 comprising four municipalities, but we have subdivided the largest municipality of Sermersooq into its Eastern and Western parts in order to show the remarkable differences between east and west within this new and geographically large municipality.

Focusing on the West-Nordic region has advantages for presenting important variations in the Arctic setting. It is, however, also a challenge as it means having to deal with several options that complicate the analyses. Different political bodies, such as nation states, the Nordic Council, and three self-governing areas; indigenous as well as non-indigenous peoples; and greatly differing environmental and social conditions must all be taken into account. The present study needs to reflect this complexity when testing the applicability and, especially, the comparability of the proposed ASI indicators. 
A village in the Faroe Islands situated between the lowland for farming, the mountains for grazing, and the sea for fishing

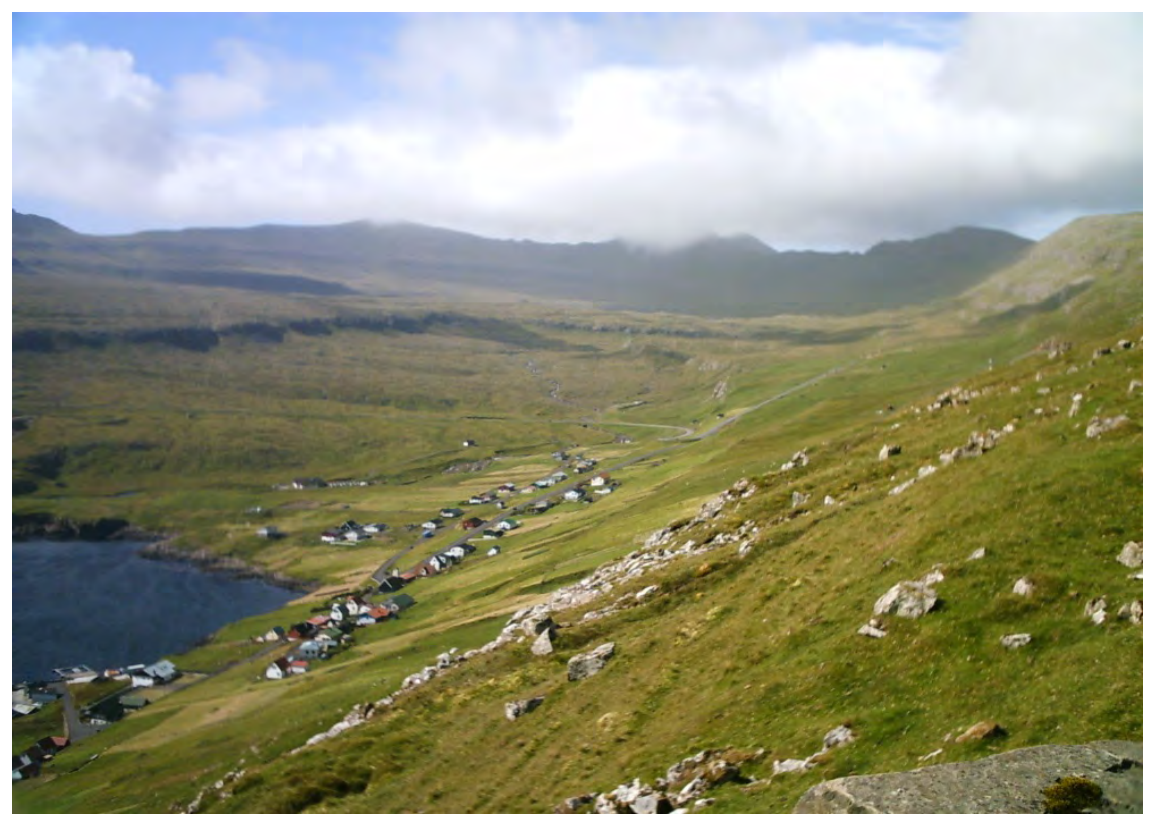

Photo: Rasmus Ole Rasmussen.

\section{The framework}

Understanding the development characteristics of the West-Nordic region is difficult without seeing the development in a general Nordic perspective. The trends and patterns of regional development do in many ways reflect the general Nordic setting, shaped by the specific geographical situation in each of the regions. Moreover, the historical background - especially cooperation through the Nordic Council and the Nordic Council of Ministers - both creates and maintains marked similarities. The background and characteristics of this cooperation are discussed further in the final sections of this volume.

Demographic and socio-economic development in the Nordic countries shows both similarities and differences when compared with other Arctic regions. Ageing has become an issue of common concern, as it has in other parts of Northern Europe. Life expectancy at birth in the Nordic region remains high compared to both the Arctic and most European countries.

The combination of reliance on renewable resources, the characteristics of island settlements, and a history of economic dependency has resulted in internal and external relations that influence the population structure today. Due to the size and level of isolation of communities a number of demographic challenges are more clearly exposed in the re- 
gion, sometimes to a degree that presents challenges for the future existence of settlements.

Access to education and skilled employment has impacted the age structure of the region. Young adults are mobile and can migrate temporarily - or, with increasing frequency, permanently - to find better education and jobs. There are marked differences in gender approaches to issues, such as education, job requirements and access to cultural opportunities, which give rise to migration-related gender imbalances that have become an issue for many communities.

\section{Settlement structures}

Before analyzing the applicability of ASI indicators, some remarks regarding the overall structure of the region would be useful. Map 2 shows the settlement population distribution as of 2005. The circles in the map show the location of all built-up areas in the northernmost parts of the Nordic Countries with more than 200 inhabitants. The area of the circle is proportional to the total number of inhabitants in a given settlement. In addition, the rate of population change is shown by colours to illustrate that trends also vary significantly, contributing to demographic polarization.

The settlement structure with small, often isolated villages, larger regional towns, and a capital city, has been a characteristic pattern in the West-Nordic region for centuries. Presently it shows a process of change, with growing populations in larger centres, and a reduction in the size of villages. Villages are typically small settlements with populations below 1,000 inhabitants. Many villages were established along with developments in fisheries or agriculture, which remain important activities, although newer activities like tourism have become dominant in some places. Depending on local resources, processing industries are also a source of some job creation. Some villages may be able to provide different kinds of services, such as a convenience store, a nursing home and sometimes a kindergarten. If there is a school it would typically provide teaching up to 6 th or 7 th grade. A nurse and/or midwife may be available but this usually depends on the accessibility to a nearby centre. Sometimes there may be homes for elders. In many Greenlandic villages there also are service houses that provide facilities for laundry, baths, and so forth.

Towns are settlements with one to ten thousand inhabitants, often serving as transportation and administrative hubs for a number of villages. Towns provide a variety of services, such as nursing homes, kindergartens and schools. In Greenland towns often have a dormitory where children from villages can stay during the week while attending school. Towns may have vocational training schools and, in larger places, also high 
schools. Health and social services include a branch of a regional hospital, nurses, doctors etc., and homes for the elderly. In many cases, towns are also regional centres with administrative functions providing a number of jobs as well. In the West-Nordic region a number of municipal reforms over the past 20 years have resulted in circumstances where the precise identification of an administrative hierarchy connected to specific places cannot be made in the same way as it was 25 years ago, although its functions have remained more or less the same.

Cities are usually identified as capital areas with a range of administrative functions. They differ markedly in size, however, and also in scope of their services available. Norwegian West-Nordic cities differ from Reykjavik, Torshavn and Nuuk because the latter places are government cities and at the same time act as regional hubs. While there are several places in West-Nordic Norway that are considered to be cities, each have administrative duties at a level that is lower when compared with the national center in Oslo. 


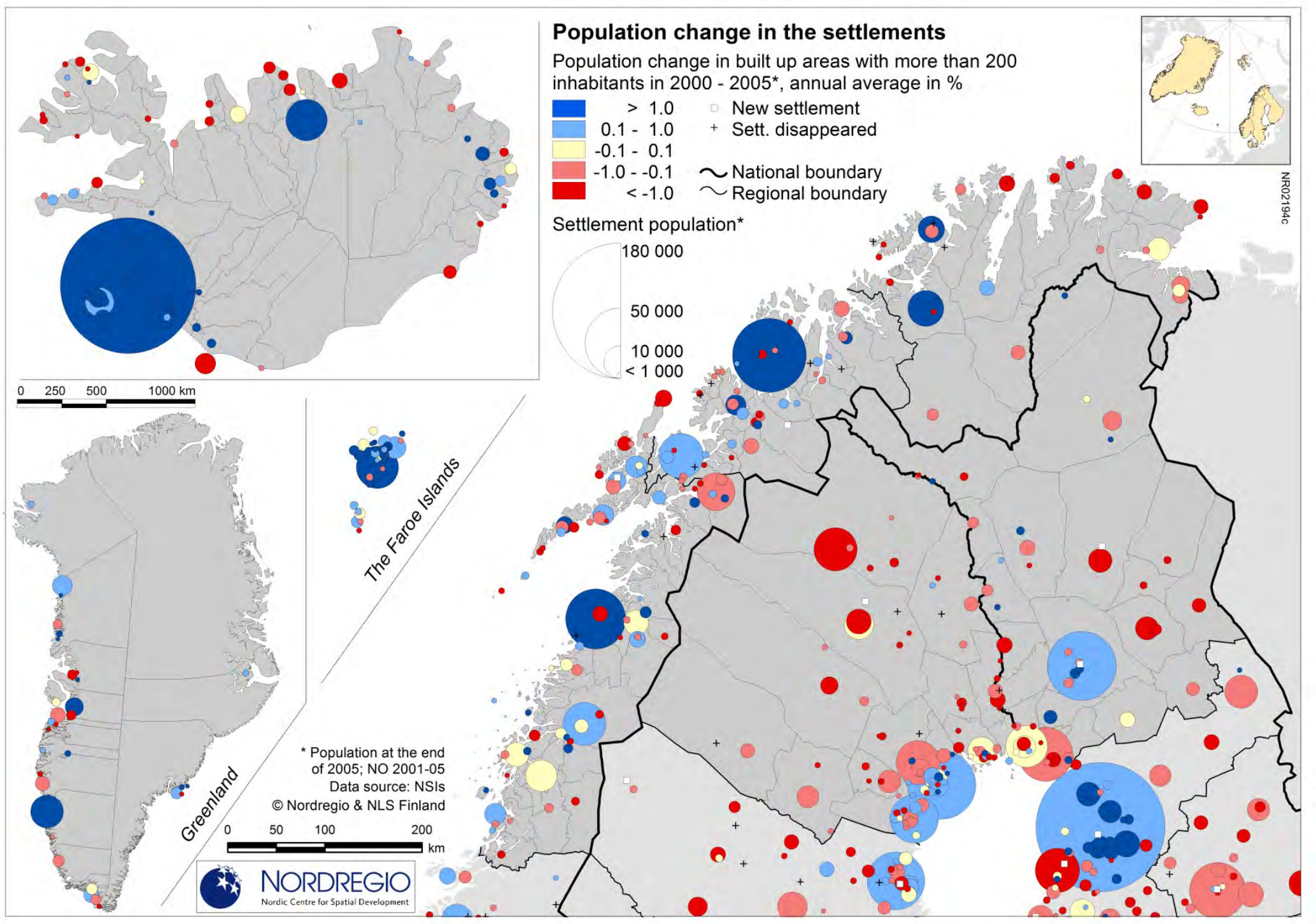


It is important to emphasize that aside from this general description of a settlement structure, there are marked differences between both countries and regions within countries. Access to transportation is decisive for services and the role of the settlement within an administrative hierarchy. Greenland presents the most extreme case by far, as none of its settlements are connected by roads.

\section{Demographic parameters of change}

Demography is a major parameter of West-Nordic change. The region is entering the final stage of the Demographic Transition model: decreasing mortality, as well as decreasing births, eventually leading to a low natural rate of growth. Norway has the lowest birth rate. Greenland and the Faroe Islands are higher, while Icelandic birth rates fall between these extremes. Death rates are exceptionally low in the Nordic countries, and comparable to that of Japan. The situation in the Faroe Islands resembles Iceland when it comes to birth rate (relatively low), while it resembles Greenland in relation to death rate (relatively higher). As a consequence it has a lower natural growth rate than Greenland and Iceland. At the same time there are close relations between the general population development of the Faroe Islands and crises in the fisheries, which can account for some of the most marked variations, especially during the late 1980s and the beginning of the 1990s. Finally, Greenland has maintained the highest birth rate, combined with a death rate similar to the situation in the Faroe Islands, leading to the highest natural growth rate among the four West-Nordic countries. For both Greenland and the Faroe Islands, lifestyle diseases in combination with an ageing population increase the death rate, and in recent years it has reached the same level as the Norwegian average. Similarly, birth rates are converging in the four countries.

A general characteristic of the West-Nordic region is the relatively high proportion of children and young persons when compared with other Nordic or northern European areas. This reflects relatively higher birth rates in particular. Although this pattern has changed markedly during the last decade the average age in West-Nordic regions remains well below that of other Nordic regions. Important sub-regional differences exist too, however, especially with regard to rurality/urbanity. In the case of Greenland, the central region in West Greenland, and especially the capital region, is by far the largest urban area with a family structure similar to that of Nordic countries overall. Greater differences occur in the eastern and northern parts of Greenland where the young account for a higher proportion of the population.

By January 2012 the average age in the West-Nordic region was 38.1 years as shown on Map 3, which is young when compared to other Nordic 
or European Countries. The population is rapidly ageing, however, as shown on Map 4. During a 10 year period, from 2002 to 2012, the average age increased by 1.2 years. In sparsely populated regions like Vestfirðir (Iceland) and Sandoy (the Faroe Islands), however, the average rose by more than three years. In the Faroe Islands a pattern of ageing in remote and rural regions is quite clear whereas the capital region has maintained a relatively younger population (by West-Nordic standards) due to high in-migration of younger persons, primarily from more remote Faroese places. 
Map 3: Average age of the population in the West-Nordic Region

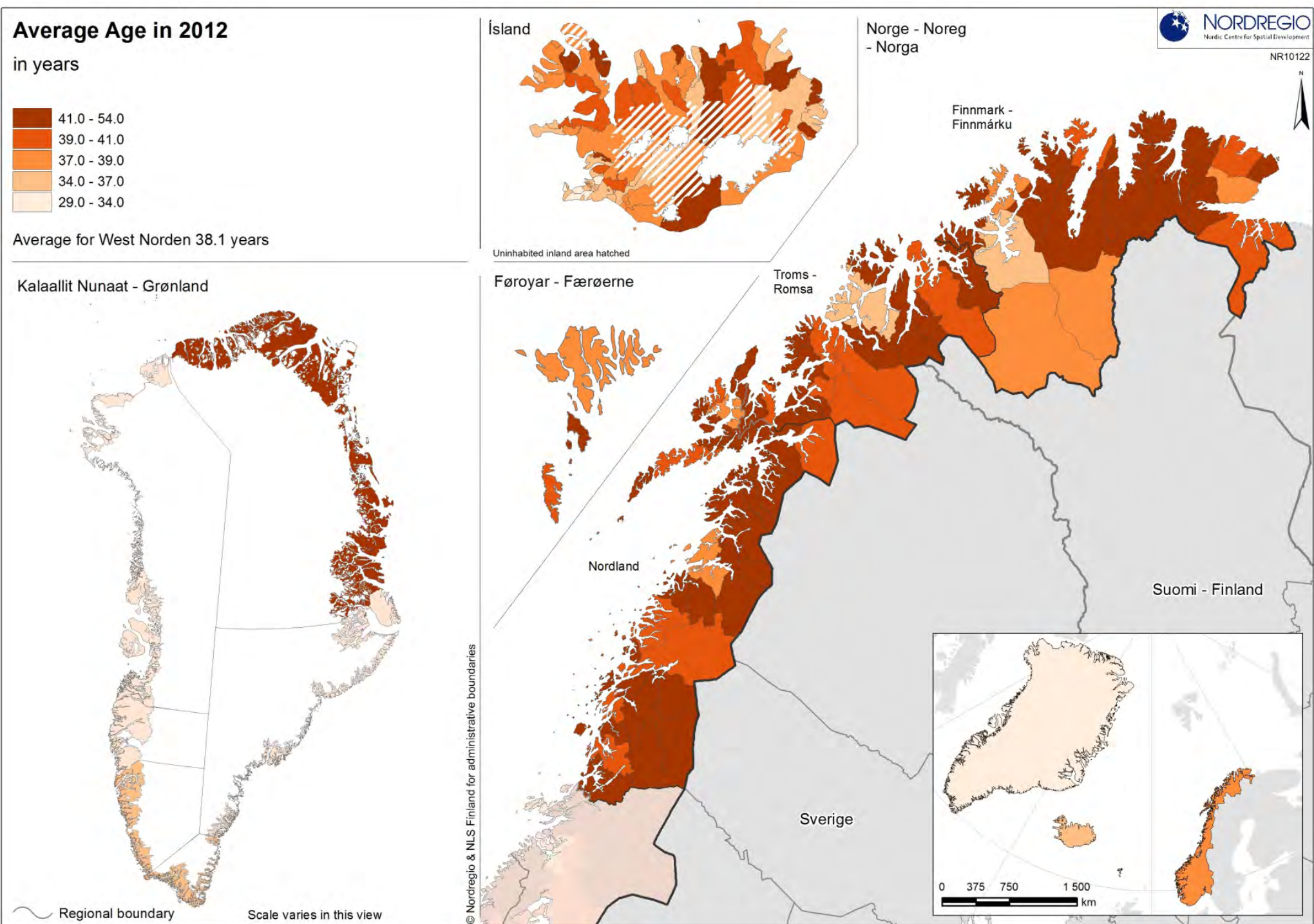


Map 4: Change in average age from 2002 to 2012 in the West-Nordic Region

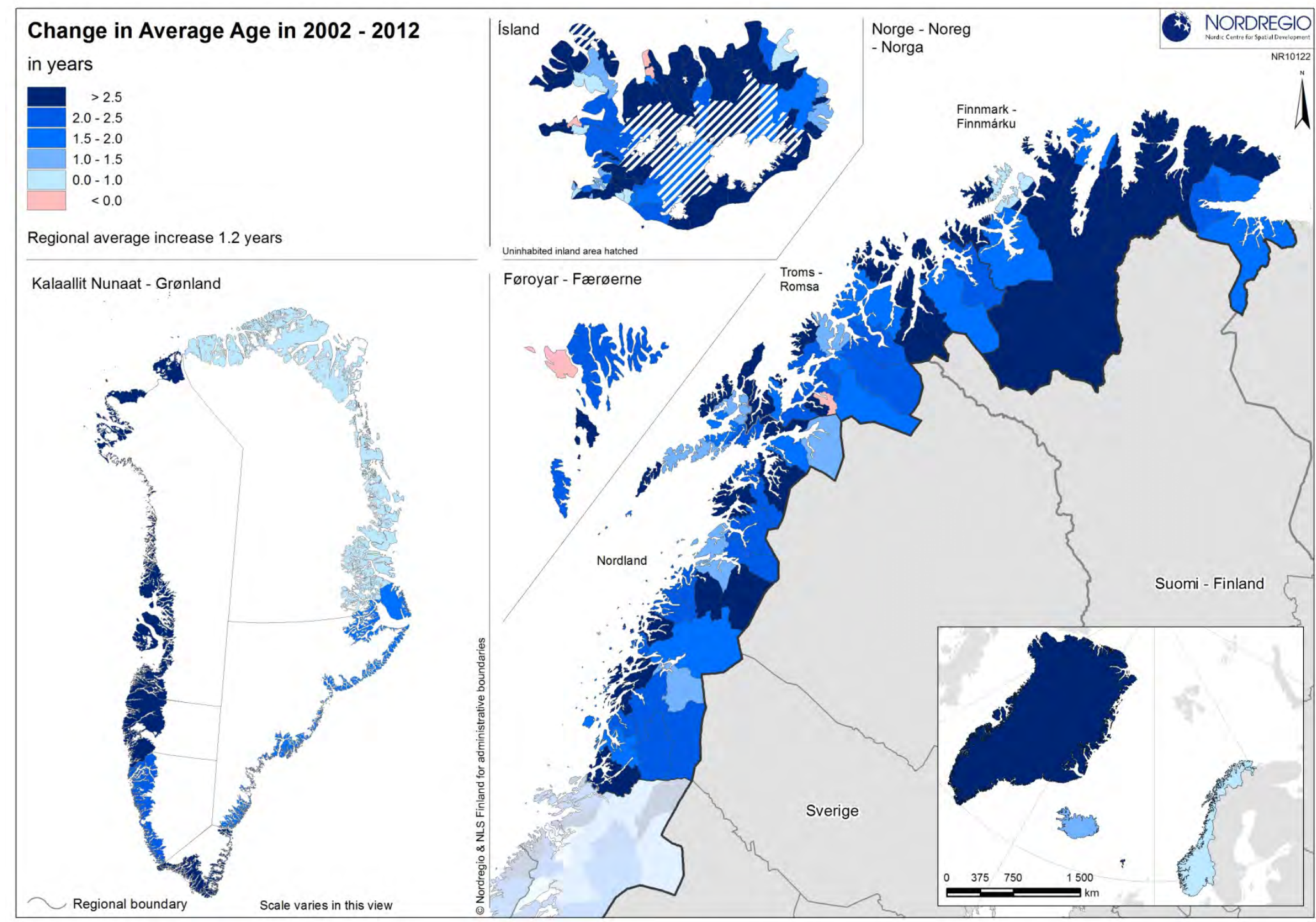


A major factor for ageing and migration patterns has been the attraction of urban centres, especially the capital areas. A clear pattern of rural or "peripheral" versus urban or "central" municipalities emerges, with the former characterized by net out-migration and the latter by inmigration. Gender differences appear in migration patterns as well. Males tend to move shorter distances, and more frequently return to their places of origin. Females, on the other hand, often follow the "stepstone" pattern of migration, from smaller places to local centres, then regional centres, to the capital region, and eventually out of the country.

Mobility is substantially higher than the average level in Nordic countries. This partly reflects the limited services available in smaller communities, including jobs, educational opportunities or special medical services. This generally reflects accessibility. Distances and infrastructure limit opportunities for commuting.

Mobility between countries is shaped by history and traditions established during centuries of colonial and semi-colonial relations. As a consequence it is difficult to look at migration within the West-Nordic region without also considering Denmark, which brings forward two issues. First we have the importance of migration or demographic mobility between Denmark, the Faroe Islands and Greenland. The connection to Denmark is crucial in many respects: education, family relations, retirement, etc. As a consequence there are connections between the labour markets of Greenland, the Faroe Islands and Denmark.

Another issue has been the recent economic crisis, which first of all hit Iceland, but also impacted other parts of the West-Nordic region, leading to increased out-migration.

Global migration has been of growing importance to the region and several groups have played increasingly influential roles in the development process. Among these groups two should be emphasized: immigrants from Thailand, who are predominantly female; and immigrants from Poland, who are predominantly male. From 1998 to 2009 the total number of Thai citizens settled in the far north, i.e. Greenland, Iceland, the Faroe Island and Svalbard increased from 356 to 824 persons.

The consequences of demographic changes have been, as mentioned, the marked increase in the elderly population and therefore an increase in the dependency ratio also. There are some differences within the West-Nordic region, with a relatively low proportion of elders in Greenland, a higher proportion in Iceland, an even higher proportion in the Faroe Islands, and the highest proportion in Norway. Although the older population tends to be more dependent in national terms, they may contribute to local economies in several ways. For example, pensions pro- 
vide cash income to elderly people and their families. They may also contribute to subsistence activities.

\section{Ethnicity}

Two Indigenous Peoples are recognized within the West-Nordic region the Kalaalit or Greenlanders in Greenland, and the Sami in Norway, Sweden, Finland and Russia.

In Greenland, ethnic classifications as "European", "Greenlander" and "Mixed" had been concepts used throughout the whole period of colonialism. But as the colonial system did not have to comply with any legal framework in Denmark, it was up to the representatives of the Colonial Government to interpret who was a Greenlander, who was Mixed, and who was European. For statistical purposes and local administration the registration of persons in Greenland has traditionally used classifications including Greenlander, European or Mixed, but such classification has never been applied on the basis of genealogy, i.e. identification of family relations or fractions of "blood" relations to Greenlandic ancestors.

The question of knowing who is a Greenlander and who is not was introduced in Greenland in connection with the modernization process, whereby persons for the building industry were hired from Denmark and paid according to wage levels in Denmark. Greenlanders working in the same building industry, however, were paid salaries complying with the level in Greenland, and the official reason for this difference were that the two groups of persons (Greenlanders and Non-Greenlanders) represented two different labour markets. To establish a "legal" background for this, the place of birth was established as the means of deciding which salary should be paid. The "Birthplace criteria" was obviously discriminatory and clearly seen as such by the Greenlanders themselves.

The main problem of actually registering who was considered a Greenlander or born in Greenland first became an issue when the formal colonial system was abolished in 1953, when Greenland became a county in Denmark, because from then on the legal setting from Denmark became the law in Greenland. There were many situations where laws in Denmark were "not applicable in Greenland", but the non-discriminatory laws based on a person's ethnic origin in the Danish system could not have been surpassed by special laws for Greenland. People were registered by "Public Registration", a central system fed by information from the municipalities, where a person's name, address, etc. were kept on files. When Greenland became a county of Denmark the system necessarily started including Greenlanders. However, the system had not been constructed in a way that included any ethnic information or details about personal relations. 
The present system of unique Personal ID numbers was introduced in Denmark in 1968 and established in Greenland in 1972. The system has unique information for all persons, including their place of birth, spouses, education, children, and so forth. In the first version for Greenland the ID number indicated whether a person was born in Greenland, but due to protests from Greenland this was changed in the final system. As a result, no ethnic references exist in the system. If distinctions are needed, only the place of birth enables some kind of registration. The Faroese rejected the system and therefore it is not possible to make similar analyses in the Faroe Islands.

As a consequence it is not possible to identify ethnicity through the system. Any child bore by Greenlanders or Danes will be registered as "born in Greenland" if that is the case, while similarly a person of any parentage could be registered as "born outside Greenland". Many ethnic Greenlanders studying in Denmark will have children born in Denmark. Consequently, these children will maintain a registration of being "born in Denmark", regardless of living in Denmark or returning to Greenland, and therefore will be effectively counted as a Dane in some statistics. Similarly, many Danes working for some years in Greenland may choose to have a child while staying there. If so, this child will be registered as being "born in Greenland", and therefore counted as a Greenlander in some statistics.

As with the case of Greenland, a general question exists concerning who are to be identified as being Sami and how many Sami there really are. As emphasized by the Nordic Sami Institute, there are several reasons why such questions are difficult to answer. People hold different perceptions about what are the requirements of being Sami, not only at the individual level but especially in relation to the institutionalization of the concept.

At the individual level the history of "Norwegisation", i.e. the idea of turning the Norwegian population into a common concept of "being a Norwegian", has been crucial. Seen from a Sami perspective this policy created pressure to abandon Sami culture and identity, and at times even to hide their identity.

In conjunction with this official policy there have been only vague attempts to institutionalize the concept and to try to officially register people as Sami. Until the 1930s a number of attempts were made, with some material gathered, although these were never very systematic or coherent. According to recent calculations the Sami Parliament in Norway suggests that there are about 100,000 Sami, while the Sami Parliament in Sweden calculates that the Sami population totals around 80,000 persons, of which 2,000 are in Russia (Kola Peninsula), 8,000 are 
in Finland, 20,000 are in Sweden, and somewhere around 50,00065,000 are in Norway.

Due to complications over definitions and registration, available statistics can be limited or difficult to interpret. Statistics Norway is able to provide some simple numbers in situations where registration has been possible. This, for instance includes the following (2007):

- Registered for voting to the Sameting: 12,650 .

- Children in Sami kindergartens: 1,150.

- People involved in reindeer related activities: 2,820.

- Children in school with Sami as a first language: 990.

- Children in school with Sami as a second language: 1,650.

\subsection{Data and Methodology}

This chapter attempts to apply the indicators selected and identified in the Arctic Social Indicators project (ASI Phase 1; Larsen et al., 2010) to the West-Nordic region. Difficulties in data collection for some of the indicators are discussed and suggested revisions to these are brought forward. Whenever it has been possible we have applied the preferred ASI indicator, as shown in the first column in Figure 1 below. In some cases we have had to adjust the indicator due to lack of data availability, and in a few cases we have elaborated on some alternative indicators. 
Figure 1: The preferred and selected indicators

\begin{tabular}{|c|c|c|c|c|}
\hline \multicolumn{5}{|c|}{ Preferred and Selected Indicators } \\
\hline DOMAIN & $\begin{array}{c}\text { PREFERRED } \\
\text { INDICATOR (ASI 2010) }\end{array}$ & $\begin{array}{l}\text { West-Nordic Region } \\
\text { INDCATOR } 1\end{array}$ & $\begin{array}{l}\text { West-Nordic Region } \\
\text { INDICATOR } 2\end{array}$ & $\begin{array}{l}\text { West-Nordic Region } \\
\text { INDICATOR } 3\end{array}$ \\
\hline Health \& Population & Infant Mortality & Infant Mortality & Suicide Rate & Net Migration \\
\hline Material well-being & $\begin{array}{l}\text { Per capita Household } \\
\text { Income }\end{array}$ & $\begin{array}{l}\text { Average taxable } \\
\text { income per capita }\end{array}$ & Unemployment rate & \\
\hline Education & $\begin{array}{l}\text { Ratio of Students } \\
\text { Completing Post- } \\
\text { Secondary Education }\end{array}$ & $\begin{array}{l}\text { Ratio of tertiary level } \\
\text { educated population } \\
\text { aged } 25+\end{array}$ & $\begin{array}{l}\text { Share of female } \\
\text { students in \% }\end{array}$ & $\begin{array}{l}\text { Access to higher } \\
\text { education institutions } \\
\text { within country/region }\end{array}$ \\
\hline Cultural Vitality & Language Retention & Language Retention & $\begin{array}{l}\text { Accessibility to } \\
\text { traditional foods }\end{array}$ & \\
\hline Contact with Nature & \begin{tabular}{|c|} 
Consumption of \\
Traditional Food / \\
Harvest of Traditional \\
Foods
\end{tabular} & $\begin{array}{l}\text { Harvest of traditional } \\
\text { foods }\end{array}$ & $\begin{array}{c}\% \text { of population } \\
\text { accessing traditional } \\
\text { food }\end{array}$ & \\
\hline Fate Control & Fate Control Index* & Fate Control Index & & \\
\hline \multicolumn{5}{|c|}{$\begin{array}{l}{ }^{*} \text { Fate control index defined as: a) The percentage of indigenous members in governing bodies (municipal,community, regional) relative to the percentage of the } \\
\text { indigenous people in the total population; b) The percentage of surface lands legally controlled by the inhabitants through public governments, Native corporations, } \\
\text { and obshchiny; c) The percentage of public expenses within the region (regional government, municipal taxes, community sales taxes) raised locally; d) The } \\
\text { percentage of individuals who speak a mother tongue (whether Native or not) in relation to the percentage of ind ividuals reporting correspond ing ethnicity }\end{array}$} \\
\hline \multicolumn{5}{|c|}{ Data sources } \\
\hline \multicolumn{5}{|c|}{ National Statistical Authorities in Norway, Iceland, Greenland and Faroe Islands. Register data with yearly updates } \\
\hline $\begin{array}{l}\text { For specific references, see } \\
\text { caption below }\end{array}$ & $\begin{array}{l}\text { Food Retai-shop branch } \\
\text { statistics (1) }\end{array}$ & $\begin{array}{c}\text { Mobility in Greenland. } \\
\text { Survey (2) }\end{array}$ & $\begin{array}{l}\text { Hunter- and fishermen } \\
\text { survey in combination } \\
\text { with official hunting and } \\
\text { fishing statistics (3) }\end{array}$ & SLICA (4) \\
\hline
\end{tabular}

As indicated in Figure 1 all the preferred indicators have been applied to the West-Nordic region but for some of them minor adjustments have been necessary. In most cases it has been possible to find the indicators at the suggested regional level, but in a few cases only national data exist.

\subsection{Health and Population Domain}

The chosen indicator for the health and population domain is the infant mortality rate, with suicide rate as a second indicator. For population dynamics the chosen indicator is net migration. Several other indicators are available, such as age structure and changes in age structure, population change, and - among the most important ones - the ageing of the population. However, net migration rate is currently the biggest challenge with out-migration of the young, especially young women. 
Figure 2: Infant mortality rates and changes in infant mortality rate from 2000 to 2012 in the West-Nordic Region

\begin{tabular}{|c|c|c|c|c|c|}
\hline \multicolumn{6}{|c|}{$\begin{array}{l}\text { Infant Mortality Rate } \\
\text { Infant deaths per } 1000 \text { births }\end{array}$} \\
\hline & 2000 & 2005 & 2010 & 2011 & 2012 \\
\hline Norway & 4,0 & 3,7 & 3,6 & 3,5 & 3,5 \\
\hline Iceland & 3,6 & 3,3 & 3,2 & 3,2 & 3,2 \\
\hline Faroe Islands & 6,9 & 6,2 & 6,2 & 6,1 & 5,9 \\
\hline Greenland & 18,3 & 15,8 & 10,3 & 10,1 & 9,8 \\
\hline
\end{tabular}

First Priority Indicator: Infant Mortality Rate. The West-Nordic region is characterized overall by low infant mortality (Figure 2), with some variations related partly to medical support. The island geography of Greenland and the Faroe Islands mean that hospitals may be hours to a full day away for many people. An increasing number of young people move to larger settlements, with health care related to childbirth and young children among the attractions. The earlier situation where childbirths were dominated by high birth rates in villages is in the process of change as more young people still choose to settle and give birth in towns with quick and easy access to medical services.

Data from Greenland serve to illustrate the differences in mortality rates between smaller and less accessible places versus middle-sized and larger towns (Figure 3). Two-year averages (2010-2011) help to smooth out the wider variations within smaller populations.

As can be seen there are marked differences between municipalities. The average for Greenland as a whole is 8.9 deaths per 1,000 live births. The only municipalities with lower mortality rates are Sermersooq west and Avataani. Sermersooq being a part of the municipality located in West Greenland, with Nuuk as its main town, shows an infant mortality of 2.1, which is even lower than the low infant mortalities in Iceland and Norway.

The other municipality, Avataanni, has a mortality rate that is comparable to Iceland and Norway. This municipality is situated in the northern part of Greenland and one explanation among others for this low level is the Thule Air Base, which is located there. Even though the base does not interfere much with the towns and villages on a daily basis it does provide top facilities and transport when needed. 
Figure 3: Average infant mortality rate in 2010 and 2011 for Greenland's municipalities subdivided on municipal total, towns and villages

\begin{tabular}{|c|r|r|r|r|r|}
\hline \multicolumn{7}{|c|}{$\begin{array}{l}\text { Infant Mortality Rate, average 2010 and } 2011 \\
\text { Infant deaths per 1 000 births }\end{array}$} \\
\hline & \multicolumn{1}{|c|}{ Kujjaleq } & Sermersooq West & Sermersooq East & \multicolumn{1}{c|}{ Qeqqata } & \multicolumn{1}{c|}{ Avataanni } \\
\hline All settlements & 11,0 & 2,1 & 16,4 & 13,2 & 3,3 \\
Towns & 5,2 & 2,0 & 8,1 & - & 3,2 \\
Villages & 17,6 & 2,2 & 23,8 & 25,0 & 3,4 \\
\hline \multicolumn{7}{|c|}{ Source: Statistics Greenland } \\
\hline
\end{tabular}

The municipality with the highest infant mortality is Sermersooq east the East Greenland part of the Sermersooq municipality - with a level of 16.4; followed by Qeqqata and Kujjaleq in Greenland West, located north and south of Sermersooq respectively. At the same time the subdivision in towns and villages reveals a much higher level for villages. However, for Sermersooq west and Avataanni the differences are only minor, and are on par with the Nordic countries in general.

Second Priority Indicator: Suicide Rate. In terms of suicide ratios there are marked differences within the West-Nordic region. Besides regional differences there is also a clear gender difference: suicide rates are markedly higher for men in all regions.

When interpreting the data from 1995 to 2009 shown in Figure 4 it is important to note that the numbers are relatively small, so they vary somewhat erratically from year to year (more so than demographic variables, such as age or net migration). Comparisons spanning several years must be interpreted with caution, as we cannot be sure without further analysis whether they represent real change or unpredictable variations.

Figure 4: Gender based changes in suicide rates 1995-2009

\begin{tabular}{|c|c|c|c|c|c|c|}
\hline \multicolumn{7}{|c|}{$\begin{array}{c}\text { Suicide Rate } \\
\text { Suicides per } 100000 \text { inhabitants }\end{array}$} \\
\hline Gender & \multicolumn{3}{|c|}{ Males } & \multicolumn{3}{|c|}{ Females } \\
\hline Year & 1995 & 2005 & 2009 & 1995 & 2005 & 2009 \\
\hline \multirow{4}{*}{$\begin{array}{c}\text { Norway } \\
\text { Iceland } \\
\text { Faroe Islands } \\
\text { Greenland }\end{array}$} & 20 & 16 & 17 & 12 & 16 & 7 \\
\hline & 18 & 16 & 18 & 2 & 6 & 4 \\
\hline & 3 & 12 & 8 & 2 & 1 & 1 \\
\hline & 171 & 89 & 100 & 54 & 86 & 27 \\
\hline \multicolumn{7}{|c|}{ Source: Norwegian, Icelandic, Greenlandic and Faroese national statistics } \\
\hline
\end{tabular}

Source: Nordic Statistical Yearbook.

Note: Faroe Islands: 1995 refers to 1996. Men 2009 refers to 2008. Women 2009 refers to 2006. Greenland: 1995 refers to 1996. Faroe Islands: Data for suicide: 2005 refers to 2006. 2009 data for men refer to 2008. 2009 data for women refer to 2006. 
Three things are clear, however. There are marked differences between the four countries with Greenland having the highest suicide rate, and the Faroe Islands the lowest. Over time there seems to be a general decline in suicide rates. And suicide rates for males are much higher than for females.

Further regional differences within the countries may provide information that can support a more detailed analysis. Regional data, however, are only available for the relatively larger populations of Norway and Iceland. These additional data lend support to some of the conclusions above. In Map 5 the regional variations in suicide in 2009 confirm two patterns noted earlier. The suicide rate is 3-4 times higher among men than women, and overall the rate of suicide has declined over the past 15 years. 


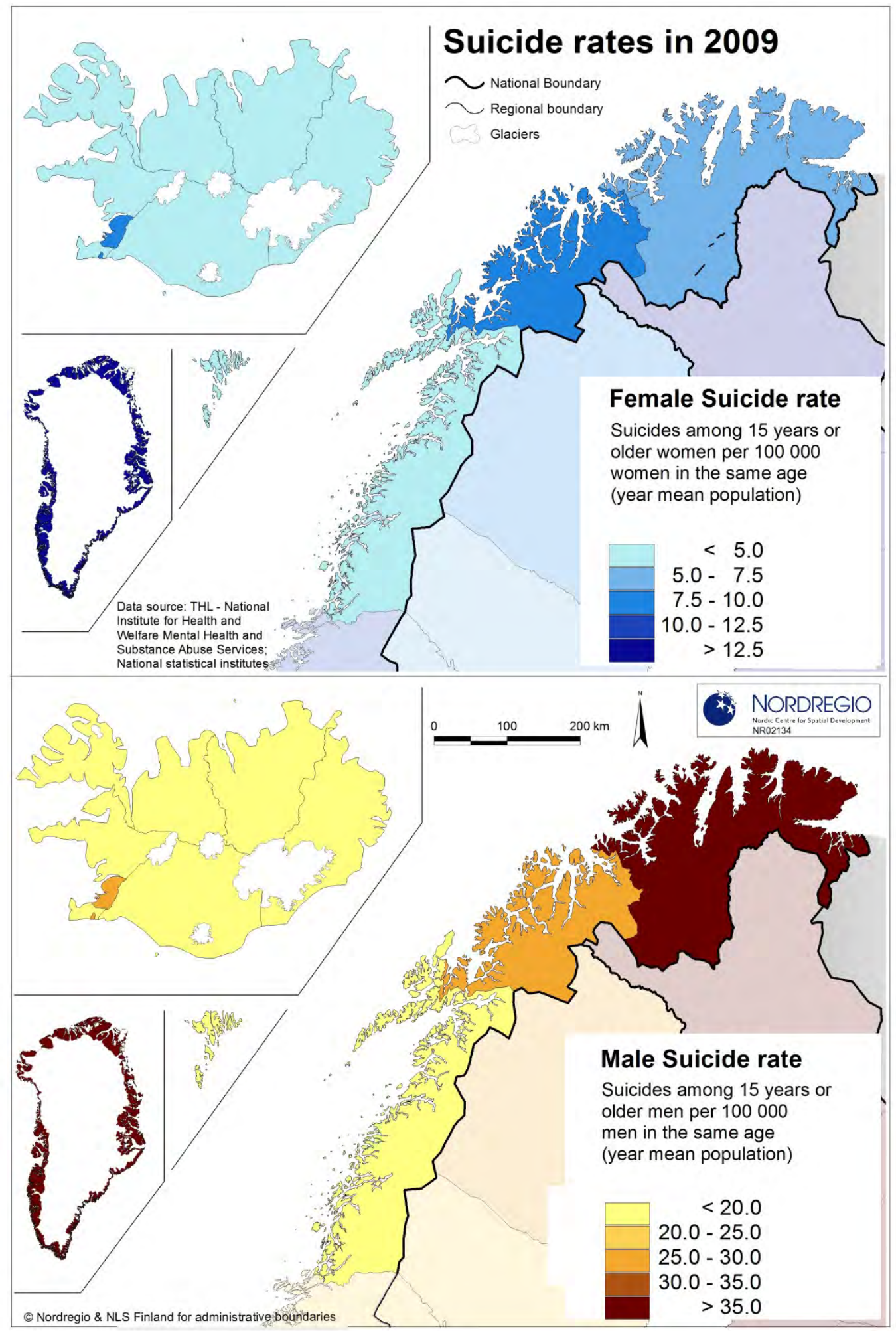


Third Priority Indicator: Net-Migration Rate. The third indicator in relation to the Health and Population domain is the net-migration rates for the period 2006-2010. Map 6 combines the two main components of migration - domestic and international migration - and shows the resulting net-migration. The blue colors indicate positive net-migration and indicate by shades which component - internal or external - has contributed the most to the result.

A dark blue color indicates positive net-migration, both due to domestic in-migration and immigration, whereas a light blue color indicates that net-migration is positive due to intensive immigration. The turquoise color indicates positive domestic in-migration that compensates emigration. 
Map 6: Migration 2006-2010 by main components

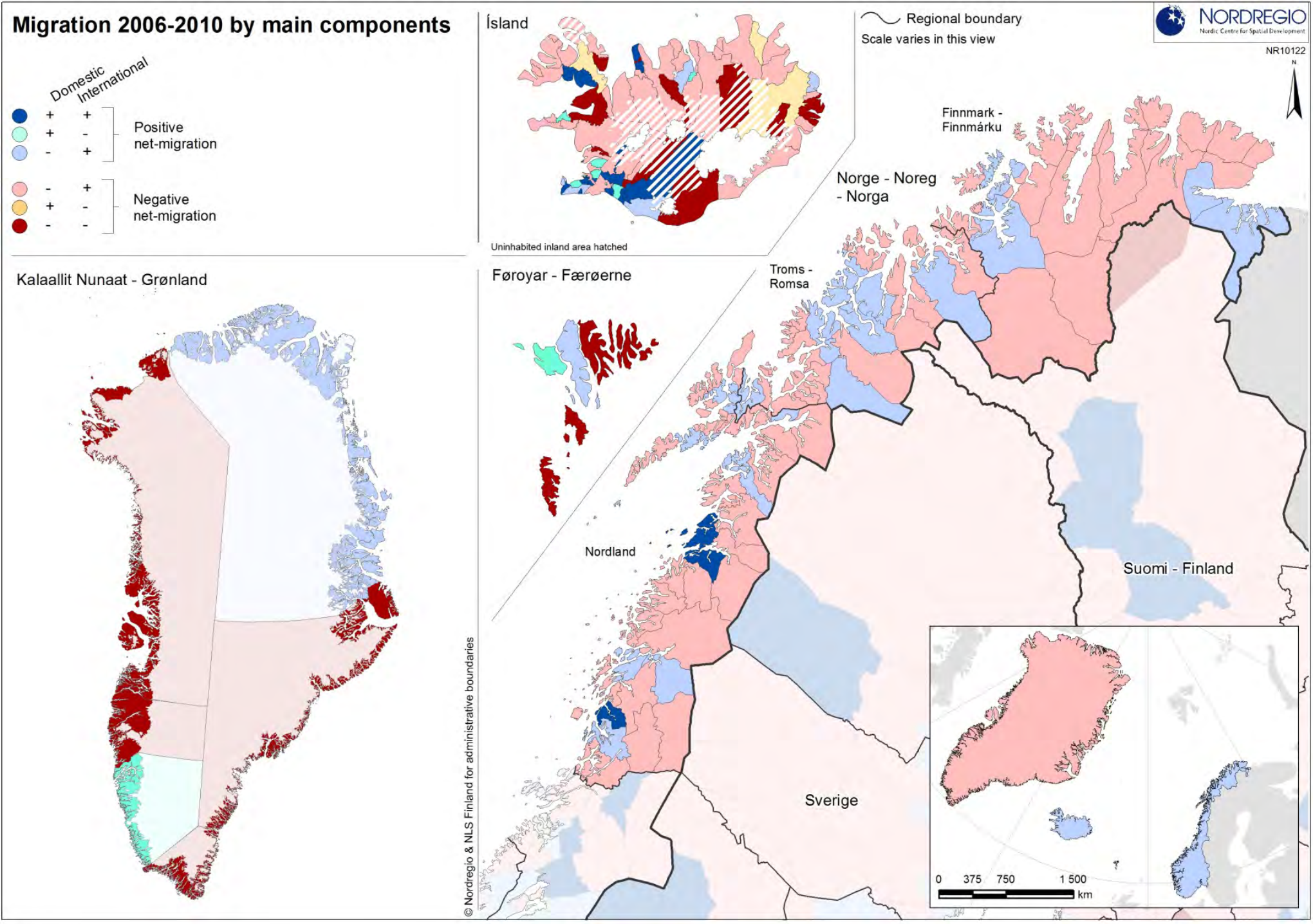


The red colors show negative net-migration with a similar use of shades: a dark red color shows negative net-migration, both due to domestic out-migration and emigration; a pink color indicates that netmigration is negative due to intensive domestic out-migration; and a light orange color indicates positive domestic in-migration that does not compensate emigration.

The whole West-Nordic region is noticeably influenced by net outmigration. This is most obvious in the cases of Iceland, the Faroe Islands and Greenland where most municipalities show negative net-migrations and generally includes both domestic and international migration as determinants. In these countries it is mostly the capital regions where positive net-migration appears. In coastal Norway a more diverse pattern of growth centres is evident, when based on levels of domestic migration, which indicates that the coastal region as such may not be experiencing net out-migration but rather a concentration of people in larger cities.

Conclusions: Three different dimensions of health. By using three ASI indicators, three different and important dimensions of the concept of health are identified in the West-Nordic region:

- Infant mortality tells us something important about physical living conditions and accessibility - whether there are access to the facilities that are needed in order to cope with critical situations in connection with birth.

- The suicide rate shows something about the capability of coping with mental conditions, especially mental stress situations. It is an indicator of the ability of a place and environment to respond to such situations.

- The net migration rate is an indicator of community health and options for maintaining viable communities where people can and will want to live and work.

All indicators are accessible through registered data and available yearly updates.

\subsection{The Material Wellbeing Domain}

While the suggested indicator for the material wellbeing domain is per capita household income, our West Nordic case study uses per capita taxable income instead. The reason for choosing per capita taxable income instead of per capita household income has first and foremost been to pro- 
vide a comparative base for future data collections. The per capita household income is influenced by changes in household structures; also ongoing changes in household size limit the comparability. Taxable income is available through registered data in all countries, which includes income from both wage work and salaries as well as other types of income, such as from hunting, fishing, agriculture etc. In addition, transfers are also included. Informal economic activities, which only encompass about $1.5 \%$ of the total income generation, may not be included.

A second indicator is the unemployment rate, which is calculated as the annual average unemployment rate for the work force (age 15-64 years). Income through salaries from formal sources is the most important economic activity, which also means that lack of income due to unemployment has large impacts on the material wellbeing.

First Priority Indicator: Average taxable income per capita. Map 7 shows the national level for Iceland, the Faroe Island and Greenland, and shows data in Coastal Norway according to the structure emphasized by the regional approach. The calculated values in national currency have been converted to US dollars to make them comparable.

The lowest value is found in Finnmark, the most northern county in Norway, while the highest value is found in the Reykjavik region in Iceland. In between these values is rural Iceland, followed by Greenland, the Faroe Islands and Nordland County in Norway at the next level. Troms County is situated next to the lowest level in Finnmark. 
Map 7: Average Taxable Income in US\$ per capita

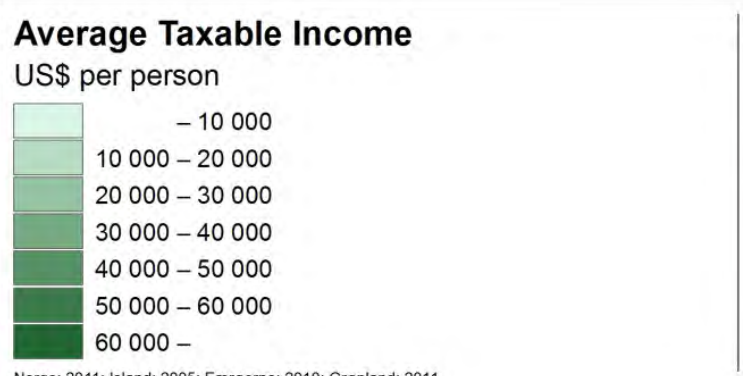

Norge: 2011; Island: 2005; Færøerne: 2010; Grønland: 2011

Kalaallit Nunaat - Grønland
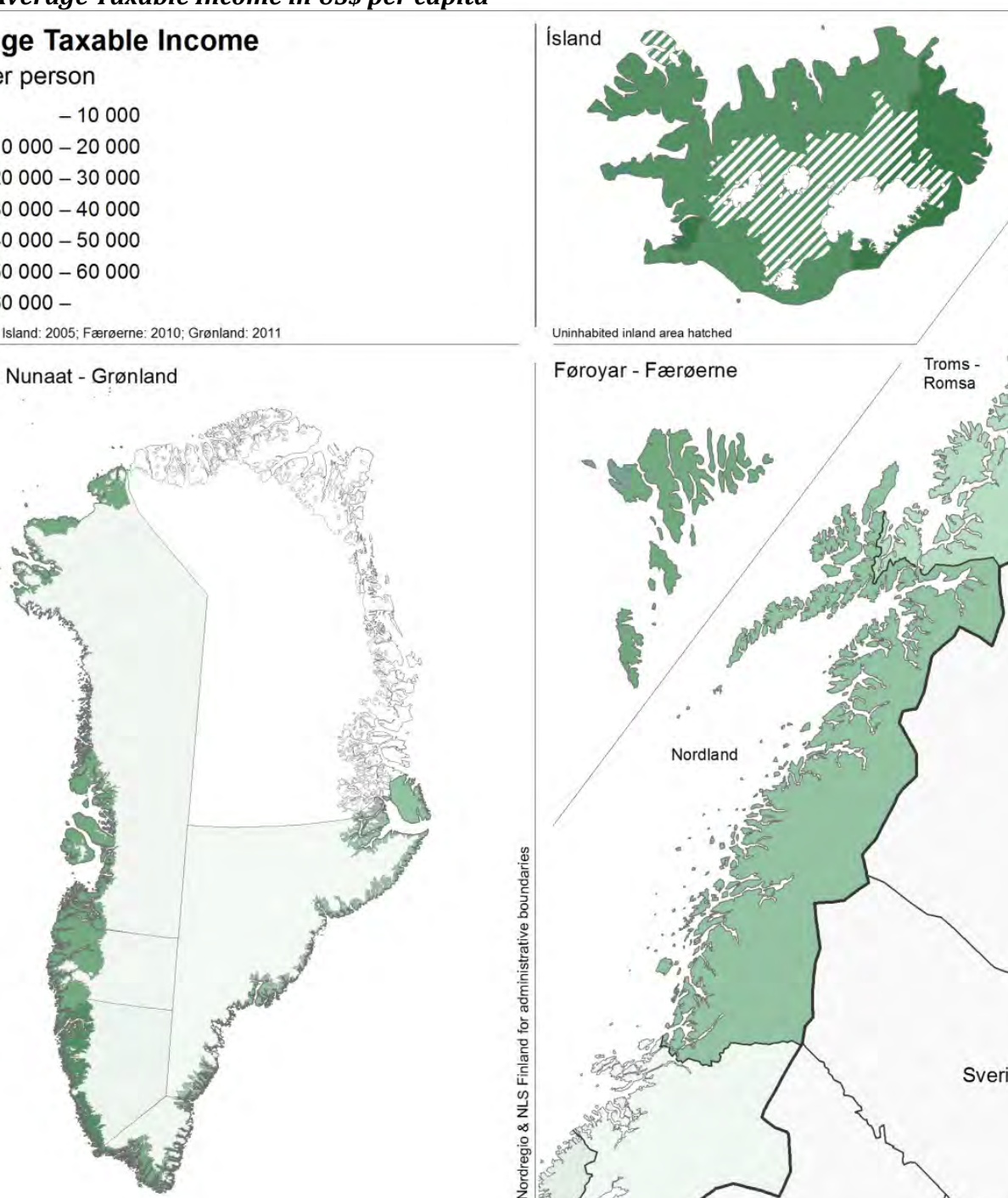

$\frown$ Regional boundary

4. NORDREGIO

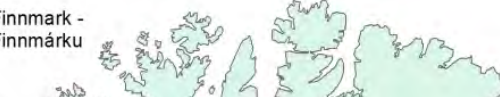

Norge - Noreg

Norga
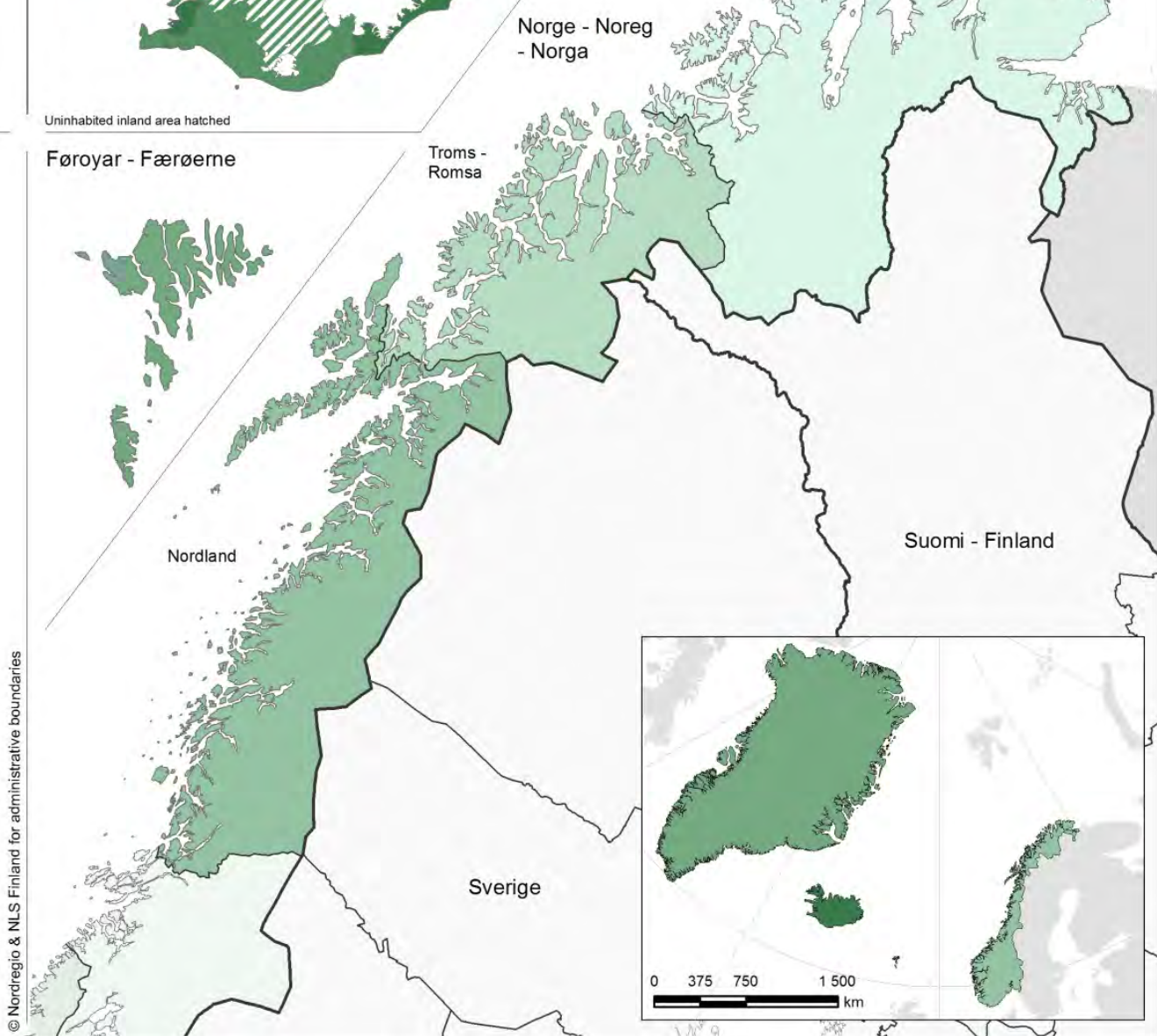

Data from Norway 2011, Iceland 2005, the Faroe Islands 2010, and Greenland 2011. 
In general, Norway has high income levels relative to other Nordic countries. A special situation exists for the most northern counties due to what is referred to as the District Policy, whereby transfer payments in different support mechanisms ensure living conditions in areas comparable with situations in more wealthy counties in the South. There may be situations where support mechanisms in some regions provide services that in other regions would be taken out of income, so simple comparisons are misleading. In situations where a different mix of services is prevalent i.e. salary and non-salary based - this may limit comparability.

The concept of poverty is much debated in relation to the Arctic. It is sometimes associated with discrimination or social exclusion but it is a common mistake to link these concepts too closely (Atkinson and Davoudi, 2000). Poverty data focuses on individuals and households, which are often easier to capture as statistical data. Social exclusion, however, often revolves around group vulnerabilities and spatial clusters of deprivation with multiple data forms, which makes it more difficult to measure.

It is important to point out that risk of poverty is not the same as being in poverty. In the Arctic community, family relations and subsistence activities provide ways of coping with income limitations. Peripheral regions, which in the North tend to have sparser populations, may also have a greater risk of poverty related to the low availability of wage work.

Second Priority Indicator: Unemployment rate. In general, all Nordic countries have unemployment rates below the EU average, and Norway has the lowest national unemployment rate in Europe. In the case of Greenland, only unemployment data for towns and cities exist. Populations in villages have limited access to unemployment benefits and are therefore not registered by the authorities.

There are clear relations between high levels of unemployment and patterns of out-migration. People with the highest level of risk of poverty are those with low incomes and a high rate of unemployment. 
Map 8: Unemployment rate for population aged 15-65 years in 2011

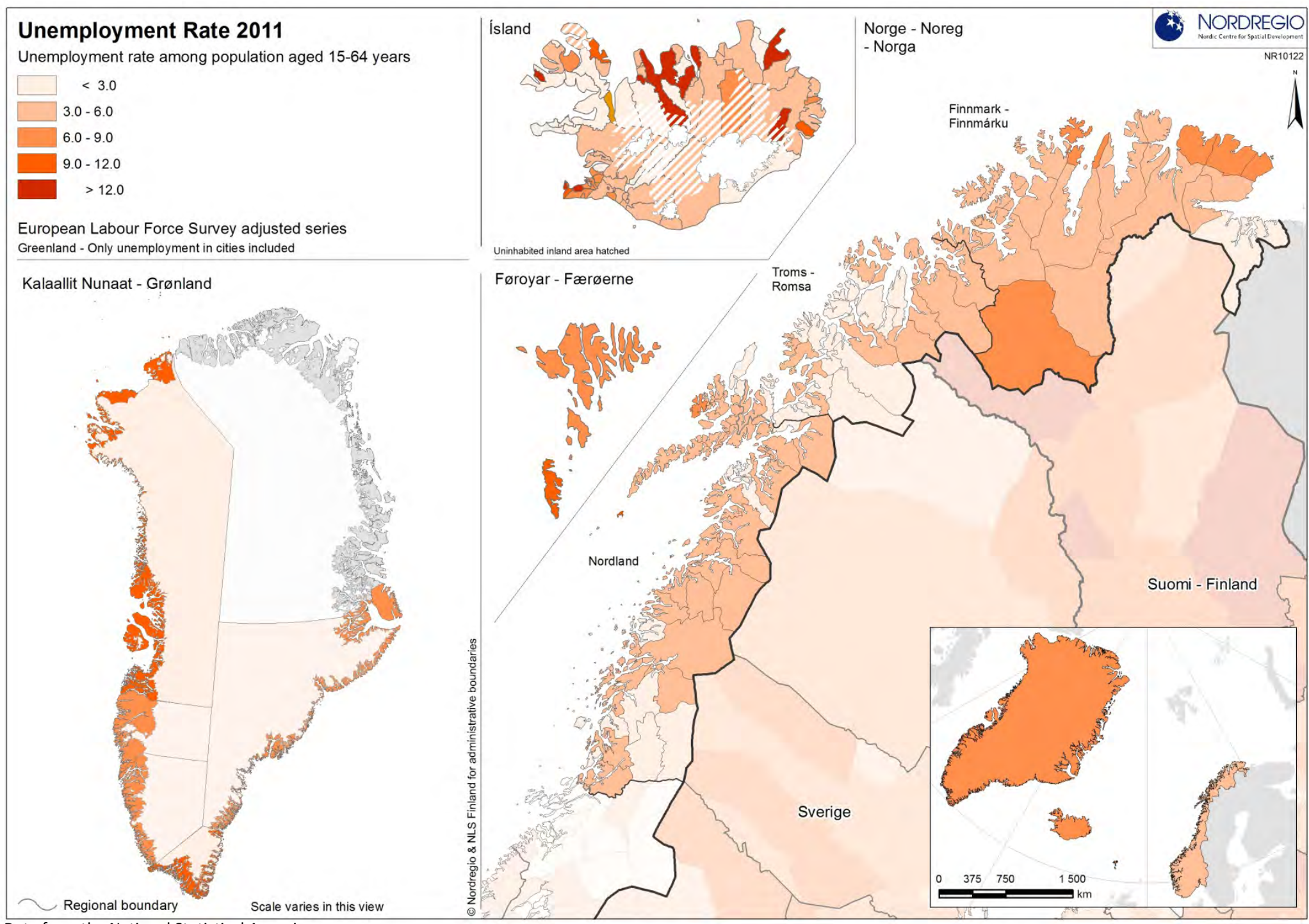

Data from the National Statistical Agencies. 


\section{Conclusions: Interrelated dimensions of Material wellbeing}

- Average taxable income per capita provides information on potential material wellbeing when wage jobs are available. It does, however, exclude material wellbeing potentially accessible through opportunities in the informal and subsistence economy.

- The unemployment rate provides information on the potential risk of not being able to realise ones income potential. However, this indicator does not include the contribution made to material wellbeing from engaging in informal and subsistence activities.

Both indicators are accessible through registered data and are available through yearly updates.

\subsection{The Education Domain}

The ratio of students successfully completing post-secondary education (persons per 1,000 population) was chosen as a preferred indicator for the Education Domain. In the West-Nordic Region the category includes levels 5 and 6 after the ISCED -1997 standard. ISCED (The International Standard Classification of Education) is a classification structure for organizing information on education and training maintained by UNESCO. Level 5 refers to first state of tertiary education that may be academically based or practically oriented / occupationally specific; whereas level 6 refers to second stage tertiary education. Commonly the two levels correspond to bachelor, master, doctoral, or equivalent degree qualifications. In Greenland the previous classification system of education is in the process of being converted into ISCED categories but at this point in time reliable data is inaccessible.

The application of the indicator to the West-Nordic Region has implied a modified version of the preferred indicator. While the preferred indicator was the completion rate, the indicator used here is the total number of persons qualified to ISCED level 5 and 6 as a percentage of persons aged 25+ in 2010. While the preferred ASI indicator shows the completion rate, it does not take into account the consequences of mobility - i.e. either out- or inmigration of persons who have acquired these skills. The number of persons with these skills is a better indicator of whether or not the situation improves or worsens in relation to educational skills. Therefore, keeping track of the number has several advantages as it tells us about the status, 
allows for a calculation of changes from one year to the next, and enables us to evaluate the direction of change in relation to migration patterns.

In addition, we have looked at the share of female students as a second indicator since the development during the last decades has shown both a substantial increase in female involvement with education, and an increase in female out-migration from the Arctic. Both parameters are therefore important for keeping track of the region's ability to respond to challenges in a "knowledge economy".

And finally we have - on a test basis - included a third indicator that focuses on access to higher education institutions within a particular country/region. Leaving a region in pursuit of higher education increases the chance of a student starting a family close to their place of education, which can decrease the likelihood of eventually returning to their region of origin.

First Priority Indicator: Ratio of tertiary level educated population aged 25+. This indicator is presented on Map 9 by means of the green colour ramp, which shows that supporting the availability of educational institutes means a marked increase in the number of persons with tertiary level education. The ISCED categories 5 and 6 include at level 5 the first state of tertiary education that may be academically based or practically oriented / occupationally specific, and level 6 referring to the second stage of tertiary education. Therefore, in addition to serving as centres for youth during their education it also attracts businesses in need of persons with tertiary level education. 
Map 9: Persons with a tertiary level of education as a share of persons aged 25+ years in 2010

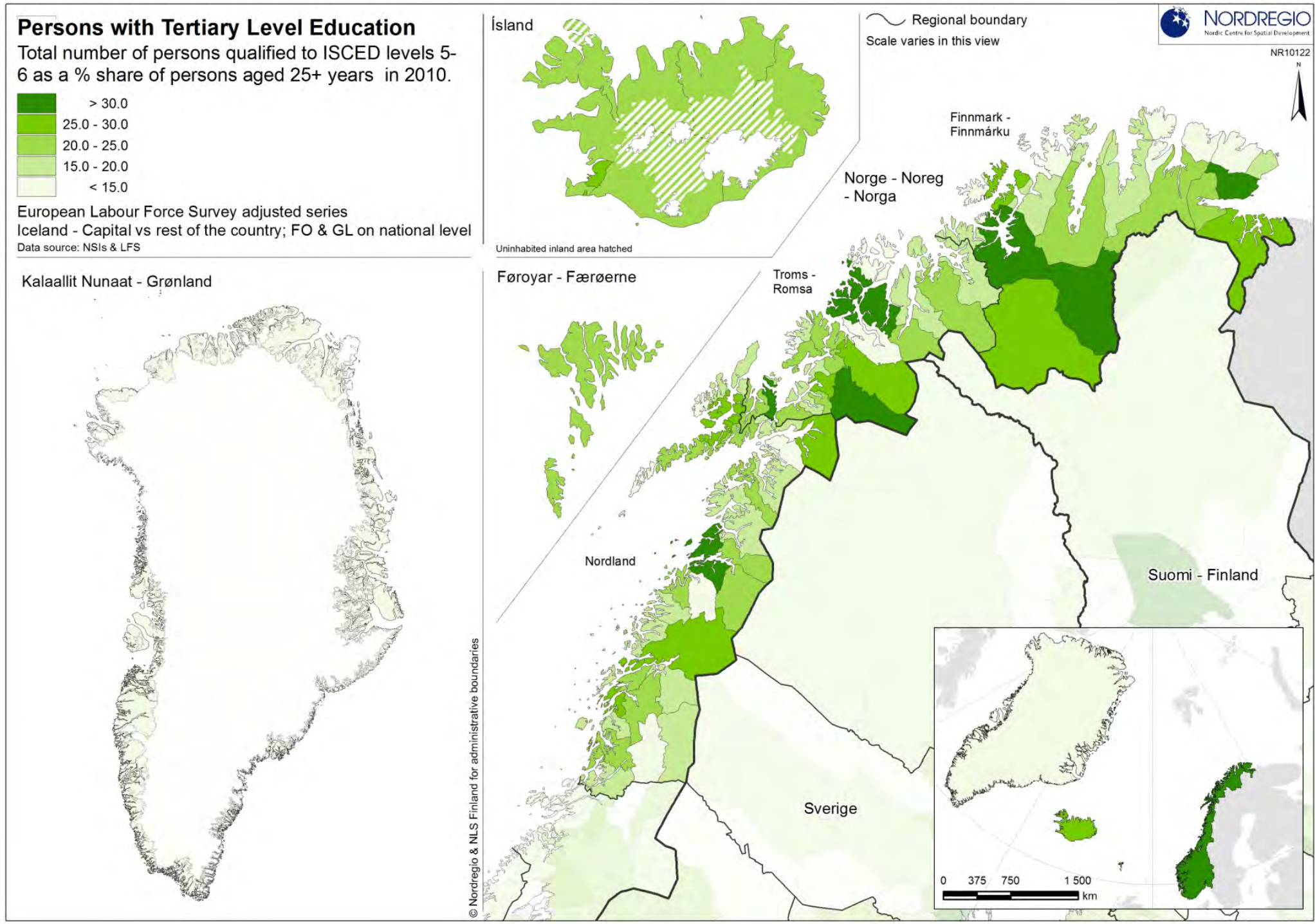


Second Priority Indicator: Percentage of female students. Using circles of different sizes Map 10 shows the total number of students in higher education at each of the educational units, while colors indicate the proportion of female students. It is clear from the color of circles which types of educational studies are dominated by females. Many colleges and technical universities attract male students, as shown by the light blue color, while the red color ramp shows the level of dominance of female students, with females accounting for more than $70 \%$ of the students in several universities. As a background for the regions, the green color ramp shows the region's level of tertiary educated inhabitants. 
Map 10: Number of Students in Higher Education (ISCED level 5 and 6) indicated by the size of the circle

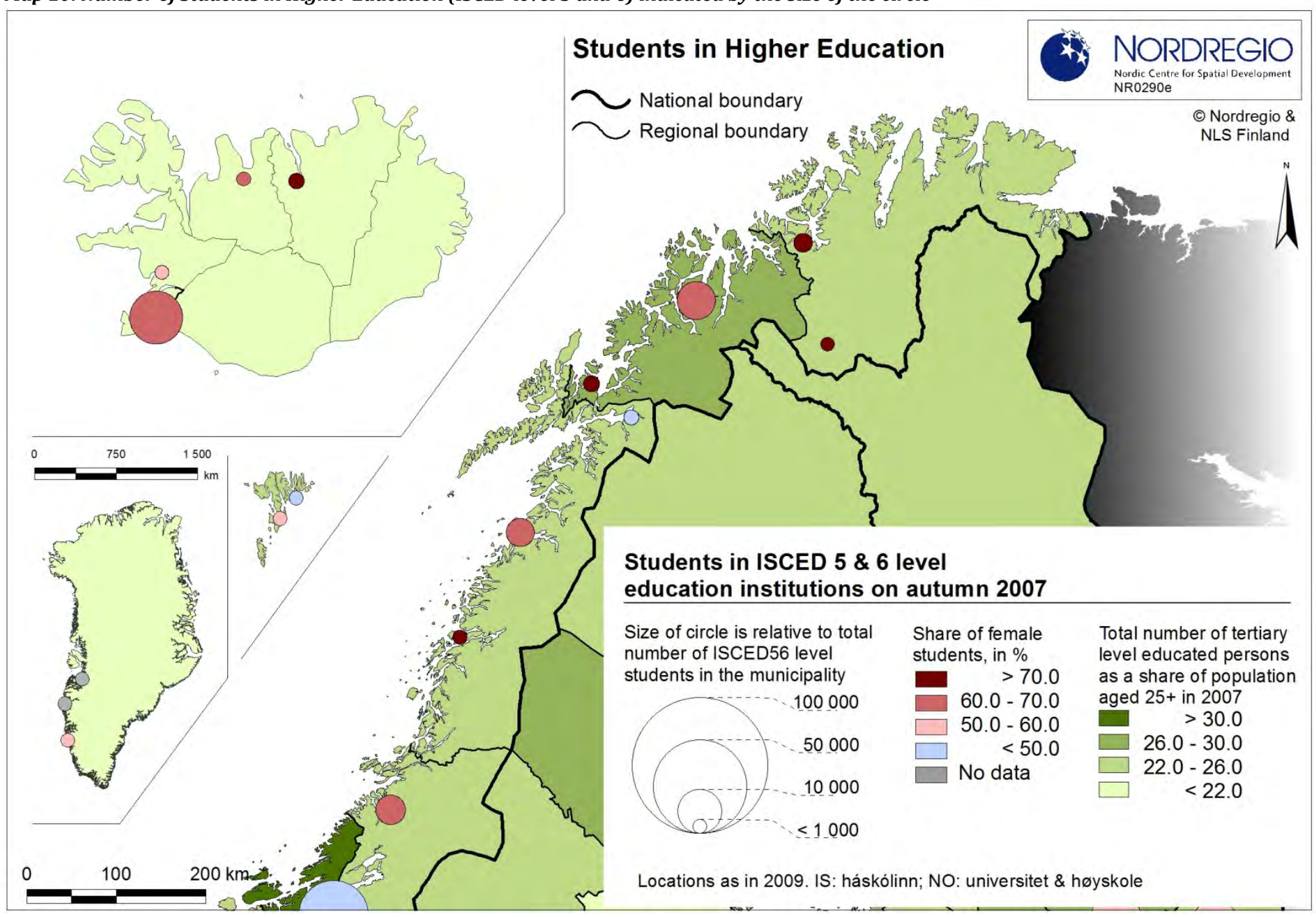

The color of the circles shows the share of female students in \%. And the background color show the total number of tertiary level educated persons as share of population aged $25+$ 
Third Priority Indicator: Access to higher education institutions within a country/region. This is an indicator we have included as a test because our research shows that out-migration from a region in search of higher education may have negative consequences for communities in the region. Having to leave a region in pursuit of higher education increases the risk of students establishing themselves with families closer to their places of education and not returning to their region of origin. Map 11 shows the distribution of higher education institutions according to institution types: colleges, university colleges, and universities in the Nordic countries. This is what is available for all students in the West-Nordic Region; the map shows the distribution of different types of institutions as an indicator of distances and accessibility. 
Map 11: Available higher education institutions available for the West-Nordic students

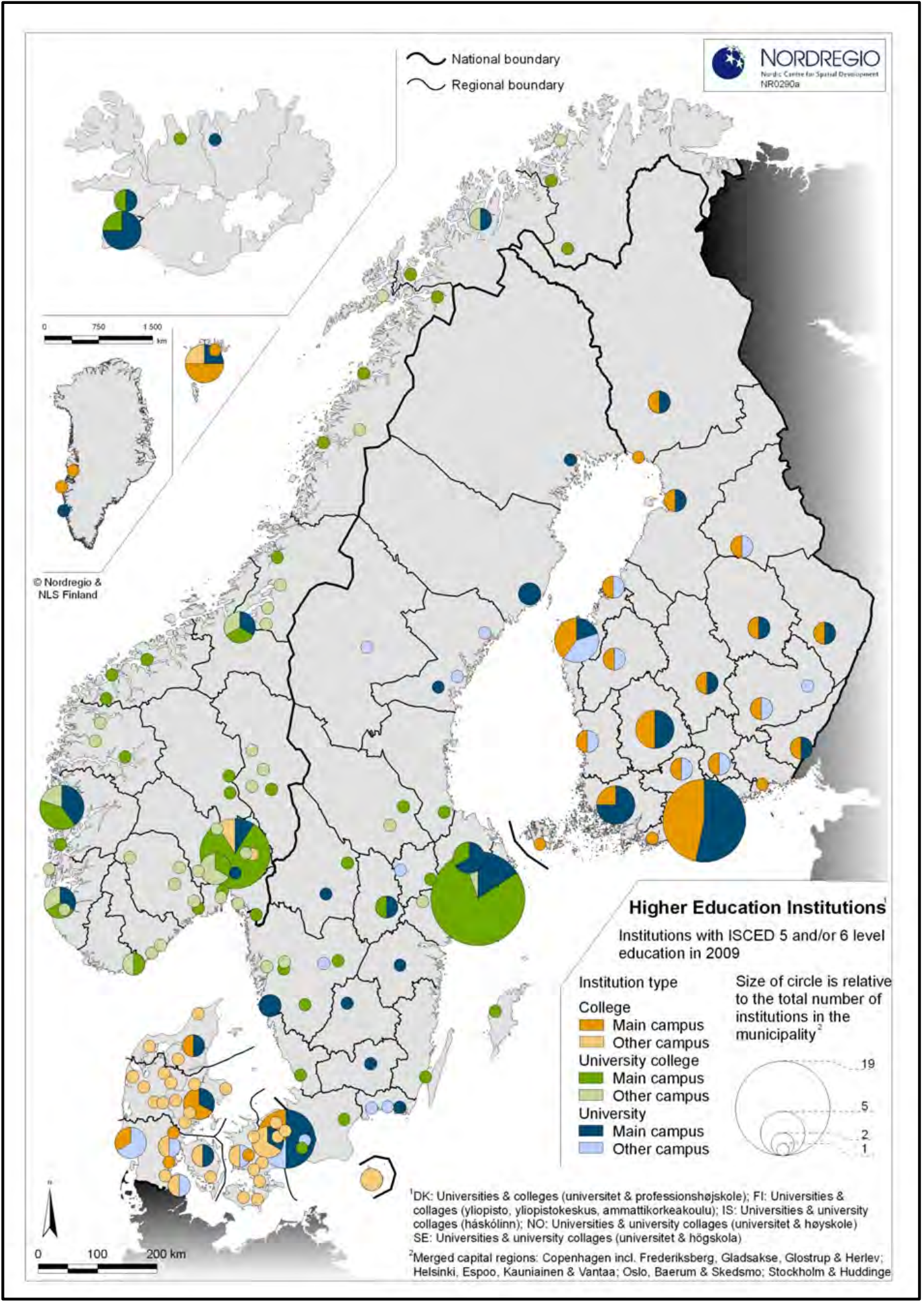


Conclusions: Conditions and outcome of educational opportunities. The three chosen indicators show the outcome of educational activities in the region. The results highlight one of the most challenging situations in this regard, namely that of involving more males in pursuing educational opportunities, and the challenge of retaining and/or attracting young people to the region after their education has been completed. Lastly, it pinpoints another critical issue - to ensure easy access to educational opportunities in communities.

- The ratio of the tertiary level educated population aged 25+ clearly shows an affinity between the level of education and educational opportunities.

- The share of female students at the tertiary level highlights the increasing challenge of reaching an equal balance between the sexes in terms of pursuing educational opportunities.

- Access to higher education institutions within a country/region also illustrates the challenge of providing educational opportunities within the region in order to attract and keep students in the region after studies have been accomplished.

All three indicators are accessible through registered data and available yearly updates.

\subsection{Cultural Wellbeing and Cultural Vitality Domain}

Cultural wellbeing in Arctic communities is based on three inter-related components: language retention, cultural autonomy, and belonging. The ASI-recommended indicator for this domain is a composite of these three.

Applying these concepts to the West-Nordic region is a challenge in the sense that the three selected concepts in the composite indicator are defined with a perception of the Arctic that only partially applies to the West-Nordic Region, which is an issue that will be discussed below.

First Priority Indicator: Language retention. The reason behind the selected components in the composite indicator is based on a set of assumptions that do not apply to all regions in the West-Nordic region.

In the Faroe Islands and Iceland the population is non-indigenous. Faroese and Icelandic are the national languages and there are no group of peoples who can be considered minorities language-wise. Both countries have had an early history of being dominated by Danish colonialism, where the Danish language dominated the administration in spite of 
the fact that only a smaller part of the population actually spoke Danish. Both countries have been successful in retaining their languages and not only using them as the everyday language but also as the administrative language at all levels.

In Greenland the majority of the population is indigenous and Greenlandic is spoken by the majority. It is a challenge, however, that Danish is the dominant language in the Capital region as well as in most of the administration. There are frequent discussions on the language situation. In regard to the last parliamentary election (March 12th 2013), a new party that has come to be represented in parliament reject the use of Danish. At the same time there are three official languages in Greenland according to parliamentary legislation from 2010: East and West Greenlandic and Inughuit languages. East Greenlandic and Inughuit languages are seldom mentioned in discussions; both of which were not mentioned by the new party during its election campaign. 
Map 12: \% share of population who indicate that they speak Greenlandic as a native language

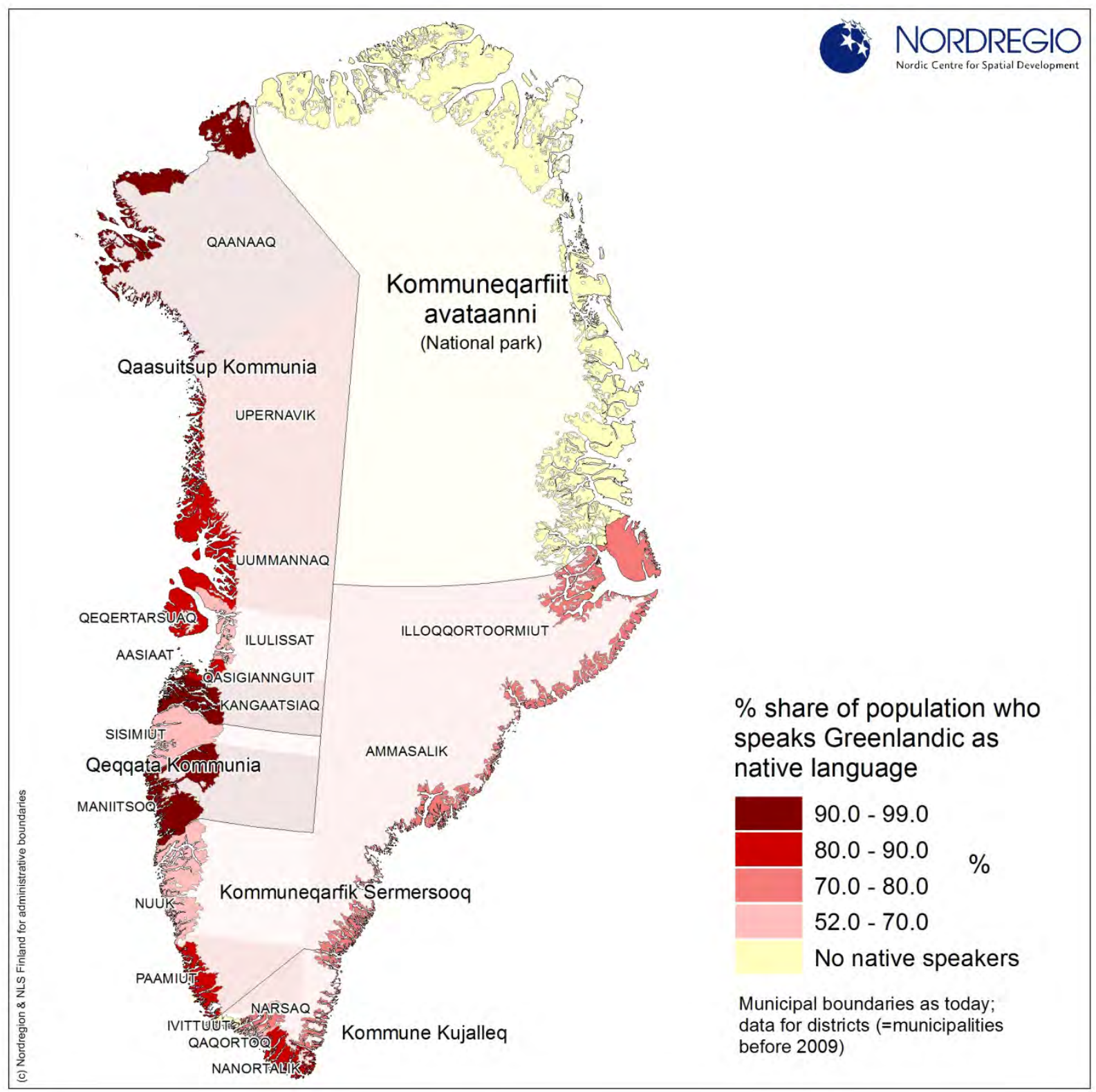

The map shows the municipal boundaries as of today, but the data and color coding are based on districts that were municipalities before the municipal reform of 2009. Data are based on a survey included in an Analysis of Mobility in Greenland 2009-2010. In the survey the respondents were asked to indicate their ability to communicate (speaking, reading, and writing) in Greenlandic, Danish, and English, as well as the language they considered to be their mother tongue. 
Map 12 shows the percentage speaking Greenlandic as their native language. Data are based on a survey included in an Analysis of Mobility in Greenland, which was conducted in 2009-2010. In the survey the respondents were asked to indicate their ability to communicate (speaking, reading, and writing) in Greenlandic, Danish, and English, as well as the language they considered to be their mother tongue. The question of East versus West Greenlandic was not included in the Survey. Greenlandic is the primary language of the Parliament of Greenland with simultaneous translation to Danish. All written materials of the central administration are in both languages.

West Greenlandic is the dominant language in most of Greenland except in the Capital region where parliament is situated together with the central administration, and Danish is most often used as the administrative language. As a consequence both Inughuit and East Greenlandic are in a "double minority" situation, with West Greenlandic being the dominant Greenlandic language, and Danish being the dominant administrative language in the central administration.

Map 13 shows the Sámi languages and dialects combining both traditional distribution and the situation as of today. The Sámi languages form a branch of the Uralic language family and are most closely related to the Finnic languages. There are ten Sámi languages of which Northern Sámi is most commonly spoken. The Akkala Sámi language became extinct in 2003 when the last known native speaker died. The traditional speaking areas are shown in the map with shades of green. 
Map 13: Sámi languages and dialects

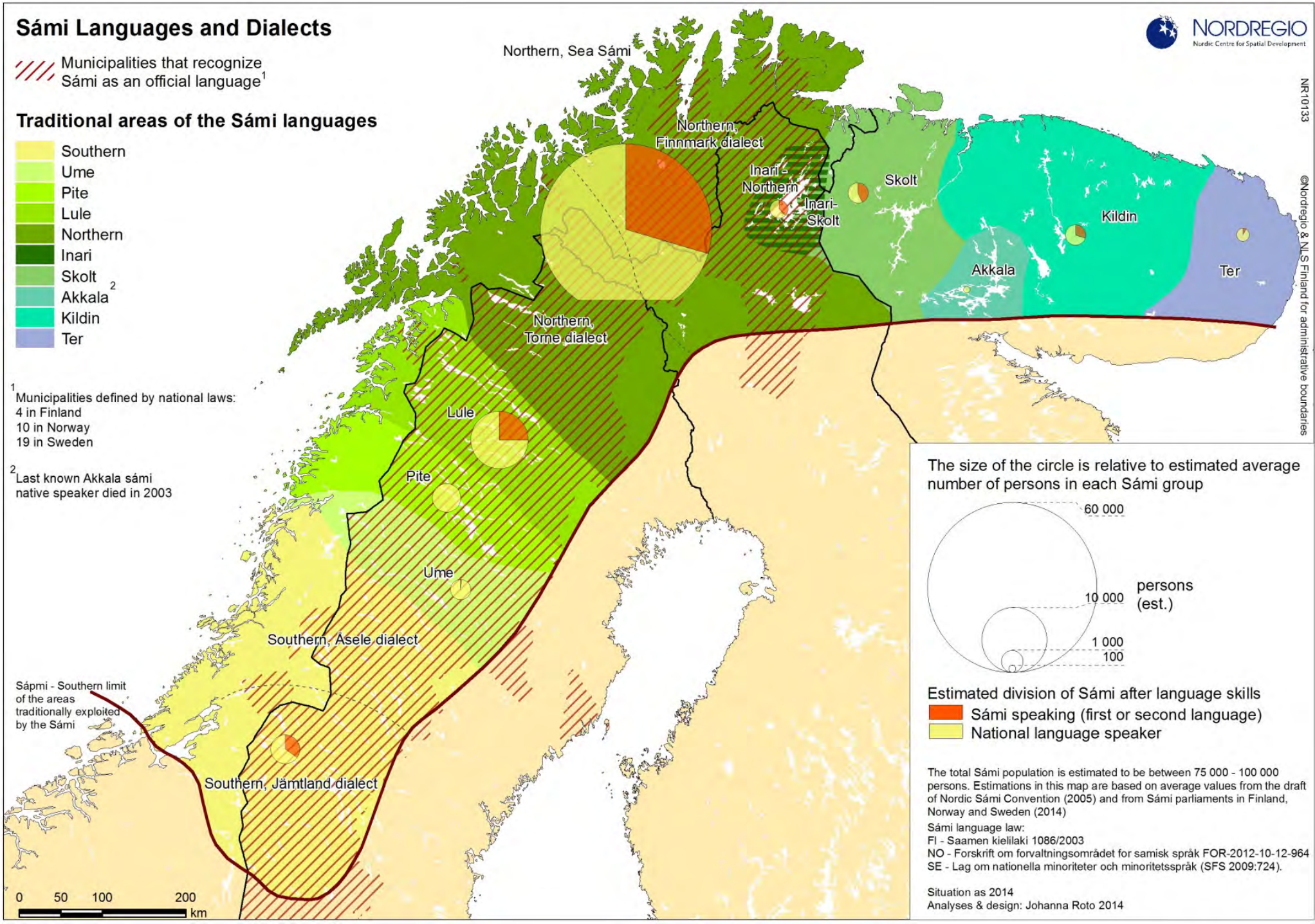


The estimated number of Sámi people varies between 60,000 and 100,000 . Based on the combined average estimates from both Sámi Parliaments and the draft of the Nordic Sámi convention, the total number of Sámi people is settled at 80,000, as shown in the map. Based on the same sources it is estimated that some 35,000 people currently speak one or more Sámi languages as a first or second language. The number of speakers in each language is shown in the map with a circle. Circles are located in traditional living areas, although a significant share of Sámi lives outside of the traditional area. The area of a circle represents the estimated number of people in each Sámi group and the orange color indicates the proportion able to speak the Sámi language.

There are 31 municipalities in Nordic Countries that recognize Sámi as an official language. There are some legal differences between the countries and rights, but in general this means that in these municipalities Sámi languages have an official status, which means that they can be used as an administrative language together with national languages. The municipalities are also obligated to organize some services of general interests, such as school, day care and elderly care in Sámi languages. (In national laws: Saamen kielilaki 1086:2003 (FI); Målvedtak i kommunar og fylkeskommunar FOR-2007-04-01-378 (Ministry of culture and church affairs) (NO); SFS 2009:724 (SE)).

Second Priority Indicator: Accessibility to traditional food. The question of harvest, distribution, and consumption of traditional food in the West-Nordic Region is similar to most of the Arctic region, in the sense that it is related to the traditional availability of food items, which is why it is quite complex. Since dependency on both land and sea resources is common, the region provides access to fish, sea mammals, lamb, reindeer, seabirds and waterfowl (including their eggs), and a large variety of lichens, wild mushrooms, and dried seaweed, which have been included in preparing food.

Dairy products are another common characteristic in most of the region. The region itself is characterized by a wealth of products that have been a stable element in traditional diets. In order to preserve foods a variety of processing methods have been important, such as smoking, salting and drying. Furthermore, dairy products have been a key element in a majority of traditional recipes.

What often attracts attention to the region's diet is the fact that sea mammals have often been important. To varying degrees consumption of seal, walrus and whales have been key to survival. These products are still available and are considered to be important in the region. 
In terms of accessibility to traditional food the West-Nordic region has an extensive distribution because most traditional food items are available through commercial systems; i.e. they can be bought in larger stores and are distributed in local market places.

Obtaining data on traditional food is a challenge. One reason for lack of access to information and data has been the proprietary interests of businesses who feel that disseminating such information could potentially help their competitors. Also, it is expensive to access the relevant information.

Apart from formal distribution, all countries provide examples of informal distribution systems, such as market places, informal relations, and subsistence, which increase access to traditional food.

\section{Air dried lamb leg, found in a delicatessen in the Faroe Islands where it can be} bought from the producers but is also available in larger food markets

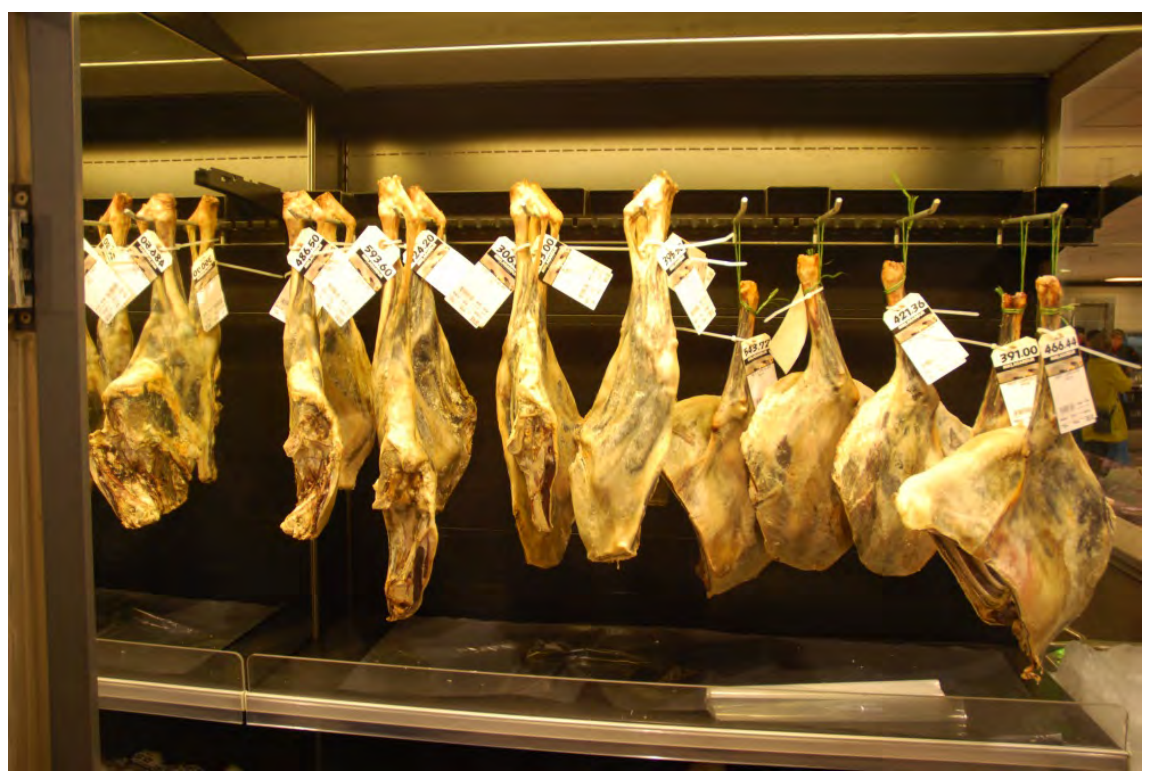

Photo: Rasmus Ole Rasmussen. 
Whale meat is a common product in the West-Nordic region, and is sold here from a booth at the harbor in Oslo. But it can be found both as booth-sale and in restaurants. The same goes for Seal and Reindeer

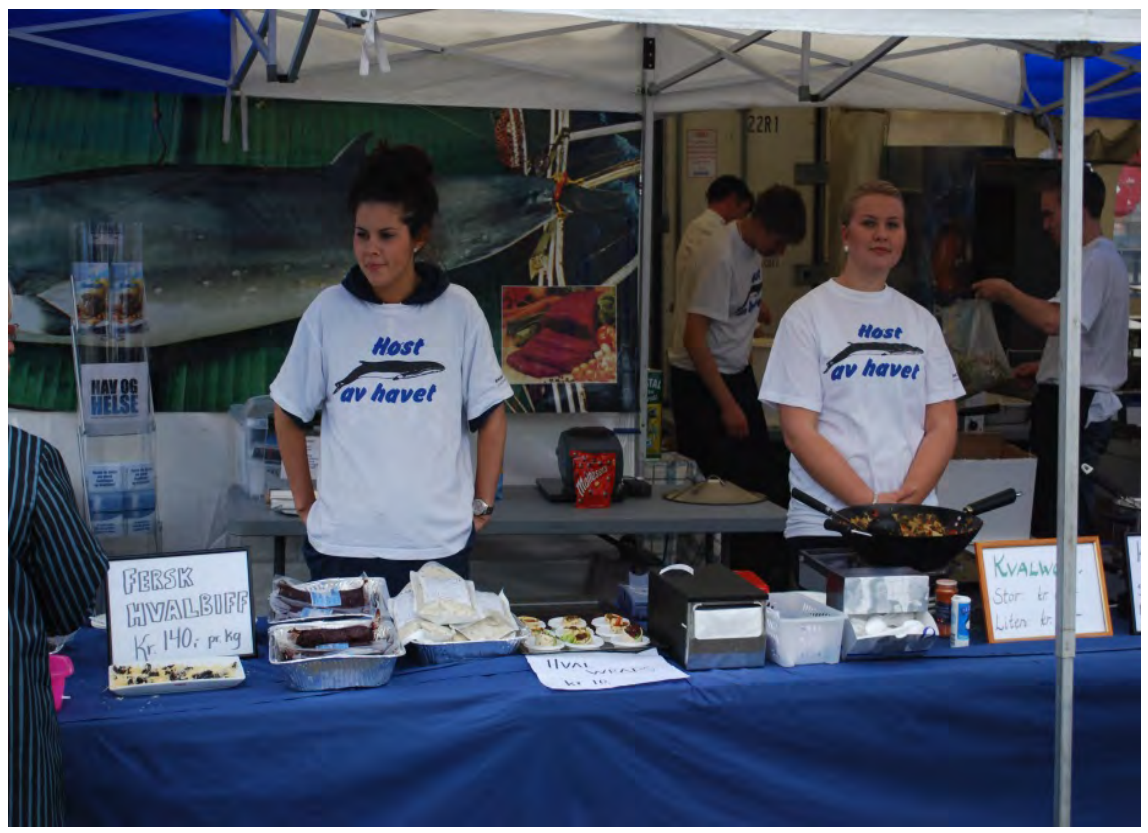

Photo: Rasmus Ole Rasmussen.

The small open market shelters still exist, especially in the larger villages, such as this one in Alluitsup Paa, South Greenland

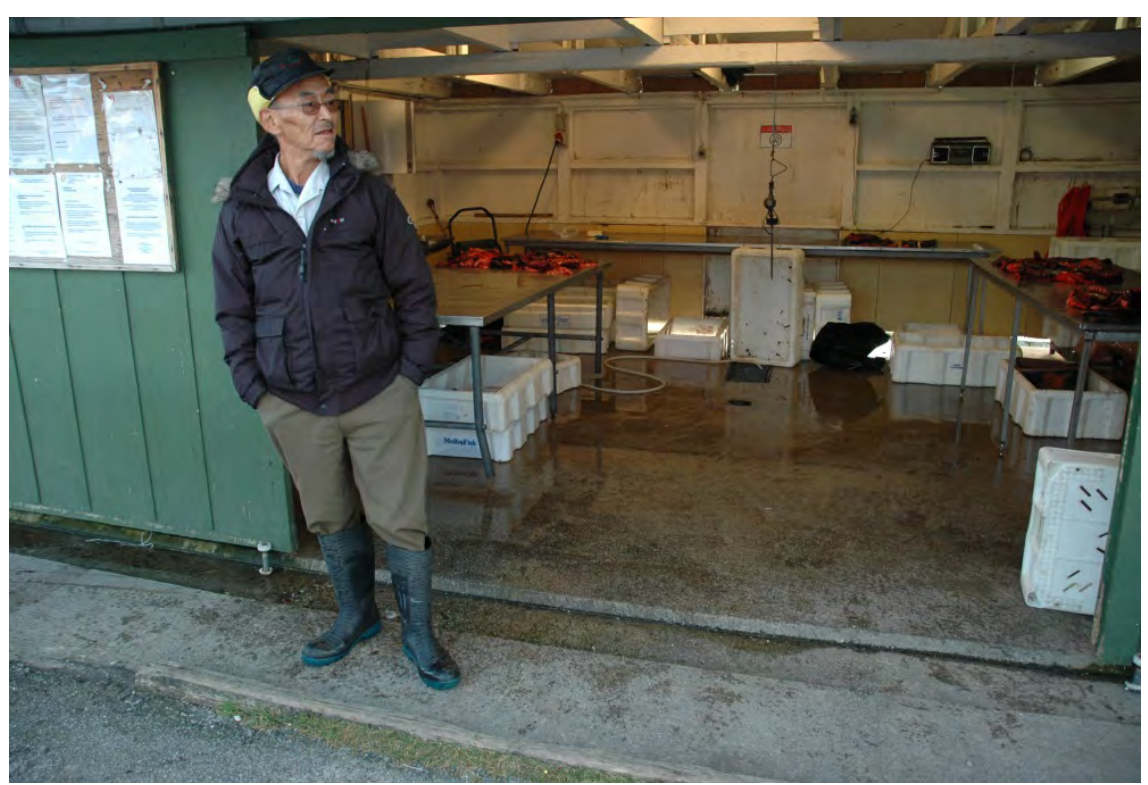

Photo: Rasmus Ole Rasmussen. 
Conclusions: Cultural Vitality. The assumptions behind the concept of Cultural Vitality and its application through the preferred indicators show some limitations in relation to the West-Nordic region. The recommended and preferred indicators may be applicable in some situations while alternatives might have been more useful in others.

- Language Retention as an indicator is very relevant in the case of Greenland and the Sámi in Northern Norway, but perhaps less so in the case of the Faroe Islands and Iceland. This is probably the situation in other regions as well.

- Accessibility to traditional foods has been used as an indicator of Cultural Vitality. However, one limitation is that it ignores animals like pigs, cattle, horses, sheep, and poultry, which have long histories as traditional products for both Indigenous and Non-indigenous peoples in the Arctic. Also, the option of including the commercialization of traditional products is not well incorporated.

At this point in time both indicators are not immediately accessible through registered data, and as a consequence two surveys have been needed in order to establish a proper baseline study.

\subsection{Contact with the Nature Domain}

Three aspects of traditional food are discussed here, with Consumption of Traditional Food / Harvest of Traditional Foods as the preferred indicator.

There are three ways of accessing traditional food which is characteristic of the region (see also the Cultural Domain):

- On one hand, through subsistence hunting, farming, and fishing for personal consumption. The number of persons involved in these activities differs but is generally considered an important part of life in the region, either through personal involvement or through family and good neighbour relations. Precise information on the exact role of subsistence activities is not generally accessible for the whole West-Nordic region. Occasional surveys on living conditions covering parts of the regions provide information on the extent of these subsistence activities but data is incomparable.

- On the other hand, informal access to traditional products occurs through sharing as well as exchange through monetary means. Again, comparable data for the whole West-Nordic region do not exist, but 
for two regions - Greenland and the Faroe Islands - some elements are available.

o In the case of Greenland the "local markets"

(Kalaaliminerniarfiit) are found in most communities in the form of outdoor kiosks where hunters and fishermen can sell the proceeds of their hunting and fishing directly to consumers. These infrastructures are maintained by local governments, which negotiate with an association of hunters and fishermen to set the price of transactions (Marquardt and Caulfield, 1996:113; Caulfield, 1993:148). Rasmussen (1998:17) estimates that roughly $10 \%$ of the harvest made by individuals is sold in these markets. Informal sales also take place between hunters/fishers and local institutions (e.g. schools, hospitals).

0 In the case of the Faroe Islands, pilot whaling has been an institutionalised activity for centuries. Thus, the availability and sharing of pilot whale blubber and meat is an important social and cultural activity.

- Furthermore, the commercialization of traditional food is for most of the West-Nordic region the main way of ensuring accessibility. The internal market of local and regional food production benefits from efficient formal and informal sales systems through retail stores, which make products available not only within the countries but also across the region. Compared to elsewhere in the Arctic, the commercial distribution of products provides broad access to traditional food products for those who enjoy them.

\section{First Priority Indicator: Consumption of Traditional Food / Harvest of Traditional Foods}

As already described in the Cultural Vitality section there are multiple paths for access to traditional food. Cases from Greenland show something about attitudes towards consumption.

In cases where traditional food is distributed through shops, the harvest will be registered through formal statistical systems. However, it is impossible to see what will be distributed to local markets as traditional food and to what extent these products are exported or distributed as semi-processed products to other producers. In Rasmussen (2005) there is a discussion on how harvested products are distributed. Figure 5 depicts the situation as it was in Greenland, in 2005. 
Figure 5: Distribution of the total value of inshore hunting and fishing produces in 2005

\begin{tabular}{|c|c|c|c|c|}
\hline \multicolumn{5}{|c|}{$\begin{array}{l}\text { Distribution of the total value of inshore hunting and fishing produces in } \\
\qquad 2005\end{array}$} \\
\hline Type of economy & Type of activity & Total value (DKK) & $\begin{array}{l}\% \text { of total } \\
\text { value }\end{array}$ & $\begin{array}{l}\text { \% of informal } \\
\text { value }\end{array}$ \\
\hline Formal & Sale to shops and for processing & 206.413 .347 & 61 & \\
\hline \multirow{7}{*}{ Informal } & Hunter's own consumption & 46.208 .304 & 14 & 36 \\
\hline & Gitts to family, relatives and fiends & 23.595 .513 & 7 & 18 \\
\hline & $\begin{array}{l}\text { Sale to relatives, friends and } \\
\text { nsighbours }\end{array}$ & 10.144.267 & 3 & 8 \\
\hline & Sale to restaurants & 5.990 .400 & 2 & 5 \\
\hline & Sale to institutions & 6.258 .672 & 2 & 5 \\
\hline & Sale at the local marketplace & 37.694 .459 & 11 & 29 \\
\hline & Total value of the informal sector & 129.891 .615 & 39 & 100 \\
\hline Total & $\begin{array}{l}\text { Total value of inshore hunting and } \\
\text { fishing produces }\end{array}$ & 336.304 .962 & 100 & \\
\hline
\end{tabular}

Source: Rasmussen 2005.

The formal economy, which comprises sales to processors, exports and local consumption, is about $61 \%$. The remaining $39 \%$ in the informal economy includes own consumption, as well as gifts to family and friends (about 21\%). In addition, there are sales to restaurants, institutions, etc. A substantial part comprises sale to relatives and friends, restaurants, institutions and local market places.

\section{Second Priority Indicator: Harvest of traditional foods}

An important issue in relation to the harvesting of traditional food is the fact that professional hunters and fishers are not the only contributors. Ordinary people who do not depend on fisheries or hunting also contribute. In Greenland all fishing and hunting activities require licenses, providing records of how professionals and the leisure time contributors are involved. The records can yield measurements for maintaining contact with nature, which is the preferred indicator for this domain.

Third Priority Indicator: \% of population accessing traditional food Data related to this indicator is rather difficult to gain information on. The SLiCA project attempted to deal with this issue through their questionnaire but information on how often traditional food is included in the diet does not provide very precise information on what it actually 
means. Similar questions have been asked of more than 1,500 persons in relation to the Mobility Survey (Rasmussen, 2010).

The main point here, however, is that traditional food is widely available because both formal and informal systems support supply.

Conclusions: Contact with Nature. As emphasized in the introduction to this domain the assumptions behind the concept of Cultural Wellbeing and its application through the indicators show some limitations in relation to the West-Nordic Region. The recommended and preferred indicators may be applicable in some situations while alternatives might have been more useful in others.

- Harvest of traditional foods is difficult to obtain data on because there is no clear division between commercial and non-commercial harvest. Therefore, to identify which foods are to be counted as traditional foods would require a finer analysis.

- Consumption of traditional Food: Questions concerning the accessibility to traditional foods seem to neglect the fact that animals like pigs, cows, horses, sheep, and poultry have traditionally been used by both indigenous and non-indigenous peoples. Moreover, the commercialisation of products is not well incorporated within this framework. However, in the West-Nordic region there are several sources providing opportunities to access products that are considered traditional by any other definition.

- To the extent traditional food is distributed commercially it will be widely available.

Providing empirical documentation for different food types is difficult. It is obtainable, although not through official registers, but requires better access to data from food supply systems, which may be proprietary. 


\subsection{Fate Control Domain}

With the West-Nordic region consisting of four countries/regions - each being a sovereign entity - it is necessary to reflect on all four measures for Fate Control applicable to each sub-region:

- The percentage of indigenous members in governing bodies (municipal, community, regional) relative to the percentage of indigenous people in the total population.

- The percentage of surface lands legally controlled by inhabitants through public governments, Native corporations, and obshchiny.

- The percentage of public expenses within the region (regional government, municipal taxes, community sales taxes) raised locally.

- The percentage of individuals speaking a mother tongue (whether Native or not) in relation to the percentage of individuals reporting corresponding ethnicity.

\section{First Priority Indicator: Fate Control Index.}

The percentage of indigenous persons being members of governing bodies (municipal, community, regional) relative to the percentage of indigenous people in the total population:

- The Faroe Islands: Members of the government at both national, regional, and municipal level being Faroese,with foreign policy depending on Denmark (Indicator is 80\%).

- Greenland: Members of the government at both national, regional, and municipal level being Greenlanders, with foreign policy depending on Denmark (Indicator is 80\%).

- Iceland: Members of the government at both national, regional, and municipal level being Icelanders (Indicator is 100\%).

- NW Norway: As citizens in Norway the Sámi are participants in elections parallel to other Norwegians. However, their situation as a recognized Indigenous People differs from other Norwegians; further explanation is therefore needed. As summarised below the indicator is $80 \%$.

- Four elections on various geographical levels are organized in Norway, namely Storting (Parliament) and Sameting (Sámi Parliaments), and as well as national and municipal elections. Each election is held every four years. 
o For Storting elections, the vast majority of those running for election represent registered large parties, as opposed to national and municipal elections where local lists are common. Sámi parties in Norway do not have any candidates in Stortinget.

o For County elections from 2011, only in the northernmost county of Finnmark one representative from a Sámi party (Samefolkets Parti; the largest Sámi party) was elected.

o For Municipal elections most municipalities with a higher Sámi population had representatives from Sámi parties after 2011 elections. For example, in the Kautokeino Municipality 13 of 19 elected representatives came directly from three different Sámi parties and in the Karasjok municipality 6 of 19 were Sámi. Please note that the figures above refer only to membership in the party.

o Sameting elections are targeted at all Norwegian Sámi over the age of 18. To be registered to vote at Sameting elections a person must regard himself/herself to be Sami and must also have Sami as their home language; or at least one of their parents, grandparents or great-grandparents must have (or have had in the past) Sami as their home language. The number of persons entitled to vote in Sameting election in 2009 amounted to 13,890 persons.

Summary: The Sámi representation differs between the different levels of administration - basically from $0 \%$ in the Storting to $100 \%$ in the Sameting. It is a challenge to convert the above mentioned numbers into one number, but a suggested $80 \%$ could be argued.

\section{Source}

- Sametingsvalet (2009) http://www.ssb.no/emner/00/01/10/sametingsvalg/

- Valgportalen (2011). Ministry of local government and regional development. http://www.regjeringen.no/krd/html/valg2011/bk4_html

- Sametingsvalet (2009) http://www.ssb.no/emner/00/01/10/sametingsvalg/

- Valgportalen (2011). Ministry of local government and regional development. http://www.regjeringen.no/krd/html/ valg2011/bk4_html 
The percentage of surface lands legally controlled by the inhabitants through public governments, Native corporations, and obshchiny:

- The Faroe Islands: In the Faroe Islands land surface is legally controlled by the Faroese government $=100 \%$.

- Greenland: In Greenland land surface is legally controlled by the Government of Greenland $=100 \%$.

- Iceland: In Iceland land surface is legally controlled by the Government of Iceland $=100 \%$.

- NW Norway: There are conflicts regarding the right to land, which is based on the fact that reindeer grazing and the nature of reindeer is different from private ownership rights in connection with, for instance, mining, agriculture, forestry, etc. Therefore, the present legal setting does not imply full legal control as this would only be applied in cases of private ownership. The system, however, still enables the interests of NW Norway which are reflected in the Norwegian legal system. As a consequence it is suggested to be $50 / 50=50 \%$.

The percentage of public expenses within the region (regional government, municipal taxes, community sales taxes) raised locally:

- The Faroe Islands:In the Faroe Islands Home Rule was introduced in 1948. This divides the responsibility for the islands into common and special Faroese affairs. Common affairs are handled by the Folketing and the Danish government, while special Faroese affairs are handled by the Faroese Home Rule authorities consisting of the Løgting, the legislature, and the Landsstýri (the executive), which is appointed by and politically responsible to the Løgting. This includes domestic issues, such as fishing, residential, school, commercial, municipal conditions, etc. The Faroe Islands have become less financially dependent on Denmark by receiving 624 million DKK per year in block grants, which is equal to $6 \%$ of its GDP. In addition, the Danish State holds expenditures for justice and defence. It is not known what this means in DKK, but based on the Block grant transfer the percentage of public expenses raised within the region would be around $94 \%$.

- Greenland: In Greenland Home Rule was introduced on May 1st 1979 and Self Government June 21st 2009. The legislation is formally approved by the Danish parliament (the Folketinget)where two members are elected in Greenland. The Folketing and the Danish 
administration issue acts and directives for the few areas not transferred to the Self Government but almost all legislation originates from the Greenlandic parliament. This includes legislature on domestic issues, such as fishing, residential, school, commercial, municipal conditions, etc.., while issues of foreign, security and legal policy are common affairs under Danish law (Landstinget). The members of the Landsting are elected at least every four years by a general election among all Danish citizens residing in Greenland who are over 18 years of age. The Landsting nominates the president of the executive (the Landsstyret) and approves the nomination of its members who act as the country's government. Each Landsstyre member serves as minister for particular areas of responsibility. Greenland has initiated a municipal reform and from January 1st 2009 the country has been divided into four large municipalities, each being led by a municipal council headed by a mayor. The municipalities are responsible for the welfare of the local communities, including childcare, elementary school, culture and leisure, as well as various social services. Greenland has become less financially dependent on Denmark but receives substantial funding from the Danish government. In 2011 Greenland received 3,533 million DKK equal to 29\% of GDP. On top of that the Danish State holds expenditures for justice and defence. It is not known what this means in DKK but based on the Block grant transfer the percentage of public expenses raised within the region would be around $70 \%$.

- Iceland: Iceland's public expenses are raised locally $=100 \%$.

- NW Norway: Norway's public expenses are raised nationally but Northern Norway generally depends on transfers from other regions in Norway. An estimate of public expenses raised within the region would be around $80 \%$.

The percentage of individuals who speak a mother tongue (whether indigenous or not) in relation to the percentage of individuals reporting corresponding ethnicity:

- Faroe Islands: Ethnicity not registered.

- Greenland: Ethnicity not registered.

- Iceland: Ethnicity not registered.

- NW Norway: Ethnicity not registered. 


\section{Conclusions: Fate Control}

In Figure 6 the four components of the fate control index are listed for each of the four regions of the West-Nordic region and a total index value has been calculated.

\begin{tabular}{lrrrrr} 
Figure 6 & Governance & Land rights & $\begin{array}{c}\text { Outside } \\
\text { money }\end{array}$ & Language & Total \\
\hline Faroe Islands & 0,8 & 1 & 0,94 & $?$ & 0,75 \\
Greenland & 0,8 & 1 & 0,7 & $?$ & 0,56 \\
Iceland & 1 & 1 & 1 & $?$ & 1 \\
Norway & 0,8 & 0,5 & 0,8 & $?$ & 0,26 \\
\hline
\end{tabular}

As mentioned above the concept or definition of ethnicity has been difficult to apply in the Nordic setting.

\subsection{Conclusions}

In general, the ASI domains have been relatively easy to apply to the case of the West-Nordic region, with precise definitions and data retrievable in the national statistical systems. Where there are variations between the four entities included in the West-Nordic region it has been possible to arrive at roughly comparable results. This applies to the domains: Health and Population; Material Wellbeing; and Education.

The domains of Cultural Wellbeing and Contact with Nature make reference to choices and activities, which are related to involvement and activities based on individual preferences and therefore depend on new types of registrations or surveys. Inherent in some concepts like "traditional foods", the inclusion of traditions that remain outside traditional analyses of indigenous peoples in the Arctic makes it is difficult to apply the analysis to populations in the Arctic that are not registered as indigenous. There is an inherited assumption that "traditional foods" would not be available through commercial systems, although this may not reflect the reality in substantial parts of the Arctic.

Finally, the Fate Control index raises some methodological questions on how to determine the level of control.

Overall, the ASI indicators are useful for tracking changing conditions in the West-Nordic region. On the other hand, it would be necessary to develop the domains on Contact with Nature and Cultural Wellbeing further in order to make them useful and applicable in a West-Nordic context. 


\subsection{References}

Act of 12 June (1987) concerning the Sameting (the Sámi Parliament) and other Sámi legal matters.

Andersson, R., J.M. Quigley and M. Wilhelmson (2004). University decentralization as regional policy. The Swedish experiment. Journal of Economic Geography vol. 4 no. 4. 371-388. http://dx.doi.org/10.1093/jnlecg/lbh031

Arbo, P. \& H. Eskelinen (2003). The role of small, comprehensive universities in regional economic development: experiences from two Nordic cases. Paper presented at the 43rd ERSA congress, Jyväskylä 27th-30th August.

Beach, Hugh, Myrdene Anderson and Pekka Aikio (1992) Dynamics of Saami Territoriality within the Nation-States of Norway, Sweden and Finland. Mobility and Territoriality: Social and Spatial Boundaries among Foragers, Fishers, Pastoralists and Peripatetics. Eds. Michael J. Casimir and Aparna Rao. New York: St. Martin's Press, 55-90.

Björklund, Ivar. (1990)Sami Reindeer Pastoralism as an Indigenous Resource. Development and Change v.21, n.1, 75-86.

Bloch, Dorete (2007). Grindehvalen og Fcerøernes grindefangst. Føroya Náttúrugripasvn.

Danmarks Statistik (2012). Statistisk Årbog.

G50 (1948). Grønlandskommissionen af 1948. København.

G60 (1964). Betcenkning fra Grønlandsudvalget af 1960, Betcenkning nr. 363, 1964. Statens Trykningskontor. København.

Gateway to Iceland, www.iceland.is

Glesbygdsverket (2005). Antalet anställda vid statliga myndigheter. Mimeo (22nd April). Glesbygdsverket, Östersund

Hamilton, L.C. Brown, B.C. Rasmussen, R.O. (2003) West Greenland's cod-to-shrimp transition: local dimensions of climatic change. Arctic, v. 56, no. 3, Sept. 2003, 271282, ill., maps. http://dx.doi.org/10.14430/arctic623

Hamilton, L.C., Haedrich, R.L., Duncan, C.M. (2004) Above and below the water: Social/ecological transformation in northwest Newfoundland. Population and Environment 25(3): 195-215. http://dx.doi.org/10.1023/

B:POEN.0000032322.21030.c1

Hamilton, L.C., Otterstad, O. (1998) Sex ratio and community size: Notes from the northern Atlantic. Population and Environment 20(1): 11-22. http://dx.doi.org/10.1023/A:1023347817418

Hamilton, L.C., Rasmussen, R.O. (2010) Population, sex ratios and development in Greenland. Arctic 63(1): 43-52. http://dx.doi.org/10.14430/arctic645

Hamilton, L.C., Seyfrit, C.L. (1993) Town-village contrasts in Arctic youth aspirations, Arctic 46(3): 255-263. http://dx.doi.org/10.14430/arctic1351

Hamilton, L.C., Seyfrit, C.L. (1994) Female Flight? Gender Balance and Outmigration by Native Alaskan Villagers. Arctic Medical Research, vol. 53: Suppl. 2: 189-193

Hamilton, Lawrence \& Seyfrit, Carole L. (1994). Female Flight? Gender Balance and Outmigration by Native Alaskan Villagers. Arctic Medical Research 53 (supplement 2).

Hamilton, Lawrence C., Rasmussen, Rasmus Ole, Flanders, Nicholas E., Seyfrit, Carole L. (1996). Outmigration and Gender Balance in Greenland. Arctic Anthropology vol. 33, no. 1.

Hansen, KG (1992) De kalder os eskimoer - aspekter af moderne vestgrønlandsk selvforståelse. Master thesis, University of Aarhus. 
ITPS (2004). Regionala effekter av högre utbildning, högskolor och universitet, A2004:002.

Josefsen, Eva (2003) Sami Landrights, Norwegian Legislation and Administration Resource Centre for the Rights of Indigenous Peoples Kautokeino.

NAMMCO: Status of Marine Mammals in the North Atlantic - The Long-finned Pilot Whale. North Atlantic Marine Mammal Commission Polar Environmental Centre N9296 Tromsø, Norway.

Neubauer, J, Dubois, A, Hanell, T, Lähteenmäki-Smith, K, Pettersson, K, Roto, J \& Stenineke, J, (2007) Regional Development in the Nordic Countries 2007. Nordregio Report 2007:1.

Neubauer, J. et al. (2007). Regional Development in the Nordic Countries 2007. Nordregio Report 2007:1.

Nordic Statistical Yearbook (2011), Nord 2011:1. Copenhagen: Nordic Council of Ministers.

Norut NIBR Finnmark, (2005). Med periferien i sentrum - en studie av lokal velferd, arbeidsmarkeder og kjønnsrelasjoner i den nordiske periferien. Edited by Berglund, Johansson \& Molina. Norut NIBR Finnmark-rapport 2005:14.

Persson, L.O. with contributions by Edvardsson, I.R., Heikkilä, E., Johansson, M. \& Stambøl, L.S. (2001). Local labour market performance in the Nordic countries. Nordregio Report 2001:9

Poppel, B., Rasmussen, R. O., \& Winther, G. (2005). Challenges to socio-economic research in a changing society - with a special focus on Greenland. I SocioEconomic Research on Management Systems of Living Resources: Strategies, Recommendations and Examples. Nuuk: Inussuk - Arctic Research Journal: 87-100

Rasmussen, R. O. (2004). Socio-economic consequences of large scale resource development; cases of mining in Greenland. Circumpolar Arctic Social Sciences Ph.D. Network. Proceedings of the Eight Conference. I Beyond Boom and Bust in the Circumpolar North. Prince George, B.C., Canada: UNBC Press: 101-131

Rasmussen, R. O. (2005). Analyse af fangererhvervet i Grønland. Roskilde: Grønlands Hjemmestyre - Direktoratet for Fangst og Fiskeri og NORS - Nordatlantiske Regionalstudier, Roskilde Universitetscenter.

Rasmussen, R. 0. (2005). Small, medium and large scale strategies: cases of social response and change in Greenland. I Socio-Economic Research on Management Systems of Living Resources: Strategies, Recommendations and Examples. Greenland Home Rule, Nuuk: Inussuk - Arctic Research Journal: 56-72.

Rasmussen, R. O. (2007). Adjustment to reality - Social response to climate changes in Greenland I. Arctic Alpine Ecosystems and People in a Changing Environment. Berlin Heidelberg New York: Springer: 167-180.http://dx.doi.org/10.1007/978-3540-48514-8_10

Rasmussen, R. O.: Gender and Generation (2009). Perspectives on Ongoing Social and Environmental Changes in the Arctic. Signs: Journal of Women in Culture and Society 2009, vol. 34, no. 3. http://dx.doi.org/10.1086/593342

Rasmussen, R. O. (2008). Globalization, Social Issues and Arctic Livelihood. In: Common Concern for the Arctic. Conference arranged by the Nordic Council of Ministers 9-10 September 2008, Ilulissat, Greenland. ANP 2008:750

Rasmussen, R.O. (2010): Mobilitet i Grønland. Grønlands Selvstyre

Rasmussen, R.O. (2011): Boscetningen i Grønland. Grønlands Selvstyre

Rauhut, Daniel, Rasmus Rasmussen, Johanna Roto, Per Francke, Sara Östberg (2008). The Demographic Challenge to the Nordic Countries. Nordregio Report 2008:2 
Ruggie, John Gerrard (1993). "erritoriality and Beyond: Problematizing Modernity in International Relations. International Organization 47(1). 139-174. http://dx.doi.org/10.1017/S0020818300004732

Sandow, E. (2008). Commuting behaviour in sparsely populated areas: evidence from Northern Sweden. Journal of Transport Geography vol. 16 no. 1; 14-27. http://dx.doi.org/10.1016/j.jtrangeo.2007.04.004

Skotvedt, T. (1993). Sami: The Indigenous Peoples of Norway. I: Continuity and Change: Aspects of Contemporary Norway. (pp. 163-174.)Ed. Anne Cohen Kiel. Oslo: Scandinavian University Press.

Stambøl, L.S., Heikkilä, E., Johansson, M., Nygren, O. \& Persson, L.O. (1999). Regional arbeidsmarkedsmobilitet i nordiske land. Bruttostrømsanalyser og etterspørselsbetraktninger i de regionale arbeidsmarkedene. Nordisk Ministerråd: TemaNord 1999:551.

Statistics Iceland: Statistical database.

Statistics Norway: Statistical database. 



\title{
5. Inuit Regions of Alaska
}

\author{
Authors \\ Peter P. Schweitzer, University of Alaska, Fairbanks, USA \& University of \\ Vienna, Austria; Raymond Barnhardt, University of Alaska Fairbanks, USA; \\ Matthew Berman, University of Alaska Anchorage, USA; Lawrence Kaplan, \\ University of Alaska Fairbanks, USA.
}

\subsection{Introduction}

The Inuit regions of Alaska are administratively defined as the North Slope Borough, the Northwest Arctic Borough, and the Nome Census Area. Together, these three regions constitute the homelands of the Iñupiat, are situated in subarctic and arctic environments, and are inhabited by ca. 25,000 people in an area of over $420,000 \mathrm{~km}^{2}$ (which is about the size of Germany, Belgium and The Netherlands taken together). One or more of the indicators for each of the domains developed in the Arctic Social Indicators report will be applied to the Inuit regions of Alaska. The chapter will present some of the differences and similarities between the three regions and, wherever the data allow it, within the regions. 


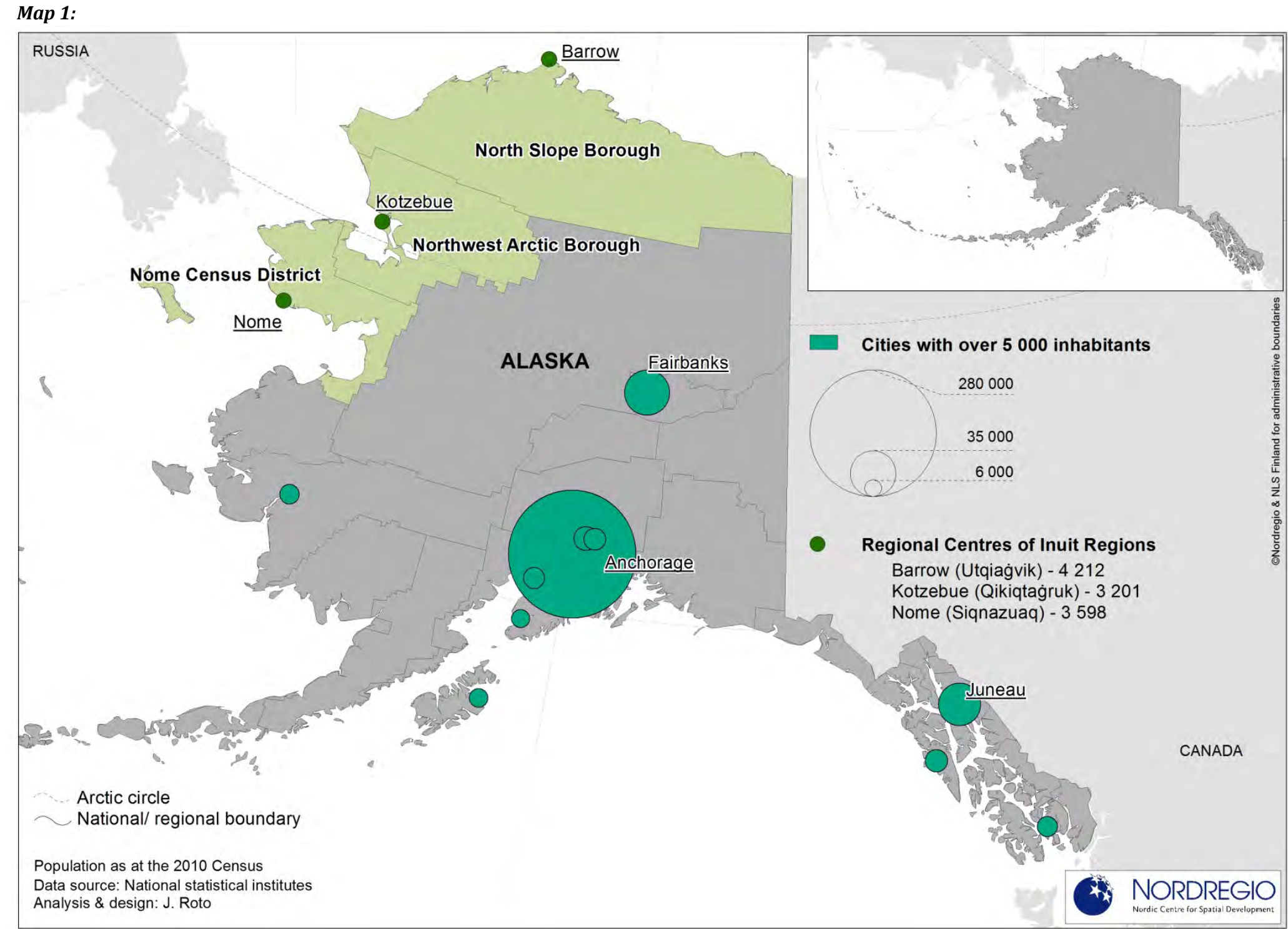


It should be clear from the beginning that this chapter does not intend to reflect the views of local residents on social indicators and human development. Instead, this chapter is based entirely on publicly available data about the region(s) and thus an exercise in trying to make sense of census data and other numbers through the lens of the ASI framework. The chapter will start with a regional overview before proceeding to individual domains, followed by conclusions.

The Inuit across the circumpolar region are a group of culturally similar indigenous peoples inhabiting the Arctic regions of Canada (Northwest Territories, Nunatsiavut, Nunavik, Nunavut, Nunatukavut), Denmark (Greenland), Russia (Siberia) and the United States (Alaska). The Inuit dialects are grouped under Eskimo-Aleut languages, with the Inupiat and Yup'ik branches residing in Alaska. The label "Eskimo" is still used in Alaska and is not considered to be offensive as it is in other parts of the Arctic (ANLC 2011).

While this chapter will only address the groups living in Alaska, the next chapter of this volume (chapter 6) will provide a pan-Inuit perspective.

An Inupiaq woman overlooking the Beaufort Sea near Barrow. Behind her, the first whale of 2011 spring whaling season is being butchered and whale blood is slowly reddening the sea ice

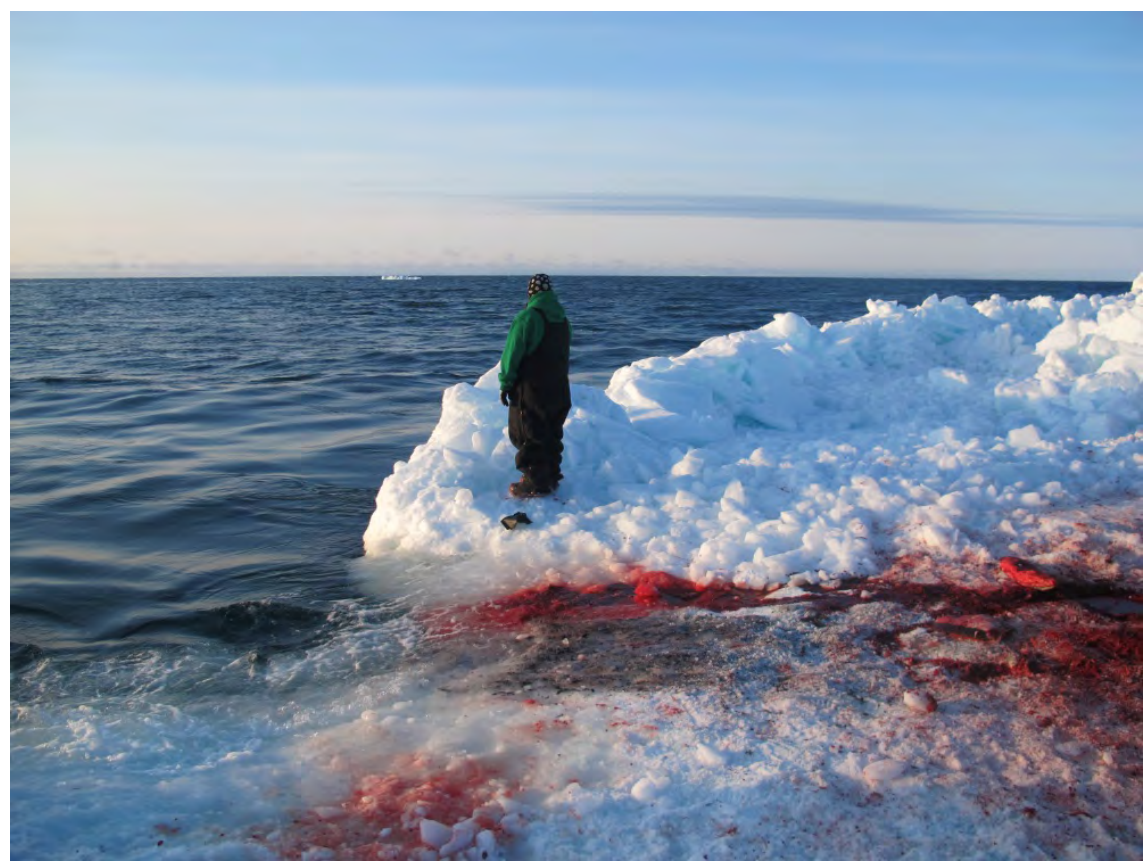

Photo taken by Ilona Kemp during spring 2011. 


\section{The North Slope Region (North Slope Borough)}

The northernmost of the three Inuit regions of Alaska is the North Slope region, which is administratively defined as the North Slope Borough. The North Slope region lies entirely north of the Arctic Circle (68 north), with the northern most point being Point Barrow at approximately 71 degrees north. The region encompasses $94,763^{\circ}$ square miles of terrain; of which $88,817^{\circ}$ square miles is land and $5,946^{\circ}$ square miles $(6.27 \%)$ is water. Its western coastline is along the Chukchi Sea, while its eastern shores (beyond Point Barrow) are on the Beaufort Sea. The North Slope region comprises $15 \%$ of the total land area in Alaska. There are no major roads except the Dalton Highway, which extends from Fairbanks to Prudhoe Bay, as well as seasonal ice roads. Travel is primarily dependent on air, though there is some travel by snow machine in winter, and marine travel during the summer. The North Slope region is currently comprised of eight villages: Barrow, Point Hope, Wainwright, Nuiqsut, Point Lay, Kaktovik, Atqasuk and Anaktuvuk Pass.

The North Slope was first permanently settled about 4,000 years ago. The Inupiat people were nomadic hunters, and gatherers traditionally following animal migrations and subsisting on whale, caribou, walrus, seal and birds. It was strictly a subsistence economy with a culture focused on the harvest of the bowhead whale. Active trading between Alaskan and Canadian bands also took place. Oil exploration in the 1960s led to the development of the petroleum reserves in Prudhoe Bay and subsequently, the building of the Trans-Alaska Pipeline in the 1970s. North Slope Eskimos cast the lone vote in opposition to passage of the Alaska Native Claims Settlement Act (ANCSA), which passed in December 1971. After the passage of ANCSA, families from Barrow re-settled the formerly abandoned villages of Atqasuk and Nuiqsut to gain control over the lands allocated to each settlement in the region. The North Slope Borough was established in 1972 with the right to tax oil companies for land use operations at Prudhoe Bay. Eben Hopson was the first borough mayor. Under his leadership, the borough invested millions of dollars in tax revenues for sanitation services, water and electrical services, health services and other amenities, which, until that time, were not available to most residents. In 1972 the borough also established the North Slope Borough School District to operate the local schools, which gave residents, rather than the Bureau of Indian Affairs, control over the education of their children.

As of the census of 2010, there were 9,430 people residing in the North Slope region. The racial makeup of the region was 33.4\% White, 54.1\% American Indian and Alaska Native, mostly Inuit, 1\% Black or 
African American, 4.5\% Asian, with the remaining 7\% from other races. $42.84 \%$ reported speaking Iñupiaq or "Eskimo" at home. There were 2,029 households out of which $39.6 \%$ had children under the age of 18 living with them, $37.8 \%$ were married couples living together, $19.9 \%$ had a female householder with no husband present, and $28.9 \%$ were non-families. $23.6 \%$ of all households were made up of individuals and $3.5 \%$ had someone living alone who was 65 years of age or older. The average household size was 3.34 people and the average family size was 3.93 (Census 2010).

In the North Slope Borough the population age was spread out with $27.1 \%$ under the age of $19,8 \%$ from 20 to $24,35.9 \%$ from 25 to 44 , $32.9 \%$ from 45 to 64 , and $4.3 \%$ who were 65 years of age or older. The median age was 35.1 years, for women 28.5 years and men 38.8 years.

\section{Members of a whaling crew in Barrow travelling out onto the sea ice with snow machines and sleds to assist their crew in pulling and cutting up the whale that has just been caught}

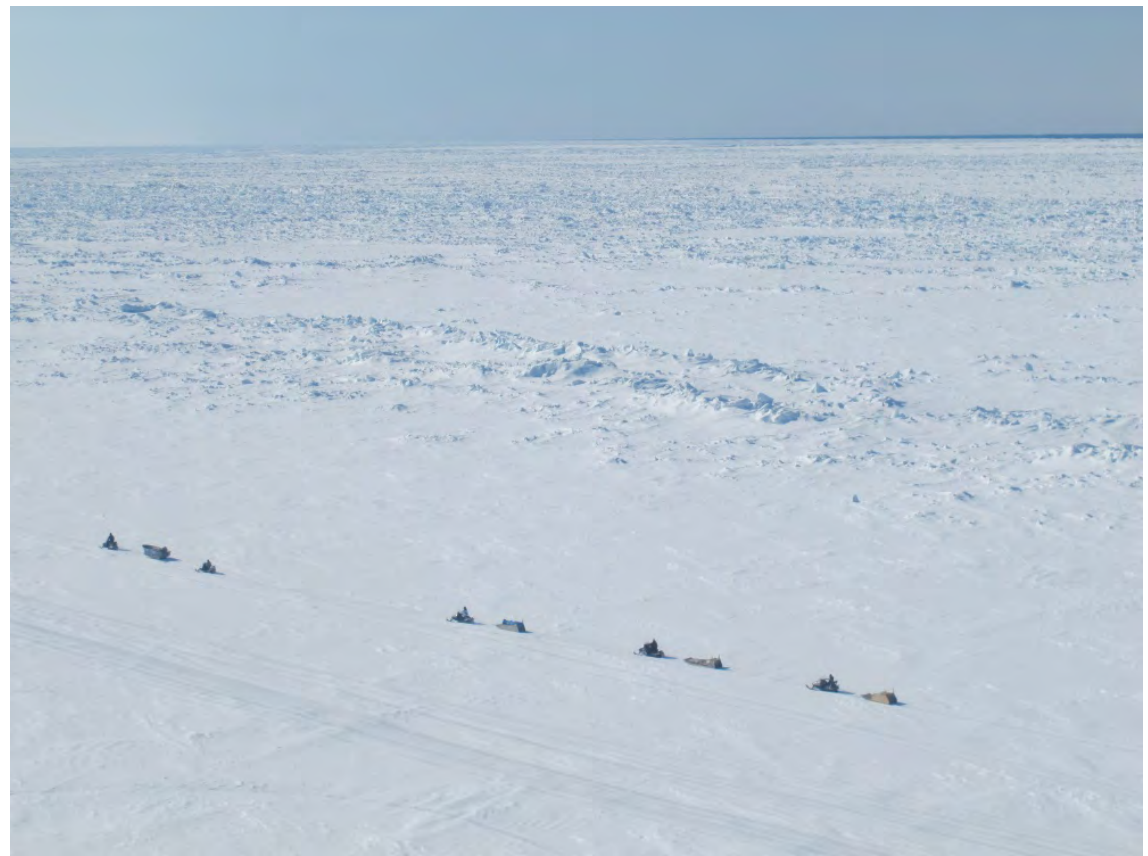

Photo taken by llona Kemp during spring 2011.

The Iñupiat people of the North Slope region have been actively engaged in promoting their language and cultural traditions through the establishment of regional and local institutions such as the Iñupiat History, Language, and Culture (IHLC) Commission, the Iñupiat Heritage Center, the Simon Paneak Memorial Museum (Anaktuvuk Pass), and Ilisagvik College. 
While the North Slope Borough has relied heavily on the development of the Prudhoe Bay and Beaufort Sea oil fields as the foundation of its economy, the Arctic Slope Regional Corporation (ASRC) has been one of the most successful of the 13 regional corporations formed under the Alaska Native Claims Settlement Act in 1971. This natural resourcebased corporation employs nearly 10,000 people, has a growing shareholder population of 11,000 , and has title to nearly five million acres of land. A founding principle of ASRC is respect for the Iñupiat heritage. The family of companies of ASRC extends into the professional fields of engineering, financial management, oil and gas support services, petroleum refining and distribution, civil construction and communications (Arctic Slope Regional Corporation 2013)

Each of the communities in the North Slope Borough has its own village corporation as well. The largest of these, the Ukpeagivik Iñupiat Corporation (UIC) headquartered in Barrow, provides social and economic resources to its 2,100 shareholders and their descendants, who primarily reside in Barrow. UIC is ranked 8th among Alaska Business Monthly's annual survey of Alaskan-owned companies. UIC owns approximately 212,000 acres of land on Alaska's North Slope and employs over 1,400 people worldwide, with over 750 in Alaska (Ukpeagvik Inupiat Corporation 2013). Other employment opportunities on the North Slope are centered on government services, tourism and construction. In addition to the corporate economy, there continues to be a heavy reliance on subsistence foods, including fishing, whale and seal hunting, gathering of plants, and harvesting of land mammals.

\section{The Kotzebue Region (Northwest Arctic Borough)}

The Kotzebue Region, with the official name Northwest Arctic Borough, includes approximately 36,000 square miles $(57,937 \mathrm{~km})$ of land as well as 3,560 miles $(5,729 \mathrm{~km})$ of shoreline and is the second largest borough in Alaska (Northwest Arctic Borough 2013). There are 11 villages in the region: Ambler, Buckland, Deering, Kiana, Kivalina, Kobuk, Noatak, Noorvik, Selawik, Shungnak and the hub town, Kotzebue. Travel to the region is by air, with locals using boats in the summer and snow machines in the winter to get around.

The region has been the home of Iñupiat Eskimos for the past 10,000-15,000 years (Maniilaq Association 2003). Subsistence is still of great importance to the inhabitants of the Kotzebue Region. The economies in many of the villages are based on hunting, fishing and gathering as well as supplemental wage employment (Hayley \& Magdanz 2008:25). Subsistence is intrinsically connected to values, identity, and social relationships as well as being an economic resource. Sharing of 
subsistence foods helps reinforce and maintain social relationships, while participating in subsistence activities teaches new generations about values and identity.

Mineral exploration and development have been the economic focus of the region since the Red Dog Mine opened in 1989. The Northwest Alaska Native Association (NANA) was founded as a result of ANCSA and owns the land that the Red Dog Mine is located on. In 1982 NANA made an operation agreement with the mining company Teck Resources Unlimited to open the mine. NANA receives yearly revenues from the mine and shares these with its shareholders (NANA). The ownership of the land gives NANA political influence as they have a voice in what happens to the land and the development of the mine. Today the Red Dog Mine is the world's largest open pit, zinc mine and is the second largest employer in Northwest Alaska (Hayley et Magdanz 2008:25).

At the 2010 census, there were 7,523 people, 1,919 households and 1,428 families residing in the borough. There were 2,707 housing units. The racial makeup of the borough was $16.3 \%$ White, $87.1 \%$ Native American, 1.1\% Black or African American, 1\% Asian, while 0.3\% identified as other ethnicities. $40 \%$ reported speaking Iñupiaq at home.

There were 1,919 households of which $45.1 \%$ had children under the age of 18 living with them, $40.4 \%$ were married couples living together, $21 \%$ had a female householder with no husband present, and were nonfamilies. $21 \%$ of all households were made up of individuals and $5.1 \%$ had someone living alone who was 65 years of age or older. The average household size was 3.72 and the average family size was 4.32 .

Age distribution was $39.5 \%$ under the age of $18,9.4 \%$ from 19 to 24 , $24.2 \%$ from 25 to $44,20.7 \%$ from 45 to 64 , and $6 \%$ who were 65 years of age or older. The median age was 25.7 years; for women 24.5 year; for men 27.1 years (Census 2010).

The borough was formed in 1986. It has three main departments: Planning, Public Services and Economic Development. A mayor and 11 assembly members are in charge of managing the region (Northwest Arctic Borough 2013). Most of the activity of the borough goes on in Kotzebue. Kotzebue lies on the coast by the terminus of the Selawik, Kobuk and Noatak rivers. The town was named after the Russian explorer Otto von Kotzebue who "discovered" the sound in 1818. Its location made the town an important trading post long before European contact (City of Kotzebue 2011). In 1897 reindeer herding was introduced to the region to try to expand economic activity (NANA 2013).

One of the major issues of the Kotzebue region is its disappearing shoreline, which threatens to take the village of Kivalina with it. The 
village of 400 people is facing a relocation of the entire village due to the fast erosion of the coast (Relocate-ak 2012). It is estimated that the current village site will stay above water for 10-15 years. The residents have had to be evacuated three times within the last 5 years due to storms threatening to top the town's sea walls (Alaska Dispatch 2013).

\section{The Bering Strait Region (Nome Census Area)}

The Bering Strait region of Western Alaska includes the Seward Peninsula and surrounding islands as well as the shore of Norton Sound. Taken as a political entity, the areas served by the Bering Straits Regional Corporation extend all the way to the southern shore of Norton Sound and lie somewhat south of the Arctic Circle. The westernmost point on the North American continent is found at Cape Prince of Wales on the eastern shore of the Bering Strait itself. Transportation to the region and within the region is largely by air. Jets fly from Anchorage to Nome, and small airplanes travel from Nome to the villages. There were scheduled flights to Providenya in Russia during the 1990s, but traffic has decreased, and the trip is now made by infrequent charter flights. Three highways extend from Nome to the north, northwest, and northeast, but these roads are not connected to the road system outside of the region. There are periodic discussions in Alaska on the possibility of building a road to Nome to connect it with Alaska's cities and open up opportunities for mining and other extractive industries, but nothing has happened yet. A link to Siberia in the form of a bridge or a tunnel across Bering Strait has also been given consideration, although no serious proposal is in the works.

Nome, with a population of 3,600 is the regional hub, with a jet airport, a port, and government offices and small businesses. The region also comprises sixteen currently inhabited villages, with populations between 100 and 800. These are Shishmaref, Diomede, Wales, King Island, Brevig Mission, Teller, Mary's Igloo, Solomon, Council, White Mountain, Golovin, Koyuk, Shaktoolik, Unalakleet, Stebbins, St. Michael (Bering Straits Native Corporation).

The Nome census area includes 9,492 residents at the 2010 census: 16.4\% White, 75.8\% Alaska Native, $0.3 \%$ Black or African American, 1\% Asian. 6.2\% identified as more than one race, primarily White and Alaska Native. There are 2,815 households in the area, of which $38.9 \%$ are husband-wife families, $17.5 \%$ are female householders without a husband present, while $14 \%$ are male householders without a wife present. $29.6 \%$ are non-family households. 
$38.3 \%$ are under $19,7.7 \%$ are $19-24,25.2 \%$ are $25-44,22.4 \%$ are $45-64$, and $6.4 \%$ are over the age of 65 . The median age is 27.6 , for women 26.7 years, for men 28.3 years (Census 2010).

About $51 \%$ of Nome's population is Alaska Natives who have moved in from surrounding villages since the modern town of Nome came into existence with the gold rush of 1900. Early explorations brought the first Europeans to the region, with the Dezhnev expedition of 1648, financed by the Russian crown. Vitus Bering, whose name was given to the strait, sailed through the strait in 1728, although he apparently missed the American coast, which was not visible through the fog. The gold rush brought a great influx of outsiders, which meant enormous cultural change. Missionaries from a number of Protestant denominations soon followed, along with Roman Catholics, and Christianized the local population as they also helped address social and health problems precipitated by the rapid culture change. The region was hit hard by the influenza epidemic of 1918, which left behind many orphans, some of whom were raised in mission schools (Ray 1991).

The indigenous population is Eskimo, with Inupiaq groups on the mainland of the Seward Peninsula as well as on King Island - now depopulated - and Little Diomede. Seward Peninsula Inupiaq is one of two major dialect groups in Alaska, the other being North Alaskan Iñupiaq and includes the Qawiaraq and Bering Strait dialects. These dialects include a number of sub-dialects, and language variation in the region is great. Siberian Yupik is spoken on St. Lawrence Island, and Central Alaskan Yup'ik is found south of Nome, in the villages along Norton Sound, where it coexists with Inupiaq, ostensibly because of the southern movement of Inupiaq populations into Yup'ik territory. Native language use is declining in the region and Inupiaq speakers tend to be the most advanced in age, although the Yup'ik areas are also experiencing an interruption of intergenerational language transmission. Most schools in the Alaska portion of the Bering Strait region have Native language programs, which teach Inupiaq or Yupik as a second language, although St. Lawrence Island has some school-aged children who have learned the Yupik language to some degree at home (Kaplan 1990).

The traditional economy of the region involved subsistence hunting and gathering. Fishing in the ocean and rivers yields a variety of fish, from salmon and herring to trout and whitefish. Sea mammal hunting has always been important, and islanders have long hunted walrus and seals. St. Lawrence Islanders conduct annual bowhead whale hunts, and whales were formerly hunted at Wales and Diomede. Over the past fifty years or so, moose have increasingly moved into the Seward Pen- 
insula, and they too have become part of the subsistence economy. Reindeer herding began in the late nineteenth century throughout large parts of northern and western Alaska, and the Seward Peninsula has the only remaining herds, which continue to supply meat for commercial sale. Gathering of greens, roots, and berries remains an important summer activity for women and children, supplementing a diet rich in meat. Annual runs of herring and pink salmon are fished commercially in Norton Sound. Employment in salaried jobs is often rare in villages and consists largely of work for the schools and Native corporations, along with jobs at the local store. Many more jobs are found in Nome, which is home to government agencies, retail outlets, hotels, a hospital, and infrastructure support, such as road crews. Summer tourism also provides local employment. The Bering Straits Native Corporation was formed under the Alaska Native Claims Settlement Act in 1971 and has 6,700 shareholders. Kawerak, Inc. provides social services, job training and other services as the non-profit corporation for the region. Additionally, each village has its local corporation under Bering Straits (Kawerak 2013).

Figure 1:

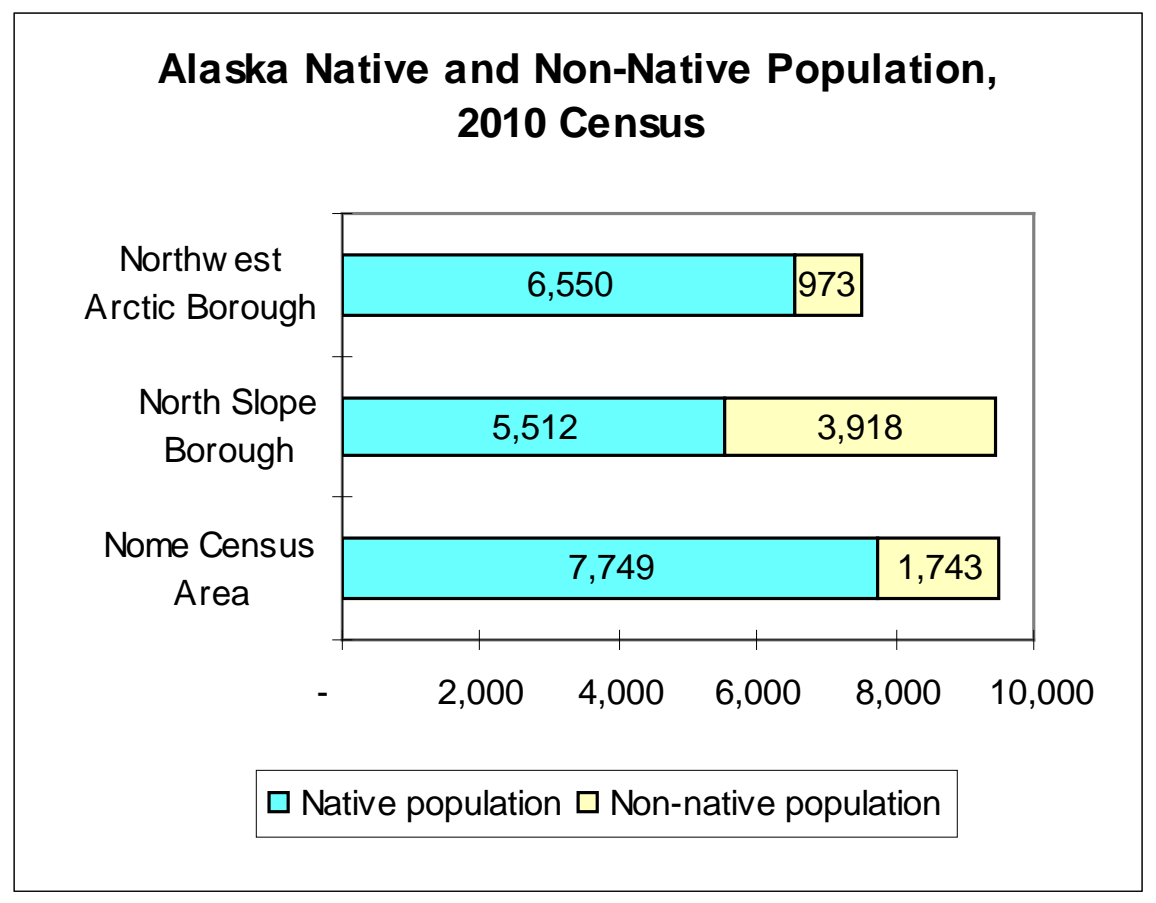

Source: 2010 Census data. 


\subsection{Data and Methodology}

The first Arctic Social Indicators report (ASI 2010) discussed the issues involved in measuring indicators for the six domains, emphasizing availability of data. The study recognized that many of these indicators make the most sense when referring to arctic indigenous people, and recommended that data for indicators be available separately for indigenous and non-indigenous populations. ASI indicators for several of the domains such as cultural wellbeing and fate control either make no sense or would be difficult to construct and interpret for non-indigenous residents. For other domains, such as material wellbeing, health, and education, there are large disparities in wellbeing.

The focus on indigenous people is appropriate for the Inuit regions of Alaska, where a majority of the population outside is of Inupiaq heritage. Most non-indigenous people in these regions are short-term residents drawn for economic opportunity, and highly mobile. Constructing indicators for indigenous residents presents two significant challenges, however. The first challenge is that typically the only source of indicator data for many of the ASI domains that separately reports data by race or ethnicity is the U.S. Census and its successor since 2000: the American Community Survey. The second challenge relates to the fact that race, or ethnicity, is a self-reported characteristic, whose social construction has evolved over time.

Before 2000, the U.S. Census Bureau required census respondents to report a single racial identity. Beginning with the 2000 census, respondents had the option to report multiple identities. While the proportion of the population reporting two or more races is still small in Alaska, it has been growing rapidly. The 2000 Census reported data at the census area and community level for individuals listing their race as American Indian and Alaska Native alone, and also separately for individuals reporting an identity of American Indian and Alaska Native and one or more other races. While the definition of race has not changed since 2000, the Census Bureau reporting conventions changed with the American Community Survey (ACS). The ACS reports data only for individuals reporting a single race of American Indian or Alaska Native and for individuals reporting any two or more races. Consequently, it is not possible to distinguish people with a mixed Alaska Native identity from other mixed-race individuals in more recent data. Table 1 summarizes the indicators available for Inuit regions of Alaska by domain, along with the data source. 
Table 1: Summary of ASI indicators used for Inuit regions of Alaska

\begin{tabular}{|c|c|}
\hline Indicator & Data source \\
\hline \multicolumn{2}{|l|}{ Health/demography } \\
\hline Infant mortality rate & Alaska Division of Vital Statistics \\
\hline Net in-migration rate, Alaska Natives & U.S. Census and American Community Survey \\
\hline Suicide rate, age-adjusted & Alaska Division of Vital Statistics \\
\hline Total population, Alaska Native and Non-native & U.S. Census \\
\hline \multicolumn{2}{|l|}{ Material wellbeing } \\
\hline Real per-capita personal income, Alaska Natives & U.S. Census and American Community Survey \\
\hline Total employment by place of residence & U.S. Census and American Community Survey \\
\hline Local per-capita subsistence meat and fish harvests & Alaska Division of Subsistence and North Slope Borough \\
\hline Net in-migration rate, Alaska Natives & U.S. Census and American Community Survey \\
\hline \multicolumn{2}{|l|}{ Education } \\
\hline $\begin{array}{l}\text { Percentage of Alaska Native adults with post- } \\
\text { secondary education }\end{array}$ & U.S. Census and American Community Survey \\
\hline $\begin{array}{l}\text { The proportion of students pursuing post-secondary } \\
\text { education opportunities }\end{array}$ & Alaska Native Policy Center \\
\hline $\begin{array}{l}\text { The ratio of students successfully completing post- } \\
\text { secondary education }\end{array}$ & Alaska Native Policy Center \\
\hline $\begin{array}{l}\text { The proportion of graduates who are still in the } \\
\text { community } 10 \text { years later. }\end{array}$ & Alaska Native Policy Center \\
\hline \multicolumn{2}{|l|}{ Cultural vitality } \\
\hline $\begin{array}{l}\text { Percentage of Alaska Native households speaking a } \\
\text { language other than English at home }\end{array}$ & U.S. Census and American Community Survey \\
\hline \multicolumn{2}{|l|}{ Contact with nature } \\
\hline Local per-capita subsistence meat and fish harvests & Alaska Division of Subsistence and North Slope Borough \\
\hline \multicolumn{2}{|l|}{ Fate Control } \\
\hline $\begin{array}{l}\text { Percentage of government spending raised from } \\
\text { local sources }\end{array}$ & Alaska Taxablea and Teck Cominco Corporation \\
\hline $\begin{array}{l}\text { Percentage of lands owned by Inupiaq Regional and } \\
\text { Village Corporations }\end{array}$ & Alaska Native Regional Corporation websites \\
\hline $\begin{array}{l}\text { Percentage of Alaska Native households speaking a } \\
\text { language other than English at home }\end{array}$ & U.S. Census and American Community Survey \\
\hline
\end{tabular}

${ }^{\text {a }}$ Office of the State Assessor (annual publication).

Health and Population: Infant mortality is the main indicator recommended by ASI (2010). To this we add the suicide rate as an indicator of behavioral health. To address the random fluctuations in the data for such small populations, we represent the indicators as multiple-year moving average rates. The Alaska Division of Vital Statistics, the source 
of mortality data, publishes a single combined infant mortality rate for the North Slope Borough and the Northwest Arctic Borough. Net migration is the recommended indicator of population dynamics in the first ASI report (2010). Again, due to small population sizes, we report rates as a percentage of the population, estimated from population change, births and deaths over a period of years.

Material wellbeing: The first ASI report recommends using percapita household income as a core indicator of economic wellbeing alongside five other supporting indicators. It is not possible to generate meaningful per-capita household income figures for indigenous residents because households can be mixed and there is no information on ethnic composition of households other than the self-described "head of household". Consequently, we used the published Census and ACS figures on per-capita income of individuals rather than households. The difference between individual per-capita income and per-capita household income is that the former includes income of people living in group quarters such as remote work camps and prisons, while the latter excludes the group quarters population. The group quarters population is very small except for the petroleum facilities at Prudhoe Bay in the North Slope Borough. The census indigenous population at Prudhoe Bay is very small, however, so the effect is insignificant for the Alaska Native population.

Net migration rate, measured as discussed above, represents another measure of material wellbeing recommended by the first ASI report. Reliable estimates of the unemployment rate, a recommended supporting indicator, are not meaningful for the Inuit regions of Alaska, due to seasonal work and a low labor force participation rate. We substitute total employment by residents (as distinguished from employment by place of work, which includes non-resident workers) as a measure of the strength of the local labor market. Subsistence harvests of local foods and other resources obtained via household production also contributes to material wellbeing. We described data on subsistence harvests below. Another alternative economic wellbeing measure that could be considered in the future is a measure of government transfer income as a share total income.

Education: The first ASI report recommended three main indicators, all of which are based on educational attendance (the proportion of students pursuing post-secondary and completing education) or retention of educated people in a community (within 10 years after graduation). Due to data limitations, the only reliable indicator of education is the educational attainment level of the population, obtained from U.S. Cen- 
sus and ACS. We focus on the percentage of the indigenous population with any post-secondary education. This measure of educational attainment is a composite indicator that measures how school completion levels of the population interact with mobility.

Cultural Wellbeing: The composite indicator of cultural vitality suggested by the ASI report incorporates cultural autonomy (indicated by presence of institutions for cultural self-determination), language retention, and belonging (measured by participation in traditional subsistence activities). Information on language retention is available in the U.S Census and ACS, and in the Survey of Living Conditions in the Arctic (SLiCA) (Kruse et al., 2008).

Census data that refer to languages other than English, as in "Population not Speaking English at Home", should not be interpreted as indicating Inupiaq exclusively, since languages other than Inupiaq and English are spoken in regional hubs, including Spanish, Korean, and other Asian languages.

\section{Drying salmon in White Mountain}

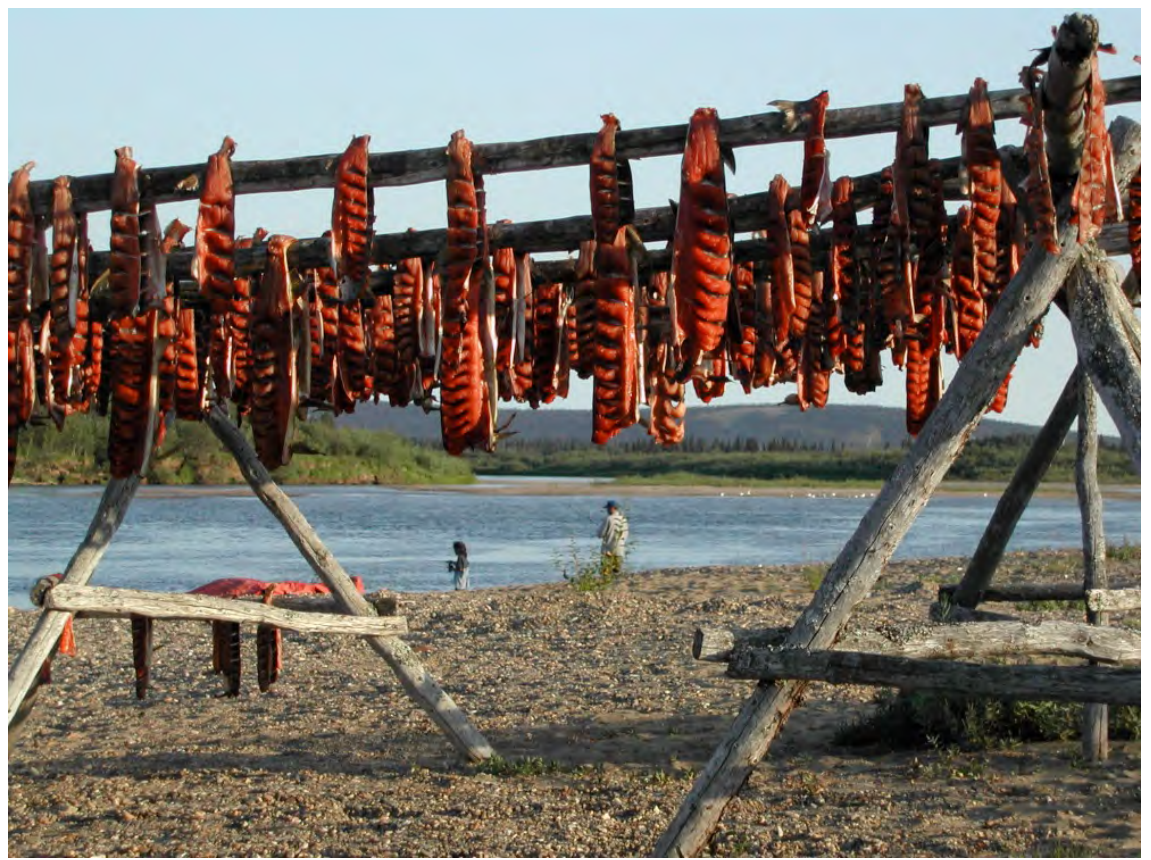

Photo taken by Elizabeth Marino during summer 2004.

Contact with Nature: The recommended indicator for contact with nature is the consumption and/or harvest of traditional foods. Data on subsistence harvests are not systematically collected in Alaska. The Alaska Division of Subsistence conducts harvest surveys in individual communities when 
funding is available. These surveys often take place in conjunction with environmental reviews for prospective industrial activities. Communities located at a distance from potential resource development may not have ever been surveyed. The North Slope Borough has also conducted subsistence harvest surveys in the past, although not recently. Consequently, it is difficult to draw inferences about differences among regions or changes over time in harvest levels. The lack of consistent measures of subsistence harvests has been cited as a critical deficiency in the social observing system in the Arctic (Kruse 2011). We report the data from communities in the three Inuit regions available (with the caveat that changes observed over time in the data do not necessarily reliably indicate actual changes).

Fate Control: The first ASI report recommended using a composite indicator of fate control with four components representing political power, economic self-reliance, cultural empowerment and control over land. Some data are available for three measures suggested in the report: the percentage of surface lands legally controlled by the inhabitants (control over lands); the \% of public expenses paid from locally generated funds (economic control); and the \% of people speaking their ancestral language (cultural control). We interpret the latter measure as referring to the indigenous population, using the indicator described above for cultural vitality.

Information about the percentage of public expenses paid from locally generated funds can be pieced together from multiple sources. The Alaska Department of Commerce, Community, and Economic Development publishes data on local tax revenues by community and local government expenditures. Tax revenues do not include a separate payment in lieu of taxes to the Northwest Arctic Borough from Teck Cominco Corporation related to the Red Dog Mine. We constructed estimates of state and federal government expenditures in the Inuit regions of Alaska from data analyzed in Goldsmith (2007).

A simple indicator of local political control of indigenous people is the percentage of the population that is indigenous (available from census data). An indicator of land control is difficult to determine at the community or even regional level. Village and regional corporations established under the Alaska Native Claims Settlement Act of 1971 (ANCSA) received land around communities. However, shareholders are individual beneficiaries who could move anywhere and exercise control over ancestral lands from afar. Data on residence of shareholders is not systematically available. Assuming that control of ANCSA Inupiaq corporations remains local to the Inuit regions, we 
measure \% of land in each regions owned by ANCSA corporations as a measure of control over land.

\subsection{Results}

\subsubsection{Domain: Health and Population}

Traditional Inupiaq health care often involved herbal medicines and healers who practiced palpation and "hands on" treatments. Infectious diseases were all but unknown to pre-contact Alaskan Iñupiat, and their arrival with whalers, miners, and others in the latter half of the nineteenth and early twentieth centuries brought disastrous results. The influenza epidemic of 1918 struck particularly hard in Northwest Alaska and decimated much of the local population. With little medical care available in remote areas, the Indian Health Service was established to provide federal health services to American Indians and Alaska Natives. Providing health services to members of federally-recognized groups was a result of the special relationship between the federal government and Native Americans. This relationship is based on Article I, Section 8 of the Constitution, and is substantiated by numerous treaties, laws, Supreme Court decisions, and Executive Orders. The Indian Health Service is the principal federal health care provider and health advocate for Native people, and its goal is to raise their health status to the highest possible level." (www.ihs.gov).

ASI (2010) suggested two primary indicators for the Health and Population domain: infant mortality and net-migration. We are in the lucky position to have data for both indicators for the Inuit regions of Alaska. Both of them are presented in Figures 2, 3, and 4. 
Figure 2:

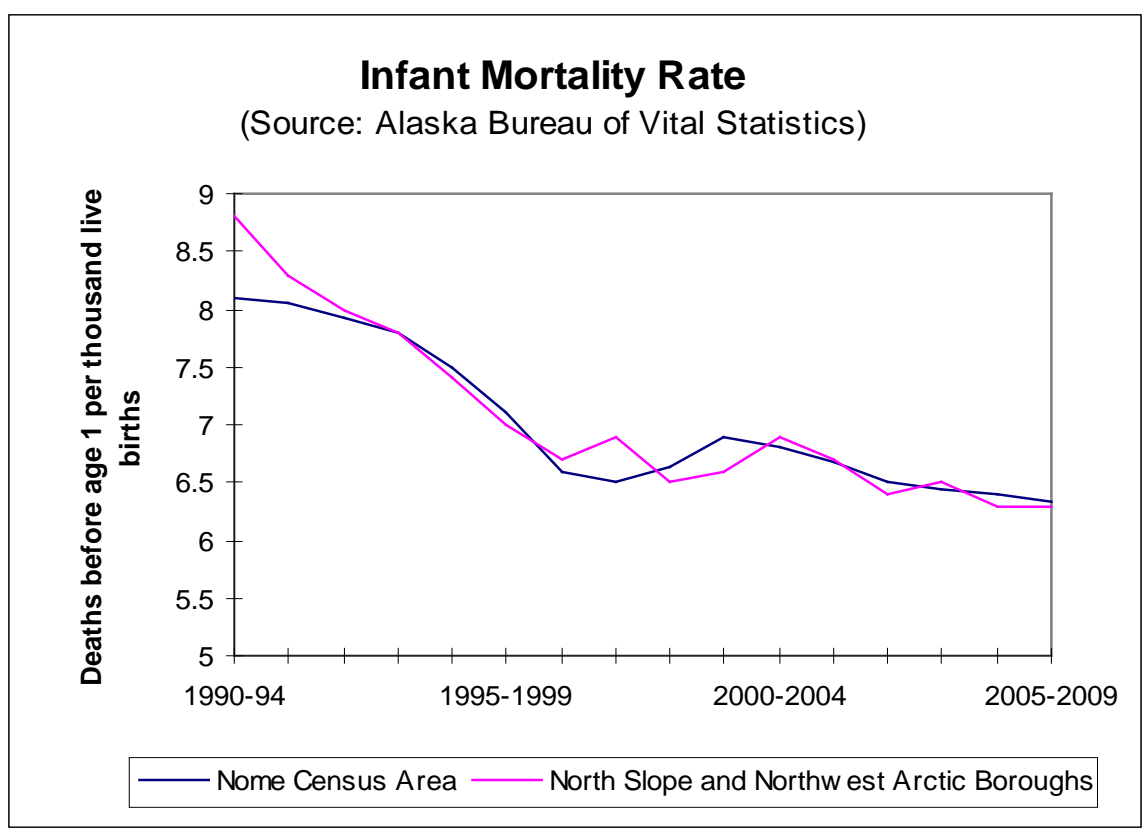

Figure 3:

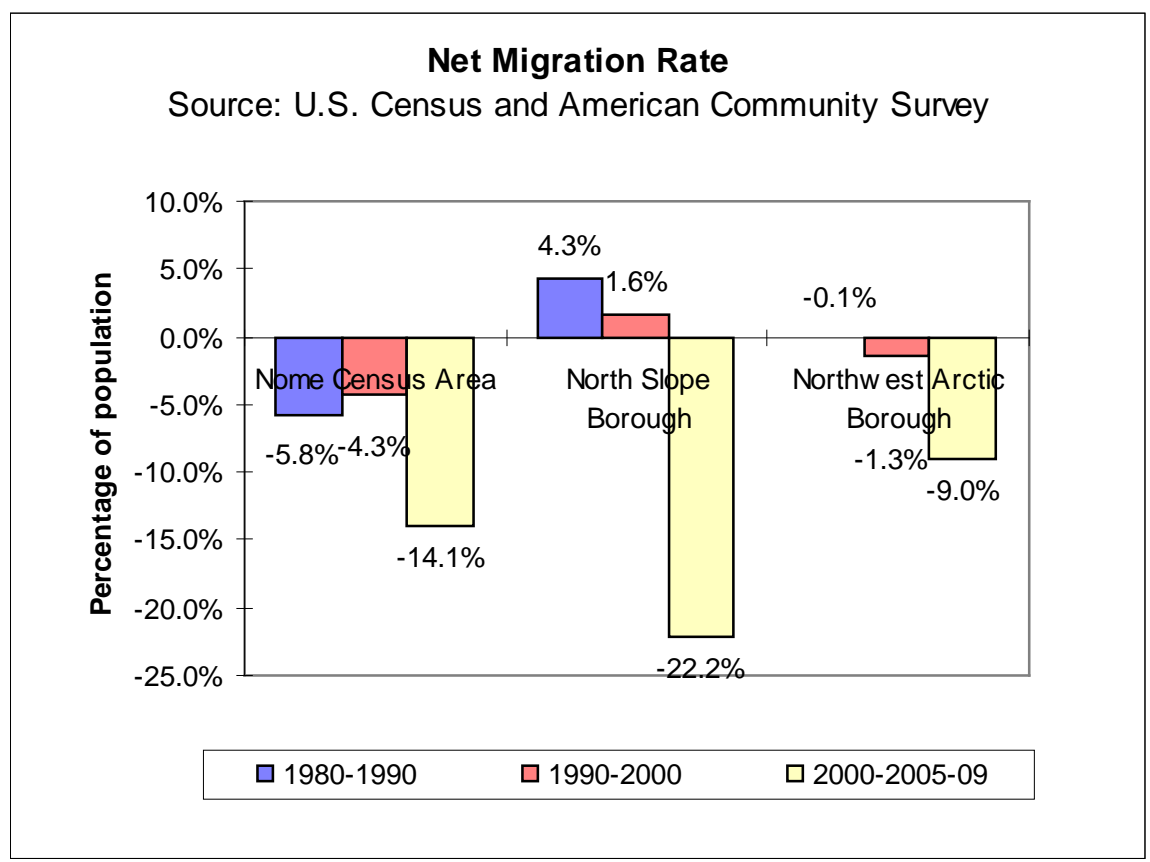


Figure 4:

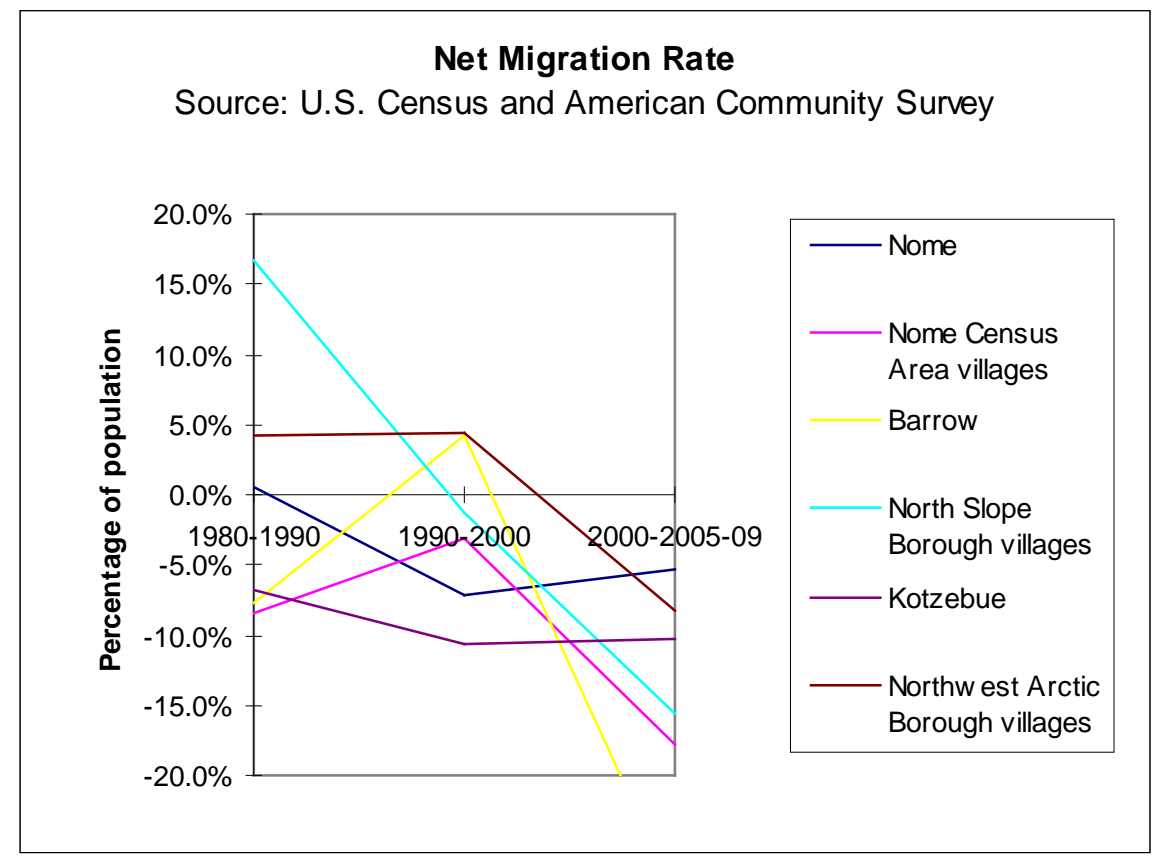

Alaska Natives, along with the Native American population in general, have important health issues that give them a life-expectancy lower than that of the general population. "On almost every indicator of morbidity, mortality, and quality of life Native Americans are substantially worse off than the dominant culture and as bad or worse off than other minorities" (Heckler 1985).

In addition to these two primary indicators, we have decided to include an additional indicator: the suicide rate. Table 2 contains information regarding this additional factor. After all, suicide or its absence is an important indicator of well-being among the Inuit of Alaska and elsewhere. Table 2 contains average annual age-adjusted suicide deaths per 100,000 for the years 2005-2007.

Table 2: Average Annual Age-adjusted Suicide Rates (2005-07)

\begin{tabular}{lcccc}
\hline Region & North Slope & NANA & Bering Strait & Alaska \\
\hline Groups & & & \\
Inupiat & 73.5 & 76.5 & 77.5 & \\
All Alaska Natives & & & 43.1 \\
All Alaska Whites & & & 17.3 \\
\hline
\end{tabular}


The primary health indicator - infant mortality - shows a straightforward positive trajectory for all three Inuit regions of Alaska. While the data for the secondary health indicator - suicide rates - are not dynamic and show only point in time, they paint a troubling picture of the situation. The Inuit from northern Alaska have suicide rates almost double of other Alaska Natives, and more than four times as high as Caucasians living in Alaska. Regardless of whether time-series data would indicate an improvement or not, the data are troublesome by themselves.

The population data - as seen through the net-migration indicator are troublesome as well. While there might be a number of external factors at play, such as high population turn-over due to extractive industry jobs, the significant net-outmigration in the recent years might indicate a potential for future years.

\subsubsection{Domain: Material Wellbeing}

ASI (2010) defines Material Wellbeing as a measure of local residents' command over goods and services. It is derived from market and nonmarket activity as well as transfers from higher levels of government. Personal income per-capita, household income per-capita, and disposable income per-capita are all measures of the ability of a region's residents to acquire goods and services through the market; thus serving as an indicator of the market component of material quality of life. The contribution made by the non-market sector is difficult and costly to measure, and would require extensive primary data collection. Therefore, the ASI suite of indicators emphasizes per-capita household income. The ASI material wellbeing indicator - per-capita household income - does not provide us with a perfect measure since it excludes the contributions made by subsistence, as well as government transfers.

In this chapter on the Alaska Inuit we have provided data on some of the indicators selected as potential ASI indicators of material wellbeing. They are highlighted here:

- Potential Indicators.

- Per-Capita Gross Domestic Product.

- Per-Capita Household Income.

- Unemployment Rate/Local employment.

- Poverty Rate.

- (Subsistence Harvest) (weight).

- Net-migration Rate. 
While the per-capita household income is the preferred measure of income, we report Alaska data instead for per-capita individual income, in order to be able to distinguish incomes of indigenous and non-indigenous people. Since household members may be from different races, per-capita household income is not available by race. The difference between household income and individual income is that household income does not include individuals living in group quarters in its average, such as people living in remote work camps, military barracks, and prisons. Data on unemployment, another ASI indicator of material wellbeing are unreliable for the arctic regions of Alaska. Many potential workers desire only parttime or seasonal work so that they may pursue subsistence hunting and fishing livelihoods. They may or may not appear in the data as unemployed; nor are they necessarily looking for work. A more reliable, although imperfect indicator of potential employment opportunities, is simply to examine trends in the number of jobs available locally.

ASI indicators on Net-Migration and Subsistence Harvest are not discussed in this section because they were not selected as the main ASI indicator for Material Wellbeing. However, these indicators are discussed in the sections on Contact with Nature and Health and Population.

The best information on per-capita income comes from the U.S. Bureau of Economic Analysis (BEA). The BEA produces the official statistics on Gross Domestic Product (GDP) and Personal Income for the nation. Because the BEA derives much of the data for the estimates from income tax returns, the agency is able to estimate personal income for all counties and census areas based on the addresses listed on the returns. Converted to constant 2011 dollars using the Anchorage Consumer Price Index, the chart shows that per-capita personal income is very similar in the Nome Census Area and Northwest Arctic Borough, which has risen from about USD 20,000 in 1979 to USD 33,000 in 2011. The local tax revenues that the North Slope oil fields provide allow the North Slope Borough to provide services to residents above the level available elsewhere in rural Alaska. Jobs created to provide those services, along with industry jobs, increased per-capita incomes in the North Slope Borough substantially throughout the period relative to the other two areas. 


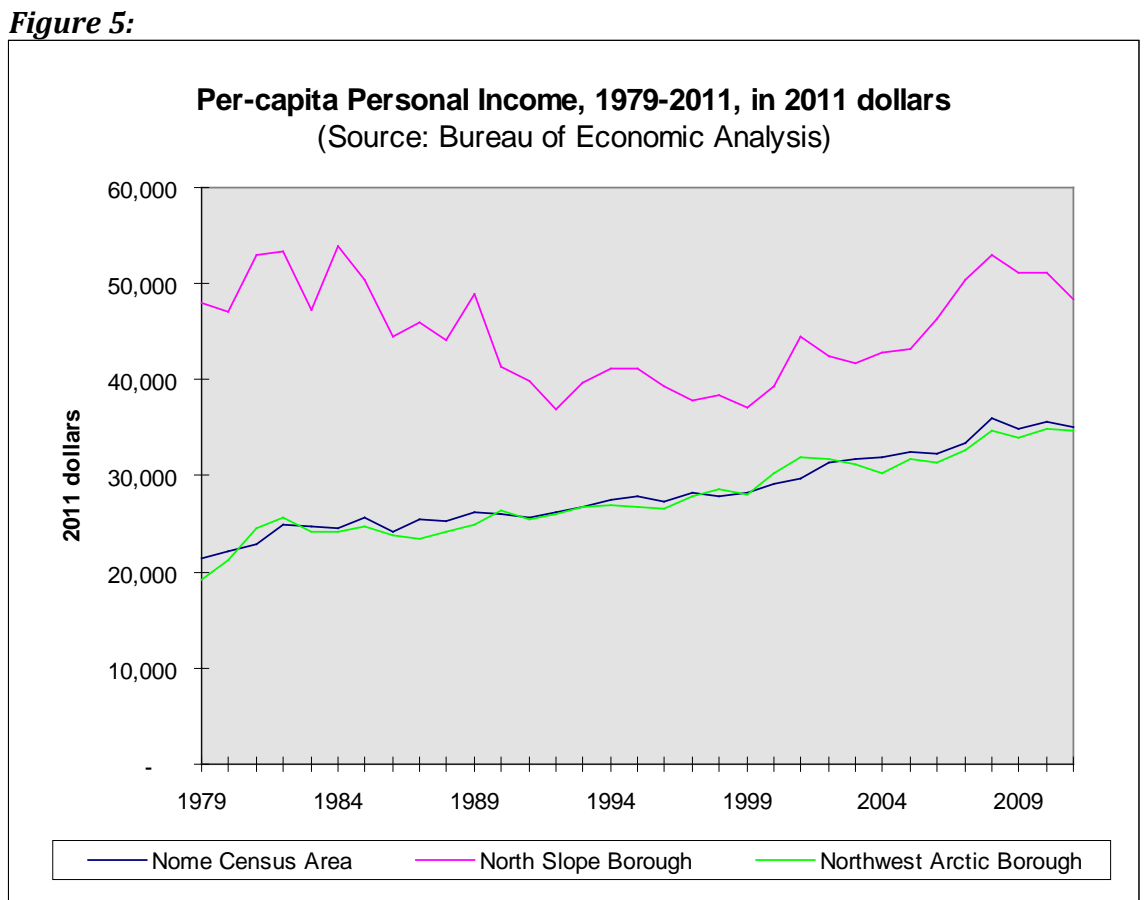

While the BEA data provide the most accurate and comprehensive estimates of personal income, they suffer from two important limitations. First, they have no information on potential differences in income for indigenous and non-indigenous residents, since tax returns do not include information on race. Second, the BEA does not try to disaggregate the estimates to communities within census areas. The American Community Survey (ACS) provides the only recent information on income by race. The ACS has a more accurate definition of residence than the BEA, since it asks respondents specifically to state where they usually live. However, the ACS is taken from a sample of households and only reports data for rural Alaskan communities and census areas in the form of moving averages over a five-year period.

Data from the American Community Survey shows that per-capita income of Alaska Native residents those who describe their race as Alaska Native or American Indian alone - is only about one-third that of nonNative residents. Since the ACS does not separately report data for individuals listing multiple non-Native races separately from those reporting mixed Native and non-Native race, income from the relatively small numbers of mixed-race individuals is included in the non-Native category in the figure. Alaska Native incomes are substantially lower than nonNative incomes in all three areas of arctic Alaska. Per-capita income of Alaska Natives in the wealthiest area - the North Slope Borough - are 
still less than half of non-Native incomes in the poorest area - the Nome Census Area. Among Alaska Natives, Nome Census Area per-capita income of about USD 12,300 is nearly $40 \%$ lower than North Slope Borough income of about USD 20,000. Northwest Arctic Borough income is roughly halfway between the other two areas.

Figure 6:

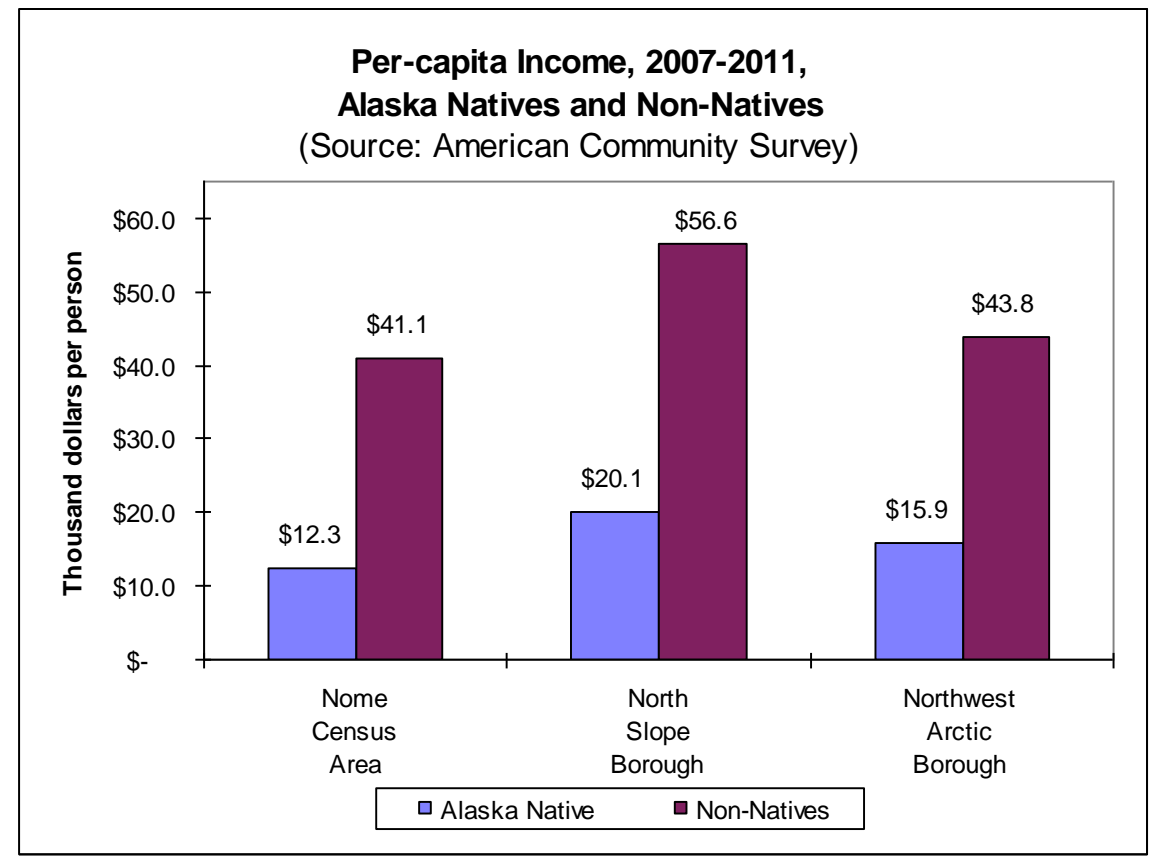

The ASI indicator of per-capita income suggests that substantial disparities in material well-being occur between Alaska Natives living in regional centers and those living in smaller communities (villages). As shown in Figure 7, per-capita income over the period 2005-2009 differed significantly for Alaska Natives between those living in the Inupiat regional centers compared to those living in villages (Source: American Community Survey). The difference in per-capita income was greatest for those living in the Nome Census Area, where the per-capita income was USD 20,400 in regional centers compared to only USD 9,600 in villages. The difference in per-capita income was smallest in the North Slope Borough, with per-capita income in villages being a high of USD 15,500 (the highest per-capita village income for the three areas of Nome Census Area, North Slope Borough, and Northwest Arctic Borough). The greatest per-capita income in regional centers for this period was in the Nome Census Area (USD 20,400), which at the same time had the smallest per-capita income for Inupiat villages (USD 9,600). 
Figure 7:

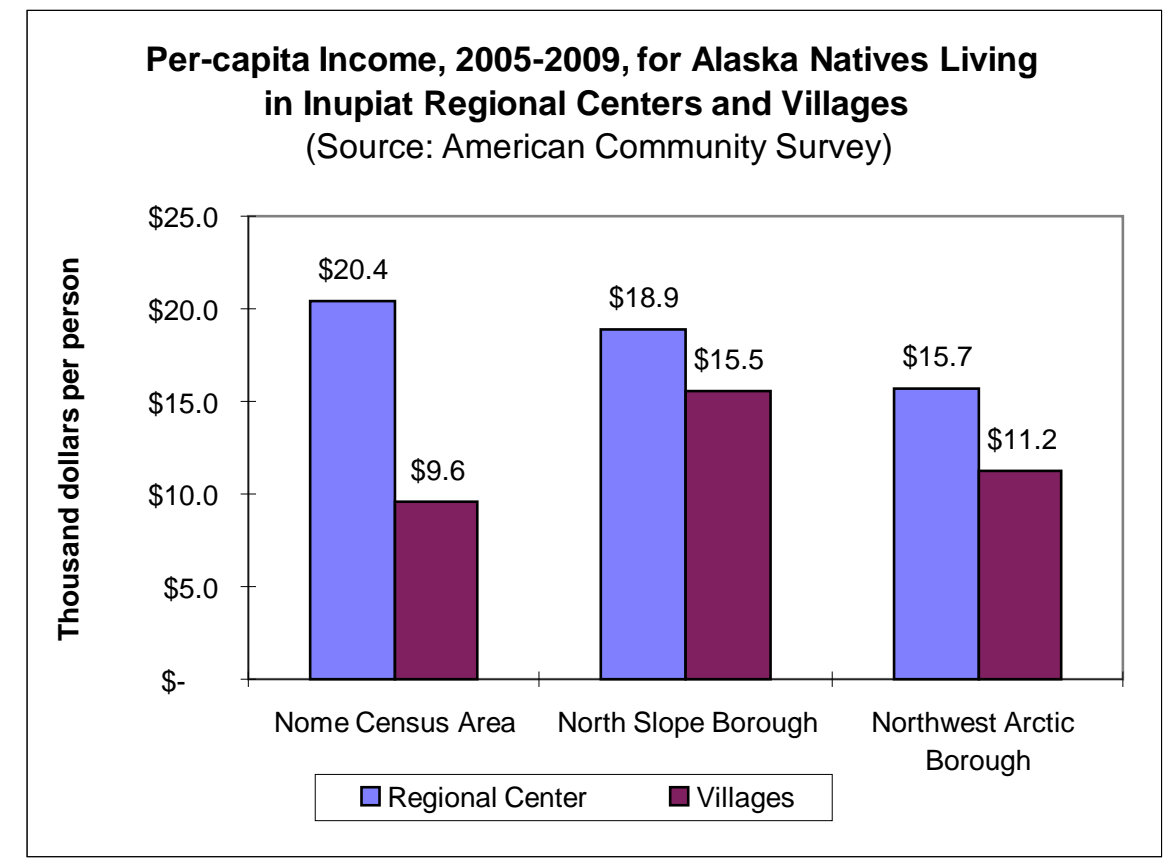

Data on total employment provide further insight into regional differences in job opportunities. As shown in Figure 8, data from the U.S. Census and American Community Survey on total employment by place of residence suggest a general upward trend in total employment over the period 1970 to 2005-2009, except for Barrow, Alaska, and the villages in the Nome Census Area and villages in the North Slope Borough where employment has been declining since 2000. Also, while employment in Kotzebue and the villages of the Northwest Arctic Borough has been increasing over the period since 1970, the rate of increase has been less prominent since year 2000. Overall, the data suggest that total employment - and in some cases rate of increase of employment - has been declining over the past decade. As mentioned above, unemployment numbers are also unreliable for these regions. Total employment, like unemployment, provides only an incomplete picture of material wellbeing, as it does not tell us anything about the characteristics of this employment, e.g. whether it is part-time, full-time, permanent or seasonal, or the rate of underemployment. 
Figure 8:

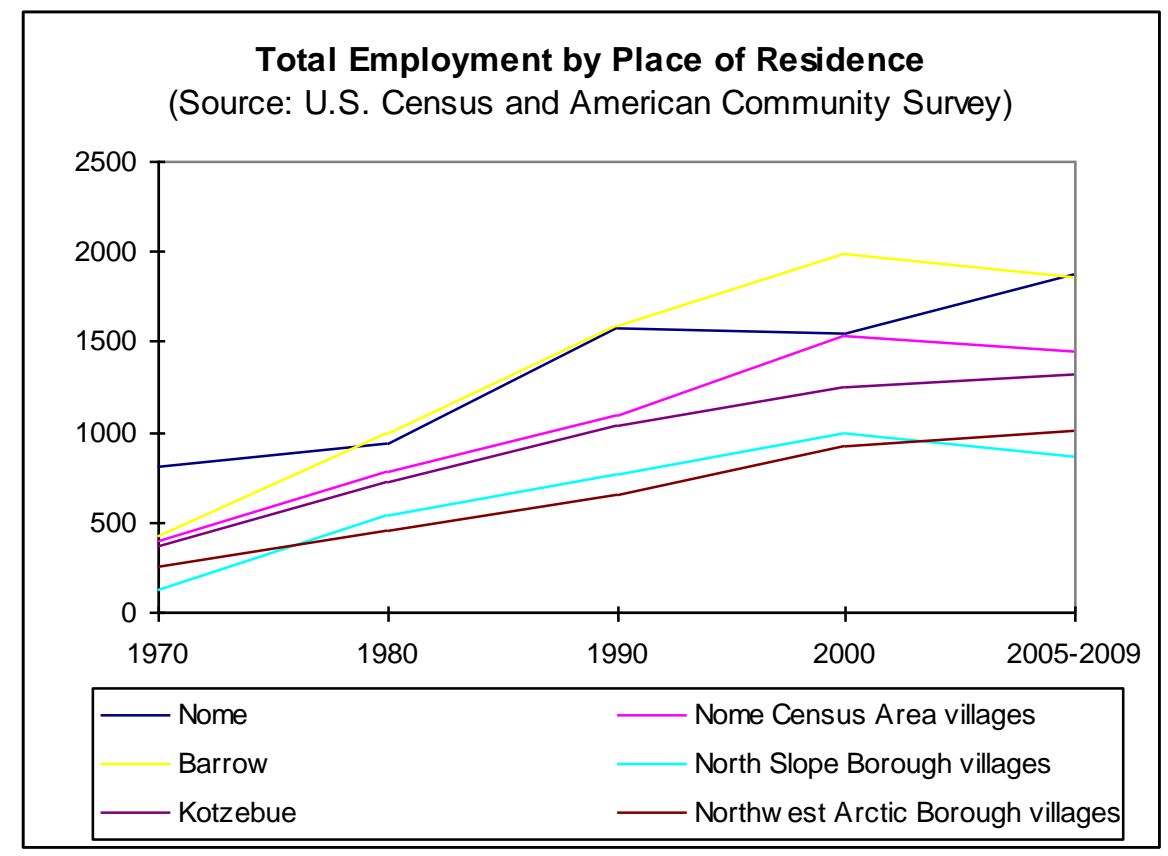

In summary, the ASI indicator (per-capita income) for material well-being suggests that large disparities exist between Alaska Natives and nonNative residents. Among Alaska Natives, additional significant differences appear between regional centers and villages, as well as between the Nome Census Area (the poorest region) and North Slope Borough (the richest), with the Northwest Arctic Borough between the other two areas. Long-term trends suggest that per-capita incomes have been rising in the Nome Census Area and Northwest Arctic Borough but still lag behind those in the North Slope Borough. Although (they) are not part of the ASI small suite indicators, data on total employment further suggest that job opportunities may have been declining over the past decade in the Nome Census area and North Slope Borough. Still, as suggested above, we need to consider the employment indicator with some caution.

\subsubsection{Domain: Education}

The evolution of higher education institutions and services in the Inupiaq regions of Alaska has varied from sub-region to sub-region, though it has been a prominent part of regional development efforts in all three sub-regions since the early 1970 s.

Following the signing of the Alaska Native Claims Settlement Act in 1971 and the concurrent opening of Prudhoe Bay to oil development, the Arctic Slope Region took the lead by forming the North Slope 
Borough and assuming responsibility for education in the region through the North Slope Borough School District. Along with taking over responsibility for the K-12 system, the North Slope Borough, under the leadership of Mayor Eben Hopson, initiated a series of efforts early on to establish a higher education presence in the region.

The first such initiative took place in 1975 with the formation of the Inupiat University of the Arctic, which operated in the region until it was closed in 1980 due to conflicting expectations of its role in the region visà-vis the University of Alaska. Six years later the North Slope Higher Education Center was established by the Borough and operated in collaboration with the University of Alaska Fairbanks for purposes of accreditation of its programs. In 1990 the NSHEC was re-named the Arctic Sivunmun Ilisagvik College, at which point it began to pursue independent accreditation with support from UAF. In 1997, under the leadership of Edna MacLean, ASIC was re-named Ilisagvik College and took the lead in securing funding from the Kellogg Foundation to form a statewide Consortium for Alaska Native Higher Education with membership from regions throughout Alaska. Six years later Ilisagvik College was formally accredited by the Northwest Commission on Colleges and Universities and in 2007 was recognized by the federal Bureau of Indian Affairs as a Tribal College, which led to it becoming a member of the American Indian Higher Education Consortium. Throughout the trials and tribulations of establishing a higher education presence in the region, Ilisagvik College has positioned itself as a lead institution in addressing the workforce and higher education needs on the Arctic Slope.

The Northwest Arctic Region took a slightly different path in its pursuit of localized higher education, though not without its own period of tumult. Given the critical need for an educated workforce as Native corporations were being formed in response to ANCSA, Native leaders made a push to extend the services of the University of Alaska out to the regional centers through the establishment of rural community colleges. The first such community college was formed in the Kuskokwim region in 1972, followed three years later by the establishment of the Northwest Community College in the Bering Strait region in 1975 and the Kotzebue Community College (now Chukchi Campus) in the NANA region in 1976. While the legislative leadership had explicit expectations for the role of the community colleges in addressing the emerging workforce needs in rural Alaska, the leadership of the university was hesitant to expand its services beyond the central campuses and entered into a contentious debate on the level of local control to be accorded the community colleges. As a result, a prominent legislator from the Northwest 
Arctic region withheld funding for the Chukchi Community College and it was closed from 1980 to 1982, while regional higher education services were relegated to a local vocational-technical center administered by the regional school district. Following a series of structural realignments in the university over the next five years to address rural education needs, in 1988 UAF formed the College of Rural Alaska and re-defined the rural community colleges as branch campuses to be administered under each of the three major administrative units (UAF, UAA and UAS), which is where higher education programs for rural Alaska are situated today (though the College of Rural Alaska is now the College of Rural and Community Development).

\section{6 graduation ceremony at Kotzebue High School}

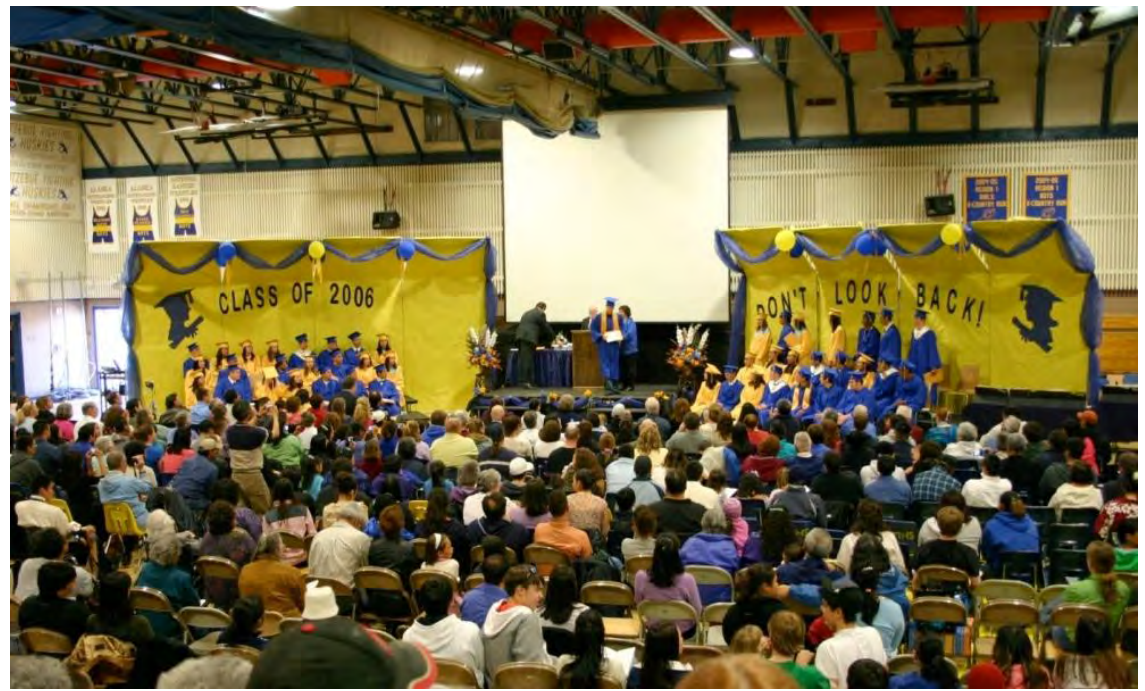

Photo taken by Amber Lincoln.

In summary, higher education has played a prominent role in the evolution of the political, economic and educational arenas that constitute the Inupiaq region of Alaska today. Following will be an extrapolation of data describing the emergence of post-secondary education programs and services across the region over the past 40 years.

ASI has established three indicators to address the education domain in the Arctic:

- Indicator 1: The proportion of students pursuing post-secondary education opportunities.

- Indicator 2: The ratio of students successfully completing postsecondary education. 
- Indicator 3: The proportion of graduates who are still in the community 10 years later.

As with the other applications, the first and primary indicator is postsecondary education attainment. Figure 9 shows the relevant percentages for the Alaskan Inupiaq regions, further broken down along the line of regional center versus all villages of that region. Not surprisingly, the three regional centers are ahead regarding the ratio of post-secondary education of Alaska Native residents. While Barrow was the leader from 1980 to 2000, Nome is in that position now, showing a steady increase since 1980. Kotzebue, which was in lock-step with Nome for the first decade under consideration, has had lower growth rates recently and scores between Nome and Barrow now. Importantly, the villages from all three regions have seen significant increases between 1980 and 2005/09. North Slope Borough villages, which had the biggest increases between 1980 and 2000, are now slightly behind post-secondary education percentages in the villages of the Northwest Arctic Borough and the Nome Census area.

Figure 9:

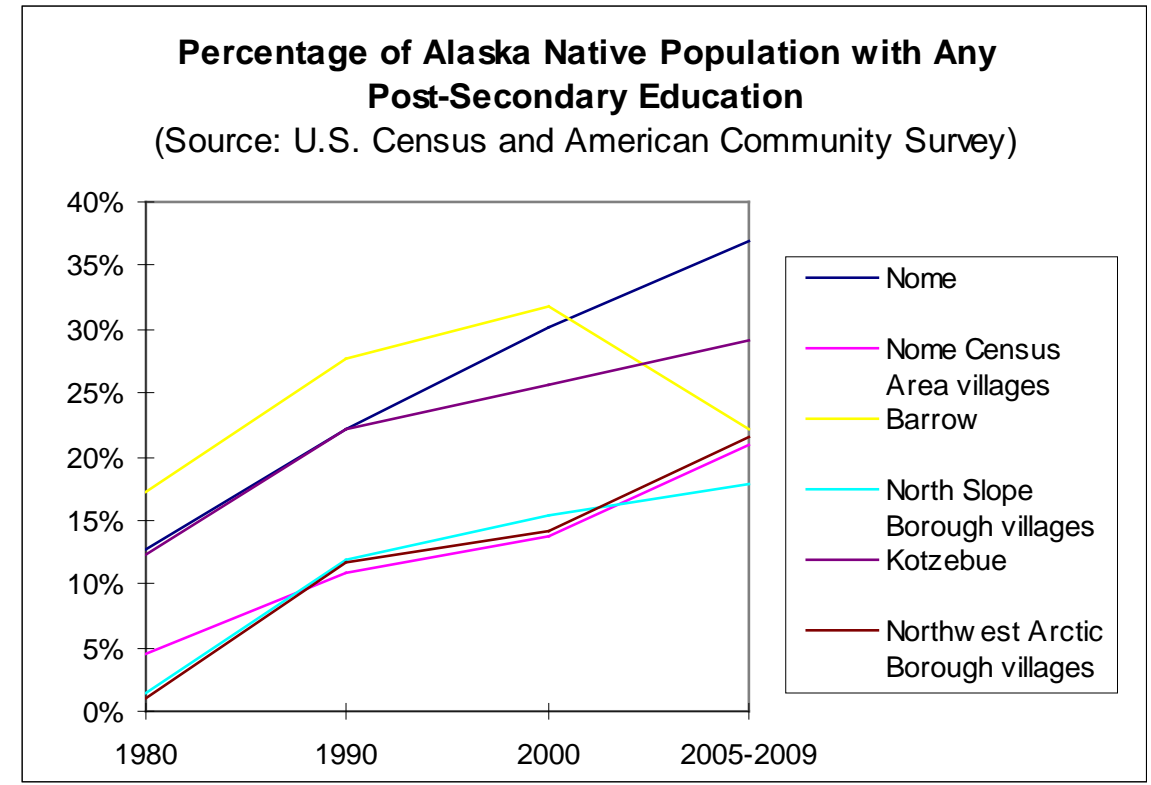

In addition to this dynamic data for the primary indicator, we have been able to acquire additional data that highlight the situation in the mid-2000s. 
Table 3

\begin{tabular}{lcccc}
\hline \% Inupiaq High School Grads & Arctic Slope & NANA & Bering Strait & Total \\
\hline Male & 67 & 65 & 67 \\
Female & 65 & 66 & 67 \\
\% Inupiaq College Grads & & & \\
Male & 2 & 2 & 3 \\
Female & 5 & 5 & 5 \\
\hline
\end{tabular}

Source: Alaska Native Policy Center.

Most of the data presented here is derived from the Alaska Natives Statistical Data Base census data compiled by Andrew Curley and Michael Levin for the First Alaskans Institute Policy Center in 2007. The data is presented in percentages rather than proportions or ratios because that is the way it was compiled in the data base, though the original data could be reconstructed as proportions and ratios. Curley and Levin disaggregated the data by ANCSA region and by gender, so it is presented here broken down by gender and by the three Inupiaq-serving cultural regions (Arctic Slope Region, Bering Strait Region and the NANA Region).

Higher education in its varied forms has been and continues to be an on-going aspiration among the Inupiaq people of Arctic Alaska, motivated in large part by the need for local expertise to meet the development goals and opportunities in the regions. The most visible response to addressing the higher education needs of the regions has been the establishment of localized higher education initiatives and institutions addressing needs at the local, sub-regional and regional levels. While the demand for higher education services has grown steadily since the early 1970s, the majority of those services have been provided at the local level through regional institutions, rather than at the state level or mainstream institutions.

\subsubsection{Domain: Cultural Wellbeing}

ASI (2010) had suggested a composite indicator for cultural well-being, dealing with cultural autonomy, language retention, and belonging. Given that the suggested indicators for belonging and cultural autonomy would have to be collected separately, we decide to focus on language retention. At the same time, ASI (2010) had suggested language retention as the primary indicator for cultural wellbeing, which further justifies our position. From here on, we focus on language issues.

Alaska is home to twenty indigenous languages and two of the great language families of North America, Eskimo-Aleut and Athabascan-EyakTlingit. The distribution of languages across the Arctic and sub-Arctic 
make it clear that these two language families must have originated in Alaska. Alaska has four Eskimo languages in addition to Aleut, and this language family must have spread eastward from Alaska, across the Canadian Arctic to Greenland. Similarly, Athabascan (Dene) languages would have originated in Alaska and spread east into Canada and south along the Pacific Coast all the way to the American Southwest.

When the first Europeans arrived in the Aleutian Islands in 1740, they encountered speakers of Aleut; the Russian America Company soon moved into areas occupied by Sugpiaq, Tlingit, and Central Yup'ik speakers. Bilingualism and even multilingualism with Native languages were usual in regions where different groups bordered each other, and with the arrival of colonists, bilingualism with European languages began to increase.

All of Alaska's indigenous languages are now considered "endangered" by linguists, meaning that they are in danger of disappearing as most are no longer being learned as first languages by children (Krauss 2007; Lewis et al. 2013; Moseley 2010). Very small languages, such as Deg Hit'an and Han, both Athabascan, have just a handful of elderly speakers remaining. The exception is Central Alaskan Yup'ik, Alaska's largest Native language with some 25,000 people and about 10,000 speakers, including young children, who speak Yup'ik as their first language.

The Iñpiatnumber about 16,000 and cover a large area of northern Alaska, including the Arctic Slope north of the Brooks Range, the drainages of the Kobuk and Noatak Rivers and Kotzebue Sound, as well as the Seward Peninsula and adjacent islands. Language, however, is severely endangered with an estimated 2,000 speakers, including few or no children whose first language is Inupiaq. Over the course of history, the Inupiat have experienced social impact from encounters with Europeans and Euro-Americans, which began with whalers who visited the North Slope in the second half of the 19th century, bringing alcohol and disease. The Seward Peninsula was the site of a gold rush in 1901, which brought large numbers of outsiders. Both whalers and miners were notoriously rough. Missionaries soon followed. Outsiders introduced new languages, especially English. Bilingualism developed and loan words were introduced into Inupiaq, primarily from English but also from Russian (through trade), and even Hawaiian and Portuguese (by whalers). In spite of the massive cultural change that resulted from large commercial ventures, there is no evidence that the language decline began until the 1930s and 1940s. Schools opened, children were punished for speaking their native language and parents were persuaded that Western education, along with linguistic and cultural assimilation, offered the best route for their children to achieve success in American society. This ethnocentric assault on 
Inupiaq culture and language must be one of the primary factors, if not the primary factor, that has brought about an interruption in the intergenerational transmission of Inupiaq from parents and grandparents to children.

Language retention is taken as an indicator of cultural wellbeing, and conversely, language shift would indicate of a measure of cultural assimilation, since it occurs in cases where minority groups are present within societies where major world languages are prevalent, along with cultural practices that are not traditional to the minority groups.

The language retention indicator was defined in ASI (2010) as: "what percentage of a population speaks its ancestral language compared with the population as a whole?" In Alaska, however, we do not have data readily available to answer this question. Instead, we redefined our indicator to "\% of Native population not speaking English at home," which is available through census data until 2000. While we are aware that this doesn't measure the exact same thing as the original definition, we are confident that this redefined indicator (see Figure 10) gives us the information we are looking for, although "non-English speakers" includes languages other than Inupiaq. 
Figure 10:

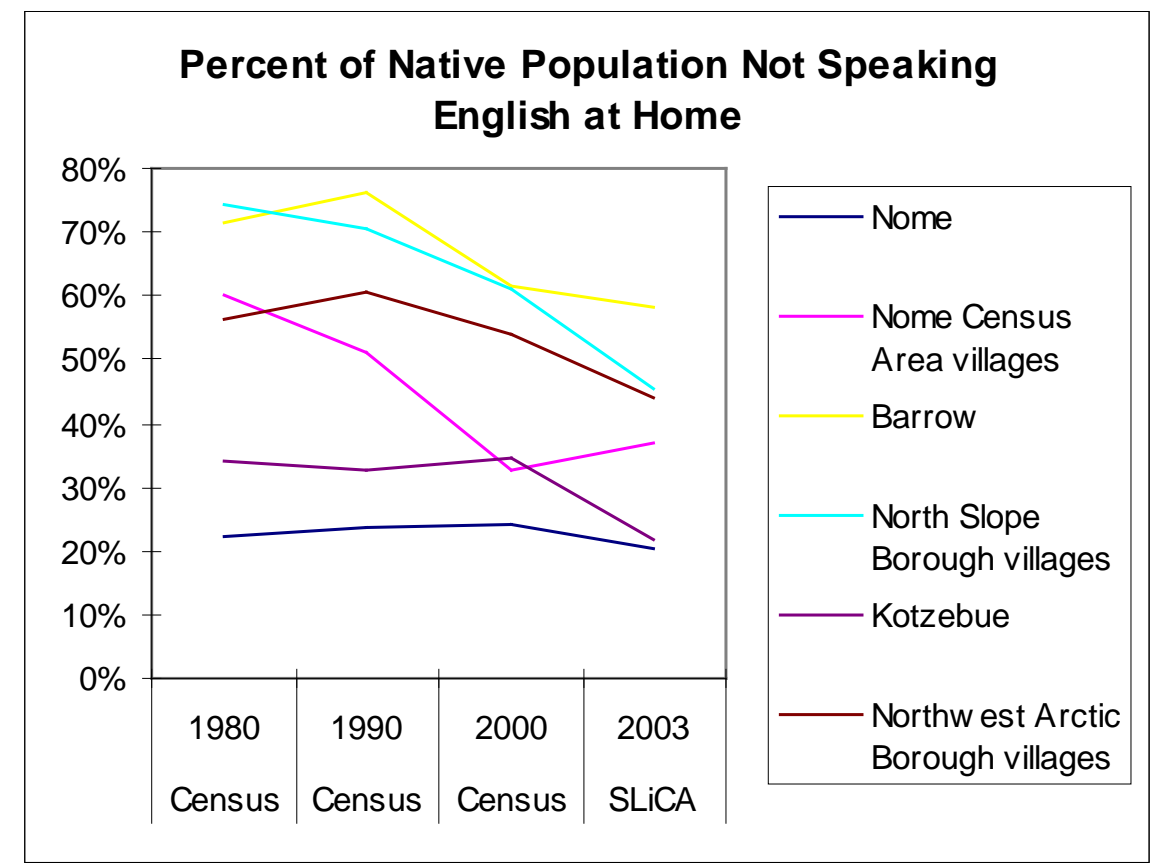

Not surprisingly, the language retention data show a downward trend for all three regions (villages and towns alike) from 1980 to 2003. Within that 23-year timespan, however, there have been positive developments as well. Barrow showed an increase from 1980 to 1990 and the Nome area villages have seen one after 2000. It deserves to be mentioned that Barrow and the villages of the North Slope Borough have remained consistently on top regarding the indicator "\% of Native population not speaking English at home". Given that the North Slope Borough experienced a massive influx of oil money during the 1970s and 1980 s, one could have expected otherwise. One potential conclusion is that increased Material Wellbeing doesn't have to have a negative impact on traditional cultural practices, such as speaking the Native language at home. On the contrary, it could be argued that language (and cultural) revitalization efforts require material wellbeing (which does not mean that material wellbeing guarantees cultural vitality).

\subsubsection{Domain: Contact with Nature}

The concluding chapter of the Arctic Human Development Report included with the following statement: "Arctic societies are place-based systems; they feature human adaptations that are closely tied to local environments. It is no accident that Arctic residents - including settlers 
as well as indigenous peoples - regularly say that 'our land is our life' and that 'we belong to the land' rather than claiming the land as belonging to them" (AHDR 2004:241). This rings true for the Inuit regions of Alaska as much as for any other region of the Arctic. As was briefly mentioned in the introduction to this chapter, each Inuit region (and often each community within a region) is characterized by a well-established cycle of subsistence activities, which follow the seasonal availability and accessibility of animals and plants. These activities range from seamammal hunting and fishing to gathering and birding. Resources include animals, such as caribou, bowhead whales, ducks, and whitefish, as well as a variety of berries and roots. While the place-based activities and resources are intricately linked to systems of local knowledge that have been developed over many generations, recent environmental shifts such as those triggered by climate change - threaten the future viability of some of these activities, while at the same time introducing new species and opportunities to the system.

The first Arctic Social Indicators report (ASI 2010), which defined "contact with nature" as one of the domains of Arctic human development to be tracked, established "consumption" and "harvest" of country food as the two potential indicators of the domain. The authors of the domain chapter provided two options so that "one could measure both harvest and consumption or could choose one or the other depending on relevance to the particular region as well as ease and feasibility of data collection" (ASI 2010:125). In the Alaskan case, the choice is rather straightforward: while the subsistence harvest of "fish and game" has been monitored since the 1970s, the consumption of subsistence foods is not regularly tracked (it seems that recent survey forms of the Alaska Department of Fish and Game, Division of Subsistence, contain questions about the consumption of subsistence foods - see Holen et al. 2012:645 - but the data are not reported by the agency). As indicated in section 2 of this chapter, the irregular one-community-at-a-time conduct of these subsistence surveys constitutes a data problem. Thus, the data presented in Figure 11 - based on various community-based surveys of the Alaska Department of Fish and Game and of the North Slope Borough need to be treated with some caution. 
Figure 11:

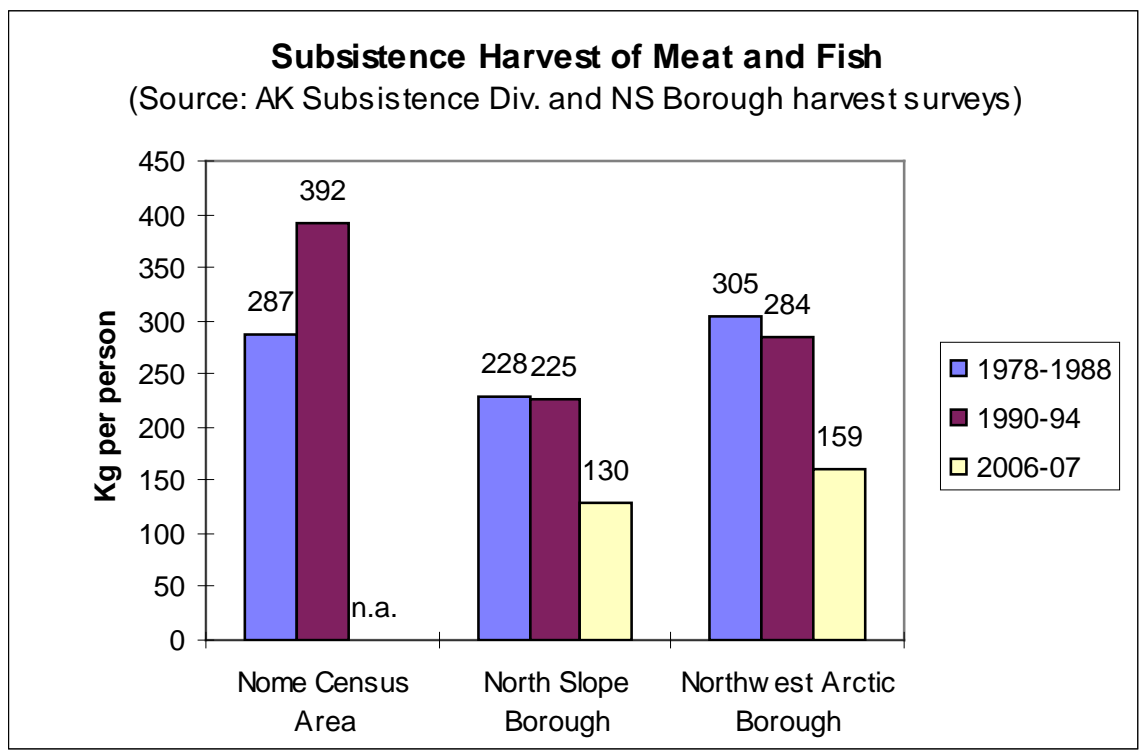

The data presented in Fig. 11 indicate stable subsistence harvests from late 1970s through the mid-1990s, with some significant increases in the Nome Census Area during that period. While there are no data at our disposal for the Nome Census area after that, the numbers available for the North Slope and the Northwest Arctic boroughs indicate significant declines in subsistence harvests. There might be other factors at play, however. For example, the North Slope Borough population has roughly tripled since the 1970s, with most growth occurring in Barrow. Also, Barrow has a relatively high proportion of non-Natives in its population, who are typically not very active subsistence harvesters.

At the same time, there seems to be a trend across the state, namely that over the past 10 years there is a slight decrease in the harvest of wild resources by rural residents (Davin Holen, personal communication, March 2013). The latest agency overview over subsistence in Alaska, in 2010 (Fall 2012), reports $198 \mathrm{~kg}$ (or 436 pounds) per person of annual wild food harvest for the agency's Arctic region (Fall 2012:3), which more or less coincides with our Inuit regions of Alaska. While this is more than what our data report for the 2000s shows, it is significantly more than what was reported in the 1980s and 1990s.

Still, the above mentioned overview report over subsistence in Alaska in 2010 makes it clear that the Arctic region has the second highest numbers in the state regarding annual harvest weight per person, only to be trumped by the Western region (Fall 2012:3). Likewise, as shown in Chap- 
ter 6, the SLiCA data indicate that the harvest of meat and fish in Alaska is higher than in other Arctic areas surveyed by SLiCA.

The conclusions for the domain "Contact with nature" in the Inuit regions of Alaska are twofold and somewhat ambivalent. While there seems to be a negative trend regarding the indicator "harvest of meat and fish", the data situation is far from ideal and might bias the results. Thus, we strongly encourage the conduct of future subsistence harvest surveys in a way that the results can be tracked over time with more confidence than they can now.

\subsubsection{Domain: Fate Control}

Prior to 1971, the fate of Alaska Native people was largely in the hands of the Bureau of Indian Affairs under the U.S. Department of the Interior. Except for a scattering of 160 acre Native allotments, most land occupied and used by Native people was held in trust by the federal government. It wasn't until the Alaska Native Claims Settlement Act (ANCSA) was enacted by the U.S. Congress in 1971 - to resolve questions of aboriginal land rights in the Prudhoe Bay oil fields - that Alaska Natives were able to begin exercising control over the lands on which their livelihood depended. The mechanisms that were established for Native people to administer the land and resources they were allocated under ANCSA was that of profit and non-profit Native-controlled corporations. Coupled with the economic interests of the Native regional and village corporations was the formation of local municipal and tribal government structures with the authority to levy taxes, implement land use plans, take control of schools, and administer a full array of community and regional services.

The impact of these new mechanisms for Native people to assume control over their future was felt most immediately in the Arctic Slope Region where the local Native leadership took the initiative in 1972 to form the North Slope Borough, encompassing nine predominantly Native communities and with access to the property tax revenue associated with the industrial developments taking place on the Prudhoe Bay oil fields. Of the $\mathbf{5 7 . 0}$ million acres of land that makes up the Arctic Slope Region, 5.5 million acres (nearly 10\%) are under the control of the Inupiaq people.

While the Arctic Slope Region had access to the tax revenue associated with the oil fields, the NANA and Bering Strait regions were less well endowed, but were able to use the economic and political opportunities associated with ANCSA to develop their own mechanisms for exercising 
control over the land and resources in their respective regions. In the case of the NANA region, the village corporations merged with the NANA Regional Corporation and entered into a regional development strategy aimed at maximizing the social and economic benefits to communities and people in the region. Of the 21.8 million acres that make up the NANA region, 1.3 million acres (6\%) are directly under the control of the people in the region. A central focus of the NANA regional strategy has been the development of a massive lead and zinc deposit located on corporation land, which has been developed in such a way as to sustain the subsistence lifestyle in the region. To back up these developments and extend the benefits of development to people throughout the region, NANA has formed the Northwest Arctic Borough though which it now administers a full slate of municipal services to Kotzebue and the surrounding villages. While the development and operation of the Red Dog mine hasn't been without its difficulties, the decisions along the way have been in the hands of the Inupiaq people for whom the region is their homeland.

Unlike the Arctic Slope and NANA regions, the Bering Strait region has had to rely largely on surface resources and investments to establish a sustainable economic base in the region. While exercising control over 2.2 million acres (6.5\%) of the 34 million acres of land in the region, the people of the Bering Strait have maintained a strong emphasis on their control over local subsistence resources, particular marine mammals in the Bering Sea coastal region. Though the mining of gold and related minerals has a long history in the region, it has been relatively small scale and is not the source of much in the way of region-wide benefits.

Along with the efforts of the Bering Strait Native Corporation, the Kawerak regional non-profit and other regional entities striving to support a sustainable economy and lifestyle in the region, nestled on an island in the central Bering Sea, is an interesting anomalous example of two St. Lawrence Island Yupik communities exercising their own version of fate control. When the Alaska Native Claims Settlement Act was enacted in 1971, the St Lawrence Island communities of Gambell and Savoonga opted to retain ownership and control of their island in lieu of compensation and the formation of corporate structures, as was the case elsewhere in the state. As tribal lands, the island is not subject to external taxation and the people living there exercise a greater degree of control over the governance and service structures they have established to address their needs.

In summary, the three sub-regions that make up the Inupiaq cultural region of northern and western Alaska provide a variety of useful exam- 
ples of ways in which Arctic communities are exercising a modicum of control over the forces that impact their wellbeing. By conducting a comparative analysis of the percentage of surface lands controlled by the inhabitants through municipal governments, Native organizations, and community structures, we can gain a better understanding of how the exercise of fate control impacts the wellbeing of northern communities. Following is the beginning of the data collection process to cross-examine the relative importance and variance of diverse modes of control.

Table 4 contains information related to the three primary data sources aimed at assessing the role of fate control as a measure of community wellbeing in the Inupiaq region of Alaska. The four potential indicators considered for the Arctic Social Indicators project were as follows:

- Indicator 1: The percentage of indigenous members in governing bodies (municipal, community, regional) relative to the percentage of the indigenous people in the total population.

- Indicator 2: The percentage of surface lands legally controlled by the inhabitants through public governments, Native organizations, and communities.

- Indicator 3: The percentage of public expenses within the region (regional government, municipal taxes, community sales taxes) raised locally.

- Indicator 4: The percentage of individuals who speak a mother tongue (whether Native or not) in relation to the percentage of individuals reporting corresponding ethnicity.

- Single Composite Indicator: Since we have no data for indicator 1, our discussion of fate control in the Inuit regions of Alaska is based on indicators, 2,3 and 4.

For Alaska, indicator 2 can be easily tracked through the land rights conveyed to Regional Native Corporations in ANCSA. The following chart lists the land holdings controlled by the three Inuit-serving Regional Native Corporations, the total acreage for each of the Inuit regions, and the percentage of lands under local control in each region.

Table 4: Percentage of surface lands legally controlled by local inhabitants

\begin{tabular}{lrrrr}
\hline Regional Corporation & ASRC & NANA & BSNC & Total \\
\hline Acres of Native surface land holdings & $5,500,000$ & $1,300,000$ & $2,200,000$ & $9,000,000$ \\
Total acres of land in region & $57,000,000$ & $21,800,000$ & $34,000,000$ & $112,800,000$ \\
$\%$ Inupiaq Land & $9.65 \%$ & $5.96 \%$ & $6.47 \%$ & $8.0 \%$ \\
\hline
\end{tabular}

Data provided by Ray Barnhardt. 
The data presented are not a complete representation of overall Inuit land ownership in that it does not take into consideration private lands held by individuals or by local governments. However, it is still useful as an indicator to track change over time as well as to make comparisons across the Arctic region.

The dynamics for indicator 3 , the "percentage of public expenses within the region", are presented in Figure 12. As section 2 ("data and methodology") of this chapter explains, the data for this indicator are pieced together from multiple sources.

Figure 12: Locally controlled government expenditures as a percentage of total Government Expenditures

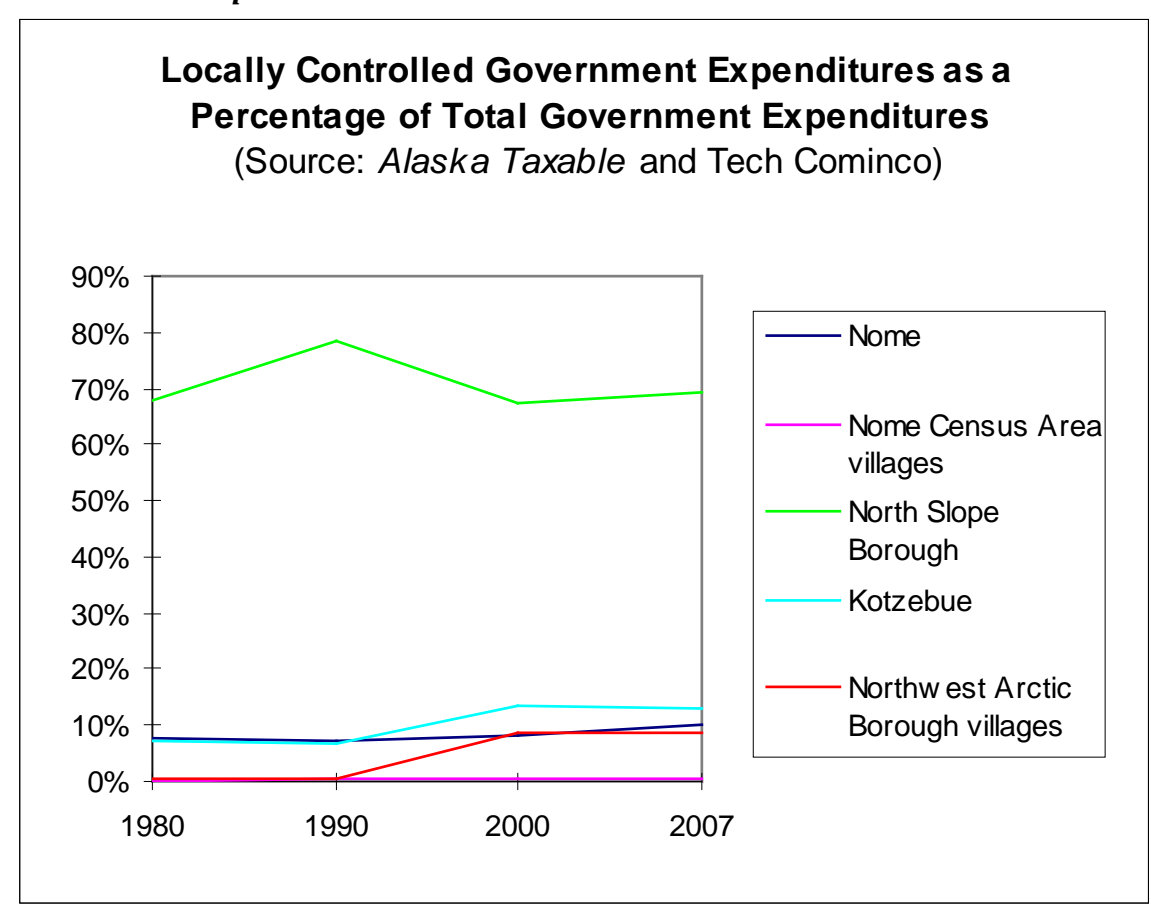

Source: Alaska Taxable and Teck Cominco.

The domain of fate control shows significant differences among the three Inuit regions. Especially, the indicator "locally controlled government expenditures" put the North Slope Borough way ahead of the towns and villages of the two other regions. As was explained in the introduction to this chapter, the high value for the North Slope Borough is the result of the borough's right to tax oil companies for land use operations at the oil fields within its jurisdiction. The indicator "percentage of surface lands legally controlled by local inhabitants" also shows the North Slope ahead (9.65\%), followed by the Bering Strait region (6.47\%). While the language 
retention indicator shows some decline for all Inuit regions of Alaska since 1980, Barrow and the North Slope Borough regions are still strongest among the regions under consideration.

It deserves to be highlighted that the complex domain of fate control has seen significant increases for all Inuit regions of Alaska over the last half century. Before the passage of ANCSA in the early 1970s, none of the region's surface lands were locally controlled, nor were there any significant locally controlled government expenditures. While language retention has generally declined, the indicator "percentage of indigenous members in governing bodies" for which we do not have data would certainly have shown an upward trend over the last decades. Thus, we can assume that a fully assembled fate control index would show a positive trend for all three regions over the last 50 years, with the North Slope Borough showing larger increases than the other two regions. Still, the major positive changes happened in the 1970s following ANCSA. Since then, the trajectories have been flat for most areas under consideration. It seems timely to consider how future positive developments could be achieved.

\subsection{Conclusions and Discussion}

The preceding sections should have made it clear that the Inuit regions of Alaska provide an interesting application and testing ground for the ASI framework. Below are some remarks summarizing the results of this chapter, as well as discussion points for further consideration.

First of all, it deserves to be noted that the Inuit regions of Alaska - and Alaska in general - are characterized by a relatively good data situation. With the possible exception of the "Contact with nature" indicator discussed above, some reliable and trackable data are available for all ASI domains. This makes the establishment of an Arctic Social Indicators Monitoring System (see chapter 7) relatively easy in this part of the Arctic.

A particular challenge of the ASI endeavor is to cover all Arctic residents, while at the same time addressing the particular challenges of the indigenous residents of the Arctic. This chapter is somewhat different since it addresses certain regions of Alaska based on ethnic criteria, which are the Inuit regions of Alaska. While all three regions under consideration have Alaska Native majorities, all of them are also home to sizable non-indigenous populations. Wherever possible we tried to calculate our indicators separately for the Alaska Native population of each region, since collapsing the data would have resulted in less meaningful results. In some cases - such as for the subsistence harvest data - this 
has not been possible, which created problems at times. Even where separate Alaska Native data are available, a contrasting fine-grained analysis of non-indigenous groups remains a desideratum.

One obvious result across most domains is that there is a lot of variation between and within regions. One such example is the net migration data, which vary widely. On the other hand, indicators with small absolute numbers - e.g., infant mortality or college graduates - show little variation. Differences between regional centers and smaller communities are sometimes significant and in other cases little pronounced. The latter is true for the North Slope region, while the Nome Census Area exhibits the largest differences between regional center and rural communities. There, village residents on the whole seem to have less formal education, have lower incomes, but are more likely to be speaking an indigenous language at home than regional center residents.

Our domains and indicators can be broadly divided into two categories: modernity and tradition indicators. While the Cultural Wellbeing and Contact with Nature belong to the latter category, most of the indicators for the Health and Population, Material Wellbeing and Education domains are in the modernity camp. Fate Control seems to take an interesting intermediate position regarding these two categories, given that some of its categories seem to measure successful adaptation to modernity, while others address the continued vitality of tradition.

Accepting this typology for now, we can state that all three Inuit regions of Alaska have been successful regarding the modernity indicators. Interestingly, it has been Nome and not Barrow - the recipient of much oil wealth and an early leader in that respect - that has witnessed the most advancement in Material Wellbeing and Education in recent years. While it is the nature of tradition indicators to measure "decrease" most of the time, the Inuit regions of Alaska have been doing reasonably well in these domains. In some cases there have been increases to report. For example, Barrow and the rest of the North Slope Borough showed on increase in Native language use in the 1990 census, while the Nome Census Area had an increase in subsistence harvests in the early 1990s. Thus, the overall assessment of human development in Inuit Alaska is positive.

Given the special nature of the Fate Control domain in-between tradition and modernity, the results for the fate controls indicators as summarized in section 5.3.6 might be of significance beyond that domain; i.e. while there were significant advances in the 1970s and 1980s, recent decades showed less growth. Notwithstanding continuous advances in Mate- 
rial Well-being, the next level regarding the Fate Control domain of Arctic Human Development is yet to be achieved in Arctic Alaska.

\section{Acknowledgments}

Unless noted otherwise, the data were provided by Matt Berman of the Institute of Social and Economic Research at the University of Alaska Anchorage. The American Community Survey figures for 2005-2009 were added by Katherine Jackstadt. Most of Berman's work was conducted as part of an AON IPY project directed by Jack Kruse and Larry Hamilton (NSF award \#0638408). Joan Nyman Larsen assisted with the Material Wellbeing Domain of the chapter.

Additional thanks go to Davin Holen and Brittany Rutherford, who helped us making sense of the subsistence harvest data. Ilona Kemp, Amber Lincoln, and Elizabeth Marino deserve thanks for letting us use some of their images. Cecilie Ebsen at the University of Alaska Fairbanks assisted with the final edit of the chapter.

\section{Iñupiaq women packing up whale meat to share with the community the day} after the catch

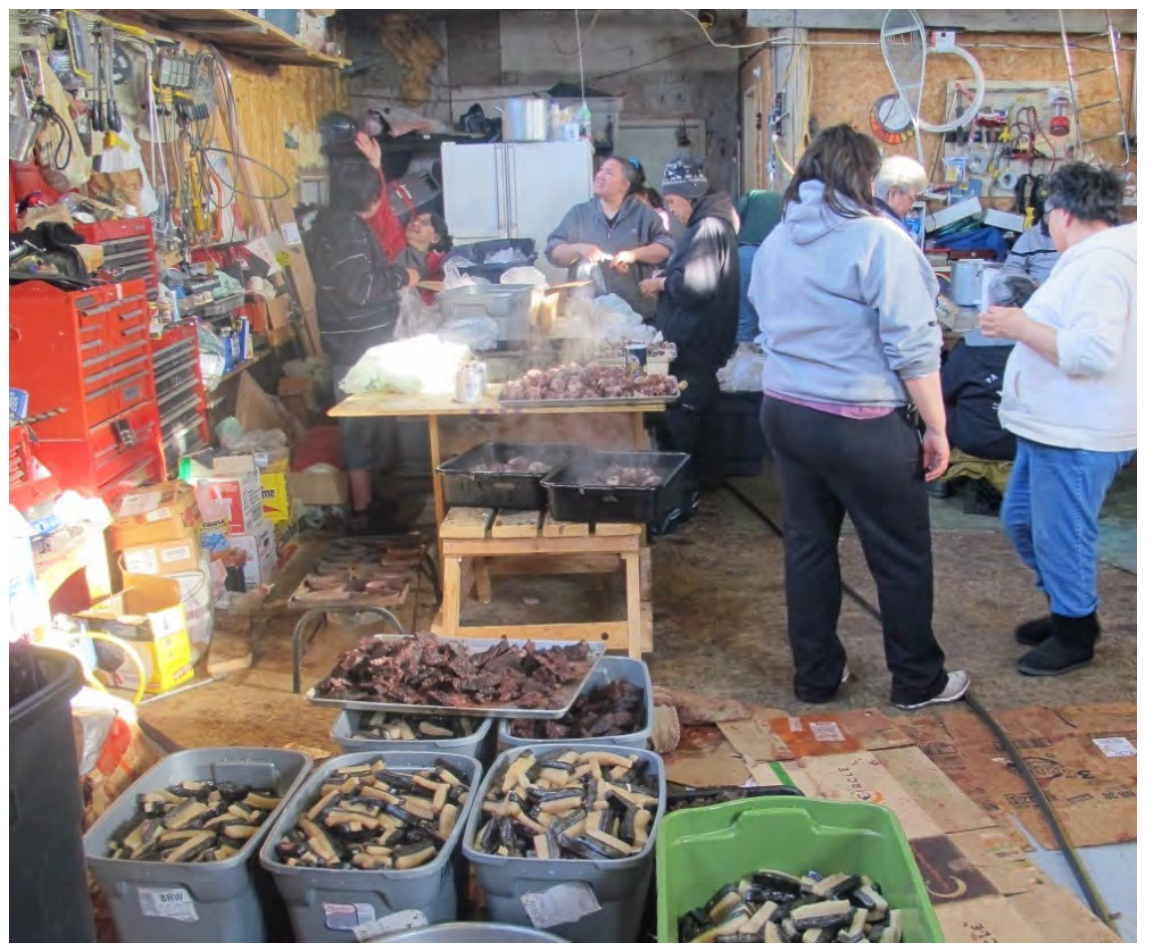

Photo: Ilona Kemp. 


\subsection{References}

AHDR (Arctic Human Development Report) (2004). Akureyri: Stefansson Arctic Institute.

Alaska Commission on Postsecondary Education (2010). Going to College in Alaska. Retrieved at: http://www.gtciak.co. Accessed on 30th April 2013.

Alaska Dispatch (2013). Threatened Alaskan Village of Kivalina May Get Needed Evacuation Route. 6th April 2013. Retrieved at: http://www.alaskadispatch. com/article/20130406/threatened-alaska-village-kivalina-may-get-neededevacuation-route. Accessed on April 29, 2013.

ANLC (2011). Inuit or Eskimo: Which Name to Use? Retrieved at: http://www.uaf.edu/anlc/resources/inuit-eskimo/. Accessed on 29th April 2013. Arctic Slope Regional Corporation (2013). Retrieved at: http://www.asrc.com/. Accessed on 29th April 2013.

ASI (2010). Arctic Social Indicators. J.N. Larsen, P. Schweitzer and G. Fondahl, eds. TemaNord 2010:519. Copenhagen: Nordic Council of Ministers.

Aud, Susan et al. (2010). The Condition of Education 2010. (NCES 2010-028). Washington, DC: National Center for Education Statistics, Institute of Education Sciences, U.S. Department of Education.

Bering Straits Native Corporation (2013). Bering Straits Villages. Retrieved at: http://beringstraits.com/northriver/wb/pages/shareholders/villages.php. Accessed on 29th April 2013.

Canadian Council on Learning (2013). What are the Factors that Facilitate and Impede Post-secondary Access and Participation of Aboriginal Students? http://www.ccl-cca.ca/pdfs/QuestionScans/QuestionScan5_EN.pdf. Accessed on 5th February 2013.

Census 2010 (2010). Profile of General Population. Retrieved at: http://factfinder2.census.gov/faces/tableservices/jsf/pages/productview.xhtml?p id=DEC_10_DP_DPDP1. Accessed on 29th April 2013.

City of Kotzebue (2011). History of Community. Retrieved at: http://www.cityofkotzebue.com/index.asp?Type=B_BASIC\&SEC=\{DED1C74C210F-41CB-8D9C-7C4184E09E0D. Accessed on 29th April 2013.

Fall, James (2012). Subsistence in Alaska: A Year 2010 Update. Anchorage, AK: Division of Subsistence, Alaska Department of Fish and Game.

Goldsmith, Scott (2007). The Remote Rural Economy of Alaska. Anchorage, AK: Institute of Social and Economic Research. Retrieved at:

http://www.iser.uaa.alaska.edu/Publications/u_ak/uak_remoteruraleconomyak.p df. Accessed on 14th March 2013.

Hadland, Jeff (2010). Tracking Alaska's Students: Measuring Alaska's Secondary Student Performance. Alaska Economic Trends 30(6): 4-11.

Hayley, Sharman and James Magdanz (2008). The Impact of Resource Development on Social Ties: Theory and Methods for Assessment. In Earth Matters: Indigenous Peoples, the Extractive Industries and Corporate Social Responsibility. Ciaran O'Faircheallaigh and Saleem Ali, eds. Sheffield: Green Leaf Publishing

Hoachlander, Gary and Joe Cocozza (2010). Merging Career Tech with College Prep: Insights from Successful High Schools. Alaska Advisory Task Force on Higher Education and Career Readiness. Webinar held on 7th October 2010.

Holen, Davin, Sarah M. Hazell and David S. Koster (eds.) (2012). Subsistence Harvests and Uses of Wild Resources by Communities in the Easern Interior of Alaska, 2011. Technical Paper No. 372. Juneau: Alaska Department of Fish and Game, Division of Subsistence. 
Kaplan, Lawrence D. (1990). "The Language of the Alaskan Inuit.” In Arctic Languages: An Awakening. D. R. F. Collis, ed. Paris: UNESCO. pp. 131-158.

Kawerak, Inc. 2013. Retrieved at: http://kawerak.org/. Accessed on May 2, 2013.

Kleinfeld, Judith and Justin J. Andrews. (2006). "Postsecondary Education Gender Disparities Among Inuit in Alaska: A Symptom of Male Malaise?” Études/Inuit/Studies 30(1): 111-121.

Krauss, Michael E (2007)."Native Languages of Alaska. In The Vanishing Voices of the Pacific Rim. Osahito Miyaoko, Osamu Sakiyama, and Michael E. Krauss, eds. Oxford: Oxford University Press.

Kruse, Jack (2011). Developing an Arctic Subsistence Observation System. Polar Geography 34(1-2): 9-35.

Kruse, Jack, Birger Poppel, Larissa Abryutina, Gerard Duhaime, Stephanie Martin, Mariekathrine Poppel, Margaret Kruse, Ed Ward, Patricia Cochran, and Virgene Hanna (2008). Survey of Living Conditions in the Arctic (SLiCA). In Barometers of Quality of Life Around the Globe: How Are We Doing? V. Møller, D. Huschka and A.C. Michalos, eds. (Social Indicators Research Series, Vol. 33). Dordrecht, The Netherlands: Springer, pp. 107-134.

Lewis, M. Paul, Gary F. Simons, and Charles D. Fennig (eds.) (2013). Ethnologue: Languages of the World, Seventeenth edition. Dallas, Texas: SIL International. Online version: http://www.ethnologue.com

Maniilaq Association (2003). About Northwest Alaska. Retrieved at: http://www.maniilaq.org/aboutNWAlaska.html. Accessed on 23rd April 2013.

McDowell Group (2006). Alaska Native K-12 Education Indicators, 2005. Volume III: Graduation, Drop-out and Continuing Education. Anchorage, AK: First Alaskans Institute.

Moseley, Christopher, ed. (2010). Atlas of the World's Languages in Danger. Paris: UNESCO Publishing.

NANA. 2013. Kotzebue. Retrieved at http://nana.com/regional/about-us/overviewof-region/kotzebue/. Accessed on April 29, 2013.

North Slope Borough. (2013). Retrieved at: http://www.co.north-slope.ak.us/. Accessed on April 29, 2013.

Northwest Arctic Borough. (2013). Our History. Retrieved at: http://www.nwabor.org/story.html. Accessed on April 23, 2013.

Office of the State Assessor. Annual Alaska Taxable: Municipal Taxation - Rates and Policies, Full Value Determination, Population and G.O. Bonded Debt. Juneau: Alaska Department of Commerce, Community, and Economic Development.

Pavel, D. Michael et al. (1998). Alaska Natives in Post-secondary Education. Washington, DC: National Center for Education Statistics, U.S. Department of Education.

Ray, Dorothy Jean. (1991). The Eskimos of Bering Strait. Seattle: University of Washington Press.

Relocate-ak. (2012). Recloate Kivalina. Retrieved at: http://www.relocate-ak.org/. Accessed on April 29, 2013.

Snipp, C. Matthew. (2005). American Indian and Alaska Native Children: Results from the 2000 Census. Washington, DC: Population Reference Bureau.

Tutorgig. (2013). Inuit. Retrieved at: http://www.tutorgig.com/ed/inuit. Accessed on April 24, 2013.

Ukpeagvik Inupiat Corporation. (2013). Retrieved at: http://ukpik.com/. Accessed on April 29, 2013. 


\section{The Inuit World: Measuring living conditions \& subjective wellbeing - monitoring human development using Survey of Living Conditions in the Arctic (SLiCA) to augment ASI for the Inuit World}

Author

Birger Poppel, Ilisimatusarfik, University of Greenland, Nuuk, Greenland.

\subsection{Introduction}

The story of how the Arctic was populated is not least about migration. One of the first migration routes departed from the Eastern part of Siberia, crossing the North American continent before arriving in Greenland and continuing either to the East or West of the island. These travel/migration activities endured for generations and origins of ancient people can be traced through myths, ${ }^{1}$ archaeological findings and, ${ }^{2}$ more recently, through insights provided from a human genome of an extinct palaeoeskimo. ${ }^{3}$ Thus, links between ancient peoples can be created, which span across the Arctic from the Bering Strait to Greenland.

What we can further learn from both myths and archaeological findings is that ancient peoples of the Arctic were hunters living off of the land and sea, following marine and terrestrial mammals in their struggle for life.

\footnotetext{
${ }^{1}$ See e.g. Rasmussen 1925, Myter og Sagn III: p. 68-69 and Gulløv 2004

2 Gulløv 2004.

${ }^{3}$ Rasmussen, M., et al. 2010; Nature 463, p. 757-762.
} 
Indigenous peoples who have inhabited a large part of the circumpolar Arctic for thousands of years call themselves Inuit (plural of "Inuk", meaning "human being"). The Inuit (totalling approximately 150,000 people) live in the easternmost part of Siberia, Chukotka (Siberian Yupik); in the North Slope of Alaska (Inupiat) and the Seward Peninsula (Central Alaskan Yupik); and throughout the Arctic and sub-Arctic Canada, in the four land claims settlement regions (Inuit and Inuvialuit) comprising: the Northwest Territories (Inuvialuit), in Nunavut; Nunavik, Quebec, in Nunatsiavut; Labrador; and Greenland (Kalaallit). ${ }^{4}$

The different dialects of the Inuit language are grouped under the Eskimo-Aleut language family (Eskaleut languages). It is estimated that roughly 90,000 people speak the Inuit language (mainly in Arctic Canada and Greenland).

The Inuit homelands or settlement regions are jointly called Inuit Nunaat.

In 1977 representatives from all Inuit Homelands - except Chukotka - met in Barrow, Alaska and founded the Inuit Circumpolar Conference (since 2010: the Inuit Circumpolar Council).

In the Charter of the Inuit Circumpolar Council (ICC 2010) "Inuit" and "Inuit homeland" are defined as follows:

"Inuit" means indigenous members of the Inuit homeland recognized by Inuit as being members of their people and shall include the Inupiat, Yupik (Alaska), Inuit, Inuvialuit (Canada), Kalaallit (Greenland) and Yupik (Russia).

"Inuit homeland" means those arctic and sub-arctic areas where, presently or traditionally, Inuit have Aboriginal rights and interests

(ICC 2010)

The close connectedness to the circumpolar Arctic and the importance of the unity among Inuit and their homeland is also stressed in the Circumpolar Inuit Declaration on Sovereignty in the Arctic (ICC 2009):

From time immemorial, Inuit have been living in the Arctic. Our home in the circumpolar world, Inuit Nunaat, stretches from Greenland to Canada, Alaska and the coastal regions of Chukotka, Russia. Our use and occupation of Arctic lands and waters pre-dates recorded history. Our unique knowledge, experience of the Arctic, and language are the foundation of our way of life and culture.

${ }^{4}$ The designation of the Inuit in the respective homelands is bracketed (AHDR, 2004). 


\section{Survey of Living Conditions in the Arctic (SLiCA)}

\section{- a methodological overview}

Inuit Nunaat and the living conditions of the indigenous peoples of this vast circumpolar region - the Inuit - are the foci of this chapter. In the following, Survey of Living Conditions in the Arctic (SLiCA) will be used as an application to the Arctic Social Indicators. The results are thus based on the SLiCA (Poppel et al. 2007; Kruse et al. 2008), ${ }^{5}$ which are applied to domains identified in the Arctic Human Development Report (AHDR 2004) and the Arctic Social Indicators Report (ASI 2010).

SLiCA is an interdisciplinary and international research project (founded in 1997/1998). The SLiCA analyses regions included in what we have defined as "the Inuit Settlement region", include: Chukotka (Western Chukotka, Anadyr, Central Chukotka, Eastern Chukotka); ${ }^{6}$ Alaska: (Bering Straits, NANA, North Slope); ${ }^{7}$ Arctic Canada (Inuvialuit, Nunavik, Nunavut, Nunatsiavut) and Greenland (Northern Greenland, Mid-Greenland, South Greenland, Disco Bay, East Greenland). The sample size, as well as the number of respondents and the response rates, are listed in Table 1.

\begin{tabular}{|c|c|c|c|c|c|c|}
\hline $\begin{array}{l}\text { Inuit settle- } \\
\text { ment region }\end{array}$ & $\begin{array}{l}\text { Indigenous peoples } \\
\text { in the survey }\end{array}$ & $\begin{array}{l}\text { Period of } \\
\text { interview }\end{array}$ & $\begin{array}{r}\text { Total number } \\
\text { of adults in } \\
\text { population }\end{array}$ & $\begin{array}{l}\text { Sample } \\
\text { size (N) }\end{array}$ & $\begin{array}{r}\text { Response } \\
\text { rate }\end{array}$ & $\begin{array}{l}\text { Respon- } \\
\text { dents (n) }\end{array}$ \\
\hline $\begin{array}{l}\text { Northern } \\
\text { Alaska }\end{array}$ & Iñupiat; Yupiit & $2002-2003$ & 11,000 & 700 & $84 \%$ & 650 \\
\hline Chukotka & $\begin{array}{l}\text { Inuit; Chuckchi; Evan; } \\
\text { Chuvan; Yukagir }\end{array}$ & 2005-2006 & 14,000 & 600 & $85 \%$ & 500 \\
\hline Canada & Inuit & 2001 & 22,000 & 5,650 & $83 \%$ & 4,700 \\
\hline Greenland & Inuit & 2004-2006 & 36,000 & $1,450 * *$ & $83 \%$ & 1,050 \\
\hline $\begin{array}{l}\text { Inuit home- } \\
\text { lands/regions }\end{array}$ & & & 83,000 & 8,400 & $83 \%$ & 6,900 \\
\hline
\end{tabular}

Note:

* Rounded (to nearest "50"/"100").

** In Greenland also the non-indigenous population was part the survey.

\footnotetext{
5 The SLiCA database and table section on www.arcticlivingconditions.org have been developed by Jack Kruse and Marg Kruse.

${ }^{6}$ For a number of reasons also non-Inuit: Chuckchi; Evan; Chuvan; Yukagir were included in the sample.

${ }^{7}$ In Alaska the Yupik were not part of the sample due to limited research funding.
} 
The SLiCA analysis is based on more than 8,000 personal interviews with Inuit and Sami adults in Greenland, Canada, Alaska, Norway and Sweden, as well as indigenous adults from Chukotka and the Kola Peninsula (Table 1).

The International SLiCA-research team in collaboration with indigenous partners at local, regional and international levels (Inuit Circumpolar Council, ICC; Sámi Council and Russian Association of the Indigenous Peoples of the North, RAIPON) developed an international core questionnaire. This questionnaire, consisting of roughly 200 questions, ${ }^{8}$ offers opportunities to examine a number of dimensions to living conditions: Communication and Technology; Community viability; Discrimination; Education; Employment/Harvest; Environment/Resource management; Family relations and social networks; Health; Household economy; Housing; Identity management; Justice/Safety; Language; Mobility; Political resources; Religion/Spirituality; and Work/Leisure.

The sampling procedures applied yield a SLiCA sample that is representative and a weighting procedures (taking into account differences in regional and community sampling probabilities and differences in response rates by gender) which subsequently makes it possible to generalize responses to entire populations by: "country" (the national level),9 "region", "region/place size", "gender" and "age groups". Interviews were conducted face-to-face in the principal language of the respondent (Kruse et al. 2008; Poppel 2010; www.arcticlivingconditions.org). ${ }^{10}$ All tables include data weighted to fully reflect the composition of populations with respect to age, gender and regional distributions.

The international SLiCA core questionnaire contained both questions about material and non-material living conditions, as well as questions aimed at measuring both quantitative and qualitative indicators, and also gave the respondents a chance to describe and evaluate their living conditions (Andersen \& Poppel 2002). Moreover, as Allardt argues, the purpose of measuring living conditions is ultimately to measure the

\footnotetext{
${ }^{8}$ The International SLiCA-research team agreed on a common core questionnaire that could be expanded in agreement with local needs. The Canadian component to the SLiCA process developed differently, as the SLiCA team and Statistics Canada agreed to merge SLiCA with the 2001 Aboriginal Peoples Survey (Kruse et al., 2008). The interviews produced 950 variables per respondent and hundreds of analytical variables (ibid.). The international core data dictionary with further information on analytic variables is accessible at http://classic.ipy.org/development/eoi/ Science Plans: SLICA data description.

${ }^{9}$ The 'Estimated Totals' in all the tables in this chapter are generalized to the entire populations in the countries/regions aged $15+$ or $16+$.

${ }_{10}$ All SLiCA data are based on personnel interviews and data are attached to either respondents or their households. All respondents are guaranteed anonymity and confidentiality.
} 
wellbeing of the individual (Allardt 1975), thus calling for the individual's subjective evaluation of his/her objective resources.

\subsection{The Concept of Subjective Wellbeing}

Subjective wellbeing is an inclusive concept, which covers all aspects of living as experienced by individuals and includes a person's subjective evaluation of his/her objective resources and other living conditions. It therefore covers both material satisfaction of vital needs and aspects of life such as personal development, being in control of one's own life and destiny, and a balanced ecosystem. However, individual experiences are closely related to the collective wellbeing of social groups, communities and nations (Andersen \& Poppel 2002).

\footnotetext{
"The concept of wellbeing is a complex one with physical, mental, emotional and spiritual aspects of living conditions. The complex interrelation between physical, mental/intellectual, spiritual, and emotional facets of wellbeing is a theme explored by many Indigenous cultures. For example, many Aboriginal societies use the "Medicine Wheel"; a symbol of holistic healing that embodies the elements of "whole health". The natural world is also a key part of wellbeing because of the intrinsic connections and interrelationships between people and the environment in which they live"
}

(Statistics Canada, 2003:5).

One of the hypotheses constituting the point of departure for the Survey of Living Conditions in the Arctic, SLiCA, was that there is a discrepancy between an indigenous perception of wellbeing and another perception defined by conventional Western social science, which researchers have incorporated in social indicator systems used in mainstream comparative studies of living conditions in industrialised societies (Andersen \& Poppel, 2002). Hence, the concept of wellbeing must reflect the ways of life and priorities of indigenous peoples in question.

\subsection{ASI Domains and SLiCA Indicators}

The Arctic Human Development Report (AHDR, 2004) recommended the development of indicators for six domains: three domains of the United Nations' Human development Index (HDI), plus three additional domains, and argued that "it would be a mistake to ignore perspectives on 
human development, especially in areas of the world like the Arctic where distinctive cultures remain influential" (AHDR, 2004:241).

In 2007 the first SLiCA results were published (Poppel et al., 2007). In order to comply with the AHDR recommendations the SLiCA team applied the six domains to the tables resulting from the analysis of data from the Inuit settlement regions.

The Arctic Social Indicators Report (ASI, 2010) was a direct follow-up to the AHDR in the sense that the main focus of the ASI working group was to further elaborate and develop indicators within the six domains recommended in the AHDR.

The list below contains the designations of each of the six corresponding domains applied in the ASI, AHDR (AHDR/HDI) and SLiCA respectively:

- Health and Population (AHDR/HDI: Longevity; SLiCA: Health including wellbeing).

- Material wellbeing (AHDR/HDI: Material success; SLiCA: Material success).

- Education (AHDR/HDI: Education; SLiCA: Education).

- Cultural wellbeing and cultural vitality (AHDR: "Maintaining cultural identity"; SLiCA: Cultural continuity).

- Contact with nature (Living close to nature; SLiCA: Ties to nature).

- Fate control (AHDR: “Controlling one's own destiny"; SLiCA: Control of destiny).

(AHDR 2004:240; Poppel et al. 2007; ASI 2010).

The indicators applied in the ASI report were selected based on the following criteria:

- Availability.

- Affordability.

- Ease of measurement.

- Robustness.

- Scalability.

- Inclusiveness.

(ASI 2010). 
As the SLiCA data were gathered through personal face-to-face interviews they most often do not live up to the criteria: availability (as the measure does not always exist in an updated version); affordability (as the data are only accessible if surveys in the different Arctic regions are carried out on a regular basis, which is more costly when using register-based data collection); and ease of measurement (as data stem from personal interviews). Robustness refers primarily to "temporal stability over time", "relevance", "significance" and "sensitivity". The SLiCA indicators were developed through in-depth discussions between indigenous partners and the SLiCA research team, from broad social goals established using dimensions of living conditions, which indicates certain robustness when it comes to description and evaluation of living conditions among the indigenous peoples in question. A substantial part of the SLiCA questionnaire was applied to the immigrant population in Greenland and the indicators are fairly robust to this group. The robustness criterion will - as pointed out in the ASI report - need validation itself (ASI, 2010). The SLiCA indicators meet the scalability criterion since data from the SLiCA project are scalable to individual, household, community, regional, and country levels. In all SLiCA survey regions but Greenland the survey is (solely) representative of the adult indigenous population (Inuit, Sami and - in Chukotka and the Kola Peninsula - also including other indigenous groups). ${ }^{11}$ The survey is therefore inclusive when it comes to age groups (adults), gender, town/settlement and regions, but not inclusive to other Arctic residents other than indigenous peoples. ${ }^{12}$

\subsection{A Case study: SLiCA as a Provider of Indicators to the ASI Framework}

The first SLiCA results were published on the project website www.arcticlivingconditions.org in March 2007. Almost 600 tables were made available (Poppel et al., 2007). ${ }^{13}$ As mentioned above, tables

\footnotetext{
11 The adult population is defined 15 years and above in Canada and Greenland and 16 years and above in all other survey regions.

12 As mentioned, the survey is representative to both the indigenous and non-indigenous population of Greenland.

13 December 2012/January 2013 tables comparing living conditions in Greenland compared with other Inuit homelands (regions) and tables comparing living conditions in different regions in Greenland (based on the formerly published tables) have been made accessible in Greenlandic and Danish. http://www.uni.gl/Forskning/ Projekter/SliCA/tabid/447/Default.aspx
} 
were organized into categories corresponding to those recommended in the Arctic Human Development Report (AHDR 2004). The categorization of SLiCA variables (and results) corresponding to the AHDR recommendations means that the Survey of Living Conditions is able to contribute to a social indicator system like the one specified in AHDR/ASI. Thus, this article uses the Inuit Nunaat (the "Inuit Homeland"/"Inuit Settlement region"/the "Inuit World") as a case study to illustrate how and under which conditions can a survey like SLiCA be designed to measure living conditions and subjective wellbeing (i.e. whether it is is able to contribute to long-term monitoring and assessment of human development in the Arctic) as well as be applied to the ASI framework for tracking change. Thus, following this overall goal the intention of this chapter is not to present an in-depth analysis of different variables and indicators or the way they might reflect "human development"/"living conditions" domains.

A number of indicators based on the above-mentioned deliberations have been selected among the SLiCA indicators to reflect living conditions within different ASI domains, including individual perceptions, priorities and wellbeing. For reasons of comparability, all of the ASI indicators will be listed in the subsections below but will not be further explored unless indicators originating from the SLiCA analysis match them. ASI indicators that are directly matched by a SLiCA indicator will be included in italic.

\subsection{Health and Wellbeing}

\subsubsection{ASI domain, ASI and SLiCA indicators: Health/population and wellbeing}

In the ASI-report from 2010 the domain dealing with health and wellbeing was named "Health and population", which included health and vital statistics as well as demographics. This domain is probably the one with most accessible data and - despite some differences in definitions of variables and indicators - the most likely domain to display comparability among key indicators. The authors recommended "infant mortality" and "net migration" as they fully live up to the ASI criteria (Hamilton et al. 2010).

The health section in the SLiCA questionnaire contains 50 questions that include questions concerning the physical and mental health of a respondent (some particularly sensitive questions were answered in a selfadministered questionnaire that was handed to and answered by the re- 
spondent). Respondents were asked to describe and evaluate both their health status and available health care in their community. Among the questions asked were some on self-rated health status and a number of questions about the respondent's use/abuse of alcohol and drugs, as well as their perceptions on social problems in the community. Finally, this section included questions about the individual's satisfaction with different aspects of life and her/his "satisfaction with life as a whole". The last mentioned question (using a five-point scale) applied the same wording as is generally used in quality of life and happiness studies, ${ }^{14}$ which makes it possible to make international comparative studies with countries outside the Arctic (Poppel et al. 2007). This question was only asked in Greenland and Alaska. The results are depicted in Table/Figure 2.

150 tables based on SLiCA data concerning health and wellbeing are published on the SLiCA project web site (www.arcticlivingconditions.org $\rightarrow$ SLiCA Results $\rightarrow$ Tables). It goes without saying that just one or a small number of health indicators can neither tell the whole story of an individual's health or - on an aggregate level - the health status of a community, region or country. Due to the ASI selection criteria, ASI indicators on health, wellbeing and population have to be selected among accessible vital statistics, whereas SLiCA indicators - originating from a methodology of using face-to-face interviews - approach health and wellbeing from an individual's perspective. The following SLiCA indicators were selected due to their significance in reflecting individual health and wellbeing:

- Self-rated health.

- Satisfaction with quality of life in this community.

- Satisfaction with life as a whole.

\section{Self-rated health}

Self-rated health not only gives each respondent the possibility to evaluate her/his health condition in general. It also seems to be a fairly good predictor of life expectancy (DeSalvo et al. 2006). Table/Figure 2 shows disparities between self-rated health statuses. Comparing the proportion of how "fair" or "poor" personal health is for each region shows that differences between the regions are significant. In Chukotka more than five out 
of ten report "fair" or "poor" health. This is five times the proportion in Canada and roughly twice the proportion in Greenland and Alaska. ${ }^{15}$

Table/Figure 2: Inuit Nunaat. Self-rated personal health. By regions/countries.

Health Table 243: Self Perception of Personal Health by Country

\begin{tabular}{lrrrrr}
\hline & Canada & Greenland & Chukotka & Alaska & Total \\
\cline { 2 - 6 } Excellent & $28 \%$ & $19 \%$ & $5 \%$ & $15 \%$ & $18 \%$ \\
Very good & $27 \%$ & $59 \%$ & $10 \%$ & $32 \%$ & $38 \%$ \\
Good & $33 \%$ & $18 \%$ & $34 \%$ & $30 \%$ & $26 \%$ \\
Fair & $9 \%$ & $4 \%$ & $29 \%$ & $20 \%$ & $13 \%$ \\
Poor & $2 \%$ & $1 \%$ & $23 \%$ & $4 \%$ & $6 \%$ \\
& $100 \%$ & $100 \%$ & $100 \%$ & $100 \%$ & $100 \%$ \\
Estimated Total & 22,240 & 39,338 & 17,666 & 11,047 & 90,291 \\
\hline
\end{tabular}

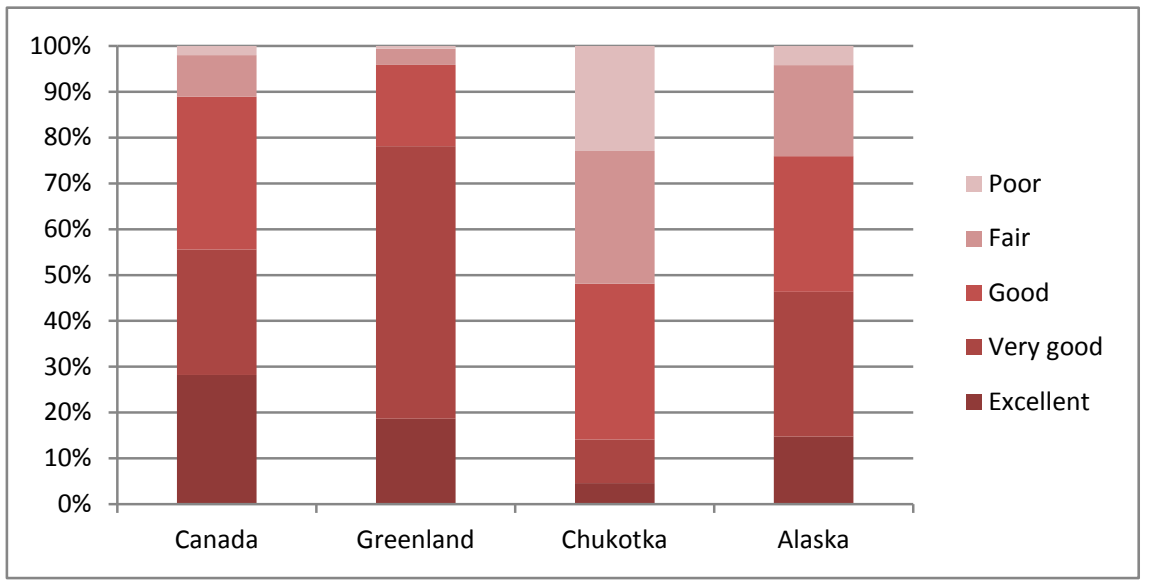

Source: Poppel et al. 2007.

Note: Greenland response categories are harmonized and adjusted to other survey regions.

\section{Satisfaction with quality of life in this community and satisfaction with life as a whole}

Satisfaction with different aspects of life, and life itself, were each part of the SLiCA core questionnaire because the main rationale of the survey was to learn about an individual's perception and evaluation of their own living conditions and quality of life.

For different reasons, the questions about the subjective evaluation of an individual's quality of life/satisfaction with life as a whole were not asked in all regions so an overall comparison was not possible.

15 Since the publication of the ASI Report in 2010 it has been noted that response categories in the Greenlandic SLiCA questionnaire have been translated in a way that means that the "excellent" category is omitted. Consequently the figure (Figure 2) and the underlying table have had to be corrected. 
Table/Figure 3: Inuit Nunaat. Satisfaction with Quality of Life in this community by Country

\begin{tabular}{llrrrrr}
\hline & Canada & Greenland & Chukotka & Alaska & Total \\
\hline \multirow{2}{*}{ Quality of life in this community } & Very satisfied & $*$ & $5 \%$ & $1 \%$ & $31 \%$ & $8 \%$ \\
& Somewhat satisfied & $*$ & $64 \%$ & $13 \%$ & $50 \%$ & $50 \%$ \\
& Not satisfied or neither & $*$ & $31 \%$ & $86 \%$ & $19 \%$ & $42 \%$ \\
& & $*$ & $100 \%$ & $100 \%$ & $100 \%$ & $100 \%$ \\
\hline
\end{tabular}

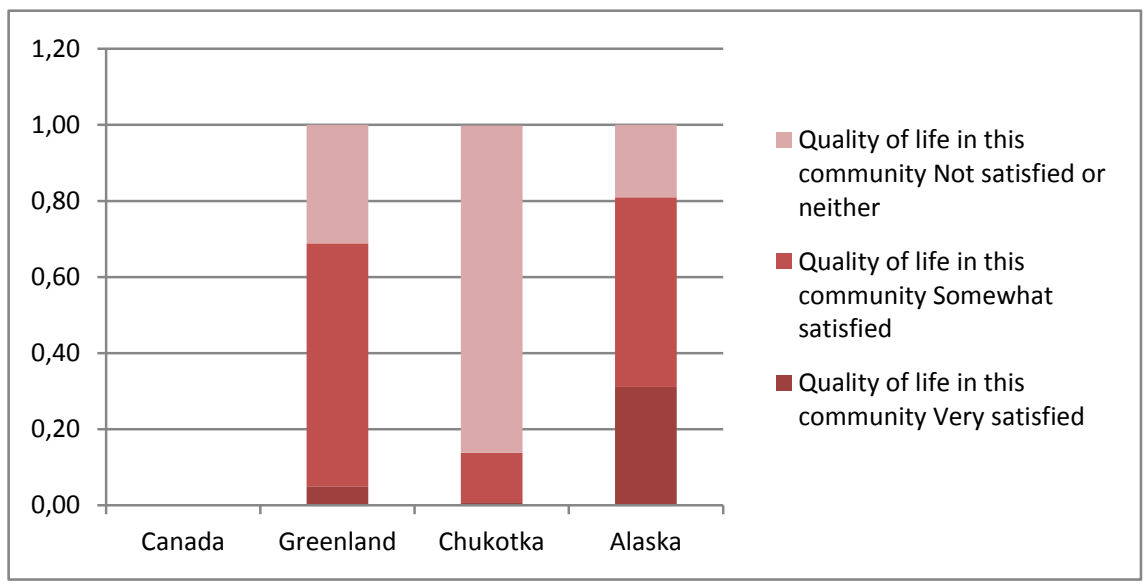

Source: Poppel et al. 2007.

Note: Canadian data not available.

Table 3 concerns the "satisfaction with quality of life in this community". The focus here is quality of "community life". Two out of ten Alaskan Inuit and more than three out of ten Greenlanders are not satisfied or neither satisfied nor dissatisfied with the quality of community life in of their communities. This corresponds with other SLiCA findings where a substantial amount of respondents identify different kinds of social problems in their communities, such as unemployment, domestic violence and suicide (Poppel et al. 2011). The figures from Chukotka are significantly different from figures in Greenland and Alaska as only one out of seven considers quality of life in their community somewhat or very satisfactory.

When it comes to "satisfaction with life as a whole", otherwise referred to in other surveys as "happiness", there are differences between Greenland and Alaska as a higher number of Inuit in Alaska are "very satisfied with life as a whole" in comparison to those in Greenland. When taking together the results from both of the two positive categories, more than nine out of ten Inuit in both Greenland and Alaska are satisfied (Table/Figure 4).

Both the overall satisfaction with life as a whole and satisfaction with a number of specific dimensions of peoples' lives were investigated. 
Based on answers to these questions it is possible to analyze the relative importance of satisfaction with different aspects of life for satisfaction with life as a whole. In other words, it is possible to examine the degree to which satisfaction with certain aspects of life can explain satisfaction with life in general.

The analysis has been made for Greenland and Alaska combined by using a stepwise regression analysis. One somewhat surprising result was that satisfaction with an individual's actual job or outcome of actual fishing and hunting activities were less important as indicators of an individual's overall satisfaction with their life when compared to their job opportunities or the amount of fish and game locally available. This means that "availability" and "accessibility" means more to the quality of life of Inuit than satisfaction with an actual job or catch. Also important in explaining overall wellbeing is the combination of market and nonmarket activities, such as hunting and fishing, for example, and the influence people have over their natural resources and environment (Kruse et al. 2008; Poppel 2006; Poppel et al. 2011).

Table/Figure 4: Inuit Nunaat. Satisfaction with life as a whole. By regions/countries

\begin{tabular}{llrrrrr}
\hline & Canada & Greenland & Chukotka & Alaska & Total \\
\hline \multirow{2}{*}{ Life as a whole } & Very satisfied & $*$ & $25 \%$ & $*$ & $56 \%$ & $32 \%$ \\
& Somewhat satisfied & $*$ & $68 \%$ & $*$ & $35 \%$ & $60 \%$ \\
& Not satisfied or neither & $*$ & $7 \%$ & $*$ & $10 \%$ & $8 \%$ \\
& & $*$ & $100 \%$ & $*$ & $100 \%$ & $100 \%$ \\
\hline
\end{tabular}

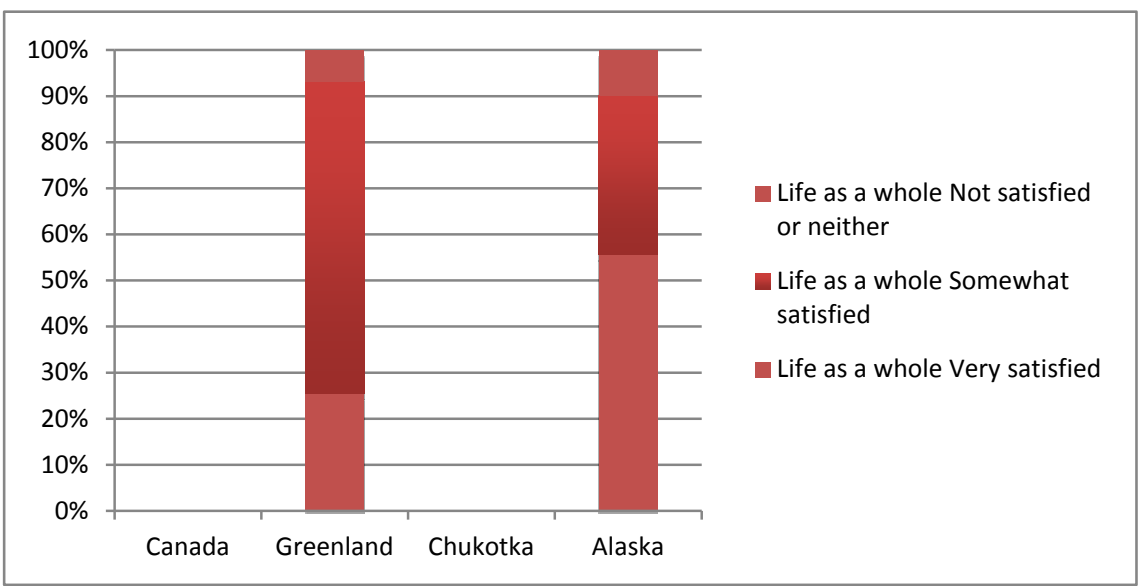

Source: Poppel et al. 2007.

Note Canadian and Chukotkan data not available. 
Children playing in the snow in January, 2013, in Nuuk, Greenland

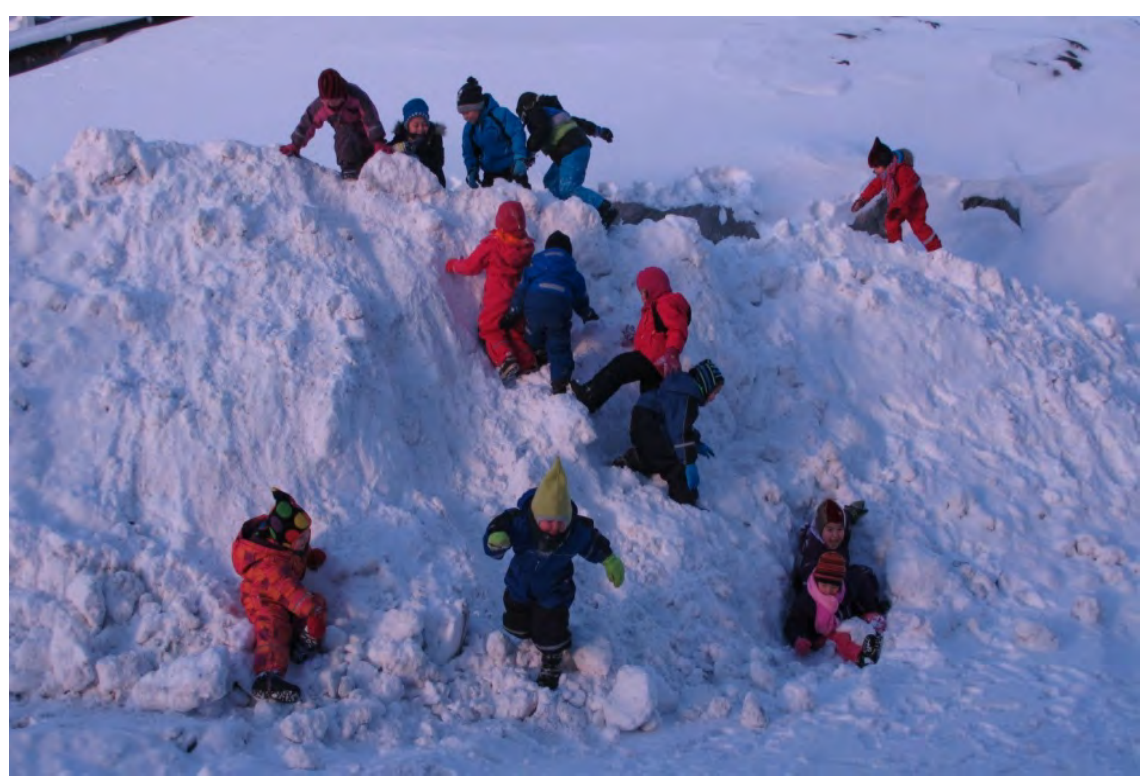

Photo: Birger Poppel.

\section{How well does SLiCA apply to the ASI domain HEALTH/POPULATION} \& WELLBEING and selected indicators?

The short and easy answer to the question raised in the headline above is that SLiCA does not apply, due to the fact that the selected indicators are vital statistics. More importantly, however, is that when it comes to subjective wellbeing and health SLiCA provides information on selfevaluated wellbeing and health. Both measures are generally accepted as key indicators and direct measures of wellbeing and health, whereas the ASI indicators under this domain are first and foremost indirect measures. Furthermore, personal interviews including questions on subjective wellbeing, different background variables and living conditions, as well as perceptions and attitudes, are preconditions and bases for more thorough analyses of cause and effect relationships. 


\subsection{Material Wellbeing}

\subsubsection{ASI domain, ASI and SLiCA indicators}

\section{ASI on "material wellbeing"}

In the ASI chapter "Material Wellbeing in the Arctic", material wellbeing is defined as "a measure of local residents' command over goods and resources", and the indicators recommended are:

- Per capita household income.

- Composite index (containing both per capita household income, public sector and government transfers and production in the traditional sector including the subsistence economy).

(Larsen \& Huskey, 2010:47).

Although the authors of the ASI-chapter on material wellbeing consider the first indicator to be fairly easy to measure, a few obstacles are notable in terms of calculating the composite index, especially since the amount of subsistence products included in individual household consumption are rarely available and the valuation of fish and meat consumed is a complicated task - even when the amount consumed is known.

\section{SLiCA on "material wellbeing"}

One of the major achievements of the SLiCA project was the development of the "Household production model" (see figure). The household in a mixed subsistence-based economy was regarded as an enterprise possessing different factors of production and being not only a production unit but also a collective consumer and investor (Usher et al., 2003). 
The Household Production Model

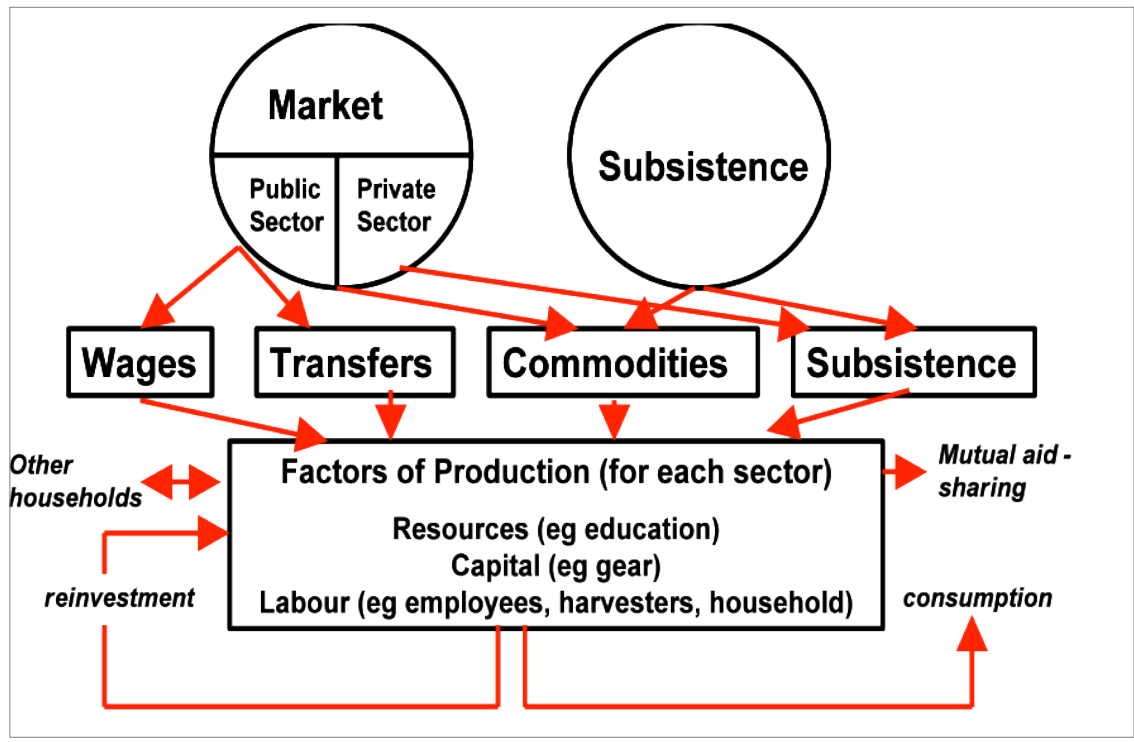

Source: Andersen and Poppel (2002).

To be able to fully understand the function of the household and to implement the household production model, data on all sources of income (wage, transfers and informal income) as well as all spending on consumption and investment had to be available. The SLiCA questionnaire thus enabled the research team to provide data on a large number of variables. Also, as questions related to satisfaction with different aspects of the individual and household economy were asked, the following indicators may be given, for example:

- Household income (from main sources of both formal and informal economy).

- Relative poverty.

- Absolute poverty.

- Ability to make ends meet.

- Satisfaction with household economy.

- Satisfaction with standard of living.

- Satisfaction with jobs.

- Satisfaction with job opportunities. 
This means that SLiCA is able to provide data on both the average size of individual and household income and distribution of incomes. Furthermore, questions were asked about satisfaction with a number of economic conditions and living standards.

Selected results are illustrated in the figures below and will be briefly commented on.

Poverty can be measured and evaluated in many different ways. In the SLiCA project absolute poverty was measured based on the US absolute poverty measure and income data from the different regions, which were made comparable using purchasing power parities (PPP) (Kruse et al. 2007). ${ }^{16}$

For obvious reasons, measuring relative poverty was less complicated. The level used in measuring relative poverty (Figure 5) was $60 \%$ of the median income. ${ }^{17}$

While there are major differences in the level of income between individuals and households in different regions, the figure shows that individuals from relatively poor areas (with incomes below $60 \%$ of the median income) exist in all regions between 40 and 50\%. The largest proportion of relatively poor individuals lives in the Chukotka region.

When comparing the Inuit population in different regions where individuals "makes ends meet" (with some or great difficulty) with parts that are not satisfied or are neither satisfied nor dissatisfied with their household income, there seems to be a pattern (not a close correlation, though) in and among the regions. In Chukotka $80 \%$ have some or great difficulty in "making ends meet" and three out of four are not satisfied or are neither satisfied nor dissatisfied with their household income. In both Greenland and Alaska, larger parts of the indigenous population find it easy or fairly easy to make ends meet in relation to larger parts that are somewhat or very satisfied with their household income.

\footnotetext{
${ }^{16}$ Comparing income data from the different regions is a complicated task and even using PPP's does not overcome this challenge as PPP's are developed for the capitol regions of the "mother countries" and thus necessarily reflects the price level and price structure of the more remote regions.

17 The European Union (EU) and the Organization for Economic Cooperation and Development (OECD) both apply this level in their analyses of poverty.
} 
Table/Figure 5: Relative poverty

Material Success Table 447: Total Household Income, Adjusted for Purchasing Power Expressed as Above or Below 60 Percent of Median Income in Country by Country

\begin{tabular}{lrrrrr}
\hline & Canada & Greenland & Chukotka & Alaska & Total \\
\cline { 2 - 5 } 60 percent or below & $47 \%$ & $43 \%$ & $52 \%$ & $45 \%$ & $47 \%$ \\
Above 60 percent median & $53 \%$ & $57 \%$ & $48 \%$ & $55 \%$ & $53 \%$ \\
\multirow{2}{*}{ Estimated Total } & $100 \%$ & $100 \%$ & $100 \%$ & $100 \%$ & $100 \%$ \\
& 22,220 & 33,022 & 15,581 & 10,195 & 81,018 \\
\hline
\end{tabular}

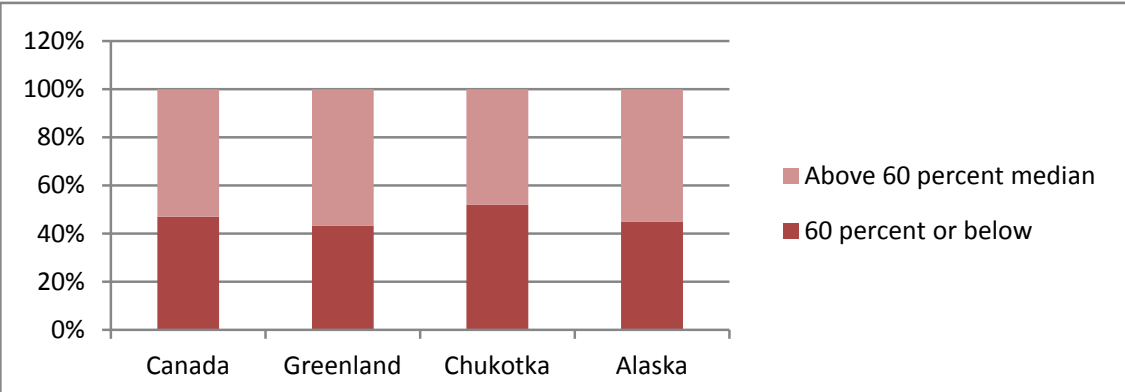

Source: Poppel et al. 2007.

Table/Figure 6: Ability to make ends meet

\begin{tabular}{lrrrrr}
\hline \multicolumn{2}{l}{ Material Success Table 475: Ease in Making Ends Meet by Country } \\
\hline & Canada & Greenland & Chukotka & Alaska & Total \\
\cline { 2 - 6 } & $*$ & $21 \%$ & $5 \%$ & $16 \%$ & $16 \%$ \\
Very easily & $*$ & $58 \%$ & $17 \%$ & $37 \%$ & $43 \%$ \\
Fairly easily & $*$ & $18 \%$ & $33 \%$ & $42 \%$ & $27 \%$ \\
With some difficulty & $*$ & $3 \%$ & $45 \%$ & $5 \%$ & $14 \%$ \\
With great difficulty & $*$ & $100 \%$ & $100 \%$ & $100 \%$ & $100 \%$ \\
& $*$ & 38,208 & 20,425 & 10,627 & 69,260 \\
Estimated Total & & & & &
\end{tabular}

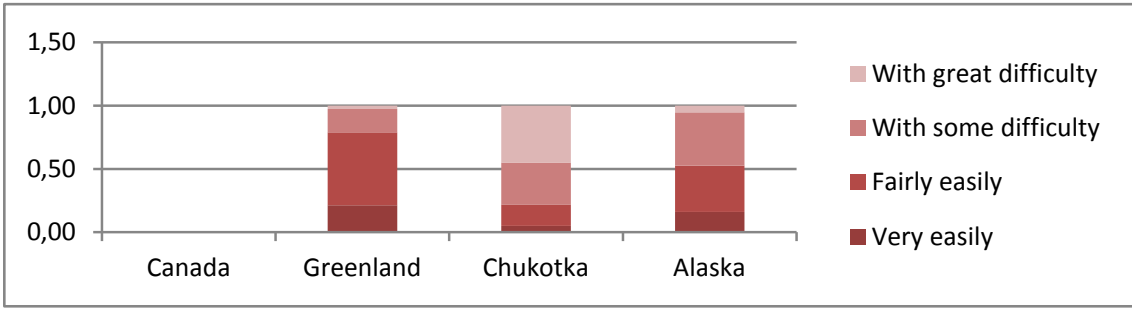

Source: Poppel et al. 2007.

Note: Canadian data not available. 
Table/Figure 7: Satisfaction with household economy

Material Success Table 465: Satisfaction With Household Income by Country

\begin{tabular}{lrrrrr}
\hline & Canada & Greenland & Chukotka & Alaska & Total \\
\cline { 2 - 5 } Very satisfied & $*$ & $13 \%$ & $4 \%$ & $27 \%$ & $13 \%$ \\
Somewhat satisfied & $*$ & $51 \%$ & $22 \%$ & $44 \%$ & $43 \%$ \\
Not satisfied or neither & $*$ & $36 \%$ & $74 \%$ & $29 \%$ & $44 \%$ \\
& $*$ & $100 \%$ & $100 \%$ & $100 \%$ & $100 \%$ \\
Estimated Total & $*$ & 37,767 & 18,739 & 10,787 & 67,293 \\
* Data Not Available & & & & & \\
\hline
\end{tabular}

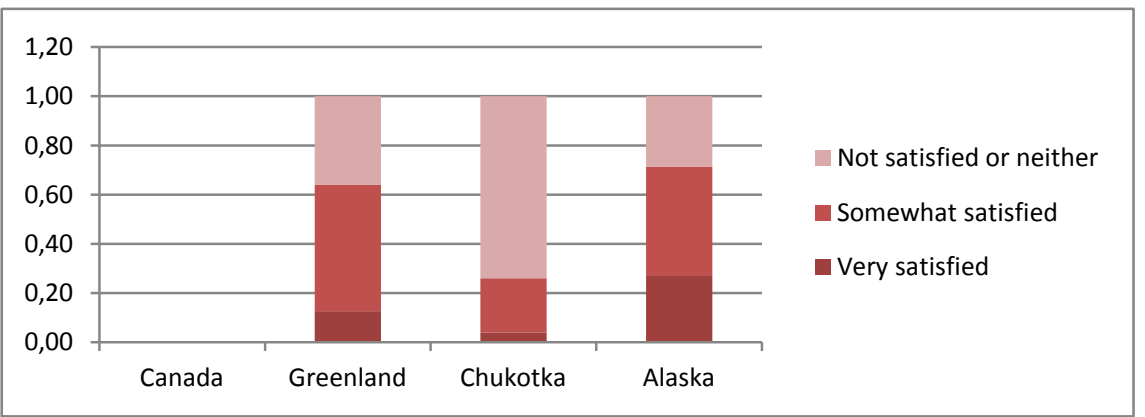

Source: Poppel et al. 2007.

Note: Canadian data not available. 
Table/Figure 8: Satisfaction with Job and Job Opportunities

\begin{tabular}{llrrrrr} 
Material Success Table 457: Satisfaction With Job and Job Opportunities by Country & & \\
\hline & & Canada & Greenland & Chukotka & Alaska & Total \\
\cline { 3 - 7 } Job & Very satisfied & $43 \%$ & $33 \%$ & $21 \%$ & $58 \%$ & $35 \%$ \\
& Somewhat satisfied & $41 \%$ & $54 \%$ & $53 \%$ & $32 \%$ & $47 \%$ \\
& Not satisfied or neither & $16 \%$ & $13 \%$ & $26 \%$ & $11 \%$ & $17 \%$ \\
& & $100 \%$ & $100 \%$ & $100 \%$ & $100 \%$ & $100 \%$ \\
& & Canada & Greenland & Chukotka & Alaska & Total \\
Job opportunities & & $11 \%$ & $4 \%$ & $1 \%$ & $11 \%$ & $6 \%$ \\
& Very satisfied & $31 \%$ & $28 \%$ & $9 \%$ & $28 \%$ & $24 \%$ \\
& Somewhat satisfied & $57 \%$ & $68 \%$ & $90 \%$ & $61 \%$ & $70 \%$ \\
\multirow{3}{*}{ Estimated Total } & Not satisfied or neither & $100 \%$ & $100 \%$ & $100 \%$ & $100 \%$ & $100 \%$ \\
\hline & & 17,870 & 36,617 & 19,508 & 10,658 & 84,653 \\
\hline
\end{tabular}

Satisfaction with job

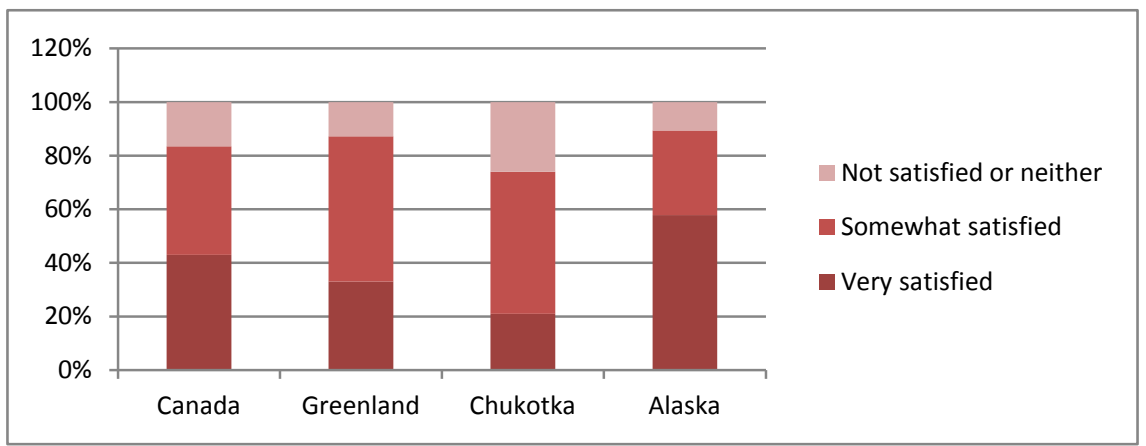

Source: Poppel et al. 2007.

\section{Satisfaction with job opportunities}

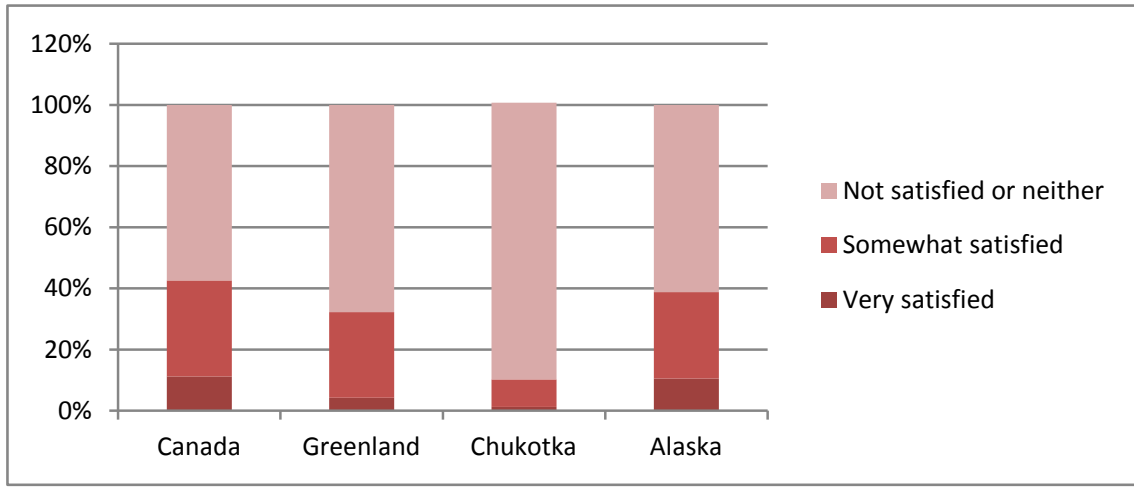

Source: Poppel et al. 2007. 


\section{How well does SLiCA apply to the ASI domain MATERIAL WELLBEING and selected indicators?}

SLiCA provides information about "household income" as a whole, as well as different sources of income. As information on the number and age of household members is also available, the ASI indicator can be calculated.

Self-reported income is often subject to discussion based on the assumption that people tend to underestimate their earnings. Following this assumption, register-based information from tax authorities is preferable. When it comes to estimating income for the informal economy, surveys seemingly have an advantage.

SLiCA has an advantage of public statistics related to "material wellbeing" at its disposal, which include evaluative questions related to one's "ability to make ends meet" and one's "satisfaction with household economy and standard of living." These questions add value to the quantitative data as they represent the individual's point of view.

\subsection{Education}

\subsubsection{ASI domain, ASI and SLiCA indicators: Education}

\section{ASI on "education"}

The AHDR states that "Education is not a neutral enterprise. It is the promotion of skills, values, history, languages, and ways of thinking and behaving" (AHDR 2004:169). In developing an indicator that encompasses "education", the authors of the Education chapter in the ASI Report suggest three indicators that are related to post-secondary education:

- The proportion of students pursuing post-secondary education opportunities.

- The ratio of students successfully completing post-secondary education.

- The proportion of graduates who are still in the community 10 years later.

From these three indicators, the second indicator was picked to be the ASI "education" indicator:

- Ratio of students successfully completing post-secondary education. 


\section{SLiCA on "education" 18}

One of the most important points of departure for the SLiCA project was defining living conditions in terms of resources that the individual can apply in different arenas (Andersen \& Poppel 2002). Focussing on the resources of the individual in relation to employment implied that both qualifications and competencies needed in traditional livelihoods and occupations within the production and service sectors had to be analysed. Thus, focus was centred on both formal education, provided by educational institutions, and informal education transferred from one generation to the next (Kruse et al. 2008). This is reflected in the SLiCA indicators listed and commented on below:

- Level of education.

- Traditional skills: learned in/improved since childhood/still used.

- Still use traditional skills today.

- Satisfaction with different conditions/circumstances related to education.

The figure below (Figure 9) is based on the question used in the SLiCA questionnaire concerning the respondents' highest level of education. ${ }^{19}$ The category "Vocational school or college" corresponds to the category "post-secondary education", which is used in the ASI. The figure shows that less than $50 \%$ of Greenlanders had a post-secondary education, which was a slightly higher percentage than in Chukotka, almost twice the rate in Alaska, and almost three times that of Inuit settlement regions in Northern Canada.

\footnotetext{
${ }^{18}$ SLiCA data and results on education are more thoroughly analysed in Kruse et al. 2008 and Rønning \& Wiborg 2008.

19 The question was phrased as an open-ended question, which gave the opportunity for more in-depth analysis but at the same time created a lot of work when trying to categorize the answers.
} 


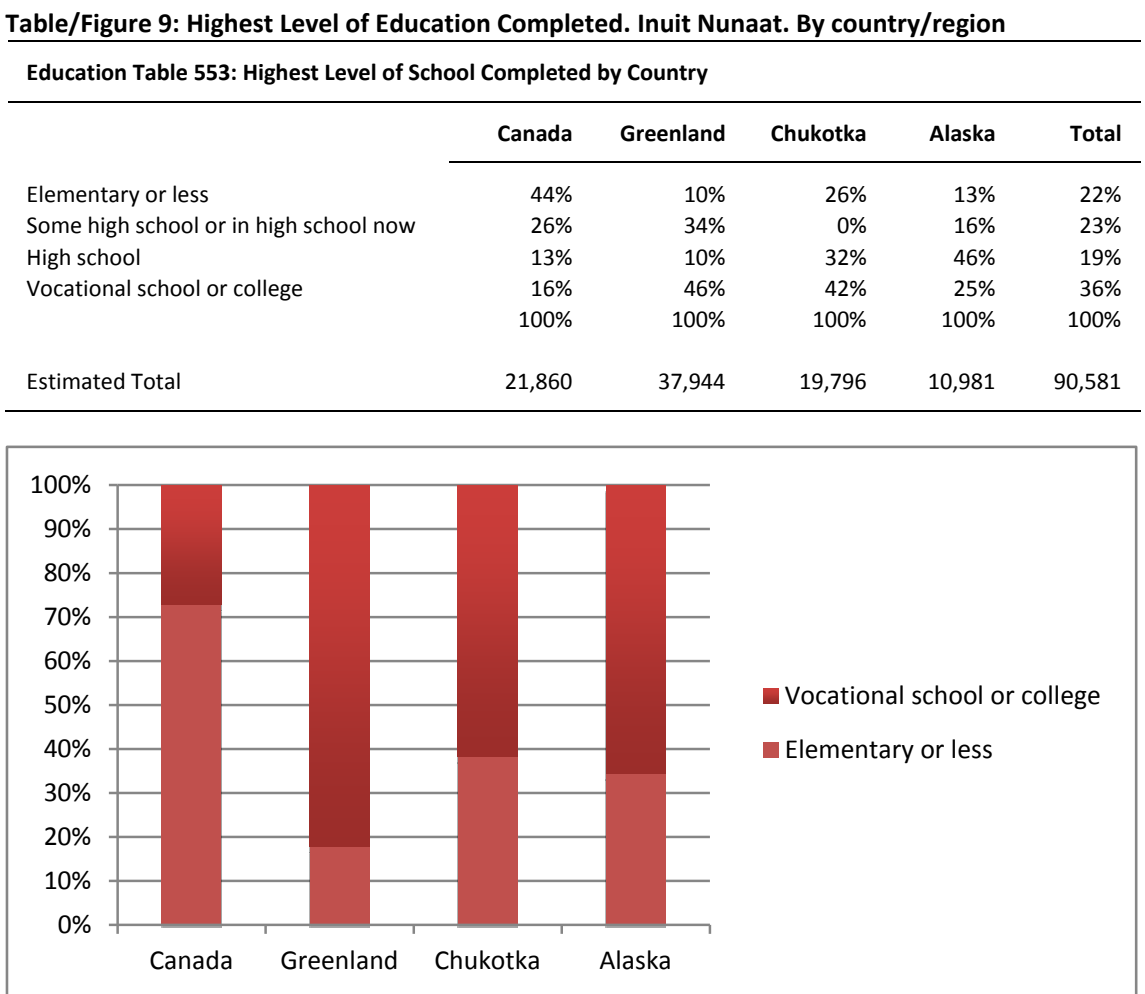

Source: Poppel et al., 2007.

Graduation of bachelors and masters students from Ilisimatusarfik, University of Greenland, February 2013

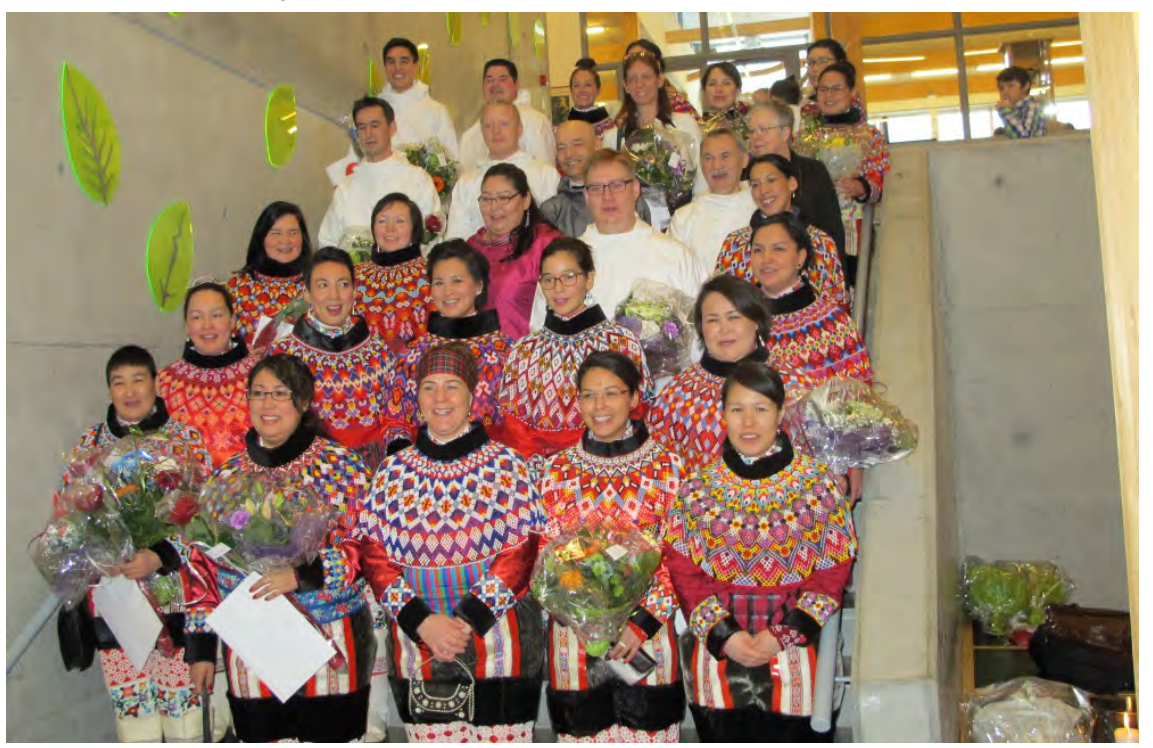

Photo: Birger Poppel. 
Almost the same share of the Inuit in Greenland and Alaska are somewhat or very satisfied with education in their community (Table/Figur 10) and the percentage is markedly higher than that of Chukotka. To get information at a more operational level data of course need to be available at a community, district or regional level. ${ }^{20}$

Table/Figure 10: Satisfaction with education in community. By country/region

\begin{tabular}{lrrrrr}
\hline \multicolumn{2}{l}{ Education Table 579: Satisfaction with Quality of Education in Community by Country } \\
\hline & Canada & Greenland & Chukotka & Alaska & Total \\
\cline { 2 - 5 } & $25 \%$ & $7 \%$ & $10 \%$ & $30 \%$ & $15 \%$ \\
Very satisfied & $48 \%$ & $56 \%$ & $31 \%$ & $37 \%$ & $46 \%$ \\
Somewhat satisfied & $27 \%$ & $37 \%$ & $59 \%$ & $32 \%$ & $40 \%$ \\
Not satisfied or neither & $100 \%$ & $100 \%$ & $100 \%$ & $100 \%$ & $100 \%$ \\
& 17,130 & 33,606 & 17,160 & 10,636 & 78,532 \\
Estimated Total & & & & & \\
\hline
\end{tabular}

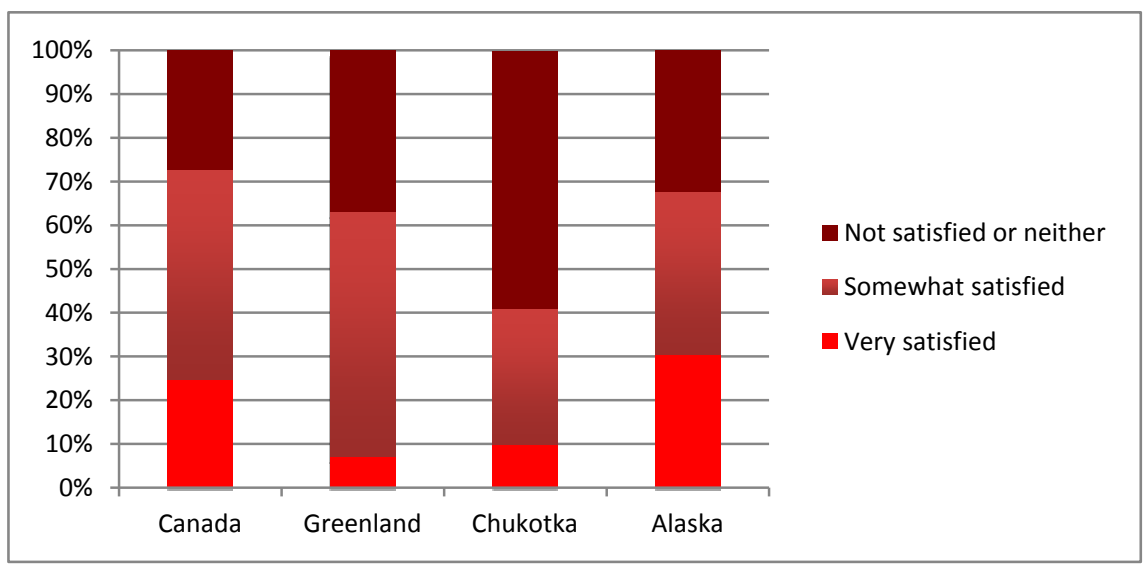

Source: Poppel et al., 2007.

As most Inuit communities can be defined as part of 'the mixed economy many Inuit households still depend on a combination of subsistence hunting and fishing and paid jobs, ${ }^{21}$ which might consist of permanent or part-time or seasonal jobs that are common in many communities. Thus, it is of vital importance to possess the skills necessary to hunt, herd or fish, survive in an often harsh natural environment, preserve meat and fish, and maintain and repair equipment used for such subsist-

${ }^{20}$ The SLiCA analyses regions according to what we have defined as "the Inuit Settlement regions", which are listed above.

21 The "mixed economy" is characterized by the co-existence of asubsistence based hunting/herding/fishing economy and a market economy. (Kruse et al. 2008; Poppel 2006; Poppel \& Kruse 2009). 
ence activities. In accordance with this perception a number of questions were asked about the knowledge of skills important to traditional livelihood; e.g. whether they were transferred during childhood or learned later; whether the respondent passed this knowledge onto his/her children; or, not least importantly, whether traditional skills were still used today (Kruse et al., 2008; Poppel, 2006; Poppel \& Kruse, 2009).

Figure 11 shows if and to what degree traditional skills are still being used by the Inuit (data from Canada are not available). More than $50 \%$ of Inuit people in the three regions confirm that they use traditional skills; with less than one out of five Inuit in Greenland and Alaska, and a little more Inuit in Chukotka, claiming that they do not use such skills.

Table/Figure 11: Traditional Skills. By country/region

\begin{tabular}{lrrrrr}
\hline \multicolumn{6}{l}{ Education Table 539: Still Use Traditional Skills Today by Country } \\
\hline & Canada & Greenland & Chukotka & Alaska & Total \\
\cline { 2 - 6 } & $*$ & $72 \%$ & $53 \%$ & $86 \%$ & $69 \%$ \\
Yes & $*$ & $16 \%$ & $24 \%$ & $9 \%$ & $17 \%$ \\
Some of them & $*$ & $12 \%$ & $23 \%$ & $6 \%$ & $14 \%$ \\
No & $*$ & $100 \%$ & $100 \%$ & $100 \%$ & $100 \%$ \\
& $*$ & 38,807 & 20,227 & 11,021 & 70,055 \\
\hline
\end{tabular}

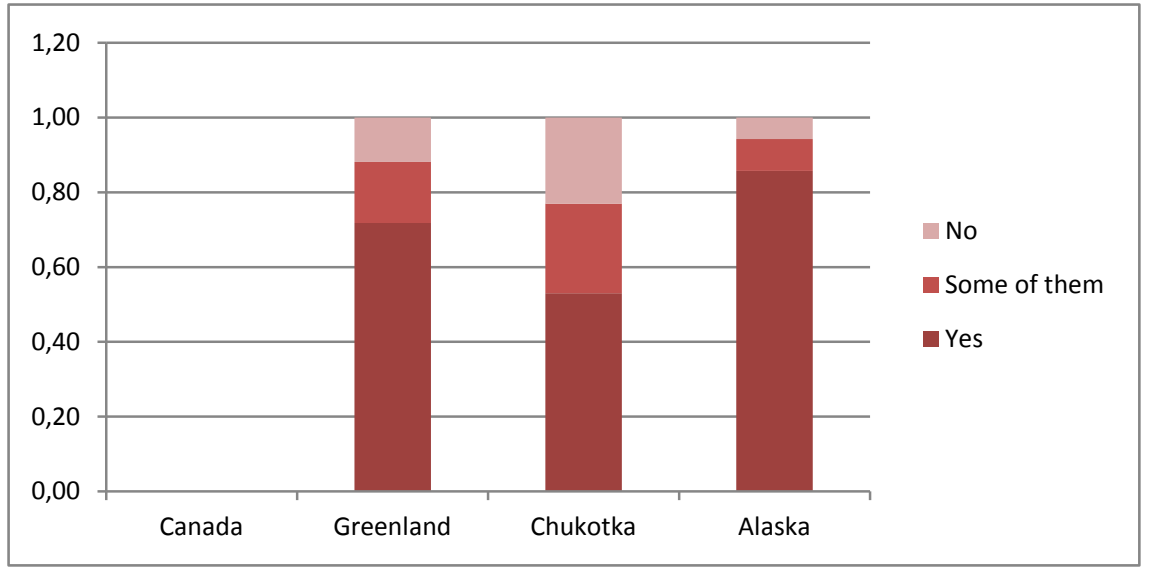

Source: Poppel et al. 2007. Note: Canadian data not available.

Note: Canadian data not available

The SLiCA data on conventional and traditional education, income and wellbeing allow us to investigate relations between these and other variables related to living conditions:

"Inuit adults with a high school degree earn on average $49 \%$ more than Inuit who did not complete high school. Inuit completing a college education earn on average $47 \%$ more than Inuit with a high school education. Perhaps it 
should not be a surprise either that the same relationship works in subsistence. The number of traditional skills learned as a child explains $29 \%$ of the variation in the number of subsistence activities pursued in the last year. Both formal and traditional education contribute to production activities that in turn contribute to overall wellbeing."

(Kruse et al. 2008:123-24)

\subsection{How well does SLiCA apply to the ASI domain Education and selected indicators?}

The SLiCA questionnaire contains questions on the level and kind of formal education, thus meeting the criteria for the selected ASI indicator. SLiCA also includes questions about the traditional education transferred informally from one generation to the next, which is important when analyzing resources to apply in a mixed (subsistence-market) economy. Furthermore, SLiCA provides information on the individual's satisfaction with, foe example, the local supply of education institutions.

\subsection{Cultural wellbeing and cultural vitality}

\subsubsection{ASI domain, ASI and SLiCA indicators: Cultural wellbeing and cultural vitality}

\section{ASI on "cultural wellbeing" and "cultural vitality"}

The authors of the chapter on Cultural wellbeing and cultural vitality in the ASI report adopted the term "cultural wellbeing", "in reference to mainstream quality-of-life research" to encompass a broad spectre of dimensions of culture including:

- Language (use of language and language retention).

- Knowledge (and its transmission).

- Communication (including education and performance).

- Spirituality, such as religion and ritual.

- Socio-cultural events and media.

- Economic and subsistence practices.

- Social organization, institutions and networks.

(Schweitzer et al. 2010:91-92). 
In conclusion, "language retention", "cultural autonomy", and "belonging" were considered "important components for an understanding of cultural wellbeing in the Arctic" and a composite indicator based on these three indicator elements to "provide a sense of the state of things within different dimensions of cultural vitality/integrity" (Schweitzer et al. 2010:105-106). In the concluding chapter "Language retention" was singled out because it was the indicator that met most of the criteria outlined for ASI indicators.

\section{SLiCA on "cultural wellbeing" and "cultural vitality"}

In the process of discovering dimensions of living conditions that were most important to the Inuit and Saami peoples of the Arctic, indigenous partners and the SLiCA research team focused on - among others: Community viability, Education, Employment/Harvest, Environment/ Resource management, Family relations and social networks, Identity management, Language, Religion/Spirituality, and Work/Leisure that all include elements corresponding to the ASI deliberations above. This also means that indicators were developed and questions asked within these dimensions (Poppel et al. 2007: tables 57-171), some of which are listed below:

- Identity markers:

o Activities and customs important or very important to maintaining indigenous identity.

- Language retention (self-reported):

o Language ability.

0 Language use.

- Participation in cultural activities.

- Satisfaction with local support of different cultural activities and values.

- Religious beliefs (both traditional Inuit, Saami and Christian beliefs).

- Sense of belonging (reflected in several questions, for example concerning respondents thoughts within last five years about moving away from the town/settlement they had previously lived in).

When asked about the importance of activities and customs for maintaining indigenous identity, the so-called identity markers that ranked highest were "view of nature", "traditional food", "childhood upbringing", "hunting and fishing", "meeting expectations of family and indigenous friends" and "contacts with other indigenous people" (Table /Figure 12), as well as using the indigenous language (which is not included in the figure). The identity 
markers both provide an insight into what is important for the Inuit, and at the same time also indicate areas of significance for policy planning.

\section{Table/Figure 12: Inuit Nunaat. Indigenous Identity}

Activities and Customs Important to Maintaining Indigenous Identity by Country

\begin{tabular}{lrrrrr} 
& Canada & Greenland & Chukotka & Alaska & Total \\
\cline { 2 - 6 } View of nature & $*$ & 97 & 98 & 96 & 97 \\
Traditional food & $*$ & 95 & 98 & 96 & 97 \\
Childhood upbringing & $*$ & 96 & 98 & 94 & 96 \\
Use of indigenous language & $*$ & 97 & 84 & 84 & 92 \\
Naming kinship relationships & $*$ & 87 & 100 & 90 & 91 \\
Preservation of traditional foods & $*$ & 85 & 89 & 96 & 87 \\
Hunting and fishing & $*$ & 79 & 99 & 95 & 87 \\
Meeting expectations of family and indigenous friends & $*$ & 88 & 81 & 94 & 87 \\
Contacts with other indigenous people & $*$ & 95 & 58 & 93 & 84 \\
Occupation or profession & $*$ & 86 & 77 & 87 & 84 \\
Harvesting of wild berries and plants & $*$ & 75 & 98 & 90 & 84 \\
Religious and spiritual beliefs & $*$ & 79 & 66 & 81 & 76 \\
Participation in traditional cultural events & $*$ & 71 & 81 & 85 & 76 \\
Clothes worn & $*$ & 78 & 71 & 76 & 75 \\
Indigenous poetry and literature & $*$ & 79 & 61 & 73 & 73 \\
\hline
\end{tabular}

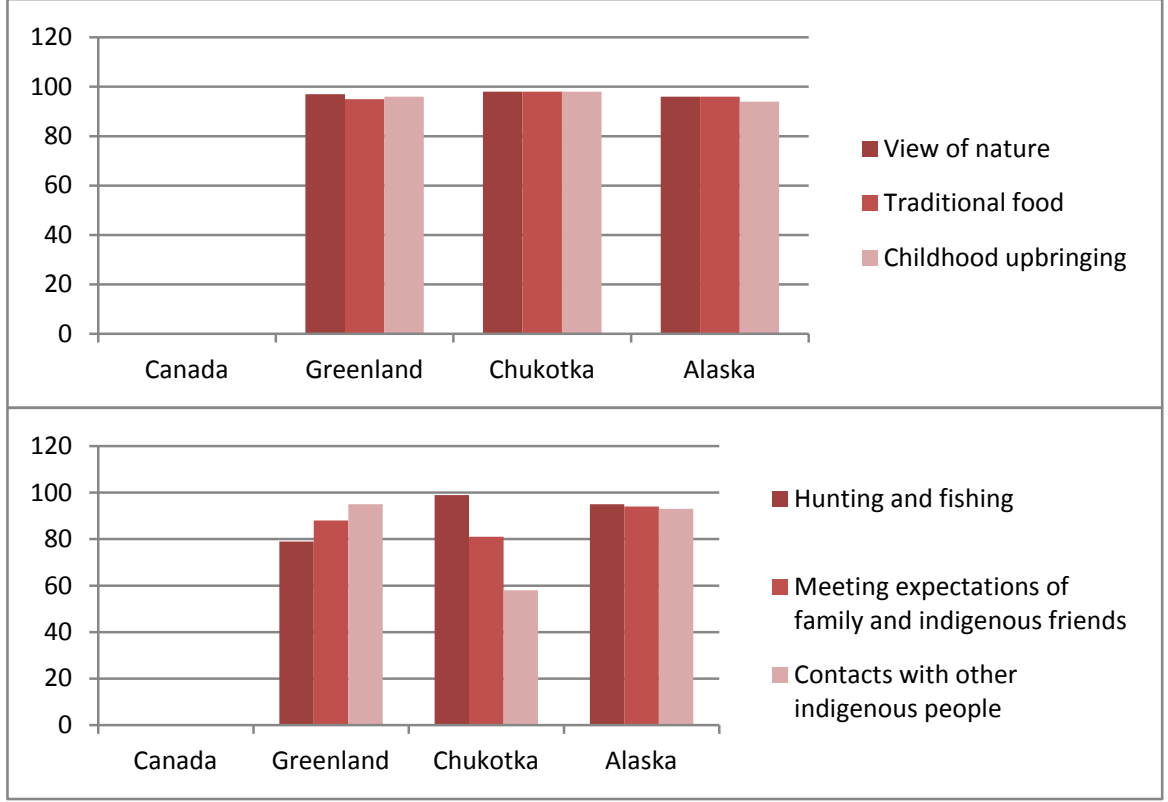

Source: Poppel et al. 2007. Note: Canadian data not available. Note: Canadian data not available.

Language retention is a very strong identity marker and is thus also exposed to a great degree of political attention. It was for instance considered a major political victory for the Greenlanders when it was agreed that the Act on Greenland Self-Government (2009) stated that the Greenlandic language is the official language in Greenland. 
Table/Figure 13 gives an insight into how the Inuit in the different regions self-report their language abilities. Whether the focus is on understanding, speaking, reading or writing there is a significant difference between self-reported abilities among the Inuit in Canada and Greenland, on one side, and in Chukotka and Alaska on the other.

\begin{tabular}{|c|c|c|c|c|c|c|}
\hline \multicolumn{7}{|c|}{ Cultural Continuity Table 91: Indigenous Language Ability by Country } \\
\hline & & Canada & Greenland & Chukotka & Alaska & Total \\
\hline \multirow[t]{4}{*}{ Understand } & Very well & $79 \%$ & $73 \%$ & $40 \%$ & $39 \%$ & $60 \%$ \\
\hline & Relatively well & $13 \%$ & $24 \%$ & $18 \%$ & $15 \%$ & $21 \%$ \\
\hline & Not at all to with effort & $7 \%$ & $3 \%$ & $42 \%$ & $46 \%$ & $19 \%$ \\
\hline & & $100 \%$ & $100 \%$ & $100 \%$ & $100 \%$ & $100 \%$ \\
\hline \multirow[t]{4}{*}{ Speak } & Very well & $77 \%$ & $71 \%$ & $37 \%$ & $32 \%$ & $56 \%$ \\
\hline & Relatively well & $12 \%$ & $25 \%$ & $17 \%$ & $12 \%$ & $21 \%$ \\
\hline & Not at all to with effort & $10 \%$ & $5 \%$ & $45 \%$ & $56 \%$ & $23 \%$ \\
\hline & & $100 \%$ & $100 \%$ & $100 \%$ & $100 \%$ & $100 \%$ \\
\hline \multirow[t]{4}{*}{ Read } & Very well & $52 \%$ & $62 \%$ & $25 \%$ & $13 \%$ & $45 \%$ \\
\hline & Relatively well & $18 \%$ & $26 \%$ & $17 \%$ & $16 \%$ & $22 \%$ \\
\hline & Not at all to with effort & $31 \%$ & $12 \%$ & $58 \%$ & $71 \%$ & $33 \%$ \\
\hline & & $100 \%$ & $100 \%$ & $100 \%$ & $100 \%$ & $100 \%$ \\
\hline \multirow[t]{4}{*}{ Write } & Very well & $54 \%$ & $58 \%$ & $24 \%$ & $11 \%$ & $42 \%$ \\
\hline & Relatively well & $19 \%$ & $26 \%$ & $15 \%$ & $11 \%$ & $21 \%$ \\
\hline & Not at all to with effort & $27 \%$ & $15 \%$ & $61 \%$ & $78 \%$ & $37 \%$ \\
\hline & & $100 \%$ & $100 \%$ & $100 \%$ & $100 \%$ & $100 \%$ \\
\hline Estimated Total & & 19,870 & 39,629 & 20,417 & 10,957 & 90,873 \\
\hline
\end{tabular}

Source: Poppel et al., 2007.

\section{Greenland dog sled championship. Ilulissat 29 March, 2014}

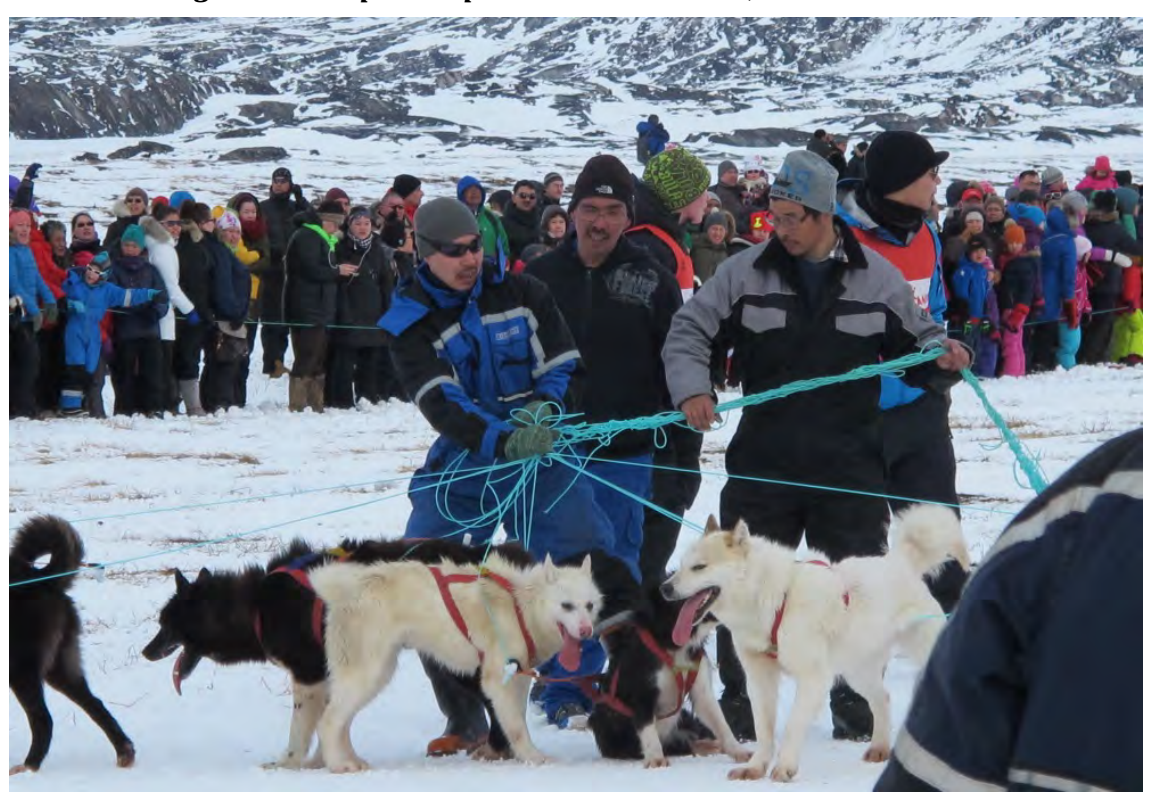

Photo by Birger Poppel. 
Cultural wellbeing and cultural continuity is often referred to in terms of "belonging" and "connectedness" to people and places (AHDR, 2004:154; ASI, 2010:104). During the SLiCA interview respondents were asked whether they had, within the last five years, ever thought about moving from the place where they were living at the time of the interview. This question was followed by an open-ended question, which elaborating on a former question asking about reasons (the main drivers) to stay or, respectively, to move.

$64 \%$ of Greenlandic adults reported that they had not thought about moving away from their communities. A significantly large proportion of people in settlements refer to "place of belonging" (including: family, "hometown" or simply, "like it here") as a reason to stay, whereas more people in towns refer to education and jobs as reasons to stay.

\section{How well does SLiCA apply to the ASI domain CULTURAL WELLBEING AND CULTURAL VITALITY and selected indicators?}

The selected ASI indicator condensing the significance of "cultural wellbeing"/"cultural vitality" is "language retention", which embraces both language ability and language use. SLiCA checks the ability and use of indigenous languages, as well as first foreign languages, and therefore meets the criteria for the ASI indicator. As the SLiCA findings are based on personal interviews, information on the ability of people to speak a language and how much and where it is mostly used is self-reported. It might support the self-reported assessments if pilot studies were carried out in order to validate survey findings.

SLiCA is able to provide further knowledge about important identity markers other than "language". Furthermore, SLiCA includes a number of questions that help us to identify a "sense of belonging" that might be seen as an important component of cultural continuity and vitality. 


\subsection{Contact with Nature (Closeness to Nature)}

\subsubsection{ASI domain, ASI and SLiCA indicators: Contact with nature (closeness to nature)}

\section{ASI on contact with nature (closeness to nature)}

The AHDR report includes "Living close to nature" as one of the "three dimensions of human development over and above those included in the HDI (Human Development Index) (AHDR 2004:240). One argument for this is that "Arctic societies are place-based systems; they feature human adaptations that are closely tied to local environments" (Ibid: 241).

Based on this conclusion made in the AHDR, authors of the ASI report chapter on "Contact with nature" identified the following potential indicators as "most suitable." The highlighted indicators below were considered the most robust for the ASI criteria:

- Time on land.

- Number of traditional activities.

- Number of people or households engaged in traditional economy.

- Harvest (kilograms per annum per capita).

- Consumption of country foods (kilograms per annum per capita).

- Income spent on nature-related activities.

- Local control of resources.

- Proportion of economy dependent on natural resources.

- Youth in traditional subsistence activities.

- Demography (youth retention).

(Crate et al. 2010:114).

Based on ASI authors' analysis, "consumption or harvest of traditional (local) food" was selected as the indicator for "contact with nature".

\section{SLiCA on "contact with nature" (closeness to nature)}

As noted in the section above, how the Inuit perceive nature is considered to be important in maintaining indigenous identity. More than $95 \%$ of people in Greenland, Alaska and Chukotka consider their "view of nature" to be an important identity marker. Likewise, a significant majority of people perceive "eating traditional food" and "hunting and fish- 
ing" to be important identity markers. These findings justify selecting "contact with nature" as an important domain for human development. The SLiCA survey provides possibilities for casting light on this domain by asking several questions about

- Consumption of local food.

- Harvest of local food (Proportion of Meat and Fish Harvested by Household).

- Participation in subsistence activities.

- Satisfaction with availability of fish and wildlife.

Figure 14 shows the proportion of meat and fish consumed by the household that people perceive is also harvested by a household member. This proportion not only informs us about the economic significance of the harvest (or to which degree a household's own harvest substitutes food bought in shops), but also the people's relationship to and dependency on their surrounding environment. The consumption of traditional food harvested by one or more household members is significant in all regions, regardless of variations (Poppel, 2006; Poppel \& Kruse, 2009). As almost two out of three Alaskan Inuit, two out of three indigenous Chukotkans, and one out of three Greenlanders perceive that over one half of what their households eats is also harvested a household member "contact with nature" measured by "harvesting for own consumption" suggests that contact with nature is more important to Alaskan Inuit than to other Inuit. As most would agree that the "proportion of own household's consumption" is a reasonable indicator for contact with nature, using this single measure alone is probably not sufficient because, for example, it does not express the proportion of population that participate in traditional and/or other activities on the land/sea. 
Ties to Nature Table 26: Proportion of Meat and Fish Harvested by Household. Traditional Food by Country

\begin{tabular}{lrrrrr}
\hline & Canada & Greenland & Chukotka & Alaska & Total \\
\cline { 2 - 5 } None & $*$ & 0.25 & 0.18 & 0.08 & 0.21 \\
Less than half & $*$ & 0.38 & 0.38 & 0.31 & 0.37 \\
About half & $*$ & 0.15 & 0.27 & 0.25 & 0.20 \\
More than half & $*$ & 0.21 & 0.17 & 0.36 & 0.22 \\
& $*$ & 1.00 & 1.00 & 1.00 & 1.00 \\
Estimated Total & $*$ & 38,316 & 20,589 & 10,888 & 69,793 \\
\hline
\end{tabular}

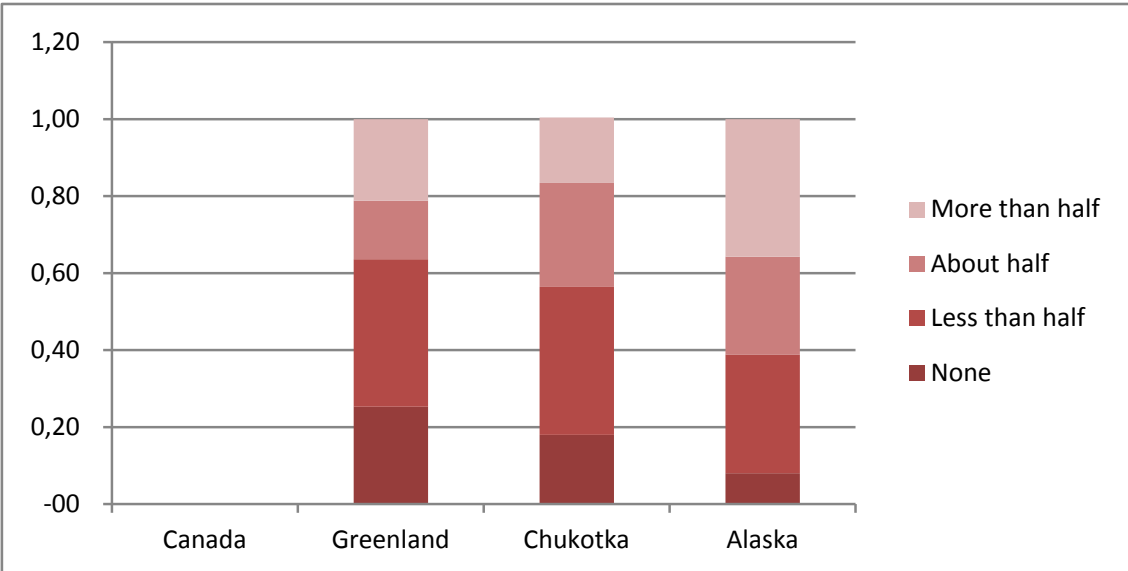

Source: Poppel et al. 2007. Note: Canadian data not available.

\section{How well does SLiCA apply to the ASI domain CONTACT WITH NATURE (CLOSENESS TO NATURE) and selected indicators?}

The ASI team selected "consumption of traditional food" and "harvest of traditional food" as indicators for the "contact with nature" domain. SLiCA applies to both indicators in relative terms, but not in absolute terms. Ideally, harvest and diet surveys would be conducted regularly to get the overall figures as a reference for individuals reporting on household harvest and consumption.

SLiCA also contains a number of questions that are only possible to get from interviewing; for example, "participation in subsistence activities" and "satisfaction with availability of fish and wildlife". 


\subsection{Fate Control}

\subsubsection{ASI domain, ASI and SLiCA indicators: Fate control}

\section{ASI on Fate control}

The Arctic Human Development Report (AHDR) suggested that "controlling one's own destiny" was one of three dimensions of human development to be included "over and above those included in the HDI" (AHDR 2004:240). The authors of the chapter on "Fate control" in the Arctic Social indicators Report further substantiated the significance of measuring "people's ability to guide their own destiny" (Dahl et al. 2010:129) and concluded that fate control "is the outcome of empowerment" (Ibid).

The authors of the "Fate control" chapter identify 12 possible indicators and group them under five categories:

\section{Political Power and political Activism}

- Political participation.

- Perceived political influence.

- Resistance.

\section{Decision-making Power}

- Proportion of local personnel in key decision-making positions.

- Local control over place names.

- Rights to land and sea resources.

\section{Economic Control}

- Self-generated income.

- Local control of the economy.

\section{Knowledge Construction}

- Knowledge/information about politics.

- Access to information.

- Language retention.

\section{Human Rights}

- Recognition of human rights.

(Dahl et al. 2010:131). 
In conclusion, the fate control indicator recommended from the ASI report is:

- Fate control index (members in government bodies; lands controlled; public expenses raised locally; speaking the mother tongue).

\section{SLiCA on Fate control}

The SLiCA research team and the indigenous partners focussed on "control over one's own destiny" or "fate control" in several sections of the questionnaire, which asked questions about

- Political participation; political influence; knowledge about politics; language retention.

- Satisfaction with influence on specific matters like renewable resources.

- Power and political activism.

- Satisfaction with Influence Indigenous People Have on Management of Natural Resources Like Fish and Game by Country.

- Satisfaction with Influence Indigenous People Have on Management of Natural Resources Like Oil, Gas and Minerals by Country.

- Language retention (commented on above - see "cultural wellbeing").

Some of the indicators are separately depicted and commented on below. ${ }^{22}$

Table/Figure 15 includes elements that contribute overall to "fate control". Participation in civic activities varies between different regions. Therefore, to be fully understood they will be analysed in a regional/local/community context.

Respondents were asked a number of questions focussing on their perception of influence on renewable and non-renewable resource use. Furthermore, a number of questions addressed concerns about the environment and the respondents' perceptions of attitudes and priorities of different authorities. In short, some of the overall SLiCA findings indicate awareness among the Inuit population of a variety of problems problems faced by indigenous peoples, which most feel a lack of influence on (Poppel et al. 2011).

${ }^{22}$ For a comprehensive SLiCA analysis on this topic see Kruse et al. 2008. 
Table/Figure 15: Control of Destiny

\begin{tabular}{lrrrrr} 
Control of Destiny Table 185: Participation in Civic Activities by Country & & & \\
\hline & Canada & Greenland & Chukotka & Alaska & Total \\
\cline { 2 - 6 } & $40 \%$ & $38 \%$ & $55 \%$ & $43 \%$ & $43 \%$ \\
Worked at a community event & $37 \%$ & $29 \%$ & $58 \%$ & $55 \%$ & $41 \%$ \\
Attended a local community meeting & $39 \%$ & $32 \%$ & $27 \%$ & $48 \%$ & $34 \%$ \\
Volunteered for local organization or group & $*$ & $6 \%$ & $49 \%$ & $43 \%$ & $24 \%$ \\
In past 12 months helped out at the school & $*$ & $25 \%$ & $26 \%$ & $7 \%$ & $23 \%$ \\
Collected signatures for a petition or candidate & $*$ & $24 \%$ & $20 \%$ & $21 \%$ & $23 \%$ \\
Member of a board, council, or committee & $*$ & $19 \%$ & $17 \%$ & $24 \%$ & $19 \%$ \\
Participated in political gathering or debate & $*$ & $12 \%$ & $17 \%$ & $36 \%$ & $17 \%$ \\
Attended regional meetings & $*$ & $18 \%$ & $9 \%$ & $13 \%$ & $15 \%$ \\
Participated in a radio or TV call-in show & $*$ & $8 \%$ & $4 \%$ & $5 \%$ & $6 \%$ \\
Wrote a letter to the editor & & & & & \\
Estimated Total & 20,400 & 39,315 & 20,541 & 10,863 & 91,119
\end{tabular}

Source: Poppel et al. 2007. Note: Canadian data not available.

May first public meeting. Community center, Nuuk, 1 May, 2014

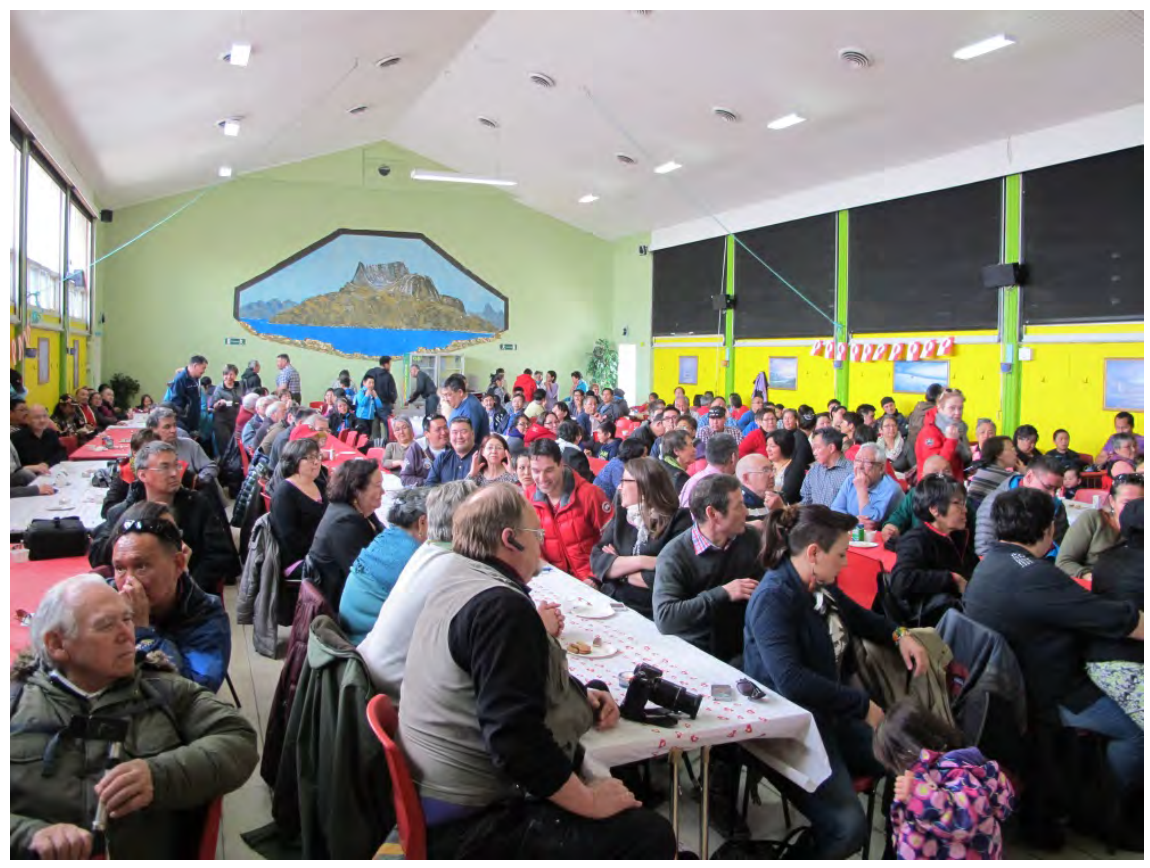

Photo by Birger Poppel. 
Table/Figure 16: Control of Destiny

Control of Destiny Table 227: Satisfaction with Influence Indigenous People Have on Management of Natural Resources Like Fish and Game by Country

\begin{tabular}{lrrrrr}
\hline & Canada & Greenland & Chukotka & Alaska & Total \\
\cline { 2 - 6 } Very satisfied & $*$ & $6 \%$ & $3 \%$ & $35 \%$ & $11 \%$ \\
Somewhat satisfied & $*$ & $48 \%$ & $26 \%$ & $39 \%$ & $41 \%$ \\
Not satisfied or neither & $*$ & $46 \%$ & $70 \%$ & $26 \%$ & $48 \%$ \\
& $*$ & $100 \%$ & $100 \%$ & $100 \%$ & $100 \%$ \\
Estimated Total & $*$ & 33,634 & 14,599 & 10,409 & 58,642 \\
$*$ Data Not Available & & & & & \\
\hline
\end{tabular}

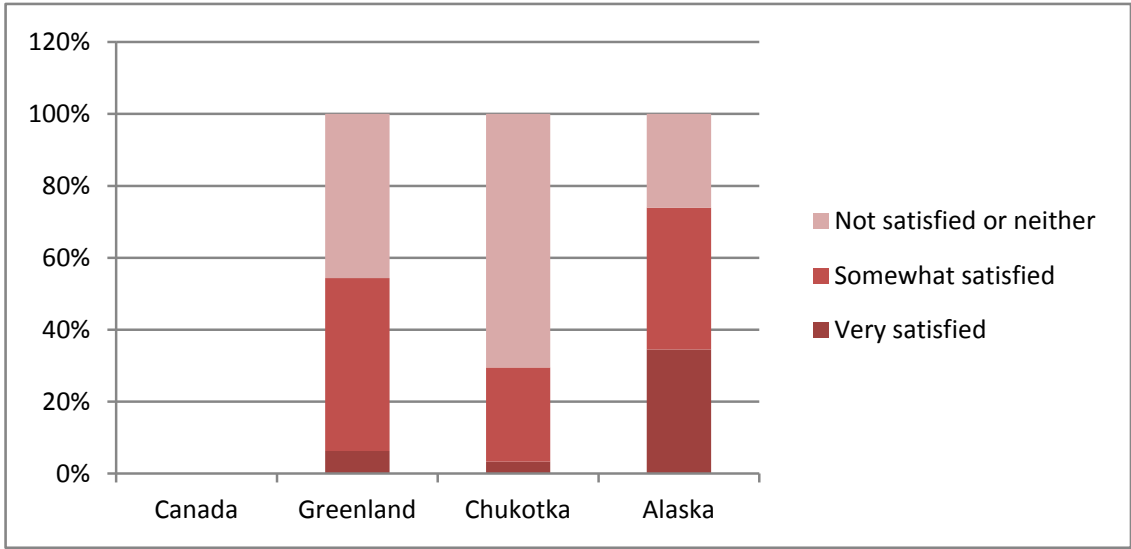

Source: Poppel et al. 2007. Note: Canadian data not available. 


\begin{tabular}{|c|c|c|c|c|c|}
\hline \multicolumn{6}{|c|}{$\begin{array}{l}\text { Control of Destiny Table 231: Satisfaction with Influence Indigenous People Have on Management } \\
\text { of Natural Resources Like Oil, Gas and Minerals by Country }\end{array}$} \\
\hline & Canada & Greenland & Chukotka & Alaska & Total \\
\hline Very satisfied & $*$ & $3 \%$ & $2 \%$ & $18 \%$ & $6 \%$ \\
\hline Somewhat satisfied & $*$ & $41 \%$ & $11 \%$ & $35 \%$ & $32 \%$ \\
\hline \multirow[t]{2}{*}{ Not satisfied or neither } & * & $56 \%$ & $87 \%$ & $47 \%$ & $63 \%$ \\
\hline & * & $100 \%$ & $100 \%$ & $100 \%$ & $100 \%$ \\
\hline Estimated Total & $*$ & 27,275 & 13,918 & 9,462 & 50,655 \\
\hline
\end{tabular}

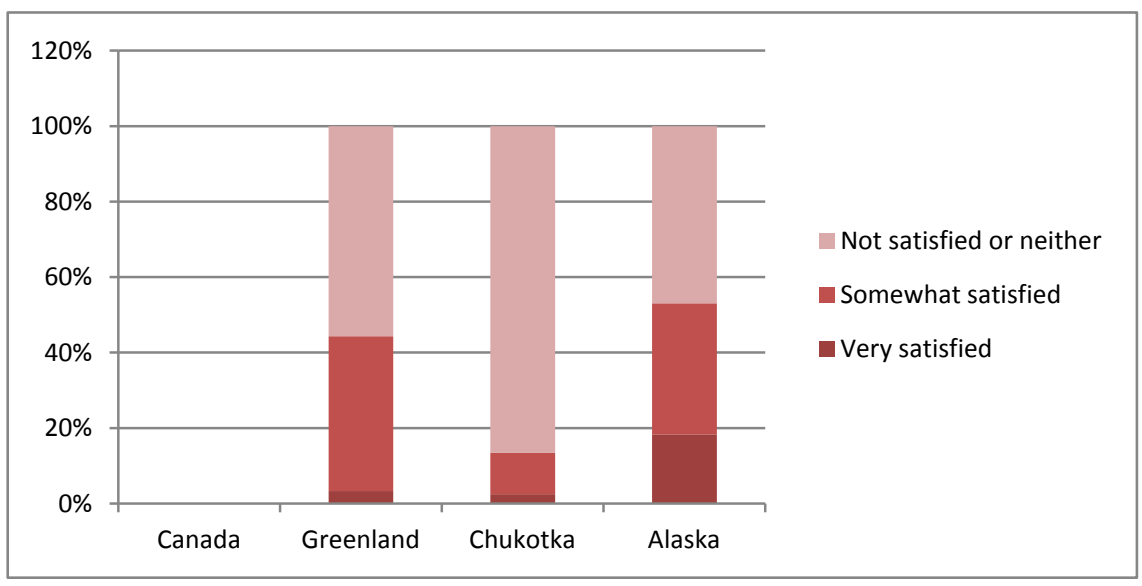

Source: Poppel et al. 2007. Note: Canadian data not available.

\section{How well does SLiCA apply to the ASI domain FATE CONTROL and selected indicators?}

The ASI recommended indicator is a "Fate control index" composed by "members in government bodies"; "lands controlled"; "public expenses raised locally"; "speaking the mother tongue". Speaking the mother tongue is the only sub-indicator that SLiCA applies to. Public authorities shall provide the other parts of the composite index.

The SLiCA questionnaire contains a number of questions that would meet most of the ASI team's 12 primary indicators like "political power", "political activism" and satisfaction with influence on the management of different resources. 


\subsection{Summary and Concluding Remarks}

\subsubsection{On Human Development and Subjective wellbeing (based on SLiCA findings) \& How well does SLiCA measure the ASI Indicators?}

- The primary objective of this chapter has been to examine to what degree do SLiCA results contribute to the ASI indicators selected in the first ASI Report (ASI, 2010). ${ }^{23}$ In brief, SLiCA indicators apply directly to three out of six domains ("material wellbeing"; "education"; and "cultural continuity and vitality"). The selected ASI indicator for contact with nature demands quantitative estimates of "consumption and harvest of traditional food", whereas SLiCA have results expressed in relative terms. The last two ASI domains rely heavily on vital statistics and publicly gathered information.

- The ASI indicators were selected on the basis of a number of criteria (see above): for example, availability and affordability. Both availability and affordability as criteria exclude SLiCA data from general survey data for ASI. On the other hand, however, this means that if some of the SLiCA indicators (e.g. evaluation of own health and subjective wellbeing) are considered interesting and important when measuring human development, then SLiCA survey documents that it is possible to gather these and other data.

- It is important to realize that personal interviews that include questions on subjective wellbeing, different background variables and living conditions, as well as perceptions and attitudes, are the precondition and basis for more thorough analyses of cause and effect relationships. And this information is only available if surveys are conducted on a regular basis - for instance, every fifth year.

- As the SLiCA survey has so far only been conducted once, it is not possible at the "Inuit Nunaat" level to track human development over time. Thus, SLiCA can be seen as a baseline study that will naturally contribute to decision making by policymakers, indigenous peoples and different Arctic stakeholders, as well as the Arctic social science community.

${ }^{23}$ An overall comparison is tabled in Annex 1. 
- Whereas tracking human development implies follow-up studies or thorough historical research of different Arctic regions, the SLiCA survey has the potential to carry through a large number of regional comparative studies and analyses. Some results will be briefly introduced in the following.

- One of the advantages of conducting a survey like SLiCA is the possibility to analyze relations at the individual level, by looking at different living conditions, satisfaction with different aspects of and overall quality of life. Analyzing the SLiCA data from Inuit Nunaat (excluding Canadian data) gives us - among other things - the following results which are important when wellbeing and human development are concerned, be it for analytical or political reasons.

- "Inuit adults who receive a poverty level personal income $(60 \%$ or less of the median income in their indigenous settlement region) are less likely to be very satisfied with their life as a whole than adults who receive higher personal incomes" (Kruse et al.,2008:123).

- “... people who work full time during at least part of the year are more likely to be very satisfied with life as a whole as people who were likely unemployed" (Ibid.).

- "Those who are more active in subsistence are also more likely to be satisfied with life as a whole" (Ibid.).

- Both personnel income, subsistence activities and satisfaction with the combination of productive activities contribute to the explanation of variation in life satisfaction (Ibid.).

- Further testing for the explanatory powers of a number of variables showed that "satisfaction with the amount of fish and game available locally", and "satisfaction with the number of job opportunities in the community" contributed significantly to explaining life satisfaction (Ibid.).

- Also "satisfaction with influence over management of natural resources and local environmental problems" contributes to life satisfaction (Ibid.).

- In conclusion: Some of the main SLiCA findings about what contributes to life satisfaction is that "... productive activities, the presence of production opportunities (i.e. fish and game, jobs), and a sense of local control are associated with satisfaction with life as a whole" (Ibid.).

- At the same time a survey like SLiCA can provide contextual data at the individual and household level that - in combination with official 
statistics - can add important contextual information to better understand and inform decision makers at different levels, including government, indigenous peoples organizations, other NGO's, civil society organizations and other stakeholders.

- The SLiCA findings below are examples (quoted from the SLiCA contribution to the Report from the Arctic Council's Sustainable Development Working Group, October 24, 2008) of contextual knowledge adding to statistical and other basic societal information:

o A combination of traditional activities and cash employment is the prevailing lifestyle of Arctic indigenous peoples. It takes money to pursue traditional activities; households with higher incomes can, and do, choose to spend income on these activities. Nine in ten Inuit think traditional activities are important to their identity.

o Health conditions vary widely in the Arctic: Most of the indigenous peoples surveyed rate their own health as good or excellent almost all respondents in Canada and Greenland and threequarters of those in Northern Alaska. The exception is Chukotka, where more than half rated their health as only fair or poor.

o Even though most are satisfied with life in their communities, indigenous people also cite widespread social problems: unemployment, alcohol abuse, suicide, drug abuse, family violence and sexual abuse are on average considered major social problems by more than six Inuit out of ten. Most problems are reported from Chukotka as at least eight out of ten cite most of these problems.

o In the face of rapid changes in the Arctic, most indigenous peoples have maintained their traditional subsistence activities. Many also continue to speak their native languages - in addition to Western languages. More than $90 \%$ of the Greenlanders and the Inuit in Canada - young and old - are fluent in their native languages. In Northern Alaska and Chukotka, indigenous people of all ages are much less likely to speak their native languages - and those who can are more likely to be 55 or older. In Northern Alaska, just 5\% of those 16 to 19 say they are fluent in a native language.

o The indigenous peoples of Chukotka, Northern Alaska and Greenland were asked about environmental concerns, if any. On average three out of four perceive climate change to be a problem in their communities and more than half of all Inuit mention local contaminated sites, pollution of local lakes and 
streams and pollution from industrial development as problems in the region. A significantly larger proportion of indigenous people in Chukotka are concerned with these problems. In Greenland pollution from other countries and in Chukotka and Alaska erosion of coastal areas or riverbanks are cited as problems by vast majorities.

(Report from the Sustainable Development Working Group, 24 October 2008).

\section{"The Spirit of Time", Prospects, and Challenges}

The SLiCA process of developing a research design and survey instrument to map and analyze living conditions and wellbeing of Inuit, Sami and indigenous peoples of Chukotka and the Kola Peninsula started in 1997/1998. Also Quality-of-Life research carried out internationally ran parallel to the development of SLiCA, which applied to Inuit and Saami peoples and included social indicators focussing on subjetive wellbeing and sustainable development. Such styles of research design have continued to attract more interest and resources in the Arctic and elsewhere. A main driver of this development has been the obvious fact that Gross Domestic Product, GDP, as a measure of human development falls short of encompassing very important aspects of societal development; for instance, the distribution of income, individuals' perceptions of personal livelihoods and living conditions, health conditions, resource use, etc. Many initiatives have been taken to develop and investigate more adequate measures. These initiatives have been globally, ${ }^{24}$ regionally and nationally/locally, 25,26 and have attempted to cover all population groups within a specific country or ethnic group (such as indigenous peoples). ${ }^{27}$ Furthermore, this development has been inspired by and has itself inspired Quality-of-life Research (theoretically, methodologically and analytically) within different academic disciplines, including social and behavioural sciences. ${ }^{28}$

\footnotetext{
${ }^{24}$ Prominent examples are: the OECD well-being indicators; the so-called Sarkozy Commission headed by Joseph Stieglitz, Amartya Sen and Jean-Paul Fitoussi; the Happy Planet Index.

${ }^{25}$ Nordic Council of Ministers has developed, among others, Sustainable Development Indicators.

${ }^{26}$ Gross National Happiness Index, GNHI developed in Bhutan.

27 United Nations initiative implemented by Tebtebbe: Indicators Resource Book; First Nations Statistical Institute, Canada; Community Well-being Index, Canada; Australian Bureau of Statistics: National Aboriginal \& Torres Strait Islander Social Survey (NATSISS), to mention just a few.

${ }^{28}$ See e.g. Sirgy et al. 2006; Møller et al. 2008; Møller \& Huschka 2009.
} 
The so-called "Sarkozy initiative" is especially important to emphasize as it concludes in a number of recommendations that substantiates the work that a number of Arctic Council/SDWG supported initiatives - including AHDR, SLiCA and ASI have accomplished. The quoted recommendations shown below highlight important life domains and also point to the necessity of including the National Statistical entities in the collection of data needed to develop meaningful indicators:

Recommendation 6: Quality of life depends on people's objective conditions and capabilities. Steps should be taken to improve measures of people's health, education, personal activities and environmental conditions. In particular, substantial effort should be devoted to developing and implementing robust, reliable measures of social connections, political voice, and insecurity that can be shown to predict life satisfaction.

Recommendation 9: Statistical offices should provide the information needed to aggregate across quality-of-life dimensions, allowing the construction of different indexes.

Recommendation 10: Measures of both objective and subjective wellbeing provide key information about people's quality of life. Statistical offices should incorporate questions to capture people's life evaluations, hedonic experiences and priorities in their own survey.

(Stiglitz et al. 2009:15-17).

"Human development shall be measured in ways that reflect subjetive wellbeing; thus partnerships with the respondents - in SLiCA the indigenous peoples of the Arctic - is key to study living conditions and welfare priorities" (Poppel et al. 2011). This was the point of departure for the SLiCA process and was also the recommendation to the Arctic Council when the SLiCA project reported to the Arctic Council Ministerial in Nuuk, 2011 (Poppel et al. 2011).

In collaboration with indigenous experts and other indigenous partners, the SLiCA project was carried out by first defining overall social goals, then selecting the indicators, and finally fleshing out the international SLiCA core questionnaire.

Applying SLiCA measures to ASI domains may at first glance seem like reverse engineering, since the development of SLiCA measures preceded the development of ASI domains. This chapter substantiates, however, that it is generally feasible to apply SLiCA indicators to the ASI framework and to most of the selected indicators. Furthermore, SLiCA is able to contribute to research with further valuable indicators.

Survey-based data, such as those produced by SLiCA, are costly when compared to data gathered by national or regional statistical entities like public registers. Single surveys are less likely to yield standardized 
measures that can be compared across surveys. Surveys are also likely to leave gaps in coverage of regions or population groups. On the other hand, differences in national statistical programs also challenge standardization and coverage of population groups. In some nations, such as the U.S. and Canada, government statistical measures are themselves developed from surveys, not public registers. SLiCA demonstrates that it is possible to achieve standardization across nations and to produce measures of human development that reflect the special circumstances of a key region in the world: the Arctic.

There is no doubt that the value of a major international research effort like SLiCA can be augmented by conducting follow-up studies using SLiCA findings as the base line for studies of rapid social change in the Arctic.

If the overall goal is to measure, assess and evaluate Arctic Human Development - and not least if the individuals' own perceptions and evaluations shall be included - it thus seems appropriate to conduct a "benchmark" survey like SLiCA every ten years for both the indigenous and other Arctic residents. ${ }^{29}$ Such a survey would necessarily have to be combined with regular and much smaller social indicator surveys to track change over time and, most importantly, to complement official statistics gathered by national and regional statistical entities, data, and other analyses from independent research. This concerted effort would bring about the necessary information and analyses for decision makers in the Arctic whenever human development is concerned.

29 See Annex 2: Final Report to the Senior Arctic Officials of the Arctic Council, 19-20th October 2010, Tórshavn: 5.1 Survey of Living Conditions in the Arctic: Inuit, Sámi and the Indigenous peoples of Chukotka (SLiCA). 


\subsection{Annex 1}

Table: How well does SLiCA measure the ASI indicators?

\begin{tabular}{|c|c|c|c|}
\hline Domain & $\begin{array}{l}\text { Preferred indicator } \\
\text { (ASI 2010) }\end{array}$ & SLICA INDCATORS & $\begin{array}{l}\text { HOW WELL DOES SLICA MEASURE THE ASI } \\
\text { INDICATORS }\end{array}$ \\
\hline $\begin{array}{l}\text { Health \& } \\
\text { Population }\end{array}$ & $\begin{array}{l}\text { Infant mortality/ } \\
\text { Net migration }\end{array}$ & $\begin{array}{l}\text { Self-rated health } \\
\text { Satisfaction with life as a } \\
\text { whole in this community } \\
\text { Satisfaction with quality } \\
\text { of life in this community } \\
\text { Satisfaction with life as } \\
\text { a whole }\end{array}$ & $\begin{array}{l}\text { The short and easy answer to the question } \\
\text { raised in the headline above is that SLiCA does } \\
\text { not apply since the selected indicators are vital } \\
\text { statistics. More important though, when it } \\
\text { comes to individual wellbeing and health, SLiCA } \\
\text { provides information of self-evaluated wellbeing } \\
\text { and self-rated health. Both measures are gener- } \\
\text { ally accepted as key indicators and direct } \\
\text { measures on wellbeing and health, where the } \\
\text { ASI indicators merely are indirect measures. }\end{array}$ \\
\hline $\begin{array}{l}\text { Material } \\
\text { wellbeing }\end{array}$ & $\begin{array}{l}\text { Per capita household } \\
\text { income }\end{array}$ & $\begin{array}{l}\text { Household income (from } \\
\text { the main sources of both } \\
\text { the formal and the informal } \\
\text { economy) } \\
\text { Relative poverty } \\
\text { Absolute poverty } \\
\text { Ability to make ends meet } \\
\text { Satisfaction with household } \\
\text { economy } \\
\text { Satisfaction with standard } \\
\text { of living } \\
\text { Satisfaction with jobs } \\
\text { Satisfaction with job oppor- } \\
\text { tunities }\end{array}$ & $\begin{array}{l}\text { SLiCA provides information about "household } \\
\text { income" as a whole, as well as the different } \\
\text { sources of income. As information about number } \\
\text { and age of household members are also availa- } \\
\text { ble the ASI indicator can be calculated. } \\
\text { Self-reported income is often subject to discus- } \\
\text { sion based on the assumption that people tend } \\
\text { to underestimate their earnings. Following this } \\
\text { assumption register based information from tax } \\
\text { authorities is preferable. When it comes to } \\
\text { estimating income for the informal economy } \\
\text { surveys seemingly have an advantage. } \\
\text { Where SLiCA has an advantage to public statistics } \\
\text { related to "material wellbeing" is in the evalua- } \\
\text { tive questions like "ability to make ends meet" } \\
\text { and "satisfaction with household economy and } \\
\text { standard of living" as these questions add } \\
\text { valuable information from an individual point of } \\
\text { view to the quantitative data. }\end{array}$ \\
\hline Education & $\begin{array}{l}\text { Ratio of students } \\
\text { completing post- } \\
\text { secondary education }\end{array}$ & $\begin{array}{l}\text { Level of education } \\
\text { Traditional skills: learned } \\
\text { in/improved since child- } \\
\text { hood/still use } \\
\text { Still use traditional skills } \\
\text { today } \\
\text { Satisfaction with different } \\
\text { conditions/ circumstances } \\
\text { related to education }\end{array}$ & $\begin{array}{l}\text { The SLiCA questionnaire contains questions } \\
\text { about level and kind of formal education and } \\
\text { thus meets the selected ASI indicator. SLiCA } \\
\text { further includes questions about the traditional } \\
\text { education transferred informally from one } \\
\text { generation to the next, which is important when } \\
\text { analyzing resources to apply in a mixed (subsist- } \\
\text { ence-market) economy. Furthermore, SLiCA } \\
\text { provides information about satisfaction with e.g. } \\
\text { the local supply with education institutions. }\end{array}$ \\
\hline $\begin{array}{l}\text { Cultural } \\
\text { Continuity and } \\
\text { Vitality }\end{array}$ & Language retention & $\begin{array}{l}\text { Identity markers: } \\
\text { Activities and customs im- } \\
\text { portant or very important } \\
\text { to maintaining indigenous } \\
\text { identity } \\
\text { Language retention (self- } \\
\text { reported): } \\
\quad \text { Language ability } \\
\text { Language use } \\
\text { Participation in cultural } \\
\text { activities; Satisfaction with } \\
\text { local support of different } \\
\text { cultural activities and values } \\
\text { Religious beliefs (both } \\
\text { traditional Inuit and Sami }\end{array}$ & $\begin{array}{l}\text { The selected ASI indicator condensing the } \\
\text { significance of "cultural wellbeing"/"cultural } \\
\text { vitality" is "language retention", embracing } \\
\text { both language ability and language use. SLiCA } \\
\text { asks about both ability and use of the indige- } \\
\text { nous language as well as first foreign language } \\
\text { and thus meets the ASI indicator. As the SLiCA } \\
\text { findings are based on personal interviews, both } \\
\text { information about ability to speak a language } \\
\text { and how much and where it is used is self- } \\
\text { reported. It might support the self-reported } \\
\text { assessments if pilot studies were carried } \\
\text { through to validate survey findings. } \\
\text { SLiCA is able to provide further knowledge } \\
\text { about other important identity markers than }\end{array}$ \\
\hline
\end{tabular}


and Christian beliefs) Sense of belonging (reflected in several questions e.g. about thoughts within last five years of moving away from the town/settlement, where respondents live)

Contact with Consumption/ HarNature vest of traditional foods
Fate Control Fate Control Index composed by:

Members in government bodies;

Lands controlled;

Public expenses raised locally

Speaking the mother tongue
Consumption of local food tion of meat and fish harvested by household) Participation in subsistence activities Satisfaction with availability and diet surveys would be conducted regular of fish and wildlife

The ASI team selected "consumption of traditional food" as well as "harvest of traditional food" as the indicators for the "contact with nature" domain. SLiCA applies to both indicators in relative terms ("how large a part ...?") but not in absolute terms. Ideally, a harvest "language" and furthermore has a number of questions that make it possible to indicate "sense of belonging" that might be seen as important to cultural continuity and vitality. to get the overall figures as a reference for the
individuals' reporting on household harvest and consumption.

SLiCA also contains a number of questions that are only possible to get from interviewing: for example, "participation in subsistence activities" and "satisfaction with availability of fish and wildlife".

Political participation; politi- The ASI recommended indicator is a 'Fate cal influence; control index' composed by 'members in knowledge about politics; government bodies'; 'lands controlled'; 'public language retention expenses raised locally'; 'speaking the mother Satisfaction with influence tongue'. 'Speaking the mother tongue is the on specific matters like renewable resources only sub-indicator that SLiCA applies to. Public Power and political activism composite index. Satisfaction with influence indigenous people have on

The SLiCA questionnaire contains a number of management of natural resources like fish and game Satisfaction with influence indigenous people have on management of natural questions that would meet most of the ASI team's 12 primary indicators like e.g. 'political power' and 'political activism' and further also satisfaction with influence on the management on different resources.

resources like oil, gas and

minerals

Language retention (com-

mented above - see "cultural

wellbeing")

ASI indicators "in blue" are those that are directly matched by SLiCA indicators.

SLiCA indicators in italic are those that either match ASI indicators or might be considered most valuable as a supplement to the ASI basic indicators. 


\subsection{Annex 2}

Meeting of Senior Arctic Officials Final Report 19-20 October 2010 Tórshavn

\section{Survey of Living Conditions in the Arctic: Inuit, Sámi and the Indigenous peoples of Chukotka (SLiCA)}

Background: Project leader Birger Poppel summarized the major objectives and conclusions of the finalized SLiCA project, which began more than 10 years ago (www.arcticlivingconditions.org). A CD-Rom containing relevant SLiCA data will be released in Nuuk. If funding is obtained, a SLiCA anthology will be available in May 2011. Poppel suggested that the AC consider running a benchmark study like SLiCA every 10 years.

Discussion: Finalization of this project is a major AC achievement. The project results are especially important for the indigenous peoples of the Arctic, as there has always been a lack of data on living conditions of indigenous peoples. The data collected is already being used and methods on how to follow up/use the data in the future were discussed. Canada raised its intention to follow-up on how to ensure Canada's data is best reflected in the final report. The Saami Council thanked the financing institutions that had made the project possible.

Decision: SAOs thanked and congratulated the Sustainable Development Working Group (SDWG) and everybody involved in the SLiCA project for its completion. The project is a major Arctic Council achievement, providing a solid socio-economic knowledge basis about the living conditions in the Arctic and an excellent foundation for policy making. The report should get widespread circulation and be of use also to other projects dealing with human dimension questions, such as the planned Arctic Human Development Report II. 


\subsection{Annex 3}

\section{Acknowledgements}

The data, tables and graphs in this section all originate from the SLiCA database constructed and developed by Jack and Marg Kruse (see also Poppel et al. 2007: www.arcticilivingconditions.org).

The Survey of Living Conditions of the Arctic, SLiCA is developed in partnership with:

- Inuit Circumpolar Conference, ICC

- Russian Association of Indigenous Peoples of the North, RAIPON

- Sámi Council

Funded by: Nordic Council of Ministers, NMR, The Greenland Home Rule Government, The Commission for Scientific Research in Greenland, KVUG, The Barents Secretariat, Nordic Arctic Research Programme, NARP, Danish Research Council for the Social Sciences, SSF, Swedish Research Council for the Social Sciences, Ministry of the interior - Dept. of municipalities, Norway, The Joint Committee on Research Councils for Nordic Countries, NOSS, Social Sciences and Humanities Research Council of Canada, SSHRC, National Science Foundation, NSF, Statistics Canada.

SLiCA was adopted as an Arctic Council project under the auspices of the Sustainable Development Working Group (SDWG) at the Ministerial meeting in Barrow, October 2000. Included in the Sustainable Development Action Plan, SDAP 2004-06, 2006-08, 2008-2010/11.

\section{The SLiCA Research team}

Principal investigators: Birger Poppel (Research Project Chief), Jack Kruse (Program Director), Larissa Abryutina, Hugh Beach, Ann Ragnhild Broderstad, Gerard Duhaime, Catherine Turcotte-Seabury;

Other team members: Patricia Cochran, Bent-Martin Eliassen, Virgine Hanna, Christian Jensen, Marg Kruse, Miillaraq Lennert, Stephanie Martin, Marita Melhus, Carl Christian Olsen, Marie-Kathrine Poppel, Ed Ward and Charles Westin.

Ilisimatusarfik, University of Greenland is the International coordinator of SLiCA (www.ilisimatusarfik.gl) http://www.arcticlivingconditions.org 


\subsection{References}

Act on Greenland Self-Government (2009). http://www.stm.dk/_p_13090.html AHDR (Arctic Human Development Report) (2004). Akureyri: Stefansson Arctic Institute. Allardt, E. 1975. Att Ha, Att Älske, Att Väre. Om välfcerd i Norden. Lund.

ASI (Arctic Social Indicators) 2010. eds. J. Larsen, P. Schweitzer, G. Fondahl. Copenhagen: Nordic Council of Ministers. TemaNord 2010:519

Andersen, T., Poppel, B. Living Conditions in the Arctic. (2002). In: Hagerty, M.R., Vogel, J. and Møller,V. (eds.): Assessing Quality of Life and Living Conditions to Guide National Policy. The State of the Art.Social Indicators Research Series, Vol. 11. Kluwer Academic Publishers. Reprinted from: Social Indicator Research, Vol. 58, pp. 191-216, 2002.

Crate, S., Forbes, B., King, L., and Kruse, J. (2010). Contact with Nature. In: Arctic Social Indicators, eds. J. Larsen, P. Schweitzer, G. Fondahl. Copenhagen: Nordic Council of Ministers. TemaNord 2010:519: 109-128.

Dahl, J., Fondahl, G., Petrov, A. and Fjellheim, R. (2010). Fate Control. In: Arctic Social Indicators, eds. J. Larsen, P. Schweitzer, G. Fondahl. Copenhagen: Nordic Council of Ministers, TemaNord 2010:519: 129-146.

DeSalvo, K.B., Bloser, N., Reynolds, J., He, J., Muntner, P. (2006). Mortality prediction with a single general self-rated health question: A meta-analysis. Journal of General Medicine, 21: 267-275.

Gulløv, H.C. (2004). Ved isens rand. In: Gulløv, H.C. (ed.) Grønlands forhistorie. Gyldendal, København.

Hamilton, L., Bjerregaard, P., and Poppel, B. (2010). Health and population. In: Arctic Social Indicators, (eds) J. Nymand Larsen, P. Schweitzer, G. Fondahl. Copenhagen: Nordic Council of Ministers. TemaNord 2010:519: 29-46.

Inuit Circumpolar Council (2009). A Circumpolar Inuit Declaration on Sovereignty in the Arctic. http://inuitcircumpolar.com/files/uploads/iccfiles/ declaration12x18vicechairssigned.pdf

Inuit Circumpolar Council (2010). Charter of the Inuit Circumpolar Council. http://inuitcircumpolar.com/index.php?ID=374\&Lang=En

Kruse, J., Poppel, B., Abryutina, L., Duhaime, G., Martin, S., Poppel, M., Kruse, M., Ward, E., Cochran, P., Hanna, V. (2007). Survey of Living Conditions in the Arctic: Project Overview. In: Poppel, B., Kruse, J., Duhaime, G., Abryutina, L. Survey of Living Conditions in the Arctic: SLiCA Results. Anchorage: Institute of Social and Economic Research, University of Alaska Anchorage. http://www.arcticlivingconditions.org/.

Kruse, J., Poppel, B., Abryutina, L., Duhaime, G., Martin, S., Poppel, M., Kruse, M., Ward, E., Cochran, P., Hanna, V. (2008). Survey of Living Conditions in the Arctic, SLiCA. In: Møller, V., Huschka, D, and Michalos, A. C. (eds.): Barometers of Quality of Life around the Globe. Springer Social Indicators Research Series. Springer Verlag, pp. 107-134.

Larsen, J.N. \& Husky, L. (2010). Material Wellbeing in the Arctic In: Arctic Social Indicators, eds. J. Larsen, P. Schweitzer, G. Fondahl. Copenhagen: Nordic Council of Ministers. TemaNord 2010:519: 47-66.

Michalos, A., (2014). Encyclopedia of Quality of Life research. Springer.

Møller, V., Huschka, D, and Michalos, A. C. (eds.) 2008. Barometers of Quality of Life around the Globe. Springer Social Indicators Research Series. Springer Verlag. 
Møller, V. and Huscka, D. (eds.) (2009). Quality of Life and the Millennium Challenge: Advances in Quality-of-Life Studies, Theory and Research. Social Indicators Research Series. (C) Springer Science+Business Media B.V.

Poppel, B. (2006). Interdependency of subsistence and market economies in the Arctic. In: Solveig Glomsröd and Iulie Aslaksen (eds.). The Economy of the North. Statistisk Sentralbyrå/Statistics Norway, pp. 65-80.

Poppel, B., Kruse, J., Duhaime, G., Abryutina, L. (2007). Survey of Living Conditions in the Arctic: SLiCA Results. Anchorage: Institute of Social and Economic Research, University of Alaska Anchorage. http://www.arcticlivingconditions.org/. 666 pages.

Poppel, B. and Kruse, J. (2009). The importance of a mixed cash- and harvest herding based economy to living in the Arctic - an analysis based on Survey of Living Conditions in the Arctic (SLiCA). In: Møller, V. and Huscka, D. (editors): Quality of Life in the New Millenium: Advances in Quality-of-Life Studies, Theory and Research. Social Indicators Research Series. Springer Verlag, pp. 107-134.

Poppel, B. (2010). Some data sources on people, peoples, communities, regions and human activities in Greenland. In: Gorm Winther (ed): "The Political Economy of Northern Regional Development - Yearbook 2008". TemaNord. Nordic Council of Ministers, pp. 254-282.

Poppel, B., Kruse, J., Broderstad, A.R., Eliassen, B-M., Jensen, C., Martin, S., Melhus, M., Olsvig, S., Westin, C. (2011). Arctic Living Conditions. (6 pages)

Rasmussen, K. (1925). Myter og Sagn fra Grønland, III, Kap York-Distriktet og Nordgrønland. Gyldendal, København.

Rasmussen M., Li Y., Lindgreen S., Pedersen J.S., Albrechtsen A., Moltke I., Metspalu M., Metspalu E., Kivisild T, Gupta R., Bertalan M., Nielsen K., Gilbert M.T., Wang Y., Raghavan M., Zhao J, Zhang X., Zhang H., Li Z., Chen M., Orlando L., Kristiansen K., Bak M., Tommerup N., Bendixen C., Pierre T.L., Grønnow B., Meldgaard M., Andreasen C., Fedorova S.A., Osipova L.P., Higham T.F., Ramsey C.B., Hansen T.V., Nielsen F.C., Crawford M.H., Brunak S., Sicheritz-Pontén T., Villems R., Nielsen R., Krogh A., Wang J., Willerslev E. (2010). Ancient human genome sequence of an extinct Palaeo-Eskimo. Nature 463, 757-762 (2010) doi: 10.1038/nature08835 http://www.nature.com/nature/journal/v463/n7282/suppinfo/nature08835_S1.htm

Rasmussen, R., Forbes, B., King, L., and Kruse, J. (2010). Contact with Nature, in: Arctic Social Indicators, eds. J. Larsen, P. Schweitzer, G. Fondahl. Copenhagen: Nordic Council of Ministers, TemaNord 2010:519: 109-128.

Rønning, W. \& Wiborg, A. (2008). Education for all in the Arctic? A survey of available information and research. Working Paper no. 1008/08. Nordland Research Institute.

Schweitzer, P., Irlbacher Fox, S., Csonka, Y. \& Kaplan, L (2010). In: Arctic Social Indicators, eds. J. Larsen, P. Schweitzer, G. Fondahl. Copenhagen: Nordic Council of Ministers. TemaNord 2010:519.

Sirgy, J.M., Alex C. Michalos, Abbott L. Ferriss, Richard A. Easterlin, Donald Patrick and William Pavot (2006): The Quality-of-Life (QOL) Movement: Past, Present and Future. I: Social Indicators Research vol. 76: 343-383.

SLiCA Data dictionary: http://classic.ipy.org/development/eoi/

SLiCA Results (Greenlandic and Danish): http://www.uni.gl/Forskning/Projekter/SliCA/tabid/447/Default.aspx

SLiCA website: http://www.arcticlivingcoditions.org

Statistics Canada. (2006). Harvesting and community wellbeing among Inuit in the Canadian Arctic: Prelminary findings from the 2001 Aboriginal Peoples Survey - Survey of Living Conditions in the Arctic. Ottawa. Statistics Canada (document 89-619-XIE). URL: http://www.statcan.gc.ca/pub/89-619-x/89-619-x2006001-eng.htm 
Sustatianable Development Working Group. (2008). Report from the Sustainable Development Working Group October 24, 2008.

Stiglitz, J.E., Sen, A., Fitoussi, J-P. Report by the Commission on the Measurement of Economic Performance and Social Progress.

Sustainable Development Working Group. (2010). Final Report to the Senior Arctic Officials of the Arctic Council, 19-20 October 2010 Tórshavn: 5.1 Survey of Living Conditions in the Arctic: Inuit, Sámi and the Indigenous peoples of Chukotka (SLiCA).

Usher Peter J., Duhaime G. \& Searles E. (2003). The Household as an Economic Unit in Arctic Aboriginal Communities, and its Measurement by means of a Comprehensive Survey. Social Indicators Research. Vol. 61, pp. 175-203. Kluwer Academic Publishers, Dordrect/Boston/London.

Veenhoven, R., World Database of Happiness, Erasmus University Rotterdam, The Netherlands Assessed on (date) at: http://worlddatabaseofhappiness.eur.nl (http://www1.eur.nl/fsw/happiness/) 


\section{PART III: \\ Conclusion}





\title{
7. Conclusion: Measuring Change in Human Development in the Arctic
}

\begin{abstract}
Authors
Joan Nymand Larsen, Stefansson Arctic Institute \& University of Akureyri, Iceland; Peter P. Schweitzer, University of Alaska, Fairbanks, USA \& University of Vienna, Austria; Andrey Petrov, University of Northern Iowa, USA.
\end{abstract}

\subsection{Introduction}

In this second volume of ASI we have moved the process of monitoring change in Arctic human wellbeing to the next phase. In the ASI-I report, launched in 2010, we identified domains for constructing Arctic social indicators, identified the criteria for selecting indicators and, based on a careful selection process that included some consideration of trade-offs, we presented a suite of indicators, which as a collective can tell us something useful about the level of wellbeing among Arctic residents. In addition, we aimed to produce a suite of indicators that could provide us with the critical information needed to draw conclusions about changes in wellbeing overtime and enable careful comparison within and between regions.

In the present volume we have presented the results of the second phase of ASI, which includes the measurement of individual ASI indicators and an evaluation of their applicability based on five carefully chosen regional case studies. Our original ambition had been to produce extensive sets of comparable data featuring ASI indicators for each of the six ASI domains. However, this task soon proved impossible given the current state of data quality and lack of data availability both at the panarctic level and at different geographical scales. It became clear that we had to limit our analysis to selected regions and, furthermore, that our set of indicators could not be compared between regions in any meaningful way given existing differences in data protocols in addition to other data issues. Furthermore, all five regional case studies required our teams to deviate to varying degrees from the technical definitions of 
individual ASI indicators. It was necessary to make adjustments to tailor the analysis to meet the regional availability of data and, hence, to settle for the best possible proxies or in some cases substitute with secondbest alternative indicators - though without compromising the validity of the analysis.

Notwithstanding existing data challenges, we were able to draw important conclusions about human wellbeing for each of the five case study regions as well as demonstrate the strength, applicability and value of the suite of ASI indicators and the proposed ASI monitoring system. Our analysis has also demonstrated that if more complete data sets were available, including primary data collection on harvest, the ASI system can provide a highly relevant and useful tool to inform the policy level and for engaging in regional and local priority setting and debates on issues of wellbeing and human development for Arctic residents. The implementation of a more complete system of ASI monitoring could be costly indeed but as far as addressing existing data limitations are concerned, the direct and indirect cost savings in terms of the potential value created by such a system should not be ignored.

\section{Akureyri, Iceland}

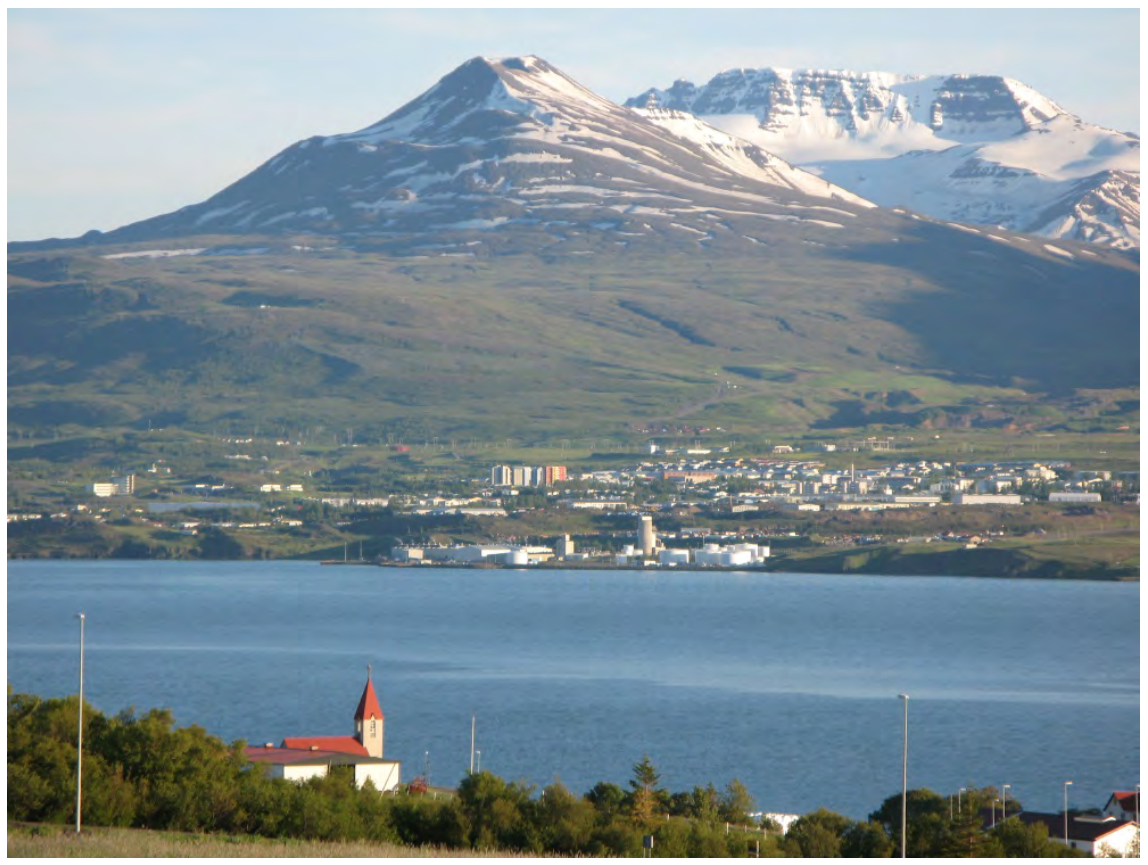

Photo: Jón Haukur Ingimundarson. 
For each of the ASI domains; Fate control, Cultural Wellbeing and Cultural Vitality, Contact with Nature, Material Wellbeing, Education, and Health and Population, ASI indicators were identified (ASI, 2010); and based on selection criteria, a small suite of ASI indicators were selected:

- Infant Mortality (Domain: Health/Population).

- Net-migration (Domains: Health/Population and Material Wellbeing).

- Consumption/harvest of local foods (Domains: Closeness to Nature and Material Wellbeing).

- Per capita household income (Domain: Material Wellbeing).

- Ratio of students successfully completing post-secondary education (Domain: Education).

- Language retention (Domain: Cultural Wellbeing).

- Fate control index, or the percentage of surface lands legally controlled by inhabitants through public governments and Native corporations (Domain: Fate Control).

The suite of ASI indicators developed was applied to five case studies representing different regions in the Arctic:

1. Sakha Republic (Yakutia), Russian Federation.

2. West-Nordic region.

3. Northwest Territories, Canada.

4. Inuit regions of Alaska, USA.

5. Inuit Nunaat - Inuit world - an application of SLiCA data (Survey of Living Conditions in the Arctic).

Our application of ASI indicators to five select case study regions reveals that significant data challenges persist in the Arctic. These challenges, however, do not prevent us from drawing useful conclusions about the state of human development and wellbeing, including the critical changes that the regions are facing on this front.

The results also reveal important trade-offs encountered by relying on a single indicator. As one chapter team writes:

\footnotetext{
"Importantly, the examination of more than one indicator for several of the domains, and the divergence of trends in terms of human development (e.g. improved infant mortality but worsening suicide rates) accentuates the perils of depending on one indicator. Until we have fully developed our competence in measuring human development in the Arctic, it would be prudent to continue to collect data on several measures for each domain" (Chapter 2).
} 
Some regions are richer in data than others. Northwest Territories and the West-Nordic Region provide examples of data rich regions. They provide us with a good measuring stock for drawing conclusions on the usefulness of an ASI monitoring system, and they reveal the potential strength of an ASI system for tracking change in wellbeing. In the case of Northwest Territories the team concludes:

"The NWT presents a case of a relatively data rich region and, thus, serves as a good case study for applying Arctic social indicators. It is important that in most instances we were able to develop region-specific indicators (or proxies) that follow the recommendations of the ASI Report. This fact confirms the success of the ASI project in providing a social indicators framework that is compatible with available data from existing sources in both geographical and temporal dimensions" (Chapter 4).

But even in these regions there are considerable data challenges associated with difficulties of spatial disaggregation and longitudinal comparisons, varying sampling methodologies, and data suppression.

At the same time, relatively data-challenged regions also provide us with useful information - in particular for testing the strength and applicability of the framework. The least data-rich region - in terms of ASI indicators and their low-cost measurement - among our five case studies is Sahka Republic (Yakutia). This case study necessitated deviations from the ASI technical definitions and required the measurement of proxies and substitute indicators. This provides useful insight into the challenges we encounter as a result of data limitations throughout much of the Arctic, as well as at different geographical scales.

A critical challenge was encountered by the original objective to devise indicators that would be relatively easy to measure in terms of costs and other resources. This ASI objective prevented us at first from selecting indicators that would necessitate primary data collection, including harvest data, despite the prominence of subsistence harvest in Arctic contexts (e.g. as exemplified by its non-market contribution to material wellbeing in particular in more predominantly indigenous regions and communities). While in the end we made a decision to include subsistence harvest among the suite of ASI indicators, the challenge involving measurement, consistency, systematic and longitudinal comparisons across and within regions is unlikely to be resolved anytime soon.

ASI indicators will require updating and fine-tuning in the years ahead. One caveat is presented by the rapid changes that prompted the investigation in the first place; rapid socio-economic changes will challenge even the most robust indicators. This highlights the importance of adjusting the set of indicators in the time ahead to increase their capaci- 
ty to capture the impacts of today's Arctic reality of global change and transformations and their impact on the various human systems.

\subsection{Summary of Major Findings}

The following summarizes some of the major findings from each of the case studies on the applicability of the ASI indicators and key conclusions on human wellbeing.

\subsubsection{Sakha Republic (Yakutia), Russian Federation}

Based on some indicators, the overall results from Sakha Republic (Yakutia) case study suggest that human development in Sakha Republic is improving while other indicators suggest that certain facets of life are still challenging. Results show that further regional and rural-urban differences persist. Like many other regions of the North, the areas inhabited by numerically small peoples experience lower-than-average attainments for most of the applied ASI indicators.

ASI indicators on health and population provide a mixed picture: While a decrease in infant mortality indicates an improvement in wellbeing, persistent high suicide rates (until recently) and continuing high rates of out-migration suggest a decline in wellbeing. The capital city of Yakutsk, where infant mortality, suicide and out-migration have all decreased, is an anomaly. Socio-economic conditions continue to be depressed outside of the capital, especially in rural areas. It appears this situation of declining wellbeing is even more notable in the northernmost areas of Sakha Republic (Yakutia).

ASI indicators on material wellbeing indicate that there has been a substantial increase in per household average income in the republic, the improvement of which is much less marked in rural areas. The fact of high out-migration and stagnant unemployment rates suggest that wellbeing is not improving throughout much of Sakha Republic (Yakutia).

Indicators on education suggest that Sakha Republic (Yakutia) is experiencing positive human development, though the experience is still very disparate geographically between the capital city and the rest of the Republic. Cultural vitality as expressed in terms of language retention suggests a challenging and adverse situation for indigenous, numerically small peoples of Sakha Republic (Yakutia); though the situation differs between various indigenous peoples and also between individuals within these peoples depending on where they live. 
ASI indicators for contact with nature show a substantial drop in the harvest of traditional foods across all three ulusy shortly after the fall of the Soviet Union, followed by a gradual increase in harvest in the early 2000s, and then, in the Nurbinskiy and Suntarskiy ulusy, a drop again.

Using the amount of land allocated to obshchinas as a proxy measure of Fate Control, results suggest an improvement in fate control over the past decade. At the same time, data suggest that obshchina lands are increasingly concentrated in fewer obshchinas. One cannot judge from the data available whether this concentration suggests a decline in Fate Control since 2003. In the future it will be critical to further examine the Fate Control measure (Chapter 2).

\section{Merge of traditions and new fashion in Art and Design, University of Yakutsk,} Sakha Republic

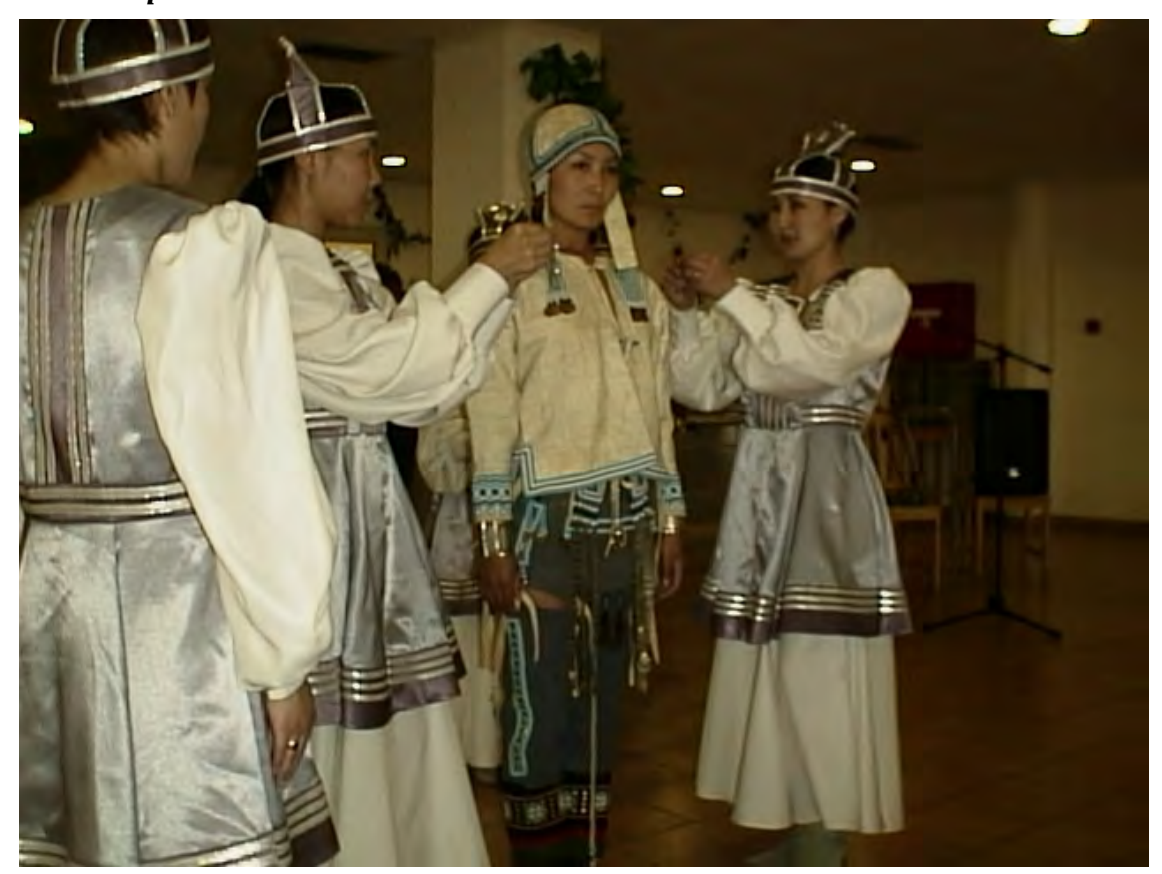

Photo: Rasmus Ole Rasmussen.

\subsubsection{West-Nordic Region}

The results for the West-Nordic application suggest that there has been general improvement in human development for the region. The ASI domains have been relatively easy to apply to the case of the WestNordic region, with precise definitions and data retrievable in the national statistical systems. Furthermore, it has been possible to retrieve 
comparative results between the four entities of the West-Nordic region. This applies to the domains: Health and Population; Material Wellbeing; and Education.

Some concepts, such as "traditional foods", include West-Nordic traditions that are outside the conventional analyses of Indigenous Peoples and the informal economy in the Arctic. This makes it difficult to apply the analysis to populations which are not registered as "Indigenous". There is an inherited assumption that "traditional foods" would not be available through commercial systems, although this may not reflect the reality in substantial parts of the Arctic, including the West-Nordic region. Thus, in cases such as the West-Nordic, our ability to obtain more valid measurements of Cultural Wellbeing and Contact with Nature depend on new types of data registrations or surveys.

Lastly, the Fate Control index raises some methodological questions on how to determine the level of control.

Overall, the ASI indicators are useful for tracking changing conditions in the West-Nordic region. At the same time, it would be necessary to further develop the Contact with Nature and Cultural Wellbeing domains in order to make them useful and applicable.

\subsubsection{Northwest Territories, Canada}

The results suggest that there has general improvement in human wellbeing in Northwest Territories (NWT) during the period 1991-2006, although there were also considerable differences among communities. NWT experienced gains in fate control and declines in cultural vitality, while material wellbeing has been stagnant. We find that ASI indicators are suitable for monitoring human development and that data exist to enable measurement and analyses of indicators from all six ASI domains. Population size and composition as well as regional differences are significant variables and should be investigated further. Data reveal a negative relationship among cultural vitality and economic wellbeing, contact with nature and economic wellbeing, cultural vitality, and contact with nature with education and suicide and fate control. The data reinforce the impact that population size and aboriginal control have upon the interpretation of indicators.

When using the ASI framework, the overall assessment of human development in NWT suggests that the territory's residents face considerable challenges in wellbeing and prosperity. Most measures put NWT behind Canadian national indicators. At the same time, recent trends appear to have a positive vector in most of the measured domains. Over 
the last two decades substantial gains were made in fate control. These gains, however, coincided with a rather stagnant material wellbeing and diminishing vitality of Aboriginal cultures (as measured by the language retention rates).

NWT communities do not perform well in respect to health and demographics. In addition, out-migration is a reality for most small remote communities. Similarly, economic wellbeing measured by per capita household income in smaller, predominantly Aboriginal communities is lower, even when income incorporates transfer payments. Jobs scarcity results in limited earned income received by residents of remote, largely Aboriginal communities.

The study found that the geography of material wellbeing remained fairly constant over the last 15 years, although the discrepancy between poorest and richest communities slightly increased, which highlights a trend of increasing disparity in material wellbeing. Most substantial income gains are found in the richest communities, which are also administrative and economic centers.

The closeness to nature indicator follows the general geography of Aboriginal population distribution and community size and location. Larger towns with few Aboriginal households exhibited very low levels of closeness to nature. In contrast, in more remote, Aboriginaldominated communities the majority of households were consuming meat and fish obtained through fishing and hunting.

High school and university degree attainment rates indicate a persistent education gap between NWT communities and the rest of Canada as well as disparities within the Territory. The education gap leads to continual earning and employment gaps in communities and population groups without access to education and training.

Aboriginal communities have higher levels of cultural wellbeing and stronger local control over their affairs but lack economic selfsufficiency. Aboriginal communities, such as Deline, Whati, Gameti and Behchoko show the highest composite fate control (Chapter 4). 
The Inuvik Community Greenhouse, NWT, where flowers and vegetables are grown by the inhabitants of Inuvik

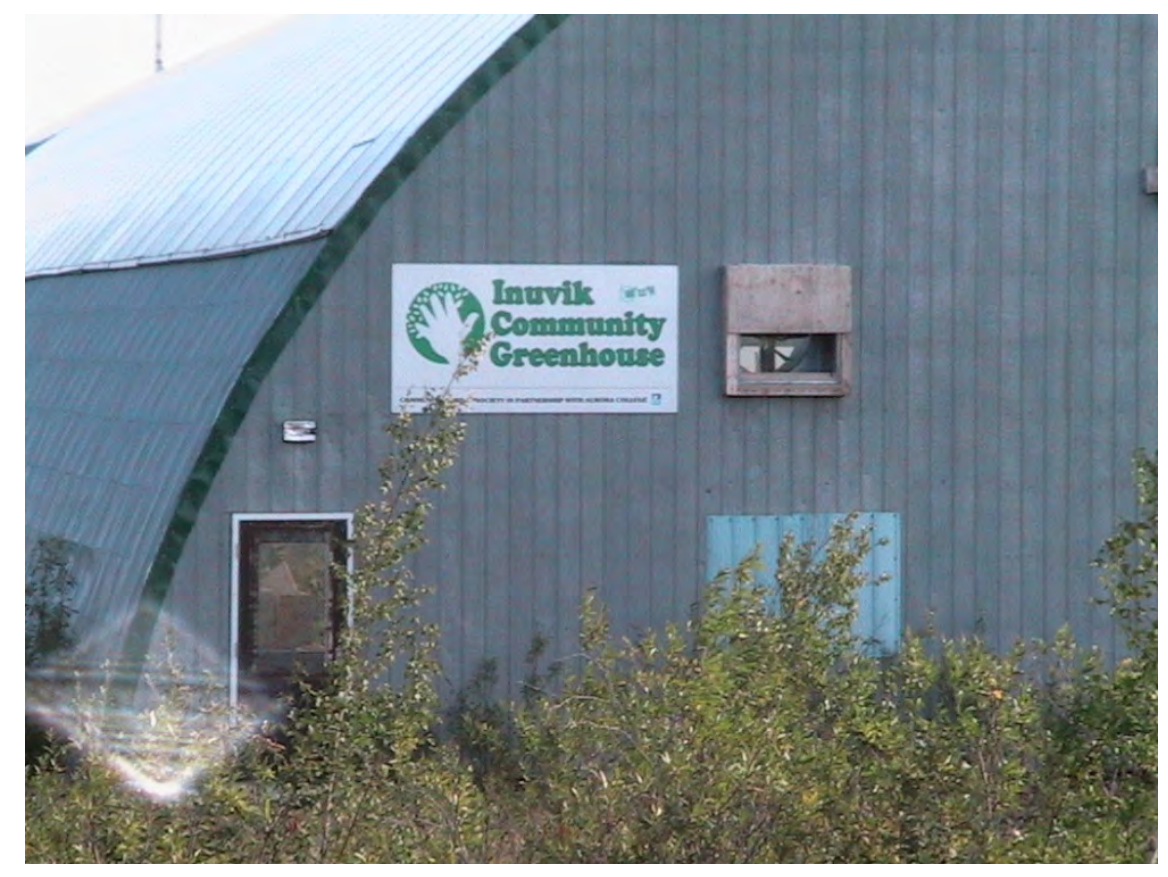

Photo: Rasmus Ole Rasmussen.

\subsubsection{Inuit Region of Alaska}

The Inuit regions of Alaska provide an interesting application and testing ground for the ASI framework. Data availability for the region is comparatively good. Results suggest considerable variation between and within regions. The regional centers are more similar to smaller communities than expected, especially on the North Slope; the Nome Census area exhibits the most differences between a regional center and its rural communities. Nome is overtaking Barrow in terms of several "modernity" indicators: per-capita income, employment, and post-secondary education.

The three sub-regions that make up the Inupiaq cultural region of northern and western Alaska provide a variety of useful examples of ways in which Arctic communities are exercising a modicum of control over the forces that impact their wellbeing. By conducting a comparative analysis of the percentage of surface lands controlled by the inhabitants through municipal governments, Native organizations and community structures we can gain a better understanding of how the exercise of fate control impacts the wellbeing of northern communities. 
Higher education has played a prominent role in the evolution of the political, economic and educational arenas that constitute the Inupiaq region of Alaska today.

Data suggest that Alaskan Natives, along with the Native American population in general, have important health issues that give them a lifeexpectancy lower than that of the general population (Chapter 5).

\subsubsection{Inuit Nunaat - Inuit world an application of SLiCA data}

SLiCA data were gathered through almost 7,000 personal face-to-face interviews. The data meet the basic ASI criteria of robustness and scalability but as the data are gathered through personal interviews they do not meet the basic ASI criteria of availability, affordability, and ease of measurement. As the first SLiCA project focused on indigenous peoples of the Arctic data are not inclusive to other Arctic residents (apart from immigrants in Greenland, mainly Danes). Still the survey can help inform the ASI measures, and may contribute to the task of establishing longterm monitoring of human development in the Arctic as some key information will only be available through interviews.

SLiCA data that coincide well with ASI indicators include for health and wellbeing: Self-rated health, satisfaction with life as a whole in this community, satisfaction with quality of life in this community, and satisfaction with life as a whole. The SLiCA survey found that the combination of market and non-market activities (hunting and fishing for example) and the influence people have over natural resources and the environment were important in explaining overall wellbeing.

The SLiCA project focused on the resources of individuals in relation to employment, which implied that qualifications and competencies required for both traditional livelihoods and occupations in the production and service sectors needed to be analysed. Using the SLiCA category "Vocational school or college", which corresponds to the category "postsecondary education" used in the ASI, the data show that less than $50 \%$ of Greenlanders had a post-secondary education that was slightly larger than in Chukotka, almost twice as large as in Alaska and almost three times that of the Inuit settlement regions in Northern Canada.

SLiCA data on cultural wellbeing include data on "view of nature", "traditional food", "childhood upbringing", "hunting and fishing", "meeting expectations of family and indigenous friends" and "contacts with other indigenous people", as well as using the indigenous language. Language retention is a very strong identity marker and is therefore ex- 
posed to significant political attention as well. Whether the focus is on understanding, speaking, reading or writing there is a significant difference between self-reported abilities among the Inuit in Canada and Greenland on one hand, and in Chukotka and Alaska on the other.

The SLiCA survey included questions on Contact with Nature. Results show that the Inuit view nature as important to maintaining the indigenous identity. Likewise, a significant majority perceive "eating traditional food" and "hunting and fishing" as important identity markers. These findings justify "carving out" contact with nature as an important domain for human development.

SLiCA also includes indicators on fate control, which correspond well with the ASI; e.g. political participation; political influence; knowledge about politics; language retention; satisfaction with influence on specific matters like renewable resources.

Based on the SLiCA case study we can conclude that personal interviews, which include questions on individual wellbeing, different background variables and living conditions, as well as perceptions and attitudes, are the precondition and basis for more thorough analyses of cause and effect relationships.

\subsection{ASI Monitoring System}

\section{Human Development Monitoring in the Arctic: Ideas and Considerations}

The long-term monitoring of human development in the Arctic would be greatly facilitated by the regular and frequent collection and reporting of relevant data, including those required for the proposed small set of ASI indicators. We suggest that any system for monitoring Arctic human development inculcates the principles of data collection, processing and dissemination outlined in the ASI I Report and subsequently implemented in the application studies in this second volume of ASI (ASI II). The core pillars of such a monitoring system should include:

- Use of high quality data that meets standards for robustness, validity, reliability, comparability, scalability and ease of measurement and interpretation (as discussed further in ASI I). The data needs to be clearly relevant to one or more of the six domains of Arctic human development (health and population, material wellbeing, education, cultural wellbeing and cultural vitality, contact with nature, and fate control), be sensitive to change over time, be available at least down 
to a regional level, and be applicable to, and reported separately for, indigenous and non-indigenous populations. Robustness entails the temporal stability of the indicator over time. Other considerations also ask to what extent collected data are comparable across countries and whether the data are accessible. Since it is desirable to monitor human development at various spatial scales (circumpolar, national, regional, community, household and individual) the data used should be scalable; i.e. collected and available at different geographical scales as far as possible.

- Preference for available and affordable data. Any monitoring system will need to rely on existing and continuously collected data available from national, regional and local agencies, and other sources that provide such data for little or no cost. Another aspect of availability is the periodicity with which regularly collected data are gathered: data collected on at least a five-year frequency are preferred. The criterion of data affordability considers the on-going costs of data collection and monitoring. A monitoring system should mostly use data gathered during on-going censuses and surveys conducted by government agencies (though not necessarily exclusively). Such a monitoring system might rely in some cases on new data collection (e.g. if a future SLiCA were to be conducted). A monitoring system would encourage collaboration among data collection entities in Arctic countries and regions, which could exist under the umbrella of an "ASI Observing Network" (see below). Collaborative resourcesharing efforts are considered to be the most cost effective way to gather the critical amount of data necessary for monitoring human development in the Arctic.

- Community engagement in monitoring. In addition to conventional data sources, such as government statistical offices, NGOs, etc., an Arctic human development monitoring system should consider how to incorporate community self-monitoring, for which appropriate methodologies will need to be developed and tested in close collaboration with the communities involved. Self-monitoring is critical for ensuring relevance, accessibility and high resolution of data collection. It is also important for increasing potential community benefits from such monitoring.

- Development of inclusive and adaptable measurement frameworks. While we suggest that a system of monitoring of human development be based on the framework of the six domains and key indicators presented in the ASI I Report, we also note that it should be adapted to the local context and needs, with the expectation that the collected 
data will meet data quality requirements noted above. In addition, a monitoring system should apply the criterion of inclusiveness when selecting indicators and data sources: that is, data for indicators need to be inclusive of all sectors of the arctic population - male and female, Indigenous and non-Indigenous, rural and urban, etc.

- Focus on dissemination and utility of monitoring for decision-support. According to any monitoring system of this type, data and/or monitoring methodologies and results collected by national and regional statistical agencies, for instance, should be free and available for all interested stakeholders, such as researchers and communities. A system for the storage and dissemination of relevant data on human development could be created in collaboration with the Arctic Portal, SAON and other partners.

\section{Ideas Regarding the Structure of a Monitoring System for Human Development in the Arctic}

The structure of a monitoring system for human development in the Arctic should, in our opinion, incorporate three components: 1) data collection; 2) data management, sharing and dissemination; and 3) research and decisions support (see Figure 7.1). The data collection component would include data gathered by various agents, such as communities, government agencies, NGOs, companies and individual researchers. These data and/or results of monitoring could be shared via a network of collaborators across the Arctic. The coordination of such a monitoring network could be guided and overseen by a permanent steering committee. Such a committee could be actively engaged in dissemination and transfer of the appropriate methodologies and development of regionally-adapted monitoring systems. We note that a pilot monitoring system for the Inuvialuit Settlement Region in Canada is already being developed, at the request of the Inuvialuit Regional Corporation and as part of the Resources and Sustainable Development in the Arctic Program (ReSDA; http://dl1.yukoncollege.yk.ca/resda/) (see Box 7.1).

Shared data and monitoring results could be made available via the Arctic Portal and other data repository and dissemination programs (SAON, etc.) to the Arctic Council, researchers and general public. A human development monitoring program could lay the foundation for current and future decennial Arctic Human Development Reports. A mechanism should be developed to provide regular updates to the Arctic Council and to other interested parties and stakeholders on the state of human development in the Arctic. 
Conceptual Diagram for a System for Monitoring Human Development in the Arctic

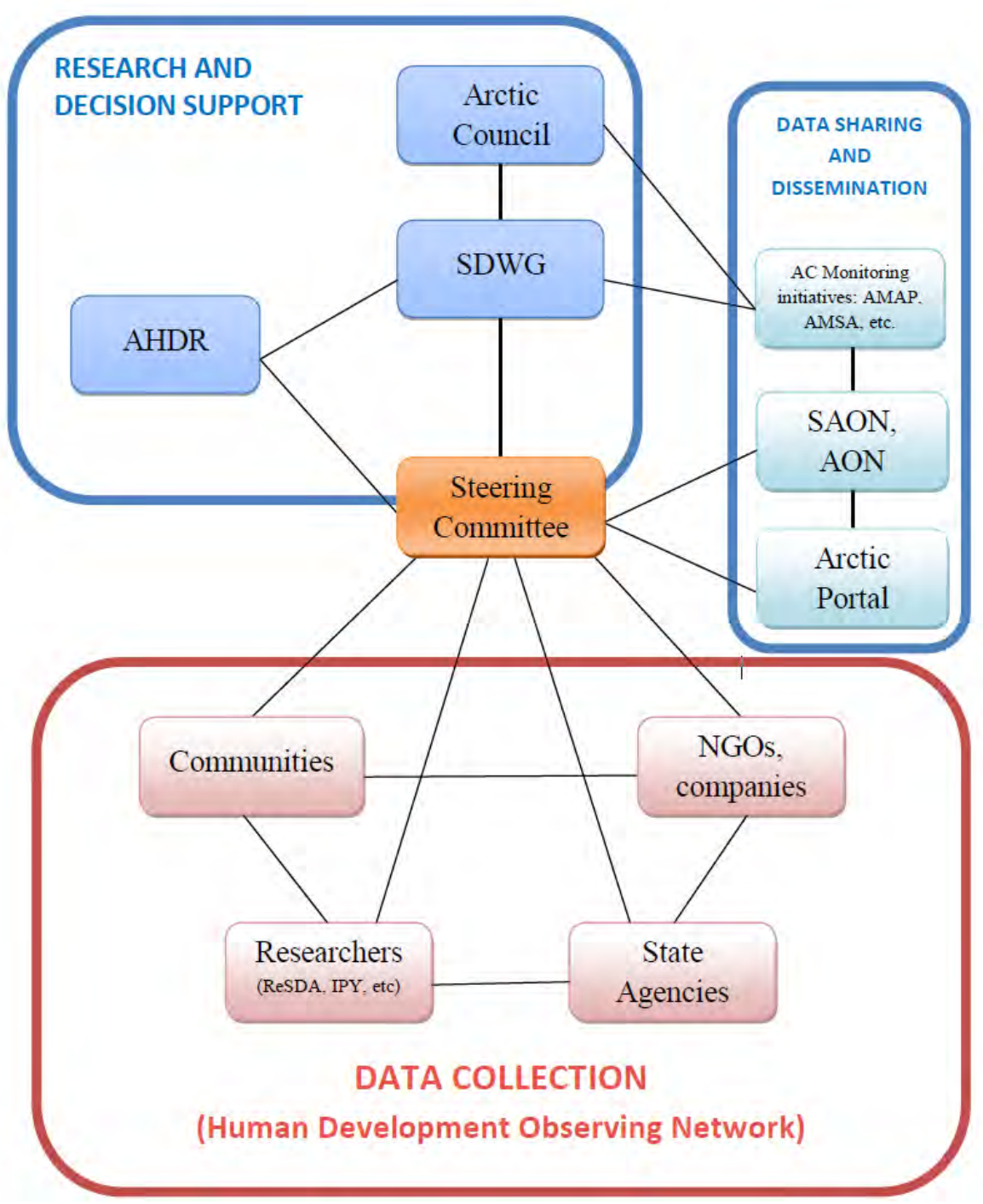

Any such mechanism would best be developed in close consultation with the Arctic Council's Sustainable Development Working Group. The monitoring network could serve as a central source for providing data on human wellbeing for Arctic Council decision support. 


\section{Box 7.1}

\section{Inuvialuit Baseline Indicators Project: A Pilot Monitoring Project}

The Inuvialuit Baseline Indicators project is a collaborative effort between the Arctic Social Indicators (ASI) project, the Resources and Sustainable Development in the Arctic (ReSDA) Program and the Inuvialuit Regional Corporation (IRC) representing the Inuvialuit of Canada. Evolving from a workshop held by ReSDA and ASI-I, Inuvialuit Baseline Indicators (IBI) project aims to develop a set of measurable, reliable and accessible indicators to monitor socio-economic conditions in the Inuvialuit Settlement Region (ISR) with an emphasis on tracking impacts of resource development. This effort is focused on creating a framework to be used by local actors to collect, manage and analyze community based data.

The Inuvialuit region has been affected by a number of resource boom cycles associated with the resource activities in the Mackenzie Delta and more recently in the Beaufort Sea. The IRC, created as a result of the Inuvialuit Comprehensive Land Claim Agreement (1984), has been collecting and publishing selected socioeconomic data to assist decision-making processes. It provides public access to this data for IRC members. Given a growing interest in Arctic resources within the ISR, IRC engaged in collaboration with a social impacts monitoring team of polar scientists to develop a system of indicators based on past experiences in ISR and across the Arctic, local relevance and data availability.

The objectives of the IBI project include: (1) using the ASI circumpolar framework of social indicators, to provide a background baseline analysis of IRC socioeconomic characteristics in comparison with the Northwest Territories (NWT), Inuit regions of Canada/USA, and other circumpolar jurisdictions; (2) using ASI experience and community consultations to identify more relevant domains that should be included in the socioeconomic monitoring system; (3) defining baseline indicators suitable for monitoring socio-economic conditions and impacts of resource development in ISR; (4) developing procedures that will enable community-based collection, management, and analysis of data by local actors; (5) collecting necessary data and expanding the IRC database; and (6) developing and disseminating Inuvialuit Baseline Indicators data and analysis to inform the region's stakeholders and to aid IRC's decision making and ensuring community awareness. 
The first stage of the project was to analyze ISR socio-economic wellbeing using the indicators framework developed by ASI under the auspices of the Arctic Council. The assessment was conducted for the six ASI domains: health and population, material wellbeing, education, cultural vitality, contact with nature, and fate control. The analysis revealed considerable internal differences within the ISR, especially between Inuvik and other communities. On most indicators ISR fared better than other NWT regions (unemployment, engagement in traditional activities, land claim status and fate control) or close to average (incomes, dependency on government transfers, consumption of county food, education). ISR fared worse than other NWT regions in respect to language retention and out-migration rates. In comparison with Inuit communities in Nunavut, ISR had a generally higher level of material wellbeing but demonstrated very low language retention, low consumption of traditional food and an inferior level of fate control. The long-term trends (between 1986 and 2010) were positive for several indicators, such as participation rate in education, educational attainment, housing, teen birth, engagement in hunting and fishing. Trends were negative for crime, ability to speak one's mother tongue and dependency on income support, among others. The analysis shows that although ISR appears to have achieved and maintained relatively high levels of wellbeing across most of the six domains, it still faces considerable social challenges and has to deal with interregional inequalities. 


\section{Suggestions for Future Options and Opportunities Regarding Monitoring of Human Development in the Arctic}

Based on the work of ASI-I and ASI-II we present some concrete suggestions on the establishment of a monitoring system for Arctic Human Development. We suggest the following:

1. An Arctic Social Indicator monitoring system be designed based on principles and data criteria outlined in ASI I and ASI II. This system should be made a priority for current and future circumpolar monitoring initiatives, including a possible future International Polar Initiative. We see such a monitoring system as requiring the following:

a) Encouraging national statistical agencies to participate in development of a metadatabase identifying ASI indicators that are already monitored by a national agency.

b) Establishing an international task force composed of national statistical agency analysts and Arctic researchers to identify the special tabulations required to produce comparable ASI indicators and to recommend approaches to produce these special tabulations.

c) Engaging local communities, non-government organizations and private parties in developing and conducting locally-focused social indicators monitoring projects, including community selfmonitoring. The methodology for such projects would be created via collaboration among communities, stakeholders and scientists.

d) Encouraging national and international funding agencies and scientific associations to assist in building a circumpolar network of scientists actively engaged in monitoring wellbeing. Promote data sharing, exchange and dissemination among researchers and research organizations.

(See ASI (2010)).

2) Collaboration be promoted among monitoring projects in the Arctic, notably but not confined to, Arctic Observing Networks (AON), Sustaining Arctic Observing Networks (SAON), and a new project that we outline here for monitoring human development. The ASI II team endorses and supports the SAON recommendations and urges further collaboration among and coordination of monitoring activities and projects focused on the Arctic. Monitoring human development through a set of robust social indicators should 
form a fundamental part of monitoring activities along with biophysical indicators of ecosystem health.

3) The possibility of initiating an "ASI Phase Three", with the objective of monitoring the six identified domains of human development in the Arctic, should be explored. "ASI III" could be the driving force in establishing and developing a comprehensive Arctic human development monitoring system.

ASI I and II have made significant progress toward the development of a system for tracking human development in the Arctic. We have identified a small set of indicators to monitor Arctic human development and tested, validated and refined this set for several Arctic regions. The next steps will be to:

a) encourage Arctic governments to adopt the indicators for the monitoring of human development

b) ensure access to data for the indicators

c) continue to evaluate the utility of the ASI indicators in different regional and local contexts

d) conduct periodic synthesis of new knowledge pertaining to human development in the Arctic (e.g. decennial AHDRs) applying data and information from a variety of contributors and sources including local communities, stakeholders, statistical agencies and research institutions.

The ultimate goal of creating an Arctic human development monitoring system would be to assist Arctic governments and communities to promote human development and the highest possible quality of life in Arctic communities. We believe that the monitoring system described in this volume, and as outlined above, would enable Arctic states and communities to measure and monitor human development in the Arctic and, accordingly when based on reliable information on trends, to take action to ensure and advance the wellbeing of all Arctic peoples.

\subsection{The International Polar Year and the Monitoring of Human Development in the Arctic}

The International Polar Year (IPY) 2007-2008 has been the largest coordinated research program in the Polar Regions to date, and has mobilized tens of thousands of researchers, students, and citizen scientists. Unlike previous IPY endeavors, IPY 2007-2008 was characterized by the inclusion of the 
social sciences and humanities, as well as of local communities, under the Human Dimension theme. Given that ASI was one of the 228 international IPY projects, a closer look at some of the other IPY projects dealing with human development in the Arctic seems appropriate.

The recently published edited volume "Understanding Earth's Polar Challenges: International Polar Year 2007-2008. Summary by the IPY Joint Committee" (Krupnik et al. 2011) provides extensive material about the organization, conduct and results of the most recent IPY. For the social sciences and humanities, two articles in that volume are of particular relevance: "Polar Societies and Social Processes" (Krupnik and Hovelsrud 2011) and "Human-Based Observing Systems" (Hovelsrud, Krupnik and White 2011). In addition, Krupnik's (2011) "Connecting to New Stakeholders in Polar Research" - which deals with the engagement of Arctic residents during IPY - deserves to be mentioned here.

The article by Krupnik and Hovelsrud (2011) discusses all 28 active social science and humanities projects that were endorsed by IPY (in addition, five knowledge exchange projects - conferences, publications, etc. - are mentioned as well). ASI is mentioned prominently on various occasions, including under the heading "from local to polar". Many of the other projects discussed in that chapter are fascinating in their own right but have little to offer to ASI.

Eight of the 28 projects are treated separately in the article by Hovelsrud, Krupnik and White (2011). All of them can be labeled as "Community-Based Monitoring" (CBM). While ASI-I and ASI-II have by design not been community-based but pan-arctic, CBM projects are methodologically relevant for the future of the ASI endeavor. One of the projects discussed is ELOKA (Exchange for Local Observations and Knowledge of the Arctic), which provides data management for local and traditional knowledge. ASI, which works with quantitative, standardized data sets most of the time, is particularly interested in ELOKA's goal of developing protocols for the collection, storage, and access of traditional knowledge data.

Another relevant CBM IPY project is CAVIAR (Community Adaptation and Vulnerability in Arctic Regions), which involved 26 communities in eight Arctic countries. Its vulnerability assessment framework not only documented climate and ecological change but also looked at social, economic, cultural and political stressors. The project involved a participatory methodology and involved local partners from the start. At the same time, it addresses complex linkages in coupled social-ecological systems, thereby bringing the social and natural sciences into dialog. Among the lessons learned are ways of how to best downscale climate models for local use. 
Vulnerability is also at the center of the EALAT project ("Reindeer Herders Vulnerability Network Study: Reindeer Pastoralism in a Changing Climate"), which was initiated by reindeer herding organizations and the Sami University College. Focused on reindeer herding, it provides venues for coordinated observation and monitoring, with the ultimate goal of empowering reindeer herders. NOMAD (Social-science Migrating Field Station: monitoring the Human-Rangifer Link by Following Herd Migration) was centered on the Kola Peninsula in Northwestern Russia and produced qualitative data by researchers and community members. CARMA (CircumArctic Rangifer Monitoring and Assessment Network), on the other hand, focuses on wild reindeer or caribou. The multitude of reindeer/caribou projects is an expression of the importance of Rangifer for the peoples of the North.

Finally, SIKU (Sea Ice Knowledge and Use: Assessing Arctic Environmental and Social Change) uses local and traditional knowledge about the environment as an indicator of change. One of the results of SIKU is that local observations can be more fine-grained than instrumental records. Involving Inuit partners from more than 30 communities in Russia, Alaska, Canada, and Greenland, SIKU not only recorded local and traditional knowledge but was engaged in ongoing monitoring activities of local ice and weather conditions. The lesson is that community members are very interested in monitoring conditions they consider important, meaningful, and relevant. Future ASI endeavors should be able to capitalize on that insight.

\subsection{Concluding Remarks}

While the pan-arctic, comparative nature of ASI-I and ASI-II has been a large part of its success, it also prevents close community interaction. The future of ASI is intended to overcome this limitation without sacrificing its global outlook. As outlined above, future ASI activities will include communities and other stakeholders at various stages of the process.

In addition, however, there is room for a multitude of local and regional spin-offs from ASI. In recent years, we have responded to many calls for permission to use the ASI framework in various contexts. As a matter of fact, we hold no patents to ASI and the principles informing ASI domains and indicators have been published and are part of the public domain. Assuming that the proper credits and references are given, anyone can use ASI as their starting point. 
We encourage the critical use of ASI indicators whatever the userdefined context may be. We are convinced that by applying the ASI framework in specific situations - similar to what we intended with this book further development will be enabled. Undoubtedly, this will lead to the recognition that certain domains and indicators are more relevant in some contexts than others. Thus, what we need from "ASI users" is neither permission requests nor royalties but feedback about lessons learned. In that spirit, we want to encourage our readers to put ASI into practice or to the test but hope that you will share your experiences with us.

\subsection{References}

Hovelsrud, Grete, Igor Krupnik, and Jeremy White. (2011). Human-Based Observing Systems. In Understanding Earth's Polar Challenges: International Polar Year 2007-2008. Summary by the IPY Joint Committee. I. Krupnik, I. Allison, R. Bell, P. Cutler, D. Hik, J. Lopez-Martinez, V. Rachold, E. Sarukhanian, and C. Summerhayes, eds. Pp. 435-456. Edmonton, Alberta: CCI Press.

Krupnik, Igor. (2011). Connecting to New Stakeholders in Polar Research. In Understanding Earth's Polar Challenges: International Polar Year 2007-2008. Summary by the IPY Joint Committee. I. Krupnik, I. Allison, R. Bell, P. Cutler, D. Hik, J. LopezMartinez, V. Rachold, E. Sarukhanian, and C. Summerhayes, eds. Pp. 575-592. Edmonton, Alberta: CCI Press.

Krupnik, Igor, and Grete K. Hovelsrud. (2011). Polar Societies and Social Processes. In Understanding Earth's Polar Challenges: International Polar Year 2007-2008. Summary by the IPY Joint Committee. I. Krupnik, I. Allison, R. Bell, P. Cutler, D. Hik, J. Lopez-Martinez, V. Rachold, E. Sarukhanian, and C. Summerhayes, eds. Pp. 311333. Edmonton, Alberta: CCI Press.

Krupnik, Igor, et al., eds. (2011). Understanding Earth's Polar Challenges: International Polar Year 2007-2008. Summary by the IPY Joint Committee. Edmonton, Alberta: CCI Press. 



\section{Sammenfatning}

ASI (Arctic Social Indicators) projektet har haft til formål at udarbejde indikatorer for menneskelig udvikling i Arktis indenfor seks nøgle dimensioner der er blevet fremhævet som værende vigtige elementer i menneskelig udvikling i Arktis. Disse dimensioner er: kontrol med egen fremtid, kulturel identitet, nærhed til naturen, uddannelse, materiel velvære, og sundhed/demografi. ASI arbejdet omfatter konstruksionen, måling, afprøvelse og anvendelsen af indikatorer, samt introduktionen af et ASI system, der kan bidrage til at besvare spørgsmål omkring ændringer og trends i menneskelig udvikling, levevilkår, og samfund i Arktis.

Arbejdet med ASI begyndte i 2006 som opfølgende arbejde til AHDR (Arctic Human Development Report, 2004). Det var netop under udarbejdelsen af AHDR i perioden 2002-2004 at seks tematiske områder blev identificeret som værende specielt relevante for menneskelig udvikling og velvære i Arktis. Den første ASI report som udkom i 2010 tog som udgangspunkt de seks tematiske områder, eller nøgle dimensioner, som AHDR havde fremhævet. Med disse dimensioner som udgangspunkt blev et antal arktisk specifikke sociale indikatorer konstrueret og målt. En række kriteria blev brugt til at udvælge de bedste indikatorer, der i blandt kriteria om indikatorens relevans, samt omkostningen ved målingen af indikatoren. Valget af ASI indikatorer faldt især på indikatorer der kunne måles og anvendes indenfor en rimelig pris i form af tid og andre ressourcer.

Baseret på en omfattende ASI proces, hvor en række vigtige trade-offs måtte tages i betragtning, blev et mindre sæt indikatorer udvalgt, der som samlet menes at give et godt overblik over menneskelig udvikling blandt arktiske beboere, både indfødte folkefærd og andre beboere i Arktis. Med ASI er det muligt at drage konklusioner om ændringer i velvære og menneskelig udvikling i Arktis og at sammenligne tilstandene indenfor og mellem forskellige regioner.

ASI arbejdet har forsøgt at opnå en rimelig balance mellem, på den ene side, fristelsen til at fremlægge et større antal indikatorer for hver nøgle dimension for at opnå et komplet billede af hvert aspekt af menneskelig udvikling, og på den anden side, ønsket om at identifiere blot een indikator for hvert tematisk område, med det formål at kunne opnå et system der kan introduceres uden store omkostninger, men som dog så 
løber risikoen at udelade vigtige aspekter af menneskelig velvære blandt folk i Arktis.

Det centrale indhold af ASI-II er fem nøje udvalgte casestudier, hvor ASI indikatorene er søgt målt, finjusteret og afprøvet. Casestudier udføres på følgende områder: Sakha-Yakutia; Vest-Norden; Northwest Territories i Canada; Inuit regioner i Alaska. Derudover er der et casestudie, som undersøger hvorvidt SLiCA undersøgelsen (levevilkårs undersøgelsen i Arktis) kan benyttes til at måle ASI indikatorer. På baggrund af disse casestudier drages der konklusioner om anvendelsen af ASI, og en hovedkonklusion er, at ASI er anvendeligt som et system til måling af ændringer i menneskelig udvikling i Arktis.

Vanskeligheder omkring adgang til data, og manglende datakvalitet, har givet store udfordringer i ASI arbejdet, hvor nogle regioner har været mere rige på data (f.eks. NWT, Canada, og den nordiske region), og hvor det andre steder har været vanskeligt at måle alle ASI indikatorene (f.eks. Shaka Yakutia), som så har nødvendiggjort afvigelser fra ASIs tekniske definitioner. Trods data udfordringer, har det været muligt at opnå rimelig gode resultater med ASI arbejdet, og det kan konkluderes at ASI er et anvendeligt system for monitoring af menneskelig udvikling $\mathrm{i}$ Arktis. Dog vil det være yderst hensigtsmæssigt at videreudvikle ASI systemet, og at øge indsatsen på at finde langsigtede løsninger til data problemerne i Arktis. 
Ved Stranden 18

DK-1061 Copenhagen K

www.norden.org

\section{Arctic Social Indicators}

Arctic Social Indicators II (ASI-II) is a follow-up activity to ASI-I (2010) and the first Arctic Human Development Report (AHDR, 2004).

The objective of ASI (2010) was to develop a small set of Arctic specific social indicators that as a collective would help facilitate the tracking and monitoring of change in human development in the Arctic. ASI indicators were developed for six domains that are considered prominent aspects of human development in the Arctic by residents in the Arctic: Health and Population; Material Wellbeing; Education; Cultural Wellbeing; Contact with Nature; and Fate Control.

The objective of the present volume of ASI is to present and discuss the findings of the work on measuring the set of recommended ASI indicators; to conduct a series of regional case studies to illustrate and test the strength and applicability of these indicators; to identify and describe data challenges for the Arctic region specifically in relation to these Arctic specific indicators and to draw conclusions about the ability of ASI to track changes in human development; and to formulate policy relevant conclusions for the long-term monitoring of Arctic human development.

The core content of ASI-II is a set of five carefully selected case studies, which form the basis for drawing conclusions about the applicability of the ASI indicators and for formulating policy relevant conclusions. Case studies are performed for Sakha Republic (Yakutia); the West-Nordic Region; Northwest Territories; Inuit Regions of Alaska; and the Inuit World, with the Survey of Living Conditions in the Arctic (SLiCA) used to augment ASI.

Findings on the state and changes in Arctic human development and wellbeing are presented. Based on our analysis and conclusions from the five case studies the framework for an ASI monitoring system is introduced. We argue that the long-term monitoring of human development in the Arctic would be greatly facilitated by the regular and frequent collection and reporting of relevant data, including those required for the proposed small set of ASI indicators.

TemaNord 2014:568

ISBN 978-92-893-3886-8 (PRINT)

ISBN 978-92-893-3888-2 (PDF)

ISBN 978-92-893-3887-5 (EPUB)

ISSN 0908-6692

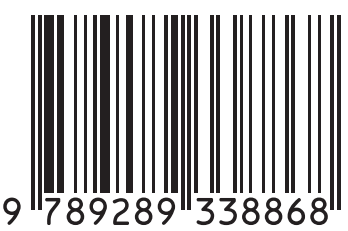

